\title{
Discourse in Action
}

From emails relating to adoption over the internet to discussions in the airline cockpit, the spoken or written texts we produce can have significant social consequences. The area of mediated discourse analysis considers the actions individuals take with texts - and the consequences of those actions.

Discourse in Action brings together the leading scholars from around the world in the area of mediated discourse analysis and reveals ways in which its theory and methodology can be used in research into contemporary social situations. Each chapter explores real situations and draws on real data to show how the analysis of concrete social actions broadens our understanding of discourse. Taken together, the chapters provide a comprehensive overview to the field and offer a range of current studies that address some of the most important questions facing students and researchers in linguistics, education, communication studies, and other fields.

Contributors: Laurent Filliettaz, Rodney H. Jones, Gunther Kress, Theo van Leeuwen, Jay Lemke, Paul McIlvenny, Maurice Nevile, Sigrid Norris, Pirkko Raudaskoski, Shawn Rowe, Ingrid de Saint-Georges, Ron Scollon, Suzie Scollon, James V. Wertsch 



\section{Discourse in Action}

Introducing mediated discourse analysis

\section{Edited by Sigrid Norris and Rodney $H$. Jones}

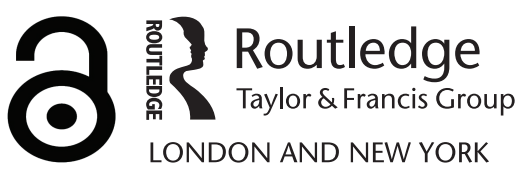


First published 2005 by Routledge

Published 2017 by Routledge

2 Park Square, Milton Park, Abingdon, Oxon OX14 4RN

711 Third Avenue, New York, NY 10017, USA

Routledge is an imprint of the Taylor \& Francis Group, an informa business

Copyright (C) 2005 Sigrid Norris and Rodney H. Jones

Typeset in Perpetua by

Florence Production Ltd, Stoodleigh, Devon

The Open Access version of this book, available at www.tandfebooks.com, has been made available under a Creative Commons Attribution-Non Commercial- No Derivatives 4.0 license.

Every effort has been made to ensure that the advice and information in this book is true and accurate at the time of going to press. However, neither the publisher nor the authors can accept any legal responsibility or liability for any errors or omissions that may be made. In the case of drug administration, any medical procedure or the use of technical equipment mentioned within this book, you are strongly advised to consult the manufacturer's guidelines.

British Library Cataloguing in Publication Data

A catalogue record for this book is available from the British Library

Library of Congress Cataloging in Publication Data

Discourse in action: introducing mediated discourse analysis/edited by Sigrid Norris and Rodney H. Jones

p. $\mathrm{cm}$

Includes bibliographical references and index.

1.Dicourse analysis - Social aspects. I. Norris, Sigrid, 1961-

II. Jones, Rodney H.

P302.84.D574 2005

$401^{\prime} .41-\mathrm{dc} 22$

2004023214

ISBN 978-0-415-35429-5 (hbk)

ISBN 978-0-415-36617-5 (pbk) 
For Ron 



\section{Contents}

List of illustrations $\quad$ x

Preface $\quad$ xi

SIGRID NORRIS AND RODNEY H. JONES

Introduction $\quad 1$

1 Discourse as action/discourse in action 3 RODNEY H. JONES AND SIGRID NORRIS

\section{PART I}

Mediated action

2 Introducing mediated action

SIGRID NORRIS AND RODNEY H. JONES

3 The rhythmic integration of action and discourse: work, the body and the earth

RON SCOLLON

4 You always have to land: accomplishing the sequential organization of actions to land an airliner

MAURICE NEVILE

PART I I

Mediational means/cultural tools

5 Introducing mediational means/cultural tools 
viii Contents

6 Vygotsky's two approaches to mediation

JAMES V. WERTSCH

7 Mediating discourses of transnational adoption on the internet

PAUL MCILVENNY AND PIRKKO RAUDASKOSKI

8 Multimodality, genre and design

THEO VAN LEEUWEN

PART III

Practice

9 Introducing practice

RODNEY H. JONES AND SIGRID NORRIS

10 Mediated actions, social practices, and contextualization: a case study from service encounters

LAURENT FILLIETTAZ

11 Place, pace, and meaning: multimedia chronotopes JAY LEMKE

12 Using multiple situation definitions to create hybrid activity space

SHAWN ROWE

PART IV

Sites of engagement

13 Introducing sites of engagement SIGRID NORRIS AND RODNEY H. JONES

14 Sites of engagement as sites of attention: time, space and culture in electronic discourse 
15 From anticipation to performance: sites of engagement as process

INGRID DE SAINT-GEORGES

PART V

Agency

16 Introducing agency

RODNEY H. JONES AND SIGRID NORRIS

17 Agency distributed through time, space and tools:

Bentham, Babbage and the census

SUZIE SCOLLON

18 Habitus, social identity, the perception of male domination - and agency?

SIGRID NORRIS

Methodology and concluding remarks:

mediated discourse analysis

19 Methodological principles and new directions in MDA

GUNTHER KRESS

References 


\section{Illustrations}

\section{Figures}

3.1 Floor-nailer 22

3.2 Cycles 26

4.1 The data segment simplified into smaller and larger action sequences $\quad 36$

$\begin{array}{lll}8.1 & \text { Visually realised 'enticement' } & 78\end{array}$

$\begin{array}{lll}8.2 \text { 'Dolphin' } & 79\end{array}$

$\begin{array}{ll}8.3 \text { Kitchener poster } & 80\end{array}$

8.4 'The First Exciting Year' 83

8.5 Analysis of the reading path of Figure 8.4 83

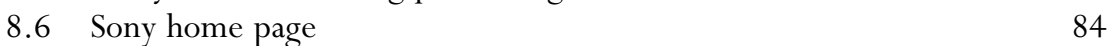

8.7 The first gallery of the Old Royal Observatory 'story of time' exhibition 86

8.8 Final gallery of the Old Royal Observatory 'story of time' $\begin{array}{ll}\text { exhibition } & 88\end{array}$

8.9 Section of 'Aboriginal guided tour' 89

8.10 Reading path through a section of the 'Aboriginal guided tour' 92

8.11 Alternative reading path through the same section of 'Aboriginal guided tour'

12.1 Creating hybrid activity space 129-131
18.1

18.1 Identity construction and perception of male domination 186

Table

$\begin{array}{lll}14.1 & \text { Percentage of space deixis } & 145\end{array}$

\section{Box}

$\begin{array}{lll}14.1 & \text { Examples } & 146\end{array}$ 


\section{Preface}

\section{Sigrid Norris and Rodney H. Jones}

'Discourse in action' - as any mediational means - has a history: for the past several years, a group of scholars has been trying to work out ways to move discourse analysis beyond the analysis of texts to consider questions about the actions people take with them, as well as with other cultural tools, and the social consequences these actions have. The approach that has developed out of these efforts is called mediated discourse analysis (MDA). It is a wide-ranging and eclectic perspective that is both socially engaged and theoretically grounded, bringing together recent advances in discourse analysis, linguistic anthropology, psychology, and sociolinguistics, and embracing questions about action, agency, communities, culture, and time. Among the social issues that MDA has thus far been used to address are workplace training, immigration, national identity, globalization, and AIDS prevention.

Those working in this exciting new area have shared ideas with one another formally and informally in papers, at conferences, in private conversations, and through correspondence. We now feel it is time to bring together some of these ideas in an edited volume that will help to articulate the commonalities of our goals as well as to highlight the diversity of contexts within which this perspective has been applied. This volume seeks to introduce the framework of MDA in a comprehensive way, while integrating work by a variety of scholars who are either working in the framework of MDA, and/or who have influenced MDA. Those represented are not limited to scholars who consider themselves mediated discourse analysts.

Discourse in Action is meant to allow students and scholars (who may not necessarily be familiar with this approach to discourse) to discover the vast variety of disciplinary approaches possible and the complexity involved when speaking of mediated discourse analysis.

We have conceived of this book as an edited volume of a different kind: it is a textbook that is divided into five parts, each of which delineates a concept of MDA. The first chapter of each part is written by the editors, giving a short 
synopsis of the concept. It is here that the reader can find definitions, information on the historical development of the terms, and the theoretical underpinnings of the concepts. To make it easy for readers to locate important terminology, we place these in textboxes at the beginning of these chapters. At the end of each part, we provide discussion questions and mini project ideas to point students and teachers in practical directions for the use of Discourse in Action.

We hope that this book will be useful to students and researchers who are interested in broad theoretical issues facing discourse analysis and sociolinguistics, as well as those who are concerned with how discourse analysis can be made more immediately relevant to today's pressing social issues.

While understanding social issues is the ultimate goal of a mediated discourse approach, we cannot emphasize enough the benefit of a clear theoretical outline (mediated discourse theory) and a workable methodological framework (nexus analysis). Therefore, instead of dividing the theoretical/methodological and the practical, we have decided to create a book that pays equal attention to theory, methodology, and social issues. With this volume we hope to provide discourse analysts, linguists, educationists, and communications scholars, as well as others, with a range of current work that addresses some of the most important questions facing these disciplines. Simultaneously, we hope to encourage scholars to look beyond their own disciplinary boundaries in seeking answers to social issues that they are addressing.

We would like to thank all of the contributors to this volume for their efforts and patience, our families for supporting us throughout, and Tom Bartlett for proofreading the final manuscript. 


\title{
Introduction
}

\author{
Discourse in action
}





\title{
1 Discourse as action/ discourse in action
}

\author{
Rodney H. Jones and Sigrid Norris
}

In a park in China, a man stands behind a tree holding a stack of AIDS prevention pamphlets. Another man passes, briefly looks at the first man and then continues on his way, Then a third man comes by, this time allowing his gaze to linger a little longer, at which point the first man smiles, takes a few steps forward and offers one of the pamphlets.

(Jones, 2001b, 2002b)

In a living room in Germany a divorced woman kneels on the floor among scattered pieces of computer equipment and wires and squints at a sheet of written instructions trying to match the physical objects with the drawings and descriptions on the sheet. Suddenly she looks up and remarks to her friend sitting across the room: 'He never let me do anything like this.'

(Norris, 2002a, this volume)

In a coffee shop in San Diego two linguists settle down with their drinks to take a break from the intellectual rigor of an academic conference. After a few minutes of casual conversation, the discussion turns to the writing on the paper cups they are drinking from, which leads to an exchange of ideas about discourse analysis which find their way into a paper one of the linguists will present at a future conference.

(R. Scollon, 2001a)

What these three seemingly disparate strips of social interaction have in common is that they are all mediated through some kind of written text: an AIDS prevention pamphlet, an instruction sheet, the writing on a paper cup. In each instance these texts are used as tools to take one or more social action(s) and to claim and impute certain social identities. Their use goes far beyond the discourse that they contain, beyond the purposes of giving someone information about AIDS prevention, teaching someone how to set up a personal computer or advertising the environmentally friendly policies of a retail coffee shop. These texts connect their 
users to each other in a complex nexus of practices, connecting these moments to policies and discourses of public health and personal attraction, gender politics and family politics, corporate capitalism and the discourse of academia.

Were we to analyze just the discourse, the written texts: the dos and don'ts of condom use; the location of the USB port; the fact that the cup is made from 100 percent recycled paper; or the spoken words - the offers, the reminiscences, the debates - we would in fact understand very little about what is going on in these social situations, nor would we understand what these pieces of discourse actually mean. The reason is that the 'meaning' does not so much reside in the discourse itself, but rather resides in the actions that people take with it.

This book is about the relationship between discourse and action, taking mediated discourse analysis (MDA) as its theoretical and methodological framework.

Mediated discourse analysis was developed as an alternative to approaches to discourse that see social action as secondary, and approaches to social analysis that see discourse as secondary (R. Scollon, 2001a). By not privileging discourse or social action but, rather, seeing discourse as one of many available tools with which people take action, either along with discourse or separate from it, MDA strives to preserve the complexity of the social situation. It provides a way of understanding how all of the objects and all of the language and all of the actions taken with these various mediational means intersect at a nexus of multiple social practices and the trajectories of multiple histories and storylines that reproduce social identities and social groups.

The principles of mediated discourse theory were first laid out by Scollon in the late 1990s (R. Scollon, 1997, 1998) and have subsequently been developed by a number of discourse analysts in a constellation of separate research projects and collaborations over the past ten years in Asia, North America and Europe (see, for example, Al Zidjaly, 2002, 2004; Boswood, 2000; de Saint-Georges and Norris, 1999; Johnson, 2002; Jones, 1999, 2001a, 2001b, 2002a, 2002b; Jones and Candlin, 2003; Jones et al., 1997; Norris, 2002a, 2002b, 2004a, 2004b; Randolph, 2000; R. Scollon, 1997, 1998, 2001a, 2001b; R. Scollon et al., 1999; S. Scollon, 2001, 2003; Scollon and Scollon, 2003, 2004). It has been applied to understanding such diverse issues as AIDS prevention, national identity, childhood literacy practices, gender identity and buying a cup of coffee.

The focus of mediated discourse analysis is not discourse per se, but the whole intersection of social practices of which discourse is a part. It explores, among other things, how, at that nexus, discourse becomes a tool for claims and imputations of social identity. At the same time, it does not see the tree in the park, the scattered computer components or the decor of the coffee shop in the examples given above as 'context,' nor does it see the written and spoken discourse as 'texts' in a more traditional sense. Instead, it turns its focus to the actions that are being taken with these tools - whether they be trees, computer 
components or written texts. MDA takes as its unit of analysis the action, more specifically, the mediated action, which is the real time moment when mediational means, social actors and the sociocultural environment intersect.

This focus on the mediated action as the unit of analysis comes primarily from the work of American psychologist James Wertsch and his colleagues (Penuel and Wertsch, 1995; Wertsch, 1991, 1994, 1995, 1997, 1998; Wertsch et al., 1995) who themselves take it from the work of Soviet psychologist Lev Vygotsky (1978, 1987).

Wertsch and his colleagues call their perspective 'the sociocultural approach to mind' (see also Bruner, 1990; Cole, 1990; Lantolf, 2000). It emphasizes that all actions are mediated through 'cultural tools' (Wertsch, 1998): objects, technologies, practices, identities, social institutions, communities, and also language and other semiotic systems. All of these tools come with histories that have shaped the kinds of things that can be done with them and the kinds of things that cannot: that is, they embody certain affordances and constraints. These affordances and constraints, however, are not deterministic of what social actors do with them but, rather, create a tension as actors appropriate them into their habitus (Bourdieu, 1977) and deploy them purposefully in social situations.

Understanding social life involves not just understanding the tools available for mediated actions nor the intentions, goals, plans or habits of social actors, but also, and more importantly, involves understanding the 'tension between the mediational means as provided in the sociocultural setting and the unique contextualized use of these means in carrying out particular concrete actions' (Wertsch 1994: 205).

Chief among these mediational means are what Wertsch calls voices: the words, phrases, narratives and 'ways of speaking' (Gumperz and Hymes, 1986) that we borrow from the sociocultural environment to interact with others and construct our accounts of these interactions. For Wertsch, nearly all actions are mediated through voices, even apparently silent actions, as even private thought involves language (Vygotsky, 1987) and private behavior, prior social learning.

Wertsch derives the concept of voices from the work of the Soviet literary critic Mikhail Bakhtin (1981a, 1986), who insists that we never speak in a voice that is purely our own, but instead 'borrow' and 'ventriloquate' the voices of others: we 'rent' meaning and then give it back to the community according to the protocols it establishes (Clark and Holquist, 1984). Every utterance is heteroglossic, in that it may contain many different voices at once, and dialogic, as each voice exists in response to, or in 'dialogue' with, other voices.

While every word we speak, every practice we perform and every identity we claim is always 'half someone else's' (Bakhtin, 1981a: 293), these words, practices and identities are also 'half our own.' When we borrow them, we change them, populating them with our own semantic and expressive intentions, speaking them 
in our own 'accents.' Thus, not only is the way we take action transformed by the tools we use, but these tools themselves are transformed by the actions they are appropriated to perform.

While sociocultural practice theory provides the broad outlines of a perspective on the relationship between discourse and action, it stops short of developing a coherent theory of discourse and a clear way to analyze it as it is deployed within complex semiotic aggregates (Scollon and Scollon, 2003) with other non-linguistic mediational means. In developing the tools to do this, MDA has drawn upon and integrated a number of traditions in linguistics, some of which have in the past been regarded as more contradictory than complementary, but all of which share with MDA the same question: How can we make the study of discourse account for its complex role in situated social action?

\section{Discourse as action}

The response to this question from many traditions in North American and European linguistics has been to point out that discourse is action, that saying something or writing something is a form of doing something, and mediated discourse analysis, in many ways, shares this 'discourse as action' perspective. Perhaps the most important development in modern linguistics, at least from the point of view of MDA, has been the increased focus in the last fifty years on language not as an abstract code but as a set of tools through which people realize particular social functions, and of discourse not as a matter of words, sentences or texts, but as a matter of social action.

One of the most famous articulations of such a perspective comes from Wittgenstein (1972), who sees language as a series of 'games' through which people construct what he calls 'forms of life,' particular ways of being in relation to others and their surroundings. For Wittgenstein, speaking or writing is always a creative performance, determined on the one hand by the 'rules' of the particular language game being played and, on the other, by the unique strategies of individual players in particular situations. Like Wertsch after him, Wittgenstein uses the metaphor of the 'tool kit' to illustrate this dynamic:

Think of the tools in a tool-box: there is a hammer, pliers, a saw, a screwdriver, a rule, a glue-pot, nails and screws. The function of words is as diverse as the functions of these objects. (And in both cases there are similarities.) Of course, what confuses us is the uniform appearance of words when we hear them spoken or meet them in script and print. For their application is not presented to us so clearly.

(Wittgenstein, 1972: 6) 
Another major advance in seeing discourse as a kind of social action came from Austin (1962) and Searle (1969). In speech act theory, utterances are analyzed in terms of the material effect they are intended to bring about on the world. They carry 'force,' which is interpreted according to various conditions present in the context.

This focus on how the meaning of discourse derives from its use is also a prominent feature of contemporary approaches to grammar, in particular the systemic functional grammar of Halliday $(1973,1978)$, who insists that 'language is as it is because of its function in the social structure' (Halliday, 1973: 65). Halliday's approach is an attempt to link the micro-sociological level of language use to the macro-sociological level, or, as he puts it, to link language to 'the social structure, the values, the systems of knowledge, all the deepest and most pervasive patterns of the culture' (Halliday, 1973: 45).

This emphasis on action can also be seen in anthropological perspectives on linguistics, particularly the ethnography of communication (Hymes, 1986; SavilleTroike, 1989), which focuses on discourse as part of a constellation of contextualized behaviors which members of cultures use to demonstrate that they are legitimate members. The notion of 'communicative competence' makes the words one says inseparable from the actions one takes, the place where these actions occur, and a whole host of other factors.

At what is often viewed as the opposite methodological pole, action has also been a concern of ethnomethodologists (Garfinkle, 1967) and conversation analysts (Goodwin, 1981; Heritage, 1989; Sacks et al., 1974; ten Have, 1999) who have sought to understand how social actors construct the 'doings' and 'beings' of everyday life through language. According to ten Have (1999: 6), such approaches re-conceive the problem of social order as 'a practical problem of social action.'

Interactional sociolinguists (Davies and Harré, 1990; Gumperz, 1982b; Schiffrin, 1994; Tannen, 1984) have also contributed both theoretically and methodologically to this focus on language as a matter of social action. By examining the ways people manage their identities in the course of interaction making use of the 'expressive equipment' (Goffman, 1959) provided by their culture, they highlight the contingent and context-specific nature of discourse in relation to social action. The primary concern of interactional sociolinguistics, as R. Scollon (2001a: 163) puts it, is how 'social actors who are acting in real time are able to strategize their own actions within a negotiative process with other social actors to achieve their desired social meanings, including their identities, footings, alignments with others and their positionings of themselves and others.' All of these issues are also central to MDA.

Another tradition whose view of discourse in relation to social action has influenced MDA is what has come to be known as the new literacy studies (Barton 
8 Rodney H. Jones and Sigrid Norris

and Hamilton, 1998; Gee, 1996; Heath, 1983; Scollon and Scollon, 1981; Street, 1984). Scholars in this area share a view of literacy as a mediational means through which people take actions in the world by which they show their identity and their membership in particular groups. Literacy is not a matter of an individual cognitive skill, but rather a matter of performing certain kinds of social actions, and thus reproducing the social practices and power relations around which these actions are organized.

One of the most ambitious attempts in linguistics to explicate the link between discourse and social action can be seen in critical discourse analysis (CDA) (Chouliaraki and Fairclough, 1999; Fairclough, 1989, 1992, 1995; Fairclough and Wodak, 1997; van Dijk, 1993; Wodak, 1996), which takes as one of its central precepts that discourse is a form of social action. According to Fairclough (1992), the project of CDA is to explore how discourse is implicated in social practice by examining the ways texts simultaneously represent reality, enact social relations of power and establish social identities. Discourse is seen as 'joint action' (Chouliaraki and Fairclough, 1999; Shotter, 1993) which draws upon conventions that naturalize particular forms of knowledge and ideologies. Particularly important in CDA is a focus on the 'hybridity' characteristic of all social uses of discourse and the analysis of how, through 'conjunctures' (Chouliaraki and Fairclough, 1999: 38) of text types and ways of speaking, speakers and writers perform strategic acts of domination and resistance.

\section{Discourse in action}

While MDA borrows insights and analytical tools from all of the above traditions, the framework it proposes differs from them in a number of important ways, ways that can perhaps best be summed up by transforming the slogan discourse as action into discourse in action.

Before saying what we mean by that, it is important to be clear what we do not mean. We do not mean 'taking into consideration the context' in which discourse occurs simply as a way of understanding the 'text' better. To treat the actions, environments and circumstances in which discourse occurs as 'context' very much misses the point of mediated discourse analysis (Filliettaz this volume; Jones 2004a), for it draws attention to different aspects of the social situation based on the analyst's interests rather than on the terms of the situation itself.

We also do not mean to suggest that discourse is simply an ingredient in action - that discourse is in action in the same way carrots are in a pot of stew. This view obscures the complex ways actions are taken through discourse and the ways discourse works its way into actions - sometimes through being 'resemiotized' (Iedema, 2001, 2003) as social practices, or 'frozen' (Norris, 2002b, 2004b) in objects and other cultural tools. 
We suggest that the relationship between discourse and action is dynamic and contingent, located at a nexus of social practices, social identities and social goals. This relationship is manifested in the tension between the kinds of actions that discourse and other cultural tools make possible and the ways people purposefully mix these tools in response to their immediate circumstances. MDA sees discourse as 'cycling' through social actions: verbal and textual tools working their way into practices, material objects, and the built environments in which we interact. Those same practices, objects and environments then reproduce spoken and written texts. In this regard, MDA shares with CDA a concern with hybridity, with the ways multiple 'voices' interact in interdiscursive dialogicality (Scollon and Scollon, 2003). However, whereas the project of CDA starts with the idea that 'discourse opens a window on social problems' (R. Scollon, 2001b), MDA seeks to open this window wider - broadening the 'circumference' of discourse analysis (R. Scollon, 2001b) to include things like objects, gestures, non-verbal sounds and built environments. A renewed interest in sociolinguistics in devising ways of analyzing such 'non-linguistic' mediational means and their use in situated interaction (see, for example, Kress and van Leeuwen, 1996; Norris, 2004a, 2004b; van Leeuwen, 1999) has enriched the work of mediated discourse analysis, as is amply evident in this volume.

It is in the question of exactly how discourse is a matter of social action, then, that MDA diverges from other approaches. MDA problematizes the relationship between discourse and action, noting that it is not always possible to 'read' social actions from discourse or to expect certain forms of discourse to inevitably accompany certain actions (Jones, 2001b). Sometimes the ideational content of the discourse has very little to do with the way it is being used to take social action.

Therefore, rather than approaching the question of how discourse is a matter of social action through the discourse, MDA approaches it through the action. The first question it asks is, 'What is/are the action/s that is/are being taken here?' and only after answering this question does it go on to ask, 'What is the role of discourse in this/those action/s?' (R. Scollon, 2001a).

In answering the second question, MDA makes use of many of the analytical tools developed by scholars in these other traditions. From conversation analysis and interactional sociolinguists MDA takes tools with which to trace the ongoing series of identity claims and imputations that people perform as they appropriate texts and other cultural tools into their interaction and the practical process of 'sense-making' that they employ (Jones, 2002b; Jones and Candlin, 2003; R. Scollon, 1998). From the ethnography of communication it takes its ethnographic approach to the collection of data and a concern with 'competences,' ways of appropriating and using tools that show one to be a legitimate member of a particular group or nexus of practice (Jones et al., 1997; R. Scollon, 1998, 2001). 


\section{Rodney H. Jones and Sigrid Norris}

And from critical discourse analysis and the new literacy studies it takes ideas about how to link actions to larger structures of social organization which Gee (1996, 1999) calls Discourses (with a capital D), ${ }^{1}$ the 'cultural toolkits' from which the tools of social interaction are appropriated and from which they take their meaning (Jones, 2001b). Gee (1996: 128) defines Discourses as the recurrent and systematic 'ways of talking, listening . . . acting, interacting, believing, valuing and using tools and objects, in particular settings, at particular times, so as to display and recognize a particular social identity.' The social actor, in this perspective, is simultaneously an individual acting within a unique social context and 'the meeting point of many, sometimes conflicting, socially and historically defined Discourses' (Gee, 1996: 132).

Mediated discourse analysis attempts to understand how broad social concerns interact with the common moments of our everyday lives: to explain how discourse (with a small d), along with other mediational means, reproduces and transforms Discourses; and how Discourses create, reproduce and transform the actions that individual social actors (or groups) can take at any given moment. We take as a route to understanding this relationship the study of social practices, which is the logical outcome of a focus on action, not social practice used in its abstract, non-count form (Chouliaraki and Fairclough, 1999), but rather the concrete practices that we repeat every day to enact our social identities. Both micro-sociological questions of the situated doings of everyday life, and macrosociological questions of power and ideology are grounded in the study of social practices (R. Scollon, 2001b). The place to look for struggles of power and ideology, according to MDA, is not, however, in any one of these practices, but in the way multiple practices converge to influence concrete social actions.

This emphasis on action rather than discourse is, for mediated discourse analysis, not just a theoretical perspective, but also something of a moral imperative. Like scholars in CDA, those working in MDA are committed to a project not just of studying social interaction but of taking social action. MDA is a project to promote social change, which gives yet another meaning to the slogan discourse in action.

Its practitioners have been traditionally concerned with making their work address problems in the world that cry out for solution (R. Scollon, 2002c). They have studied not just food and commerce, sexual politics and AIDS prevention, but also the restructuring of identities in areas undergoing political change (de Saint-Georges and Norris, 1999; Jones et al., 1997; R. Scollon et al., 1999), the ways individuals and groups interact with and within bureaucratic structures like the US Census Bureau and the US Department of Immigration (Johnson, 2002; Pan and S. Scollon, 2004), how unemployed youths appropriate social practices and build identities in government training programs (de Saint-Georges, 2001), how people with handicaps or social stigma construct identities with the tools 
available in their sociocultural contexts (Al Zidjaly, 2004), how macro-political events can affect the micro-politics of our everyday interactions (S. Scollon, 2003), and how marginalized groups appropriate and adapt tools from dominant discourses to strategize their access to social resources (Jones, 2002b).

Central to mediated discourse analysis, then, is the desire to effect positive change by focusing on projects that help people to see beyond abstract notions of power and to start noticing the moment to moment workings of power in their everyday actions. Approaches that uproot social problems from their sociocultural contexts, that uproot words from the bodies that are speaking them (R. Scollon, 2002), that uproot behaviors, attitudes or beliefs from the sociocultural contexts of their formation and the historical bodies of those who perform them, that uproot our present lives from their histories, are approaches that have limited power to bring about positive social change.

Mediated discourse analysts take the position that to understand the power relations and ideological forces in our societies, it is necessary to start with the everyday actions that go into creating them. The most pressing social problems in the world must be understood not as a matter of the dealings of large institutions (governments, corporations) and abstract ideas (justice, democracy) but, rather, as a matter of our individual actions within the semiotic aggregates (Scollon and Scollon, 2003) that institutions and ideologies produce.

The place to begin understanding questions of global economic practices, for example, is in the concrete act of handing money to another person in exchange for a particular good or a service in a particular place. Understanding gender relations can begin with looking at how a divorced woman uses the various pieces of her sociocultural world, from computer components to home decor, to create a new nexus of practice and construct a new identity. Understanding the effect of Chinese government discourse about AIDS on the knowledge or behavior of Chinese gay men, might start not with an analysis of larger questions of law, morality or public policy but, rather, with the concrete action of one man handing another an AIDS prevention pamphlet in a public park. That is not to say that the study of the macro-sociological environment is not important - in fact, it is essential, and MDA often includes the analysis of media texts, public opinion surveys and other means of understanding the broader discursive environment in which individuals act. But, really understanding these broader Discourses must begin with understanding the 'real time' concrete actions they are used to take.

\section{Introducing mediated discourse analysis}

In order to provide the reader with both an overview of the main concepts of MDA and a sampling of strategies researchers in MDA use, this book is divided into five parts: 


\section{Rodney H. Jones and Sigrid Norris}

- Mediated action

- Mediational means/cultural tools

- $\quad$ Practice

- $\quad$ Sites of engagement

- Agency

Each part is accompanied by a short introduction reviewing the key concepts authors use in their chapters and highlighting the theoretical or methodological problems they are addressing. At the end of each part there are discussion questions and suggested projects for students. The last chapter provides a practical outline on how to conduct a study using the principles of mediated discourse analysis, including: how to choose a nexus of practice to study; how to narrow the focus to the relevant actions and the relevant mediational means; how to collect data using participant observation and other methods that will yield a multifaceted view of the nexus of practice. The chapters themselves, for the most part, illustrate their theoretical arguments with reference to actual studies, and it is here that the reader can see true examples of the ethnographic methodology of MDA.

Mediated discourse analysis, as described above, thus, does not conceive of itself so much as a separate 'school' or discipline or theory, but rather as a nexus of practice (R. Scollon, 2001a) at which different research traditions converge. And, like every other nexus of practice, MDA is characterized by contingency and unfinalizability. MDA is, as Scollon (2001b) writes, an approach that constantly 'seeks to examine the limits of its own theory and method.' This contingency and reflexivity is evident in the chapters of this volume, each of which aims not just to explain a key aspect of MDA, but to examine it, problematize it, expand on it, reconfigure it, and to suggest new directions in which it might be developed.

Many of the scholars represented would not necessarily label themselves 'mediated discourse analysts.' They come from the fields of CDA, conversation analysis, education, multimodal discourse analysis, sociocultural psychology, as well as MDA. All of them, however, have greatly influenced MDA with their own work and have been influenced by it. This range of representation shows the breadth and interdisciplinary spirit of MDA theory. The audience we imagine in assembling this collection of scholars includes those in a variety of disciplines (communication and cultural studies, linguistics, psychology, social work and sociology among them) interested in exploring ways of bridging the gap between theory and practice and between a larger macro-sociological perspective and a more delicate analysis of the micro-sociology of everyday life, and scholars who are interested in finding ways to make their work relevant to the important social problems they see around them. In this sense, this volume is not intended as a definitive introduction to MDA so much as an invitation for other scholars to consider and add to what we have outlined here. 
The book begins by introducing and exploring the basic unit of analysis of mediated discourse analysis: the mediated action. In this section, Ron Scollon reconsiders the mediated action, and how, when, and where it actually occurs. He argues that all mediated actions occur simultaneously on various timescales, each with its own rhythm, and that to really understand actions, analysts need to take into account this 'layered simultaneity' (Blommaert, 2004). Then, Maurice Nevile further explores the issues of timing and trajectories of mediated actions, as well as the ways actions function in the process of collaborative meaning making, through the analysis of the complex sequencing of actions involved in landing a commercial aircraft.

In Part II, the mediational means itself is discussed, both in terms of its mode of existence and the way it functions as a link between individual actions and social structures and discourses. James Wertsch begins this discussion with a detailed analysis of Vygotsky's theory of mediation, pointing out differences between the way mediation works with physical tools and the way it occurs with psychological tools such as 'inner speech.' Then, Paul Mcllvenny and Pirkko Raudaskoski discuss how mediational means like new communication technologies can transform the ways identities and social practices are constructed in the context of international adoption. Finally, Theo van Leeuwen examines the affordances and constraints inherent in the structure of texts with particular emphasis on multimodal genres.

Social practices are the topic of Part III. Here, Laurent Filliettaz explores the relationship between action, gesture, discourse and rhythm in order to show how contextualization is best conceived of as both a pre-constructed entity and as a moment-by-moment achievement of recognizable social practices. After that, Jay Lemke discusses how place and pace figure in the social practices that have developed around a particular computer game. Finally, Shawn Rowe, in his study of the way children interact around a science museum exhibit, explores how people strategically invoke and mix various social practices through the creation of hybrid activity spaces.

Part IV is devoted to the site of engagement and continues to develop the concern with timescales and trajectories introduced in the first part. In the first chapter of this section, Rodney H. Jones considers the relationship between sites of engagement and real time and space, with particular emphasis on the complex spatial and temporal contours of computer-mediated communication. After that, Ingrid de Saint-Georges considers how ethnographic fieldwork itself creates sites of engagement, or, what she calls, 'time-space stations' through the anticipatory and narrative discourses of the participants and researcher.

Part V deals with one of the most important, but thus far least examined questions in MDA: the question of agency. Who exactly is it that is performing the mediated action? Is agency a matter of the individual consciousness or a matter of multiple goals, interests and intentions spread across individuals, groups, 


\section{Rodney H. Jones and Sigrid Norris}

mediational means and social practices? Suzie Scollon takes up the issue of agency in relation to the ways Chinese immigrants in the US interact with the bureaucratic regulations of the federal census. Agency, she argues, is not a matter of individual will but, rather, something that is distributed across multiple individuals and groups and resemiotized in physical tools like census forms. Sigrid Norris, in the last chapter of this part, contrasts the ways a married and a divorced woman use discourse and other mediational means to construct a sense of agency or control over their lives, and how this process is related to larger discourses of gender relations and power.

All of these chapters, on the one hand, show the diversity of theory and method that has contributed to the development of mediated discourse analysis. On the other hand, they also highlight the themes common to MDA: a concern with action before discourse, a preoccupation with finding ways to integrate macrosociological analysis with the fine-grained analysis of situated social interaction, and a desire to apply the tools of discourse analysis to understanding and solving pressing social problems. Hopefully they will serve not just to inform readers about the possibilities of this new approach to discourse, but also inspire them to think about the theoretical principles we are presenting, to challenge them to make their own contributions to the understanding of how discourse is a matter of social action. Most of all, it is hoped that the approach outlined here will inspire readers to reflect in a new way on their own real-time, concrete actions and understand how they might be related to larger issues of power, equity and justice. As R. Scollon (2002: para. 12) reminds us, the ultimate aim of mediated discourse analysis, or any other intellectual pursuit, is not just to help us understand other people's actions, but to help us understand the potential of our own everyday actions to create positive social change.

\section{Note}

1 Gee distinguishes 'capital D Discourse' from 'small d discourse' (language in use), and defines discourse analysis as the 'study of Discourses in discourse' (1999). 


\section{Part I}

\section{Mediated action}





\title{
2 Introducing mediated action
}

\author{
Sigrid Norris and Rodney H. Jones
}

Mediated action: Unit of analysis.

A mediated action focuses on two elements: the agent and the mediational means, emphasizing an inherent irreducible tension between the two.

The concept of mediated action must always remain problematized.

The focus of analysis is always on social actors as they are acting because these are the moments in social life when the Discourses which we are interested in are instantiated in the social world as social action.

The focus of mediated discourse analysis is the mediated action - within a dialogical chain of such social actions as well as within a hierarchy of simultaneously occurring practices.

Lower-level action: The smallest interactional meaning unit.

Higher-level action: Bracketed by an opening/closing and made up of a multiplicity of chained lower-level actions.

Often we find several embedded and/or overarching higher-level actions.

Frozen action: Higher-level actions, which are entailed in material objects. 
The unit of analysis for mediated discourse analysis is the mediated action. The concept of a mediated action was proposed by Wertsch (1991) and is largely based on Vygotskyian psychology. Wertsch (1998) discusses in detail the irreducible tension between actor and mediational means, saying that '[the] analysis of mediated action focuses on two elements: agent and mediational means' (Wertsch, 1998: 25). This constant tension, then, is expressed in the unit of analysis as an agent acting with or through a mediational means. A mediated action is thus never carried out by an actor alone, but is always and only possible if both elements of agent and mediational means are co-present.

R. Scollon takes on the notion of mediated action and emphasizes that, for ' $[t]$ he concept [of mediated action] to remain useful, [it] must always remain problematized' (R. Scollon, 1998: 11). Thus, the concept of mediated action is always contingent, and, for it to be useful as a unit of analysis, it must be constantly interrogated. R. Scollon (2001a) emphasizes that 'the focus is on social actors as they are acting because these are the moments in social life when the Discourses which we are interested in are instantiated in the social world as social action' (R. Scollon, 2001a: 3). Here, he also builds on Wertsch (1998), who points out that sometimes, when analyzing a mediated action, the agent may be of greater influence, while at other times, the mediational means may take on priority within the action itself. R. Scollon (2001a) argues further that ' $[t]$ he mediated action (within a dialogical chain of such social actions as well as within a hierarchy of simultaneously occurring practices) is the focus of mediated discourse analysis.' This dual focus on social actors and actions taken, including the mediational means through which the actions are performed, allows analysis of the actions in their complexity. Reducing this complexity in any way is something we are trying to avoid in mediated discourse analysis.

R. Scollon (2001a) develops the framework of mediated discourse analysis further, broadening the complexities to integrate the macro and the micro, calling for a nexus analysis. Here, he highlights the facts that mediated actions form - and are a part of - chains of dialogic actions. All social action, as R. Scollon (2001a: 6) states, "is based in tacit, normally non-conscious actions. "Practice" is the term most commonly used to refer to action-in-the-world.' R. Scollon follows the notions found in Nishida (1958), Bateson (1972) and Bourdieu (1977, 1990), ‘taking practice as the milieu of social action' (R. Scollon, 2001a: 6).

Norris (2004b: 11), looking at multimodal interaction, divides mediated actions into lower-level actions, as the smallest interactional meaning units; higher-level actions, as actions that are bracketed by an opening/closing and made up of a multiplicity of chained lower-level actions; and frozen actions, which are entailed in material objects.

As can be seen in this brief introduction, defining and mapping the contours of mediated actions is a perpetual work in progress. Mediated discourse analysts 
constantly strive to build a better understanding of this central concept. In the following two chapters, R. Scollon and Nevile build on the notions that we have discussed so far. In Chapter 3, R. Scollon illustrates that actions are rhythmically entrained to at least six different (but integrated) pace-makers (Zeitgeber), problematizing the mediated action and some common concepts of time. Then, in Chapter 4, Nevile looks at interaction in an airline cockpit and demonstrates how the pilots create and act on understandings of organization of actions in larger and smaller sequences, problematizing the levels of mediated action that have been discussed so far. 


\title{
3 The rhythmic integration of action and discourse: work, the body and the earth
}

\author{
Ron Scollon
}

What is it that's going on here?

(Erving Goffman, Frame Analysis, 1974a: 8)

The facts of human natural history that throw light on our problem, are difficult for us to find out, for our talk passes them by, it is occupied with other things. (In the same way we tell someone: 'Go into the shop and buy ...' - not 'Put your left foot in front of your right foot etc. etc. then put coins down on the counter, etc. etc.')

(Ludwig Wittgenstein, Remarks on the Philosophy of Psychology, 1980: 83)

\section{What after all is action?}

Mediated discourse analysis (MDA) has strategized its work by focusing on the mediated action, that is a social actor taking an action through the use of some mediational means (Wertsch, 1991). This is a way of positioning the focus at a point that is neither the individual (the social actor) nor the society (the mediational means) but the point at which these are brought concretely into engagement. Within MDA, discourse is seen as a kind of mediated action. Discourse is language in use, but we do not mean language 'in general' or abstractly; we mean some particular word, sentence, phrase, intonation, or perhaps a genre that is appropriated by a social actor to accomplish a specific action at a specific place and in a concrete moment. In this view discourse is not just the action, not just the language; it is the bit of language as it is used in taking an action.

The focus on action in MDA which gives us this view of language (and, of course, other semiotic systems) as mediational means has been useful but it has not been without problems. The two problems that I will address in this chapter are, first, that actions are always complex, never simple, and, second, that the relationships between discourse and non-discursive action are also complex. 
As the epigrams from Goffman (1974) and Wittgenstein both suggest and as Norris (2004b) discusses in detail, action may be viewed at 'higher' and 'lower' levels - we are going shopping or we are walking or we are stepping or we are lifting a foot and placing it ahead of the other, leaning forward onto that foot while lifting the other. Which is the appropriate level at which to assign the word 'action?' And what then is happening at the levels below and above the level we've called attention to? Of course we have the useful tri-stratal proposal of Leont'ev (1978) of action-activity-activity system which certainly addresses some of this problem. But we still must deal with how we talk about action, both as participants in social actions and as analysts. Our common language of action tends to blind us to other levels or types of action.

The second problem may be even more difficult to work out for MDA because it has been argued convincingly by many that language (i.e. discursive action) relates to action (i.e. non-discursive action) in several ways. Language may be the action itself, as in pragmatics (Austin, 1962; Searle, 1969); it may complement action, as shown in gesture research (McNeill, 1992; Goodwin, 1981) as well as pragmatics (Filliettaz, 2004b); it may follow action, as much research on narrative has shown (Schiffrin, 1996, 2000; Johnstone, 1990) as have the discursive psychologists (Harré, 1998; Wetherell, 2003); it may anticipate the action (de Saint-Georges, 2004; S. Scollon, 2001), be irrelevant to action as a secondary involvement (Goffman, 1959; Filliettaz, 2004b), or even obstruct action (Gu, 2002).

Most troubling but also interesting are the cases where the discourse, or in this case it might be better to say language, is either irrelevant to the action or at such a distance from the action that it isn't easily located (Yelyseieva Tovares, 2003), or the cases where the discourse is somehow resemiotized (Iedema, 2003) into objects or internalized into practice and so not overtly present in the action as language at all.

My purpose in this chapter can hardly be to solve these thorny issues. My goal is the more modest one of trying to sketch out the dimensions of the problems of the entrainments of action in time and space in a wider circumference (Burke, 1950; Scollon and Scollon, 2004) so that subsequent research will have a somewhat more systematic framework for addressing them.

\section{The floor-nailer}

On July 23, 2003 Rex Luxton, my brother-in-law, and I laid a northern pine floor in a small bedroom in our house in Alaska. Figure 3.1 is a picture of a moment in that stream of action.

In Figure 3.1 the pine floor planks have been cut and roughly laid out in several ranks ahead of the nailing, which is proceeding in the photo from left to right. Ron had hammered the plank to be nailed into a tight fit and is holding it with his 


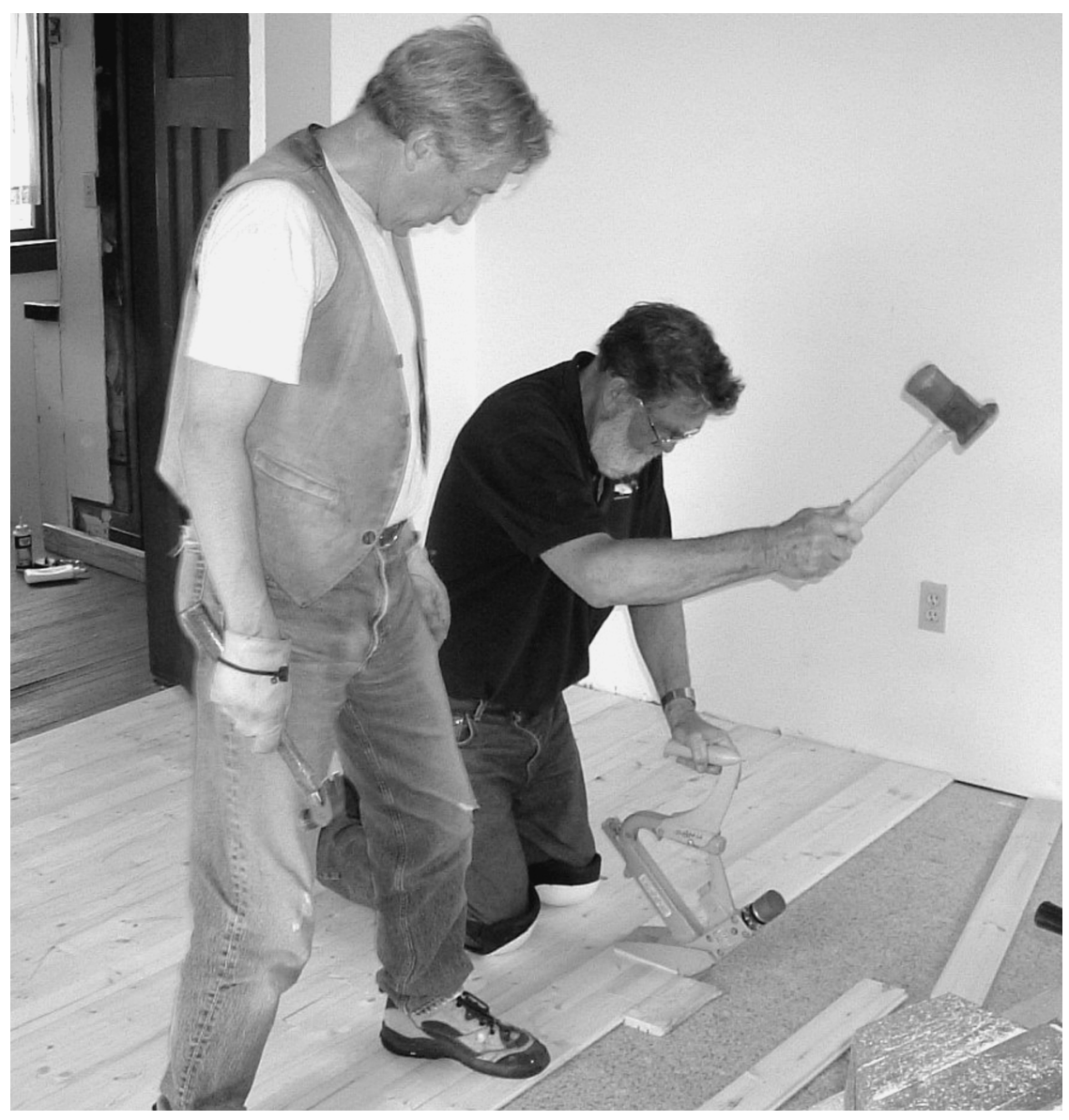

Figure 3.1 Floor-nailer

weight by standing on it. Rex is swinging the mallet against the floor-nailer, a small hand-operated machine designed to do just this one job. The photo has arrested his hand in mid-swing.

At the narrowest level (the cardiac-respiratory level) this hammering moves with a steady, rhythmic beat which I can replicate using line conventions:

$$
\begin{aligned}
& \text { bam - bam - BAM - (rest), } \\
& <\text { shift - the - floor-nailer }>\text {, } \\
& \text { bam - bam - BAM - (rest), } \\
& <\text { shift - the - floor-nailer }>\text {, } \\
& \text { bam - bam - BAM - (rest) }
\end{aligned}
$$


This regular rhythmic pulsation allows the smooth integration of Ron's movement along the plank being held in place. He moves to his right in time with the shift of the floor-nailer to the right. The floor goes down quickly and smoothly. It is important to notice that neither of the team speaks to the other as this is happening.

Dorothy comes to the door and asks, 'Rex, do you want me to bring you some coffee or are you guys going to take a break?' Rex answers, 'When we get these next two rows down, we'll come down for a break.' And with this burst of talk we anticipate closing out one stretch of work (measuring and snapping a centerline, gluing and face-nailing the first two rows, and cutting and laying about 20 rows).

Rex asks, 'How many's that?' We count. 'I get 24.' He says, 'The same' after a pause as he looks across the room. We're about a third of the way across the floor. 'Will we be done by lunch?' I answer, 'Those last three or four will go a lot slower.' He suggests, 'Afternoon break.'

So with this bit of talk we tie up one segment of a few hours of work and sketch out a schedule for the rest: a coffee break, another stint of work up to lunch and then finishing up in the few hours right after lunch. In this way we organize the 24-hour daily cycle (the circadian cycle) into a sequence of events at the level of the intermediate metabolic cycles; coffee, lunch, and afternoon break are interspersed with 2-3-hour periods of work on the floor.

Rex and Dorothy were on their summer camping vacation (the solar cycle: camping in Alaska occurs in the warm summer months of the annual cycle). Within that cycle, they were visiting us for a week in Haines where they were waiting for the Alaska State Ferry to take them and their camper south via the Inside Passage to the terminal at Bellingham, Washington. This portion of their summer was a working visit which included on the first day helping us load the flooring into a storage place in the basement of the house and then on the second day started with the flooring of the small bedroom. This week included laying three other floors.

And, finally, there are a host of entropic cycles. The flooring materials were northern pine which was recently milled in the Yukon Territory. When it was delivered we were told that it was best to not leave it just loosely stacked for any great length of time because as the wood began to absorb moisture in the damper climate of Haines (on the Pacific Ocean) it could begin to warp and it would be harder to work with. No specific cycle of moisture absorption was given, but we wanted to get the floors down when the wood was at its straightest.

That was one entropic cycle that was central in this action cycle. Another was human fatigue. The floor-nailer works with a $4 \mathrm{lb}$ mallet. There were physical limits to how long we could hammer with the mallet before our muscles needed a rest. 


\section{Ron Scollon}

The action that was arrested in Figure 3.1 was a layered simultaneity ${ }^{1}$ (Blommaert, 2004) in which the regular pulsations (bam - bam - BAM - (rest)) of the hammering were layered within metabolic cycles of eating and working. Those cycles were layered, in turn, within a cycle of six days of work which included not only flooring but quite a few other jobs. Those six days of work were encompassed within a summer vacation. And throughout these projects we bent and broke nails, we splintered floor planks, we drank coffee and tea, ate meals and in hundreds of other ways entrained our actions to the materials we used.

\section{Rhythmic pace-makers (Zeitgeber)}

This example illustrates what I mean when I say that actions are rhythmically entrained to at least six different (but integrated) pace-makers (Zeitgeber):

- The cardiac-respiratory cycle: pulsations of the heart and of breathing

- The metabolic cycle: ebbs and flows of ingestion, digestion, and elimination, pain cycles, drowsiness cycles

- The circadian cycle: 24-hour revolution of the earth about its axis

- The lunar cycle: 28-day revolution of the moon about the earth

- The solar cycle: 365-day revolution of the earth about the sun

- Entropic cycles: formation and decay of material substances

The first two of these are anatomical or human-biological pace-makers. Hammering, sawing, walking, lifting, speaking, writing by hand or with a machine give short rhythms of the cardiac-respiratory system (fractions of a second to a few seconds). Within a metabolic cycle a stint of work, a conversation, a meeting, a trip to the store, a sporting event, or a meal, center on a cycle of a few hours at the most. This cycle is constrained by the needs of eating and digestion or the length of time we can sustain continuous physical or mental effort.

The next three cycles we might call geosemiotic cycles because they are entrained to the earth and its relationships to the moon and the sun. Most of our activities from a day of work to a vacation hike are timed to fall within the 24-hour cycle of waking and sleeping which, even in the polar latitudes, brackets our lives into 24-hour segments. Our lives are further entrained to the lunar cycle both physically (the rising and falling of tides so crucial to fishermen; menstrual cycles; rising and falling crime rates in urban centers) and through the longstanding conventions of monthly pay periods and billing cycles (mortgages, credit cards, or utilities). And, third, the annual cycles of seasons are geared into such projects as urban planning, roadworks, school cycles, or job rotations.

The sixth cycle has to do not only with the material tools we use to undertake action (hammers and saws, word processors and paper, desks and chairs, roadways 
and signs, books and buildings) but with our bodies themselves as material entities. These cycles are as many as the materials we use to carry out our lives; highly volatile glues and solvents evaporate within seconds but our plastic soda bottles threaten to outlast the planet. The entropy cycle of each substance contributes a cycle of its own to the conduct of the actions of our daily lives.

In writing so far I have used the concept of 'entrainment' to speak of the relationship between an action and one of these cycles. It is important here to be clear about what I mean by this. While there is substantial research on the physiological and anatomical entrainments of the human body to the circadian (24-hour) cycles (Moore-Ede et al., 1982), we know considerably less about cycles with both shorter and longer periodicities. Here, then, I follow Lemke (2000b), who argues that the relationships between higher- and lower-level timescales is one in which higher levels constrain (but do not predict or cause) the units of the lower levels. In this sense I would argue that, for example, the solar cycle with the rotation of seasons sets constraints within rather broad 'moments.'

Replacing the windows in an Alaskan house is an activity, an action sequence, that is better done in the summer than in the winter because of the exposure to the weather that this entails. Within that constraint, the action of opening up the gap in an exterior wall could happen in June, July or August, on a Tuesday or a Saturday, at 8:00 am or at 3:00 pm. Nevertheless, if we shift down to the circadian cycle, it is better to do the job at 8:00 am than at 3:00 pm because the job comes down to one that is constrained by the circadian sleep-wake cycle and by the metabolic cycle. It takes about 5 hours to open up the gap, place in the new window, and seal it up against the weather. That work/material cycle is more easily accommodated if it is inserted conveniently between two meal breaks.

In this way, when I write of entrainment between actions and cycles, what I mean to say is that the periodicity of the cycle sets constraints on actions that can be taken within that cycle. I do not mean to say that there is any fixed linkage between an action in a larger cycle (replacing the window) and an action in a smaller cycle (trimming back the excess wallboard ends). Also, I do not mean to say that an action that is entrained to a longer cycle would take a length of time to accomplish that equals the periodicity of the longer cycle. It is good to do the windows in the summer but it does not take all summer to do the job.

Blommaert (2004) alerts us to the ideological power of reducing such constraints and entrainments to simple metonyms. He refers to this process as synchronization. An example of this would be to say that Rex's summer vacation was (nothing but) his six days of working on our new floors; or that the summer of 2003 was all about Rex laying floors in our reconstruction project; that laying wood floors is nothing but hammering on the floor-nailer; or that learning to use the floor-nailer is all there is to being able to lay a wood floor. To reduce the multiple cycles that circulate through an action to the meaning of just any one of 


\section{Ron Scollon}

them is to reduce the fundamental complexity of action to unitary meanings. ${ }^{2}$ Such reductionism is disabling to the richer analysis we hope to achieve with mediated discourse analysis. As Wittgenstein pointed out in the opening epigram, such reductions are blinding to both social actors and to analysts of action. They often serve an ideological discursive-rhetorical strategy as well as to hide the more complex operations behind a few highlighted actions.

With these clarifications we can turn to Figure 3.2, which shows these multiple cycles circulating through a moment of action.

These cycles are integrated somewhat like the integrated gears in a vehicle's transmission system, the differential gearbox. In a vehicle, the differential allows the drive shaft, which is turning at one speed, to transmit its power to separate driving wheels which revolve at different speeds while turning corners. Analogously, a social actor is engaged in action simultaneously in all of these cycles and

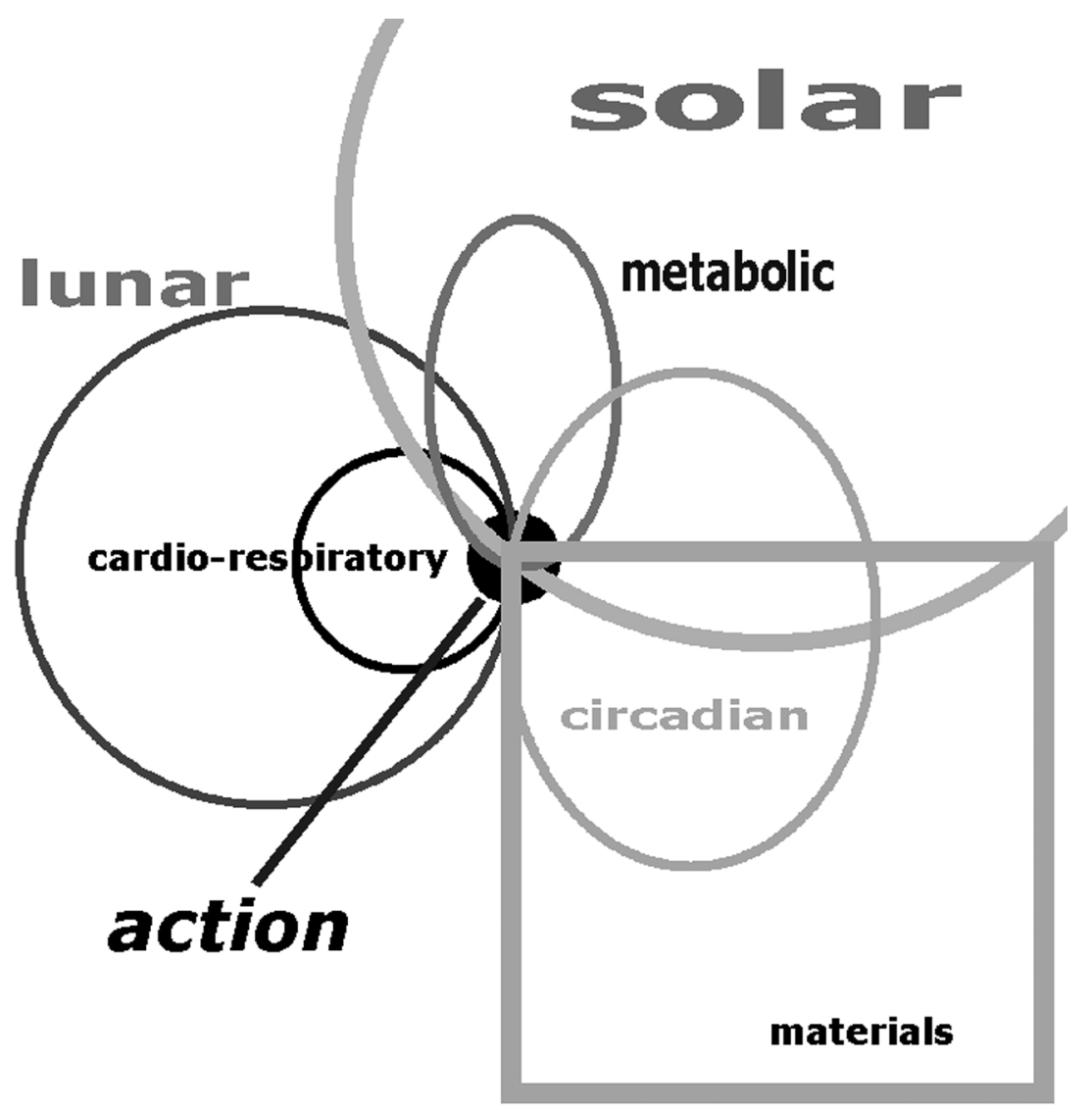

Figure 3.2 Cycles 
these cycles are, in turn, integrated with each other. Thus I suggest that all agency is differential in this sense of the word. Most commonly our analysis of the actions of social actors has strategically (or conventionally) isolated just one of these rhythmic cycles for attention; we speak of 'taking a step' or of 'taking a walk' but not often do we speak of taking a walk as taking a sequence of steps. This suggests that mediated discourse analysis needs to break away from the common discourses of human action in its analyses to examine in each case the full range of rhythmic cycles within which an action is integrated.

\section{Spatial spheres}

Perhaps it is a miracle that in working on 2,000 square feet of flooring two people, both amateurs at this work, did not have an occasion in which the standing person stepped on the kneeling floor-nailer nor did we have an occasion on which the 4lb mallet landed on the foot or shin of the person standing to provide the weight to keep the planks snug while they were being nailed. This close integration of the actions of two people with tools and materials within a confined space points to a second set of spatial entrainments that, ultimately, are inseparable from the temporal entrainments I have just discussed.

Edward T. Hall (1959) introduced the idea that as social beings when we communicate face-to-face, or side-by-side as in this example, we do so from within semiotically meaningful 'bubbles' of space. While Hall's writing and much of the writing following from his work has focused on the sociocultural meanings of these spaces and distances, it was the geographer Hägerstrand (1978) who began to work out how our fundamental ubiation, to revive a venerable old word, as bodies in the world (Scollon, 2004) is central to any analysis of how we act.

It would be important on another occasion to investigate the human spheres of action (ubiations) entailed, for example, when the body is in action without a material tool, in action with an inactive tool such as reading a book, or a highly active tool such as cutting with a saw or pounding with a hammer. For my purposes here, however, I can only provide a sketch of the way in which spatial considerations interact with the rhythmic cycles I have described above. Perhaps there are three of these:

- bounded spaces such as the rooms of houses, garden fences or concert stages constrain the actions that may be taken within them. Laying the floor in a large room afforded space for two people to work along with a small stack of flooring strips, a chop saw, multiple hammers and prybars, the floor-nailer and boxes of cut scrap ends of flooring strips. The small bathroom attached to the sauna had to be done by one person and all the other materials had to be placed outside of the house in a space next to the back door. 
- permeable spaces are afforded by opening doors and windows. By opening the window in the bedroom we were able to position the chop saw with the inactive zones of the ends of longer boards extended outside of the house. Conversely, when sanding the flooring the airspace had to be closed to keep dust from spreading throughout the house.

- unbounded spaces such as outdoor impromptu shops or functionally unbounded spaces such as airplane hangars or warehouses allow actions to take place without undue consideration of boundaries.

There are many interactions between these ubiations or spatial considerations and the temporal cycles I have introduced before them, though I do not have the space to explicate. To give just one example, I open the window to dispose of the inactive zone of the board I want to cut or I put the table saw and chop saw outside the house by the back door. This comes up against both circadian and solar time cycle constraints. There is a bed and breakfast within 20 feet of my outside workspace. On the circadian cycle this constrains my work to hours that allow a reasonable sleeping and waking cycle for the guests. On the solar cycle, opening up windows to work, or working outside, can only be done on fair weather summer days. In this case the circadian cycles and the solar cycles produce effectively bounded spaces for the work actions I would want to take.

\section{The problem of point of view}

Like many studies of action, I began with a moment of action (Figure 3.1: bam bam - BAM - (rest)) and worked outward to see how this action was a point of circulation of other cycles of longer periodicity. This can be a restrictive and ultimately disabling strategy for analysis, however. As one opens up the cycles it seems quite straightforward to see this moment within the defining compass of the longer cycles as if they had emanated out of this moment like ripples from a pebble tossed into a still pond.

Life, however, is never a still pond. If we come to this moment of action from the point of view of many other cycles that are circulating through the moment we might see it very differently. Is this a moment in the cycle of restoration work on the house? That restoration work began a year before this when we had the roof replaced and is not yet completed as I write the first draft of this chapter in November some four months later. In a wider cycle it could be thought of as a moment in the life cycle of the house built by O'Dell in 1912, remodeled many times over by a sequence of owners, and now, yet again undergoing these material changes.

But this action is also a moment in the cycle of Dorothy and Rex's summer vacation of two months. Or should we see it as a moment in the cycle of the relationship between Ron and his brother-in-law, Rex, a cycle now in its third decade? 
Or is it a moment in the cycle of the floor-nailer and mallet rented from Haines Home Building? How many people and floors in this community are linked through the use of this one small machine? Or, more broadly, is it a moment in the business cycle of sales and rentals that go to make up this company? Even more broadly it could be seen as a moment in the annual economic cycle of summer building projects that make up much of the annual income of the community.

The number of cycles that circulate through this action of floor nailing is very large and not, in principle, limitable. I make this latter point because just now as I am using this as an example in writing a book chapter I am retroactively circulating an academic discourse through this moment. While it might be obvious that all of these cycles may be important, it is not obvious how limits may be placed on our understanding of these cycles of discourse and action which circulate through any moment of action. This leads me then to re-address my central problem: how are action and discourse integrated given this much more complex notion of action?

At the outset I noted that discourse (or language) may be the action itself, may complement action, may follow action or precede it, or may be irrelevant to or obstructive of action. I believe this is true for any of the cycles or spatial spheres within which we consider action. But we also now have some limited amount of research that begins to show us how we can address these problems. Narrative studies make it clear that retrospective accounts of either action (Labov, 1972) or histories (Wertsch, 1997) are powerful anticipatory discourses that set limits on what is a possible or meaningful future action. In an important ethnographic study of work and workplaces, de Saint-Georges (2004) has noted that anticipatory discourse in the form of schedules, plans or projections for projects are important contraints on the actions of worker/trainees, and retrospective discourse tends to take the form of evaluations. In her research it was clear that on the job itself there is relatively little talk, with long stretches of work or listening to the radio. This is much the same as I have found in my data concerning these restoration projects from flooring to replacing windows. Also, Filliettaz (this volume) has shown how discourse at any moment works to frame both prior and subsequent actions in cycles that lie outside of the ongoing moment of interaction.

If we open up the scope of what we consider to be discourse we find that discourse permeates our actions at all levels in the form of what Iedema calls resemiotizations (Iedema, 2003), Bernstein (1990) calls recontextualizations, or Silverstein and Urban (1996) refer to as entextualizations; Vygotskians would refer to internalizations (Scollon and Scollon, 2004). Don Bollinger (1990) lays hardwood floors professionally. He resemiotizes his practical experience as a book on how to lay, sand and finish floors. Suzie takes this book out of the Haines public library and, thinking that we might ourselves put in a tongue and groove floor, we read it to see if it is feasible for us to do this. Simultaneously we discuss flooring 


\section{Ron Scollon}

materials with our friends at Haines Home Building and Supply. In those conversations words, phrases, technical terms and ideas from Bollinger's book come into our daily speech. That leads, through several telephone calls and faxed price lists to our agreement to buy 2,000 square feet of northern pine milled in the Yukon, Canada.

Note that by the time the wood is brought into the house and stacked it is no longer (for us) just so many pieces of tongue and groove wood. It is plank flooring which we compare with the photographs in Bollinger's book. When the wood is delivered, Brad, from whom we've bought the wood and who delivers it to us, takes 20 minutes to go over with me how to lay the floor. As he speaks I compare in my mind what I've read in Bollinger's book and raise questions at points of difference. In this way spoken and written discourses come into dialogue and become progressively internalized as potential practice. I have yet to lay a piece of wood. For one thing we have no floor-nailer, a machine that both Bollinger and Brad have said is an essential tool for the job. Is there one in Haines? Asking around in the three possible stores we find that there is one and we can rent it.

By the time we come to the task of laying the floor we have gone through some weeks of talk and text, telephone calls and faxes, specifications and price lists, floor measurements and discussions of possible finishes. This all becomes resemiotized as neat stacks of plank tongue and groove flooring in the basement, a floor that is measured and which has a chalk centerline snapped onto it. By the time we start to face-nail (a term now internalized as part of our linguistic practice, first learned in making a tongue and groove sauna 15 years earlier and revived in reading Bollinger) the first row, much discourse has been internalized or resemiotized as practice. As we nail the first rows and then begin to use the floor-nailer in Figure 3.1 we do not speak; much of the discourse has by now been sunk through these anticipations and resemiotizations into practice. Overt discourse as discourse in complement with the action emerges only at points where it seems to one of us that we've strayed from our anticipations or our (obviously rather limited) knowledge and practice doesn't cover the case.

These resemiotizations produce cycles of action and discourse that circulate through any moment of action as practice, as tool, and also as more overt discourses such as text and talk. It is in this sense, I argue, that all action is differential and this layered simultaneity of multiple cycles of discourse is both a challenge and a powerful opportunity for us to enrich our thinking about discourse and action within the framework of mediated discourse analysis.

\section{Notes}

1 Blommaert (2004) has developed his idea of 'layered simultaneity' from Braudel's idea that we can only comprehend the long-term historical cycles of epochs (Braudel's longue 
durée) by an analysis of the intermediate cycles (such as political regimes) within which are the yet shorter-term cycles (événement) of events (see, for example, Braudel 1981) and from Wallerstein's writings on the development of the world system (see Wallerstein, 1983). In the analysis I am developing here I would situate Braudel's event cycle at the lunar cycle level and his intermediate cycle at the solar cycle level. I do not doubt that Braudel's longue durée could be entrained to longer planetary cycles but I have not taken on that question here.

2 As I have noted earlier, it is a further such metonymy to reduce multiple and intersecting actions of multiple social actors to the actions of any single agent. 


\title{
4 You always have to land: accomplishing the sequential organization of actions to land an airliner
}

\author{
Maurice Nevile
}

\begin{abstract}
As a cautionary saying in aviation circles puts it, you never have to take off, but you always have to land. In this chapter I draw on insights and methods of ethnomethodology and conversation analysis (EM/CA: see Hutchby and Wooffitt, 1998; ten Have, 1999) to consider processes of talk-in-interaction in the airline cockpit as pilots collaborate to develop necessary understandings and perform actions to land their plane. ${ }^{1}$ The airline cockpit is a task-oriented high-technology work setting where it is critically important to perform activities and complete actions in strict sequence. That is, one activity or action becomes appropriate, or even possible, only when some other activity or action has been completed, and is understood to be so by both pilots. The pilots routinely orient to and achieve this sequential organization of their work, moment-to-moment, by drawing upon and coordinating a range of available resources. That is, talk-in-interaction for actions in the airline cockpit is mediated by textual materials such as formal procedures, wordings and checklists, information available from visual displays, aural alerts and other sounds, and non-talk activities such as moving levers and pushing buttons. Mediated actions in the cockpit involve not just the use of, but the situated and temporal realization of, these resources in ways that are constitutive of the work of airline pilots. I will focus here on two features: the use of prosody to construct and distinguish between action sequences, and a particular orientation for precise timing of non-talk activities relative to talk - a readiness for action.

This chapter is therefore an EM/CA take on matters significant to MDA, such as the role and coordination of various communicative modes and levels of action (Norris, 2004b; this volume) and the emergence, trajectory and evolution of actions and systems over time (R. Scollon, 1998, this volume; Lemke, 2000b). In particular, what I see in and make of the data is guided most immediately by interest in EM/CA in the sequential order in naturally occurring human social interaction, in micro analysis of how participants collaborate to organize their contributions by projecting and recognizing what is being done, and so what is a relevant next thing to understand, say or do.
\end{abstract}


EM/CA has much to offer MDA (R. Scollon, 1998, 1999). In EM/CA, especially after Goodwin (1981), there has been a steadily growing interest in the sequential organization of means, other than talk, by which participants accomplish social actions in interaction, including gesture, body positioning and movement, gaze, and the location and use of objects and physical features of the setting (e.g. ten Have and Psathas, 1995). This interest has turned to interaction in complex sociotechnical work settings (e.g. Button, 1993; Goodwin, 1995, 1996; Heath and Luff, 2000), and has informed studies of human cognition, and cognition for work, as situated, embodied and socially shared understandings, evolving over time (Resnick et al., 1991, 1997). This is 'knowing' as it arises and is used locally, dynamically, in temporally unfolding naturally occurring interaction, what Goodwin (1996: 399) refers to as 'the interactive organization of knowledge.' In particular, my interest here furthers work on situated cognition in the airline cockpit (Hutchins, 1995b; Hutchins and Klausen, 1996; Hutchins and Palen, 1997).

\section{'Flaps ten thanks': the data}

I use naturally occurring data, a transcription from a video recording of pilots at work landing a scheduled passenger flight. I produced the recording by arrangement with a leading Australian regional airline ${ }^{2}$ as part of a larger research project on routine talk-in-interaction in the airline cockpit (Nevile, 2004). The transcription here reflects the concern of EM/CA to include many more details than the participants' words, such as precise measures of silence, prosodic features (e.g. pitch variation, sound lengthenings), and participants' non-talk activities (e.g. body position and movement, interaction with objects). Transcription notation is given at the end of the chapter.

To a non-aviation audience, the transcription may appear bewildering, perhaps nonsensical, because of the specialist nature of the actions and terminology. On the other hand, to a pilot the data might look so simple and straightforward as to be uninteresting, taken for granted. Yet, it is precisely this simplicity and takenfor-grantedness in which I am interested, the pilots' organization and understanding of their work as routine and unremarkable. Exactly what do the pilots say and do, and how and when do they do so, to collaborate to complete a number of actions in sequence to land their airliner as an entirely routine accomplishment? What is it, beyond the knowledge and skills imparted by professional manuals and training programs, that constitutes competent practice for an airline pilot? These are not trivial questions, and as simple as the segment might look to some, many flights have come to grief because something went wrong, was not done appropriately, or went unnoticed, at just the point in the flight corresponding to the segment examined here. For example, there are instances of airline flight crews 


\section{Maurice Nevile}

landing without the landing gear (wheel assemblies) correctly lowered (BASI, 1996; FSF, 1997).

Here is the full data segment. The PF is the 'Pilot-Flying,' the pilot in control of the plane and responsible for making the input and decisions that immediately affect its handling and performance. The PNF is the 'Pilot-Not-Flying,' whose duties include assisting the PF. The segment begins as the plane is just a few minutes from landing, as the PF calls for the wing flaps to be set at 10 degrees. Wing flaps are moveable surfaces that are extended to make the wings larger to increase their lift at the lower speeds for landing and takeoff. The segment concludes as the plane touches down. I use the fictitious destination Smalltown (line 32) to conceal the identity of the flight and so preserve the pilots' anonymity:

(1) (37.7)

(2) PF: flaps ten thanks::,

(3) (5.6)

(4) PNF: -kay: you've got flaps ten.

(5) (39.3)

(6) PF: gear down thanks,

(7) (13.0)

(8) PNF: a:nd down four greens.

(9) (9.5)

(10) PF: flaps twentyfi:ve ERP go-around ${ }^{\circ}$ thanks ${ }^{\circ}$.

(11) (6.0)

(12) PNF flaps: (.) twentyfive,

(13) (3.4)

(14) PF: checks thanks,

(15) PNF: okay gear,

(16) (0.9)

(17) PF: down. $>$ four $<$ greens,

(18) PNF: down. four greens,

(19) (0.2)

(20) PNF: flaps,

(21) (0.4)

(22) PF: twentyfive set,

(23) (0.3)

(24) PNF: twentyfive set,

(25) (.)

(26) PNF: ERP,

(27) (1.0)

(28) PF: go around, 
PNF: a:nd landing clearance.

I'll summarize what happens in the data. The segment can be logically broken into three parts, coinciding with three larger action sequences as the pilots work to land the plane: preparing the plane for landing; conducting the landing checklist; and descending through the 500-feet altitude mark. Each larger action sequence is composed of smaller action sequences. First, from lines 2 to 12, the pilots perform actions to prepare the plane for landing, by setting the wing flaps to a required position (lines 2-4), then by lowering the landing gear (lines 6-8), and finally by re-setting the wing flaps (lines 10-12) and choosing an engine power setting ('ERP go-around', line 10). For each action the 'Pilot-Flying' (PF) talks to call for the action, the 'Pilot-Not-Flying' (PNF) performs the required nontalk activity (e.g. moving a lever), and then the PNF talks to claim the action as complete. For example, to lower the landing gear the PF says 'gear down thanks,' (line 6), the PNF then moves the lever to lower the gear and monitors the instrument panel for four green lights to illuminate, indicating that all is well (the gear is down and locked in place), then claims that the gear is down with 'a:nd down four greens' (line 8).

In the second part of the segment, the pilots conduct the landing checklist (lines 14-33), initiated by the PF's call of 'checks thanks,' (line 14), and finished when the PNF calls 'check's complete' (line 33). We know the pilots understand this to be the end of the checklist because there is no further talk or action with respect to the checklist, but what follows is a 52.6 second period without talk as the plane continues its descent to the runway.

In the third and smallest part of the segment (lines 35-37) the plane descends through the altitude of 500 feet, a critical point in the descent and approach. The action for the pilots here is to acknowledge verbally that this point has been reached, and to confirm that the approach is progressing as it should and that it is appropriate to continue.

Figure 4.1 shows the same data segment but simplified schematically to show how the turns at talk occur as smaller and larger action sequences. ${ }^{3}$ 


36 Maurice Nevile
2 PF: $\quad$ flaps ten thanks::
4 PNF: -kay: you've got flaps ten.

Figure 4.1 The datä segment simplified into smaller and larger action sequences

\section{Organizing larger and smaller sequences of action: prosodic signaling of incompletion and completion}

Interaction in the airline cockpit is directed and constrained by formal manuals that outline procedures, wordings and checklists (also available in cockpit displays) that specify the actions pilots must perform and their relative ordering. All of the actions and almost all of the talk in the segment here are mediated by these textual materials. My interest here (Figure 4.1) is in the processes of interaction by which this mediation is realized, by these pilots here and now, and specifically in how the pilots create and act on understandings of organization of actions into larger and smaller sequences, as higher- and lower-level actions (Norris, 2004b). One way these pilots accomplish the sequential organization of their work is through prosodic features of their talk, specifically, using either rising or falling pitch at the end of turns at talk to signal completion and incompletion. 
A number of EM/CA researchers consider the role of prosody for the organization of interaction (see e.g. Couper-Kuhlen and Selting, 1996; Selting and Couper-Kuhlen, 2001), and some show how flat or slight rising pitch at end of turn is one way by which participants signal forms of incompletion, that some talk or other form of contribution may or should be coming next, possibly to produce some sort of completeness of talk or action or understanding, or at least that such completion is called for. Selting (2001: 246) calls this 'continuing prosody.' While such talk is hearably incomplete and can project something to follow, falling turn-ending pitch can signal completion and that nothing is projected to follow. Prosody is a resource that pilots may draw upon as they sequence their talk and actions.

I will look first at the simplest example, the last part of the segment as the plane descends through the critical altitude 500 feet (lines 35-37). The required procedure here is for the PNF to monitor his altitude display and call out when the 500 -feet altitude is being passed. The PF is required to then check the display on his side of the cockpit and say 'check' /'checked' to confirm the altitude. This is what happens:

PNF: a:nd five hundred,

(0.4)

PF: $\quad$ checked.

(57.8)

((sounds indicating plane has landed))

The required procedures do not ask for the PNF to use rising turn-ending pitch, but this is what he actually does, as shown in the transcription by the ',' ('a:nd five hundred,' line 35). The slight rising pitch projects incompleteness, and can be heard as signaling that something else is required to follow. On the other hand, the PF's response, completing the action of checking the altitude, is said with falling terminal pitch ('checked.', line 37). We know this is heard and understood as completing the action, unproblematically, because there is no further talk of the altitude, and some 57.8 seconds of silence pass before the plane touches down.

I will now look at the first two smaller actions to prepare the plane for landing (lines 2-8). The PF ends his turns, calling for some non-talk activity and talk from the PNF, with slight rising pitch, producing what can be heard as incomplete talk, projecting the need for some next thing. He says 'flaps ten thanks::,' (line 2), and 'gear down thanks,' (line 6). In response, producing the talk that claims the actions to be completed, the PNF ends his turns with falling pitch. That is, the PNF says '-kay: you've got flaps ten.' (line 4), 'a:nd down four greens.' (line 8). The prosodic features of the talk can signal the relation of the two pilots' turns as paired 
members of a sequence of turns at talk for each action, one signaling incompletion, and the other completion.

However, this neat prosodic pattern is broken for the third action, setting the flaps to twentyfive, when the PF initiates the action with falling turn-ending intonation ('flaps twentyfi:ve ERP go-around 'thanks'.', line 10), and the PNF ends his turn in response with slight rising pitch ('flaps: (.) twentyfive,', line 12). That is, the PF, initiating this action, uses completing intonation, and the PNF, finishing the action, uses intonation that can be heard as projecting something to follow. Why might this be so, what might this prosody allow the pilots to do? Recall that this is the third and last action sequence in the larger action sequence to prepare the plane for landing. The PF's turn-ending falling pitch may therefore be orienting to this finality, and certainly it can be heard this way by the PNF. That is, the PF's prosody can present this called-for action as the last action, as completing a known sequence of three actions. Why then might the PNF use slight rising turn-ending pitch in response, producing talk that can be heard as projecting more to follow? The PNF may be orienting to shared knowledge that the completion of these three smaller actions makes relevant a next larger action, the landing checklist. That is, the PNF's hearably incomplete talk can be heard as projecting, even prompting, the landing checklist, which is initiated by the PF only some 3.4 seconds later.

So, prosodic features of the pilots' talk can be heard as accomplishing the sequential organization of action at more than one level, that is, for sequences of talk for specific smaller actions, and also beyond single smaller actions to complete a larger sequence of actions or to project a relevant next larger sequence of actions.

We can note a similar feature as the pilots conduct the landing checklist (lines 14-33). The checklist consists of a large action sequence composed of 'challenge/ response' type smaller sequences of talk, where the PNF calls each item to be checked (the challenge) and then each pilot has a turn at response to claim the item as checked. The PF initiates the checklist, opening the new sequence with slight rising intonation ('checks thanks,', line 14), but what is most interesting to note is that, as they progress through each item in the checklist, both pilots use slight rising turn-ending pitch. This rising pitch allows the pilots to present each turn at talk in the smaller sequence as incomplete and projecting something to follow; however, in the case of the third (final) turn in these mini-sequences of talk what is projected is in fact the next checklist item, the next mini-sequence of talk and checking activity within the larger action sequence of the checklist. For example, this is the sequence to check the landing gear:

(17) PF: down. $>$ four $<$ greens,

(18) PNF: down. four greens, 
Here, the PNF's turn at line 15 projects visual checking activity by both pilots, and the turns at talk (17-18), which will claim that checking activity to have been done. The PF's turn at line 17 projects the PNF's checking and subsequent talk (at line 18). The PNF's talk at line 18 is the last talk for this item, completing the item; however, by using rising pitch the PNF's talk is able to project the next item and action sequence for the checklist ('flaps,', line 20). That is, what is to follow is not something for this checklist item, but the next checklist item, so the talk to complete one mini-sequence also projects the initiation of the next mini-sequence. In this way, as the pilots complete mini-sequences of talk and activity for each item in the checklist, the PNF is able to present the larger sequence of the checklist itself as ongoing, open, as yet-to-be-completed. Each checklist item, each minisequence, is therefore presented as just one small part of an as-yet-incomplete whole. The PNF uses this aspect of prosody to maintain the larger action sequence (the checklist) across a series of smaller action sequences (each item) which, together, constitute that larger sequence.

As before, this apparently neat prosodic patterning is broken, though again in ways that seem interactionally significant for the pilots' creation and understanding of the sequential organization of their work. Here is how the checklist ends:

(32) PF: not required (0.3) in (0.3) Smalltown.

(33) PNF: check's complete.

As the PNF calls for the last item in the checklist, the landing clearance, for the first time he uses falling turn-ending pitch (indicated by '.') when calling for an item ('a:nd landing clearance.', line 30). This falling end pitch is one way the PNF can signal the 'lastness' of this item, that while this talk may be heard as projecting something from the PF to complete the item, this is the last time the PNF's talk will do so. The PNF is able to signal the impending end of the checklist sequence as a whole by using pitch which can be heard as completing something. Note, too, that this turn is the first item call to be prefaced by 'and', making further salient its status as the last in a list. In response, for the first time too, the PF's talk to complete an item is also produced with falling turn-ending pitch ('not required (0.3) in (0.3) Smalltown.', line 32), presenting his understanding of completeness, that there is no next item to project, that the larger action sequence of the checklist as a whole is completed. The talk that explicitly ends the checklist, the PNF's 'check's complete.' (line 33), is also said with falling terminal pitch. Falling pitch is one way these pilots show their understanding that this item, this talk, this action, is the ending of the checklist. 
40 Maurice Nevile

So, after a series of mini-sequences of turns where each turn at talk was ended with slight rising and hearably incomplete pitch, the final three turns of the larger action sequence (lines 30, 32 and 33) are all ended with falling pitch. It seems that prosody, specifically the choice of rising or falling turn-ending pitch, is a resource that these pilots draw on to develop and demonstrate their evolving understandings of a larger or higher action sequence, formed by progress through a series of smaller or lower sequences of action, as in progress or as ending. This is one way that pilots develop their moment-to-moment understandings of what they are doing, of where they are up to and what is next.

What is interesting for EM/CA studies of prosody (see Selting, 2001) is how the 'continuing prosody' identified here projects completion of a sequence, not a turn. It occurs where the turn is pragmatically complete but the sequence of which it is a part is not complete, or the smaller sequence is complete but the larger sequence of which that sequence is a part is not complete. So this continuing prosody, pitch that is left hanging, occurs with turns that are not themselves somehow incomplete, and are not fragments. It projects more-to-come, but does not occur mid-turn, projecting further talk by the speaker (i.e. turn-holding pitch). Rather, it occurs at turn's end, projecting furthering talk by the recipient. The continuing prosody therefore acts here like a kind of a prompt, much like the turn ending 'for', 'or', 'at', 'and' etc. described by Lerner (in press). It is another way of 'doing continuing' (Selting, 2001: 249).

\section{Organizing talk and non-talk activities: a readiness for action}

The video recording allows us to consider how non-talk activities mediate the sequential organization of interaction in the airline cockpit. By including details of non-talk activities, the transcription reveals their relative timing to talk as the two communicative modes emerge together to construct a trajectory of actions. We see evidence of an orientation to a state of readiness for action. One pilot (the PF) calls for particular actions, and the other pilot (the PNF) responds in a manner that minimizes delay for his contribution, the non-talk activities for the action and subsequent talk to claim completion of those activities. That is, the data show a moment-to-moment readiness by the recipient (the PNF) to interpret particular talk for its significance for initiating an action sequence and, specifically, for what it demands of him, as the recipient, as a relevant response. The PNF is ready to hear the PF's talk as a cue for his own next conduct, a cue for him to act in particular ways.

The part of the segment where non-talk activities are clear on the video is where the pilots make final preparations to the plane for landing: 
(1) (37.7)

(2) PF: flaps ten thanks::,

(3) $\quad(5.6)=(0>0.2>5.6)$

$\uparrow$

((click sound from movement of flaps lever))

(4) PNF: -kay: you've got flaps ten.

(5) (39.3)

(6) PF: gear down thanks,

$\uparrow$

(6a) PNF: ((raises left hand from leg, moves hand towards gear lever))

(6b) PNF:

(7) (13.0)

((lowers gear lever))

(8) PNF: a:nd down four greens.

(9) (9.5)

(10) PF: flaps twentyfi:ve ERP go-around ${ }^{\circ}$ thanks ${ }^{\circ}$.

(10a) PNF: $\quad$ ((left hand on flaps lever, moves hand

$(6.0)=(0>0.2>6.0)$ to ERP button))

(11a) PNF:

(12) PNF flaps: (.) twentyfive,

(13) (3.4)

(14) PF: checks thanks,

I'll comment generally first. We can see that at this stage of the flight the pilots understand that the purpose of the PF's talk is to initiate relevant actions, each one involving some non-talk activity by the PNF (e.g. moving a lever, pushing a button), and then some associated talk from the PNF to claim the action as complete, and so claim to have performed the relevant non-talk activity to make it so. We know this because it is what the pilots do, and each pilot treats his own and the other's contributions as unremarkable. That is, neither pilot does or says anything to suggest that his own or the other's contribution was in any way worthy of mention as surprising or inappropriate. The sequence of talk and activities here constitute a form of agreement between the pilots that this is how things are done to land an airliner. The actions are performed in strict order, with the exact timing at the discretion of the PF. Separating the different actions called for by the PF, there are substantial periods without talk: a little over 39 seconds (line 5), 13 seconds (line 7) and 9.5 seconds (line 9). There is also a 3.4-second break 


\section{Maurice Nevile}

between the PNF's call of the last action being completed (line 12) and the PF's call for the landing checklist to begin (line 14).

The data show that the PNF is oriented to minimizing delay for his contribution to the conduct of the actions, and that this is an important part of the way the pilots organize their work as sequenced actions. Procedures dictate that the PNF cannot begin non-talk activity for some action until the action is called for by the PF and, indeed, procedures dictate that the PNF cannot wait by resting his hand on a relevant lever or button. However, what we see is that the timing of the PNF's responses is strong evidence that the PNF is, indeed, poised ready to respond, and that such readiness is characteristic, or even a constituent feature, of the PNF's contributions for this stage of the flight, and the sequential organization of the pilots' work. The timing is evidence of the PNF's understanding of the significance of the PF's talk for initiating his own contributions in the sequences of talk and activity for different actions.

I'll turn to the data. In lines 2 and 3 we see that for the action to set flaps to position ten, a click sound indicating movement of the flaps lever can be heard just 0.2 seconds after the PF calls for this action with 'flaps ten thanks::,' This timing strongly suggests that the PNF began moving his hand (towards the lever) during the PF's talk calling for the action. This is precisely what the PNF does for the action to lower the landing gear, for which the video recording is more revealing. We see that the PNF begins to raise his left hand from his leg, and move it to the gear lever, immediately after the PF finishes saying 'gear' and begins to say 'down' (lines 6, 6a and 6b). The PNF's hand is in position on the lever, and lowers the lever, as the PF ends his talk by saying 'thanks,'. This timing enables the PNF to complete the activity of moving the lever to lower the gear as the PF completes his turn at talk to call for this activity, and immediately after the PF has said the two critical words for the action, 'gear down'. So the word 'gear' is trigger enough for the PNF to act on an understanding that the PF is calling for the gear to be lowered. The PNF completes the action by producing talk to claim that the gear is lowered and locked in place. For the action to move the flaps again, this time to position twenty-five, when the PNF comes into view his left hand, previously resting on his leg, is already at the flaps lever as the PF ends his talk with 'thanks' (lines 10 and 10a). Again, the PNF has begun to move his hand towards the relevant lever, to perform the required activity, as the PF produces the talk to call for that activity. The PNF is therefore able immediately to perform the last action, pushing the ERP button (line 11a) to select required engine power ('go-around'), just 0.2 of a second into the subsequent 6.0 second silence after the PF's talk.

The timing suggests that part of accomplishing the sequentiality of action is a readiness to perform relevant non-talk activity immediately it is called for, and so ensure minimal delay between talk and the non-talk activity it initiates. The PNF 
does not move his hand to the required lever until after the PF has uttered relevant wording to call for this, but does so immediately such wording appears. Even after what in ordinary conversation would be lengthy periods of silence, the PNF is able to use just the opening word or words of the PF's talk, not the whole turn, as the cue to begin the relevant next contribution, some non-talk activity by him. The PNF orients to a sense of immediacy in carrying out his contributions, his talk and non-talk activities, for the called-for actions. In short, what the segment here shows is that if you are helping to land an airliner, and you are asked to do something, you do it as soon as you can, even to the point of doing it as it is asked for.

\section{Conclusion: the use of prosody and timing to construct and distinguish between action sequences}

Much of what pilots say and do to fly and land their plane is required of them, mediated by formal manuals of procedures and wordings, including checklists. Actually realizing these requirements in situ, in real time on actual flights, is further mediated by non-talk activities such as moving levers and pushing buttons, and information from visual displays and critical sounds. I have considered these forms of mediation by examining in micro-detail processes of talkin-interaction for pilots' sequential organization of actions to land their plane. I discussed the use of prosody to construct and distinguish between action sequences, and evidence of a readiness for action, a particular orientation for precise timing of non-talk activities relative to another's talk. We have seen how the sequential organization of actions is accomplished to produce an entirely smooth and unremarkable landing. The pilots draw on and coordinate various interactional resources, different communicative modes (Norris, 2004b), to make relevant and timely contributions and so manage, perform, and understand, simultaneously, smaller and larger sequences of action. In this way we can begin to see how professional knowledge and expertise in the airline cockpit is enacted as experience. We see precisely how pilots create and live their work as pilots' work.

I do not claim that what we see here is what all pilots always do, but we can treat the data as informative, as representative of how pilots do their work, because the pilots themselves treat their contributions as typical, as unremarkable and unproblematic. Central to analyses in ethnomethodology and conversation analysis is the focus on seeing how the participants themselves interpret and understand what is going on. Although pilots may perform thousands of landings in the course of a working life, each and every landing must be accomplished, as Anderson et al. (1989: 143) put it, as 'yet another one, first time through,' 'here and now, for the first and only time.' You always have to land. 
44 Maurice Nevile

\section{Transcription notation}

The transcription notation used here is adapted from a system originally developed by conversation analyst Gail Jefferson. Recent variations of the system can be found in Hutchby and Wooffitt (1998) or ten Have (1999).

$\begin{array}{ll}\text { PF } & \text { Pilot-Flying } \\ \text { PNF } & \text { Pilot-Not-Flying } \\ >_{\text {four }}< & \text { Talk that is noticeably faster than surrounding talk } \\ \text { a:nd } & \text { Lengthening of a sound. The longer the sound the greater } \\ & \text { the number of colons used } \\ & \text { Talk that is quieter than surrounding talk } \\ { }^{\circ} \text { thanks }{ }^{\text {f }} & \text { Talk that is louder than surrounding talk } \\ \text { five } & \text { Falling pitch } \\ \cdot & \text { Slightly rising pitch, talk that sounds incomplete } \\ (3.4),(0.3) & \text { Silence measured in seconds and tenths of seconds } \\ (.) & \text { Silence of less than a fifth of a second i.e. less than }(0.2) \\ ((\text { click sound })) & \text { Description of contextual features e.g. sounds other than } \\ & \text { talk } \\ ((\mathbf{m o v e s} \text { hand })) & \text { (in bold) description of non-talk activity } \\ \uparrow & \text { Arrows point upwards to the precise point in talk or silence } \\ & \text { where non-talk activity or event occurs }\end{array}$

\section{Notes}

1 I thank Sigrid Norris and Rodney Jones for helpful comments on an earlier draft of this chapter, and special thanks to Sigrid for suggesting some initial directions. This paper was completed with funding support from the Faculty of Arts at the Australian National University, and for this opportunity I thank Adam Shoemaker (Dean) and Ian Chubb (Vice-Chancellor).

2 For this data I am immensely grateful to Skywest Airlines of Western Australia, and especially to the captains and crews who welcomed me aboard. I alone am entirely responsible for all transcriptions, interpretations and findings from the recordings.

3 We can think of the larger or higher-level action sequence as the 'landing sequence,' which includes the actions below as well as others (such as controlling speed, and talking to air traffic controllers) that occur prior to this data segment. 


\section{Mediated action: questions and mini projects}

\section{Questions for discussion}

1 Based on the ways Scollon and Nevile use the concept of the mediated action, how do you think adopting action as the unit of analysis changes the way we see discourse? What are some of the challenges or difficulties of approaching discourse in this way?

2 According to Scollon, our common ways of speaking about actions often blind us to the different levels (or timescales) on which actions take place. He also suggests that ways of talking about actions often have ideological underpinnings. Can you think of an example of how the ways we speak of actions can limit the ways we see them and how this might have ideological implications?

3 Scollon suggests that our actions are 'entrained' to different temporal cycles. How do these cycles affect the kinds of actions being taken and the relationship between actions entrained to one cycle and actions entrained to another? Give examples.

4 Nevile shows how people use various communicative resources as they work together to organize larger and smaller sequences of action. What are some of these resources and how are they used to organize actions along different temporal cycles?

\section{Mini projects}

1 Choose a particular everyday action that you carry out and delineate how all six pace-makers that Scollon describes in his chapter are integrated within your own performance of that action.

2 Transcribe 20 seconds of videotaped interaction and show how many sequences and layers of action you can differentiate, following Nevile's example in his chapter, and discuss how these actions are sequenced. 



\section{Part II}

\section{Mediational means/ cultural tools}





\title{
$5 \quad$ Introducing mediational means/cultural tools
}

\author{
Rodney H. Jones and Sigrid Norris
}

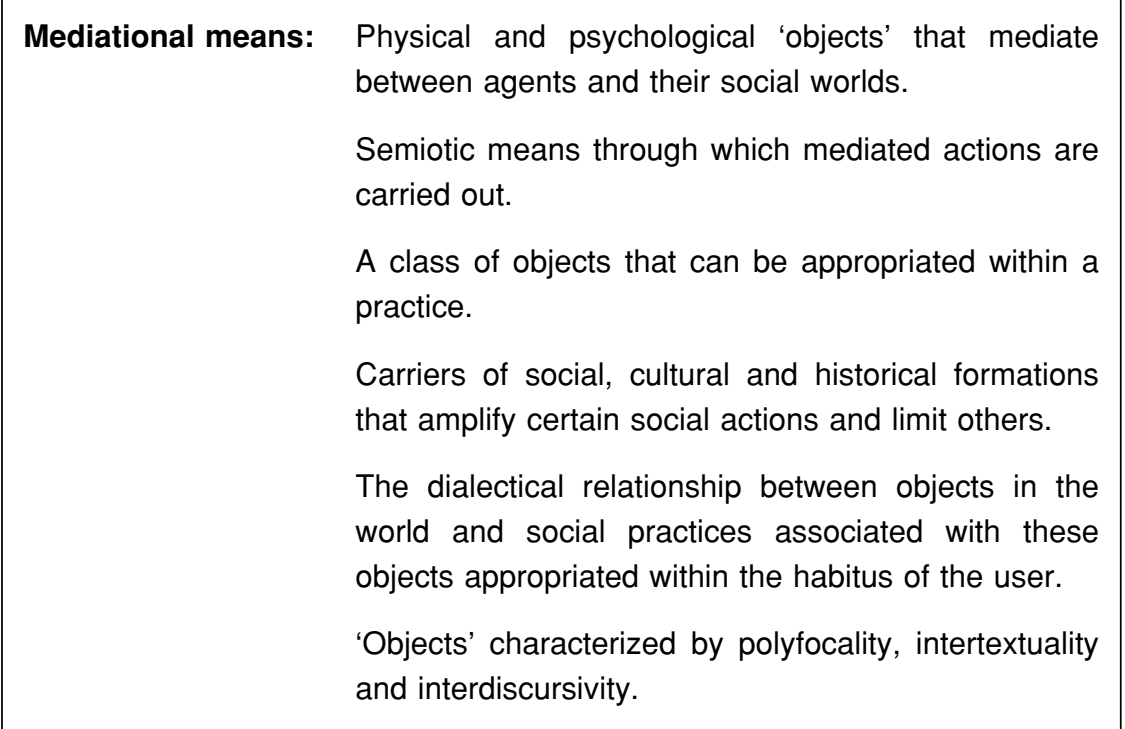

All human actions are carried out through what mediated discourse analysts call mediational means. Wertsch (1998) divides mediational means into two types: 'technical tools,' consisting of material objects like a pole-vaulter's pole, a typewriter keyboard, or a microphone; and what Vygotsky (1981: 137) refers to as 'psychological tools': 'language; various systems for counting; mnemonic techniques; algebraic symbol systems; works of art; writing; schemes, diagrams, maps, and mechanical drawings; (and) all sorts of conventional signs.' Wertsch insists, however, that all mediational means, whether technological or psychological, are essentially material. Symbolic tools like languages, for example, find 


\section{Rodney H. Jones and Sigrid Norris}

material expression in the physical world in the form of written texts and acoustic signals. At the same time, all mediational means are also essentially psychological

and 'semiotic;' that is, they exist simultaneously in the world and in the minds of their users or, to use Bourdieu's (1977) term, in their habitus. Just as psychological tools are made material through texts, utterances, practices, and identities, material tools are integrated into psychological representations of social practices in the user's habitus. In fact, it is only through being appropriated into the habitus as parts of social practices that objects become mediational means, as they arise as a codification or materialization of social practices (Scollon, 2001a).

According to Scollon (2001a: 14), 'mediational means are neither external objects nor internal psychological constructs alone, but rather represent a dialectical relationship between objective materiality and psychological or intramental process.' Rather than being 'a class of objects in the world,' he writes, they are essentially 'representations of objects . . . as integrated within specific practices in the habitus.' Understanding mediational means, therefore, requires taking both the socio-cultural histories of our habitus and the socio-cultural histories of mediational means into account.

Mediational means are also carriers of social structures, histories, and ideologies in as much as they manifest certain patterns of affordances and constraints concerning the actions that can be taken through their use. All mediational means amplify certain kinds of actions and limit others. A microphone, for example, allows its user to make their voice heard over a great distance and by a large number of people, but it limits their ability to speak privately or intimately with particular individuals or to conceal potentially embarrassing asides. At the same time, however, the constraints and affordances embodied in mediational means are not entirely deterministic of what users can do with them. Mediational means are, by their very nature, 'multifunctional' and 'polysemic,' open to appropriation into a wide range of practices outside of their normative uses within - and in combination with - other mediational means (Scollon, 2000). Thus, limitations imposed by tools can often be overcome through recontextualizing them or purposefully mixing them with other tools that offer different configurations of constraints and affordances. In this way, while mediational means transform social actions, social actions also transform mediational means.

A final important concept in considering mediational means concerns their ontogenesis, or how objects become mediational means through the process of what Scollon calls technologization. Technologization is essentially a social process by which objects are integrated into recognizable social practices that are used to enact recognizable social identities. The technologization of cultural tools, therefore, is the basis for the creation of communities and institutions (Jones, 2001). Technologization subsequently gives rise to standardization (Scollon, 2000), whereby cultural tools come to exert such pressure on participants in communities 
that not only does their use signal 'membership,' but failure to use them or their 'misuse' provokes social disapproval.

In the following three chapters Wertsch, Mcllvenny and Raudaskoski, and van Leeuwen approach the concept of mediational means from different angles.

In Chapter 6 Wertsch explores the complex relationship between tools in the world and tools as they are appropriated into practices within the habitus of users. Building on the work of Vygotsky (1986), he develops the concepts of explicit and implicit mediation; that is, mediation that occurs using material tools and mediation that occurs using representations within the habitus of users.

In Chapter 7 Mcllvenny and Raudaskoski take up the examination of the tension between the ideological projects embedded in mediational means and the agendas that users bring to their use. They explore the use of the internet in the practices of transnational adoption, enumerating the various mediational means available to prospective parents and to adoption authorities, demonstrating how actors mix and adapt these tools to fit particular purposes and how the affordances and constraints embodied in the tools and in the circumstances of their use have consequences for the kinds of identities and relationships made possible.

The study of mediational means demands the development of a multimodal approach to semiotics, and it is to this that van Leeuwen's contribution in Chapter 8 turns. Exploring the ways traditional strategies for analyzing genres can be applied to multimodal texts, van Leeuwen points out how the 'reading paths' created by such texts create constraints on their use by readers. 


\title{
6 Vygotsky's two approaches to mediation
}

\author{
James V. Wertsch
}

Tracing the intellectual ancestry of mediated discourse analysis is both fascinating and challenging. ${ }^{1}$ Indeed, there may be almost as many genealogies as there are individuals who set out to trace them. There are, however, a few figures whose place in this story is undisputed, and Lev Semënovich Vygotsky (1896-1934) is one of them. While not employing all the key terms found in contemporary writings, Vygotsky did address many of the issues raised by this field of study. A useful way to start when trying to understand how he fits into today's discussions is to examine his interpretation of its two basic terms: 'mediation' and 'discourse.'

Vygotsky's claims about mediation ('oposredstvovanie') were explicit and ran throughout his writings. Indeed, it has been argued that Vygotsky's most unique and important contributions came in connection with this issue (Wertsch, 1985b, 1991). As evidenced at several points in his writings, he seems to have recognized this himself. In a lecture he gave near the end of his life, for example, he began by saying that, 'A central fact of our psychology is the fact of mediation' (Vygotsky, 1982: 166).

But this is not something that surfaced only at the end of Vygotsky's career. His focus on mediation, especially as it concerns 'signs,' or 'psychological tools' as opposed to 'technical tools' - is evident throughout his writings. For example, in a 1930 report on 'The Instrumental Method in Psychology,' he described psychological tools as 'artificial formations ... . [that] are social, not organic or individual' (Vygotsky, 1981: 137) and went on to include under this heading: 'language; various systems for counting; mnemonic techniques; algebraic symbol systems; works of art; writing; schemes, diagrams, maps, and mechanical drawings; all sorts of conventional signs' (Vygotsky, 1981: 137).

Whereas Vygotsky clearly qualifies as a progenitor of mediated discourse analysis with regard to mediation, the link with the notion of discourse is somewhat less direct. There is no single Russian term that obviously translates into English as 'discourse,' at least at the time Vygotsky was writing ('diskurs' is a recent addition to Russian discussions in sociolinguistics and other disciplines). However, 
his focus on what we today call discourse is obvious on several counts. As was the case for many other scholars of his day in Europe and the Soviet Union, Vygotsky's primary analytic focus was on speech ('rech'), or the use of language, as opposed to the linguistic code in isolation from communicative action. This focus was the point of explicit formulation by some of Vygotsky's contemporaries such as Mikhail Mikhailovich Bakhtin (1981a) but, more important, it was part of the general framework that guided scholars of language and communication in his context.

The emphasis Vygotsky gave to this point - as well as the problems we have sometimes had in appreciating this emphasis in the West - can be seen in the curious story of the title of his best-known book in English, Thought and Language. This was first published in 1962 by MIT Press and was a much abridged version of the Russian Myshlenie i Rech', which appeared in 1934 (153 pages in English vs. 318 pages in Russian). It is possible to translate the Russian term 'myshlenie' as 'thought,' but its preferred rendering would be 'thinking,' especially in Vygotsky's writings. Another noun in Russian, 'mysl', 'shares the same root with 'myshlenie' and readily translates as 'thought.' Indeed, Vygotsky used 'mysl" in the title of Chapter 7 of Myshlenie I Rech', where it usually - and appropriately - is translated as 'thought.' Rendering both Russian terms as 'thought' reduces the possibility of recognizing the contrast Vygotsky often made when using them. This contrast consists of the fact that the meaning of 'myshlenie' emphasizes the notion of an activity or process, whereas 'mysl" does not, instead having more of a connotation of entity.

While it may be understandable how two terms sharing the same root in Russian could be rendered in English as 'thought,' things stand somewhat differently when it comes to the term 'language' in the English translation of Vygotsky's 1934 classic. The Russian equivalent of 'language' is 'yazyk,' a term that can also be translated as 'tongue.' This noun shares nothing in common with 'rech',' the term in Vygotsky's title that has been translated as 'language.' Instead, 'rech"' is clearly to be translated as 'speech,' 'speaking,' or even 'discourse.'

Perhaps even more so than in the case of 'thought,' then, the emphasis that Vygotsky placed on action and process is missing in the use of 'language' in the English title Thought and Language. It is only in Norris Minick's complete 1987 translation of Vygotsky's volume that the terms 'thinking' and 'speech' are used in the title. This is not to question the quality of the translation in general of any of the MIT editions. Virtually every translator that has been involved has been accurate in using 'speech' and 'thinking' in the main body of the work.

So why the tendency to use 'thought' instead of 'thinking' and 'language' instead of 'speech' in the title of Vygotsky's most important book? And is it, after all, so misleading? I believe that the answers to these questions are to be found in the conceptual traditions into which Vygotsky's works have been translated. The 


\section{James $V$. Wertsch}

sort of emphasis on utterance, as opposed to sentence, and on 'metalinguistics,' as opposed to linguistics, as Bakhtin went to such lengths to set out, was not part of the Western, or at least US, mainstream study of language in 1962 when Vygotsky's book first appeared in English. As a result, I suspect that the focus on process was lost as part of an attempt to draw more readers to this text. This suspicion stems from experiences I have had with publishers as they sought to find titles that would appeal to American readers by using existing professional terminology.

However, the vibrant context provided by today's scholarly communities in mediated discourse analysis, sociolinguistics, pragmatics, and associated fields make it possible to revisit Vygotsky's writings from a new perspective. And it is likely that if Myshlenie i Rech' were being translated now, the title might be something like Thinking and Discourse, a rendering that, in my view, always would have been closer to the spirit of the original. With this as background, I wish to turn to an explication of the central concept of mediation in Vygotsky's writings.

\section{Vygotsky's two perspectives on mediation}

During the last decade of his life - the period during which he worked as a psychologist and lived primarily in Moscow - Vygotsky focused on different aspects of mediation. From this period of frenetic activity one can find countless lectures and publications that touch on the issue in one way or another, and it might appear that a set of disparate, even contradictory ideas emerged. I believe, however, that order can be found in this by drawing a distinction between two basic kinds of mediation.

The distinction I have in mind has as much to do with the varying disciplinary lenses through which Vygotsky approached the world as with actual objective differences between forms of mediation. He was busy during this period speaking to psychologists, teachers, and professionals concerned with handicapped populations, and in doing so he employed a professional language of the psychology and physiology of his day, a form of speaking that qualifies as what Bakhtin (1986) called a 'social language.' At the same time, however, Vygotsky continued to employ the theoretical framework and social language he had acquired in his early study of semiotics, poetics, and literary theory. These two social languages need not be viewed as entirely distinct or 'mutually unintelligible,' but in many instances they led Vygotsky to take somewhat different perspectives on issues such as mediation. The result was two perspectives on mediation.

When employing the first of these social languages, Vygotsky spoke in the idiom of psychology, especially what we would today view as a form of behaviorism, or perhaps cognitivism, to come up with an account of what might be called 'explicit mediation.' The mediation involved in these is explicit in two senses. First, it is 
explicit in the sense that an individual or another person who is directing this individual overtly and intentionally introduces a 'stimulus means' into an ongoing stream of activity. And second, it is explicit in the sense that the materiality of the stimulus means, or psychological tools, involved tends to be obvious and non-transitory.

In contemporary research, various forms of explicit mediation have been studied in analyses of 'distributed cognition' (Hutchins, 1995a; Salomon, 1993). Hutchins (1995b) examines human agents' uses of various 'sociotechnical systems' to organize their memory and cognitive processes. For example, in an analysis of 'how a cockpit remembers its speeds,' he makes an explicit call for cognitive science to go beyond its focus on isolated individuals and to take into account the role of cultural tools such as airplane gauges and instruments in human mental functioning. While this instance seems quite removed from some of the forms of explicit mediation Vygotsky studied, it clearly qualifies under this heading.

Standing in contrast to explicit mediation is 'implicit mediation,' which tends to be less obvious and hence more difficult to detect. The distinction does not apply in an ironclad or simple way when trying to sort out kinds of mediation. Indeed, the issue often has more to do with the theoretical notions Vygotsky employed than with objective difference between forms of mediation themselves.

Under the heading of what I am calling implicit mediation I particularly have in mind Vygotsky's discussions of the role of social and inner speech in mediating human consciousness. Because of the ephemeral and fleeting nature of these forms of mediation, they are often 'transparent' (or invisible) to the casual observer and are hence less easily taken as objects of conscious reflection or manipulation. Furthermore, implicit mediation in the form of social and inner speech involves a cultural tool that is an inherent part of many forms of human action and hence does not need to be artificially and intentionally introduced into it.

The distinction between explicit and implicit mediation makes it possible to disambiguate what otherwise might appear to be a very mixed, if not confused set of ideas in Vygotsky's writings. Without it, one can easily end up arguing at cross purposes when discussing his ideas with others because the two forms of mediation operate in different ways and have different implications for how we can understand and intervene in human social and mental processes.

\section{Explicit mediation}

Comments about what I am calling explicit mediation can be found at many points in the writings of Vygotsky and of his students and colleagues. For example, it provided the foundation of his method for studying the development of concepts (e.g. Vygotsky, 1987: Chapters 5 and 6), as well as for studying memory development in the 'Forbidden Colors Task' used by Aleksei Nikolaevich Leont'ev 


\section{James V. Wertsch}

in research he conducted in Vygotsky's laboratory (cf. Leont'ev, 1932; Vygotsky, 1978: 38-51).

In general, the notion of intentional, explicit mediation falls under the heading of what Vygotsky called the 'functional method of dual stimulation,' a notion he outlined in Chapter 5 of Thinking and Speech on 'An Experimental Study of Concept Development.' There, he wrote:

In using this method, we study the development and activity of the higher mental functions with the aid of two sets of stimuli. These two sets of stimuli fulfill different roles vis-à-vis the subject's behavior. One set of stimuli fulfills the function of the object on which the subject's activity is directed. The second function as signs that facilitate the organization of this activity.

(Vygotsky, 1987: 127)

In studies involving dual stimulation Vygotsky's basic procedure was to encourage subjects to use a set of artificial stimuli, or signs, signs that were overtly introduced into a subject's activity by an experimenter. For example, in the Forbidden Colors Task, subjects engaged in a task requiring them to remember a list of color terms. They were given a set of colored cards and told that these cards could help them remember what color terms they had already used. In this case, the first set of stimuli, which 'fulfill the function of the object on which the subject's activity is directed,' was the set of color terms used by the subjects as they responded to the experimenter's questions. The second set of stimuli that were to function 'as signs that facilitate the organization of this activity' were the colored cards introduced by the experimenter.

These colored cards were explicitly introduced by the experimenter as a second set of stimuli (i.e. 'signs') into an ongoing task setting that already involved the first set of stimuli, and the basic aim of the study was to document how children use these signs more effectively with age. Most 5- and 6-year-olds did not seem to realize that the signs being offered by the experimenter had anything to do with their performance on the task, whereas 10- to 13-year-olds clearly did. The developmental path involved is one that moves from a point where the stimuli had very little meaning and hence efficacy to a point where subjects came to appreciate their significance for organizing their performance.

The fact that understanding these results involves understanding how the stimuli took on more and more meaning with age suggests that we are not speaking of stimuli in any strict sense at all. After all, the language of stimuli and responses at least in the Western behaviorist tradition - is intended to make it possible to avoid issues such as meaning and mind. So why did Vygotsky formulate his ideas in this manner? It seems to me that at least part of the answer to this lies in the fact that he was trying to speak to an audience that spoke a language formulated in these terms. 


\section{Implicit mediation}

Claims and assumptions about what I am calling implicit mediation emerge at numerous points throughout Vygotsky's writings, but perhaps the most elaborated version can be found in Chapter 7 of Thinking and Speech, a text he completed near the end of his life. The title of this chapter is 'Thought and Word' ('Mysl' i Slovo'). (Following the practices used by translators of some of Bakhtin's works (Holquist and Emerson, 1981), this chapter title could also be rendered as 'Thought and Discourse'.)

The two terms in this chapter title represent two poles of an opposition in Vygotsky's view. He formulated this opposition in order to highlight a conceptual problem he saw in much of the existing literature on thinking and speech. This was the problem that in 'nearly all studies of thinking and speech . . . [there is a] tendency to view thought and word as two independent and isolated elements' (Vygotsky, 1987: 243-244). His account of verbal thinking - an account in which opposition, tension, and dialectic characterized the relationship between the two terms - was an attempt to overcome this problem.

In his critique of the kind of false and misleading isolation of thought and word that he saw in the research of his day, Vygotsky proposed taking 'word meaning' as a unit of analysis, something that allows us to recognize that it is 'a phenomenon of both speech and intellect' (Vygotsky, 1987: 244). Throughout this chapter Vygotsky emphasized the need to focus on the dialectic between thought and word, or discourse. He viewed this dialectic as a sort of developmental struggle and asserted that this was 'the primary result of this work [and] . . . the conceptual center of our investigation' (Vygotsky, 1987: 245). In his view, 'The discovery that word meaning changes and develops is our new and fundamental contribution to the theory of thinking and speech' (Vygotsky, 1987: 245).

Vygotsky saw this claim about the developmental relationship between thought and word as applying to 'microgenetic,' as well as ontogenetic processes, a point that is reflected in his assertion that word meaning 'changes during the child's development and with different modes of functioning of thought' (Vygotsky, 1987: 249). Regardless of which 'genetic domain' (Wertsch, 1985) is at issue, the general picture Vygotsky presented was one in which thought is posited to be an inchoate, 'fused, unpartitioned whole' (Vygotsky, 1987: 251) that comes into contact with words, which involve generalization and discrete, sequential representation.

With regard to the latter realm, Vygotsky posited 'two planes of speech' and argued that 'the inner, meaningful, semantic aspect of speech is associated with different laws of movement than its external, auditory aspect' (Vygotsky, 1987: 250). This provided the foundation for an account of inner speech that was used by Luria (1975), Akhutina (1975), and others in their analyses of 'dynamic aphasia.'

The general line of reasoning is one in which inner speech, with its peculiar properties such as 'predicativity' and 'agglutination' differs from the grammatical 
organization of external, auditory speech, but even so, inner speech imposes the first round of segmentation and sequential organization on thought as it makes its way to overt expression.

In Chapter 7 of Thinking and Speech, then, the story line is one in which two forms of representation collide and mutually transform one another. One form 'thought' ('mysl') - is relatively inchoate, fused, unpartitioned, and nonsequential, and the other - 'word,' or 'discourse' ('slovo') introduces segmentation and sequencing. For my purposes, what is important in all this is that the mediation involved is not explicit, that is, not the object of conscious reflection and not externally or intentionally introduced. Instead, mediation is something that is necessarily and automatically built into mental and communicative functioning as a result of using language.

When developing this line of reasoning, Vygotsky was heavily indebted to one of his mentors, Gustav Gustavovich Shpet (1879-1937). In Chapter 7 of Thinking and Speech Vygotsky did not cite Shpet (although he did cite him in earlier work), but the reason for this omission is almost certainly political in nature. As outlined by authors such as Martsinkovskaya (1996), Nemeth (1997), and Zinchenko (2000), Shpet's problems with Soviet authorities, problems that would eventually lead to his brutal interrogation and execution in 1937, were already starting to emerge in the early 1930s. Recent accounts of Vygotsky's political acumen by Cole and Levitin (in press) make it clear that he would have been aware of what was - and was not - permissible in the atmosphere of the early 1930s in the USSR.

In any event, we know that as a student Vygotsky attended Shpet's seminars for two years (Vygodskaya and Lifanova, 1996), and the themes that were discussed there undoubtedly included those outlined by Shpet in his writings, especially in his 1927 monograph The Inner Form of the Word: Studies and Variations on a Humboldtian Theme.

Building on the conceptual groundwork laid by Wilhelm von Humboldt, Shpet emphasized that:

Language is not completed action, 'ergon,' but protracted activity, 'energeia,' that is, as Humboldt explained, 'the perpetually repeated work of the spirit, directed at making articulate sound the means for expressing thought.' . . . Synthesis in this case does not consist of tying together two abstracted units: pure thought and pure sound, but two members of a unified concrete structure, two terms of relationship: object oriented sense content . . . and the external form of its verbal expression-embodiment ... in sensory perceptible forms. These forms are transformed through a relation to sense from natural forms combined in the 'thing' to social signification specifically in the signs of cultural meaning.

(Shpet, 1996: 94) 
Shpet's constant insistence on language as activity is quite consistent with Vygotsky's primary focus on speech, as opposed to language. And Shpet's argument that the dialectic or synthesis involved is not between pure thought and pure sound is consistent with Vygotsky's critique of investigators who mistakenly viewed 'thought and word as two independent and isolated elements.' Instead of focusing on such elements as if they can be considered separately, Vygotsky, like Shpet, insisted on examining them as part of a unit of analysis that is inherently developmental, complex, and dynamic. In Vygotsky's terms:

This central idea . . . can be expressed in the following general formula: The relationship of thought to word is not a thing but a process, a movement from thought to word and from word to thought. Psychological analysis indicates that this relationship is a developing process which changes as it passes through a series of stages ... The movement of thinking from thought to word is a developmental process.

(Vygotsky, 1987: 250)

Vygotsky's most detailed comments on how this developmental process occurs appear in his analysis of inner speech, where his indebtedness to Shpet is clearly evident. In some instances the parallels are striking, and it appears that Vygotsky borrowed large segments of Shpet's ideas wholesale. However, the latter's analysis of the inner form of the word (vnutrennyaya forma slova) is not identical to Vygotsky's account of inner speech (vnutrennyaya rech'). Shpet was a hermeneutic phenomenologist dedicated to working out a set of problems whose roots were in Husserl and Humboldt. Although Vygotsky was clearly aware of the ideas of all these figures, he often transformed them in the service of research and practice in schools, clinics, and the psychological laboratory.

A somewhat clearer idea of how Shpet and Vygotsky agreed and disagreed can be gleaned from the following summary provided by the former of what he had in mind when analyzing the inner form of the word:

We take the following . . . as a guiding definition [of inner form]: (1) negative definition: The inner form is not a perceptible sound form, and it is also not a form of thinking itself, understood abstractly, and it is not a form of an object that constitutes the thinking content that is a modification of being an object that would also be understood abstractly; (2) positive definition: Instead, the inner form uses a sound form to designate objects and to connect thoughts according to the demands of concrete thinking. In this process it uses external form to mark some modification of a thinking or objective content, something that is named in the given case by sense.

(Shpet, 1996: 110) 


\section{James $V$. Wertsch}

This characterization of the inner form of the word outlines a conceptual space between external speech on the one hand, and abstract thought or motive on the other, that in certain respects is strikingly similar to Vygotsky's account of inner speech. In particular, the 'negative definition' outlines a set of issues that both authors used as a way to set their claims off from those of other theorists of the time. At the same time, however, there remain some important differences between the two theorists, differences that reflect the divergent theoretical foundations and research goals. Vygotsky focused on developing an account of basic mental processes that occur across cultural contexts. Indeed, he and others in his group of colleagues and students often tended to view cultural differences as variation related to different stages of development in a universal Enlightenment project. As I have outlined elsewhere (Wertsch, 1996), Vygotsky often was ambivalent about this project, but it nonetheless crept into his writings at many points, including his account of inner speech.

In contrast, Shpet's account of the inner form of the word was much more heavily indebted to Humboldt's Romantic project of understanding cultural difference. As a result, he tended to focus on how the inner form of the word and of a language distinguish one group from another. Extending his notions of how language must be considered as a process rather than object, he argued that, 'One can view language not only as a substance, but as a subject, not only as a thing, or product, but as a production process, as energy' (Shpet, 1996: 78).

From this perspective, the inner form of a language is not an inert object waiting to be used by active agents, but has a sort of agency itself. This organismic approach to language lies behind Shpet's (1996: 79) account of the creation and maintenance of different speech communities:

The language of a nation, just as the language of any more or less well formed social formation - a class, profession, work or trade group, the language of the courtyard or market, and so forth - similar to an individual language, is a fact of 'natural' speech of a national, dialect, and so forth. The special nature of this is part of the context of general socio-historical conditions of a given social formation. These define a given form of speech as a 'thing' among things, all of which belong to material-historical and socio-psychological explanation.

(Shpet, 1996: 79)

\section{Conclusion}

As is the case for other theorists whose work was frenetic and generative, Vygotsky's style was not to present and stick with simple, concrete definitions of complex phenomena. Instead, he was constantly drawn into wide-ranging 
considerations stemming from theory and practice over his career. And he was 'polyphonic' in the sense of speaking to different professional and disciplinary groups.

The result of all this is that the central concept of mediation has at least two different interpretations in his writings. These are what I have dubbed 'explicit' and 'implicit' mediation. The former was often the topic of Vygotsky's writings in psychology and pedagogy and involves conscious, externally introduced forms of mediation such as the color chips used in the 'Forbidden Colors Task.' This is a notion of mediation that continues to play a role in contemporary discussions of instructional practice and of distributed cognition.

In contrast, Vygotsky's treatment of implicit mediation was part of his discussion of speech, especially inner speech. In this case, the cultural tools used to mediate human action are not consciously or externally introduced, but follow from the use of human language. The notion of implicit mediation in Vygotsky's writings owes a great deal to the writings of Gustav Gustavovich Shpet, but the two authors' analyses diverge on some important points.

The major reason for introducing the distinction between explicit and implicit mediation is to disambiguate some of the diverse strands of Vygotsky's conceptual work. When drawing on him as one of the intellectual progenitors of mediated discourse analysis, it is increasingly important to differentiate his various claims to avoid bogus and unnecessary arguments about how he did or did not contribute to today's ongoing discussion in this vibrant intellectual enterprise.

\section{Note}

1 The writing of this chapter was assisted by a grant from the Spencer Foundation. The statements made and the views expressed are solely the responsibility of the author. 


\title{
$7 \quad$ Mediating discourses of transnational adoption on the internet
}

\author{
Paul McIlvenny and Pirkko Raudaskoski
}

Transnational (or intercountry) adoption is a global phenomenon with a diverse range of practices which are increasingly under scrutiny. Notable differences are found in practices across both 'sending' countries (such as China, Columbia, India, South Africa and South Korea, and 'receiving' countries (such as Denmark, Finland, the US, the UK, Canada and Australia) (Selman, 2000). In this chapter, we focus on transnational adoption in Denmark and English-speaking countries, primarily the US. The Scandinavian countries have signed the Hague Convention (1993), an international agreement on transnational adoption, and in those countries the adoption process is thoroughly regulated at all stages by the state. A few private agencies exist but they must be fully accredited - for example, by the Danish Ministry of Justice in Denmark. Countries such as the US have a much more liberalized 'market' with less state regulation, so private sector agencies and lawyers flourish to facilitate parent-initiated adoptions (Dorow, 2002; Williams, 1994). The result is that quite different discourses are mobilized that are often more legalistic, individualistic and parent-centered. In both cases though, the prospective adopter(s) is/are an intense site of inspection, an intersection of a broad range of medical, judicial, educational, psychological and linguistic practices.

Increasingly, adopters have been using the internet to prepare for and monitor the adoption process and to publish accounts of their experiences. Our goal in this chapter is to document some of the ways in which mediational means are appropriated or contested in virtual spaces and the social consequences of these appropriations. Our case study focuses particularly on the discourses of adoption and the mediated actions of adoptive parents prior to their first contact with the adopted child.

Research studies of transnational adoption are increasingly common, but come predominantly from psychological, psycho-social or social welfare perspectives. In contrast, we take a discourse studies approach that develops a theoretical and methodological bridge between mediated discourse analysis (MDA) and other 
approaches to mediation, agency and action. With this approach we trace a host of discourses and contingent practices that are heterogeneously assembled to 'translate' a child from one familial 'place' or nexus of practice in the world to another, crossing linguistic, socio-cultural, racial, class and national boundaries. Transnational adoption is a case in which nature and culture, child and actor, as well as kinship and belonging, are clearly problematized in nexus of practice (Howell, 1999). In particular, we focus on the crucial role of the internet and the set of mediational means it makes available to prospective parents, specifically their personal web pages and online diaries that anticipate the 'transnational' mobility of the 'waiting' child.

\section{Mediated discourse analysis, actor-network theory and virtual ethnography}

MDA is a critical response to the dearth of research addressing, among other things, the relations between discourse, practice, materiality and social action. It also has the potential to provide a bridge between more sociologically based theories of online behaviour such as actor-network theory (ANT) and virtual ethnography and more textualist approaches to discourse, a bridge that promises to yield a better understanding of 'how the transformations from practice, action, and habitus to person, characteristics, and identity is performed through discursive practices and other practices of technologization and objectivization' (R. Scollon, 2001b: 158).

ANT has radically transformed our understanding of actors, agency, mediation and technology, providing a sustained challenge to any conception of 'the social' that is populated only by rational human actors (Latour, 1993, 1999). Following the principle of symmetry, Callon (1991: 134) identifies an 'intermediary' as 'anything passing between actors which defines the relationship between them' while 'an actor is an intermediary that puts other intermediaries into circulation' (Callon, 1991: 141). Combining this performative relational perspective with MDA's focus on mediational means in social practices, we find a useful methodological tool to track the circulation and assemblage of cultural tools across sites of engagement. ${ }^{1}$

With our focus on the internet and the participation of adoptive parents, we are conducting what could also be called a virtual ethnography (Hine, 2000). With the recent development of the virtual and networked society, virtual ethnography problematizes the distinction between, on the one hand, 'the social' as populated by bounded locations and homogeneous groups who materially occupy the more 'real' offline world and, on the other, the immaterial 'unreal' online world. Instead, Hine (2000), Shields (2003) and others reject this dichotomy between what is often misunderstood as the 'real' versus the 'virtual.' Hine (2000: 60) 


\section{Paul Mcllvenny and Pirkko Raudaskoski}

proposes that we refocus on connectivity and develop 'a sensitivity to the ways in which place is performed and practised,' and to the 'mobility across a heterogeneous landscape and the differential engagements which this enables and requires.' We should investigate further the making and re-making of space and time through mediated interactions. The internet, however, offers weak entry and exit points into the 'community,' and thus makes it difficult to produce an ethnographically 'thick' description. Moreover, it is tricky to uncover the practices of 'going online' when communication practices and mediated actions are de-contextualized, transient, distributed, asymmetric and mobile. Rather than selecting a territory, the researcher has to identify a 'virtual' nexus of practice and determine the important nodes and nodal events in the emerging social and discursive network (see Latour, 2003 and his arguments for a sociology of association). Strathern (1996) recommends that we follow connections in networks and see where they are cut in practice to limit the infinite extension of those networks a methodological move that echoes that of nexus analysis (Scollon and Scollon, 2004). Thus, in this study, we attempt to follow the prospective adoptive parents, traversing on- and offline, as they navigate through the complex networks and processes of transnational adoption. At the same time, we map the ways in which 'the child-to-be-adopted' (adoptee) is scaled, remediated and resemiotized up until the first physical contact between the adoptive parent(s) and the child.

\section{Transnational adoption and the internet}

Adoption agencies are increasingly using the internet to mediate their institutional knowledge, practices and contacts with clients, and many prospective adopters use the internet to garner information, advice and contacts to help them through the adoption process and the institutional procedures. ${ }^{2}$ At this stage we are interested in how adopters construct their websites, network with others locally and internationally, orient to other sites or sources of information, share advice and create 'public goods,' and narrate publicly their own personal experiences and problems. In contrast to Slembrouck's (2003: 105) study of the 'native point of view' in child protection cases, it is clear that prospective adoptive parent(s) often do make contact with each other and develop certain forms of 'community' over and above the constitution of a group within the field of institutional and professional practice.

The (minority of) prospective adopters who start a website at some point in the adoption process may do it in the so-called pre-pregnancy or pregnancy phases (Howell, 2003), or it may even appear in the form of a travelogue (or 'blog') during the trip to the sending country to pick up the child. Authors may continue to update the website, for particular audiences; however, after a period of time it may no longer be accessible on the internet. The personal homepages and 
websites by the adoptive parents are constructed in ways that afford a variety of different functions (cf. Karlsson, 2002), for example:

- as a 'maternal archive' (Berlant, 1997) or family 'creation narrative' (Freidlander, 1999), by which the child, at some future date, can 'discover' his or her 'origin' story;

- as a 'pedagogical resource,' useful for other adoptive parents to 'learn' from;

- as a reflexive resource for the author(s);

- as a means to track in limited ways a social network or community of practice (e.g. to link outside the website to other 'waiting' parents, web-rings, discussion forms, etc.).

The home(page) is not so much a place/space, but consists of regular patterns of activity and structures in time (Morley, 2000: 16). The practice of keeping websites, and especially diaries, is part of a patterning, a nexus of practice (R. Scollon, 2001b), that also involves reporting on the home's patterns and structures. These websites can be 'revisited' by prospective adoptive parents, who enter a territory in which 'one can speak to the other without providing background information. No footnotes are needed; from few words, much can be understood' (Heller, 1995: 6).

\section{Analysis}

The central experience and source of greatest anxiety for many prospective adopters is the long process of gaining approval from the relevant authorities and, thereafter, the experience of waiting for the allocation or referral of a specific child and, if all goes well, for their first physical contact with that child. For those couples or individuals who can browse the web or create their own websites, the 'intimate public sphere' (Anagnost, 2000; Berlant, 1997) of the internet can serve as a forum for self-reflection on this temporal and affective process. We are particularly interested in how cultural technologies such as diary journals and waiting lists - and their diverse cycles, scales and trajectories - are maintained, anticipated, aligned, translated and circulated by different actors in their virtual practices and, thus, how different knowledges and agencies (e.g. institutional versus 'lay') are mediated and translated. We are also interested in how social actors themselves are resemiotized and deployed as cultural tools to enact and reproduce the practices and identities associated with this 'waiting.'

\section{Adoption web diary or journal}

One can find many personal websites on the internet in which prospective adopters have kept a journal or diary of their experiences of the adoption process. The 
production of the diary takes place at a 'virtual' site of engagement, in which various mediational means are used to mediate the action of reporting on the past day, week or month to an unknown or imagined audience (or community). This results in a (special) object in the world, a website/diary that can then become a mediational means for another action. Diary entries are treated by the author and reader as sequential (and serial) objects (Mulkay, 1986; Silverman, 2001). For example, each entry is accountable as 'the next' in a (dialogic) cumulative series. Authors orient to the just prior entry as projecting expectations, which are renegotiated in the current entry. Moreover, the rhythm of the diary entries provides a kind of 'common presence' (see Morley, 2000: 18-19) for those 'virtual audiences' who follow as the drama of the diary unfolds.

In the web diaries, the adoptive parents orient to adoption as what one couple call the 'unknown territory' [Dianne and Kasper: DK], ${ }^{3}$ about which they gather information about adoption as an institutional and emotional process. When reporting on the information gathering they engage in, including information packages and meetings with the adoption agencies, the parents sometimes make visible their knowledge about the institutional context. For instance, one parent writes, 'The book is totally based on the old legislation' [Janne and Felix: DK]. The web is deemed an important source of information, to such an extent that some feel that the adoption agencies' information evenings are redundant. While they are in the institutional process, the Danish parents often give accounts of the obligatory courses they have participated in. It is interesting to see what is omitted from their commentary. Racism, for example, has been accentuated in the obligatory course for prospective adopters, but the parents seem to ignore it in their web diaries and concentrate, instead, on the emotional side of being infertile, or they just mention 'a focus on the children and the problems one can expect to have' [Janne and Felix: DK]. What do receive a lot of attention are the video recordings of selected orphanages that are shown in the course. Their emotional reactions are reported; for example, 'It is hard and I notice that I become very much moved' [Janne and Felix: DK].

\section{Scaling the 'child-to-be-adopted' as a virtual 'object' or 'actor'}

In their study of the neonatal care work, Middleton and Brown (2001) argue that 'what the neonate is - subject or object - is subject to continual negotiation.' In particular, this occurs through a phenomenon they call 'scaling.' This involves a shift in how the 'thing' - the neonate - is rendered or made actual, which can limit or enhance the scope of mediated action. We can usefully compare their scenario with the distributed labor of managing the effective care and consequent transfer of a child from one environment of (absent or temporary) care to another. With transnational adoption, what a child is when he or she becomes 'available' 
while under the care of an orphanage in a sending country is subject to continual negotiation by social workers, carers, state officials, judges, adoption boards, agency operators, etc. However, from the perspective of the prospective adopter much of the work of adoption in the receiving country is to pre-figure the 'child-to-be-adopted' and the 'adoptive family' before physical contact is made. Prospective parents engage, and are engaged by, various institutions, in virtual affective labor, for example to demonstrate paternal 'desire' (Telfer, 1999), all of which renders the child in particular ways. Doctors who report on the child's health, however, render the child in other ways under different constraints (and prospective parents can do likewise; see Cartwright, 2003). These are all examples of 'scaling' the child. Hence, for instance, the child can be scaled down as a set of medical symptoms or behavioral indicators on a medical record, or scaled up as a social child - a complementary addition to a heteronormative family unit, or even as a representative of a 'race' (e.g. 'Asian adoptees') or a member of a notional kinship or national group (e.g. 'our China girl'). Whichever scaling is negotiated, the virtual 'child' circulates as an 'intermediary' with particular forms (or a lack) of agency.

Another way of understanding this is that over time the 'child-to-be-adopted' is resemiotized (Iedema, 2003) or its properties are 'shifted' in, up or down. Iedema states that 'resemiotization is meant to provide the analytical means for (1) tracing how semiotics are translated from one into the other as social processes unfold, as well as for (2) asking why these semiotics (rather than others) are mobilized to do certain things at certain times' (Iedema, 2003: 29). Latour (1999) refers to 'shifting' to designate the act of signification through which a text relates different frames of reference to one another; that is, various actants - humans and nonhumans - manage a shift of properties and an exchange of values between different representations (and mediational means). We are interested in how the 'adopted child' and the 'functioning adoptive family' are 'scaled,' shifted,' co-materialized and resemiotized over time for practical purposes.

In some online diaries, at first the 'child' does not figure overtly at all, but the adopters' main interest lies in finding other people in a similar position: 'We did not know anybody who had adopted' [Dianne and Kasper: DK]. A child is mentioned for the first time in the following (early) diary entry which reports on the same parents' emotion (of relief): 'It was a very optimistic decision, and it was a beautiful thought that there with certainty would come a child, after the long time with uncertain IVF treatments.' Even though 'children' are mentioned later in this entry, they are scaled up as having a geographical location (the couple did not want to adopt from Eastern Europe). Often, 'children' figure again in connection with the adoption agencies, but they are almost routine objects of the verb 'mediate.' Thus, they are scaled up as a 'business transaction' that the agencies are involved in (cf. Dorow, 2002). When these parents report on their 
consideration of the sending country, they explain the difficulty they have had in choosing because their 'first and foremost' wish is (just) 'a child.' Their neutral stance is not absolute, however, since the child does have to come from a particular 'sending' country. In making a choice, the couple resorts to the countries they have visited before or whose official language they know. What is interesting is their main concern that the practicalities of the trip are an important factor in their choice of the sending country, and thus the 'virtual' child is implicitly scaled up as a member of a familiar nation or linguistic community.

The 'functioning adoptive family' is, at the beginning of the process, scaled down by the applicants to some easily measurable and officially identifiable material features like wages, accommodation, age and health status - necessary information to volunteer in their application to adopt. But there is also a more subtle and less easily identifiable side to the 'functioning adoptive family,' namely, the ability for the parent(s) to take care of a child, the marriage relationship, and other emotional matters - the family scaled up to a social unit. This hybrid nature of the functioning adoptive family comes to the fore in the 'social report' in Denmark, a report that the family's social worker writes about them on the basis of his or her meetings and discussions with the parent(s). The institutional nature of this hybrid becomes accentuated in the following extract from a diary. The material nature of the envelope in which the important decision arrived is described, and a word-for-word quote from the letter is used to emphasize the legal and official nature of the procedure: 'A fine big envelope, with the decision from the committee, and also with the very important social report which "on this date” is sent to the A.C. International Child Support' [Janne and Felix: DK].

\section{Waiting: linear chronology, milestones and lists}

The printed literature produced by the state, the local authorities, the adoption agencies and the support groups - among others - shapes adoption as a process punctuated by a timeline of milestones and associated expectations. Much of this literature also finds its way in a mediated form onto the adoptive parents' public websites. There is a tension, however, between the agency's provision of general information for all clients and each client's demand for more specific information about what they can expect when they join the adoption process with a particular agency (for a selected country) and about the progress of their specific case.

Several web diaries witness the sending of the application to the authorities as the start of a long process. The 'wait' begins, and the parents commit themselves to the institutional and emotional procedures: 'We send the thick envelope together: both of us has a hand on the envelope when we let go of it and it falls down in the posting box. We go home with a strange feeling of happiness, emptiness and expectation' [Åse and Nicolai: DK]. The adoptive parents comment 
on the period it takes for the adoption committee to approve their application to be adoptive parents as 'the long nerve-racking first phase of the waiting time' [Dianne and Kasper: DK]. The next phase for the adoptive parents is to wait to be allocated a child from the 'sending' country they have chosen, for which procedures vary. The waiting list kept by the adoption agency, and made public by some agencies, is one crucial mediational means for adoptive parents in this phase. Depending on the procedures of the receiving country, the waiting list is usually a simple stack or queue comprising the anonymized ciphers of those approved clients who are waiting for the agency to match them with a 'child-tobe-adopted' in the sending country. Case numbers are assigned to every client so that they can be processed by the agency, but of more interest to us is the practical reasoning that clients engage in to recover information about their case, as well as its history relative to others, from information gleaned from the list and other sources. We are especially interested in the online public waiting lists that parents can 'browse' on the internet at their leisure, which some agencies provide as a service to their clients. Online public waiting lists seem to appear only in Denmark, in both of the two authorized private adoption agencies, $A C$ Denmark: Adoption Support International and DanAdopt. The lists are updated at regular intervals, usually monthly. Some adoption support groups or associations remediate and personalize the lists for their own purposes. These lists are an evolving mediational means - a cultural technology sustained by practices that interface or 'translate' between the practices of the adoption agency and their 'clients' - which serves as a resource for mediated action in such virtual spaces.

On the web, the parents express their happiness about moving up the waiting list, especially when the number is close to or under ten, which for many countries means that the parents are in a 'batch of referrals.' Thus, there is little excitement in, 'And so has DanAdopt's homepage been updated - we have moved to $\mathrm{nr} .31$ on the waiting list' [Minna and Rasmus: DK] when compared with, 'Good news!! I finally got hold of Suzanne from our agency. She confirmed that we ought to be in the next batch. Her guess is that within about a month they'll receive the next batch of referrals. It's getting very exciting!' [Inger and Tom: DK]. The first quote also shows the couple's orientation to the fact that the waiting list is being periodically updated. What is also clear is that the 'natural' progression is to go up, not down, and thus a drop is accountable: 'So DanAdopt's homepage has been updated - unfortunately just with somebody extra on the list - before us. So now we are nr. 37 - it certainly goes the wrong way :-( But we have heard that there are children on the way to referral, so we wonder if the waiting list will be updated again next week - and if we so move a bit the right way' [Minna and Rasmus: DK].

But are the children waiting too? Some agencies, especially in the US, may advertise (with photographs, personal information, etc.) the availability of 'waiting 
children.' Cartwright (2003) argues that this functions initially as a 'lure,' to draw prospective clients into the adoption market and to imagine 'their' child or themselves as parents of children 'like these.' Additionally, the term 'waiting child' is 'often used ideologically in place of orphan or abandoned child. It shifts the emphasis from the child's past history and current circumstances to a child's implied state of mind, constructing it as a subject who desires a (new) family' (Cartwright, 2003: fn. 2, p. 105). We add that the present progressive tense indicates that the children are waiting (patiently, as a patient) for an undisclosed event that will release them from waiting any longer. The child-to-be-adopted is scaled down and his or her agency is distributed to benevolent others - they become a mediational means. The implied, unconstrained agent is, of course, the prospective adopter who can 'select' the child and who generously consents to adopt him or her, and thus end the waiting period. Moreover, the economy of adoption is reassuringly, for the adopter, assumed to be a buyer's market, yet a sense of urgency is maintained (trade sooner rather than later in an economy of desire). Even though the condition of waiting is displaced onto the child and not the parent(s), this client-centered discourse elides the institutional labour and gatekeeping that the parent(s) must traverse before the child will be able to be adopted and first contact will 'release' the child from their state of 'waiting.'

Telfer (2003: 74-75) argues that the temporal sequences (structured by the administrative and regulatory structures) are 'necessary, but by no means sufficient conditions for the inculcation of key social knowledge that is held to be crucial for the parenting of a child from "overseas".' Telfer also notes that at some point in the process of adoption parents begin to dare to wonder about the child who might 'belong' to them, but there are limits to their sense of agency while 'being in the pipeline.' There is a chronological and projective linearity, yet the outcome is entirely ambiguous. In our corpus, one can find the pre-figuring of the desired adoptive child in the repeated promises to 'the waiting child' that the event of exchange/contact is coming or imminent. For instance, the assurance 'We'll be there soon Abbey . . . we'll be there soon!' could be seen on the My China Jewel [US] website even before a specific child was even referred to the couple. The child is scaled up as an absent member of the family, in stark contrast to the Scandinavian websites that avoid talking about a forthcoming 'child.'

\section{Centers of calculation}

One can find other representational practices at work, for example statistics and tables on waiting periods (as well as numbers of children adopted from each country) constructed by intergovernmental organizations, the state, adoption agencies, parent-support groups or individuals. One particular parent-run website in the US orients to the practice of waiting by harvesting many practical tips on 
information sources, tips that are appropriate to 'Waiting Parents Before and After Referral.' 4 They have links to many practical websites that give checklists and advice on appropriate tasks and goals for a waiting parent. One of these links points to the 'China Adoption Referral and Age Graphs,' ${ }^{5}$ maintained by Ralph Stirling. The graphs and charts are usually updated regularly and show the most recent statistics on the time from sending your dossier to China to receiving a referral. By gathering data from prior adoption cases directly from the families adopting children from China who are subscribed to the APC email discussion list (a-parents-china@groups.yahoo.com), Sterling can present statistical representations of the adoption process which are updated weekly. ${ }^{6}$ The data collected for statistical use include the important dates for Chinese adoptions (DTC, referral, travel and birth), the gender of the child, twin status, age requested, city and province, and adoption agency. The charts that are produced from the database can be used by parents to determine, among other things, a likely waiting period and the relative position of their process as a trajectory in relation to prior cases. Sterling also uses an online web-form interface to elicit appropriate data from the adopters, which is then entered into a private database. Following Latour (1999), we can see that Sterling has constructed a 'center of calculation,' a site where inscriptions are combined and make possible a type of calculation, one in which auditable features of a selection of China adoption cases in the US over a number of years are stored, collated and presented for public consumption. This website illustrates the degree to which parents themselves have developed (and shared) cultural tools to monitor and predict the adoption process in ways that would not be possible without the help of other adopters.

\section{Conclusion}

We have documented some of the ways in which institutional discourses and texts are appropriated in mediated actions in virtual spaces with social consequences, as well as how parents themselves construct, share and calibrate mediational means and 'cultural tools' for managing their experience of the lengthy adoption process. We have shown how the adoptive family and the adoptee are figured as quasiobjects, as a heterogeneous assemblage of biology, the 'social' and culture, and thus how their origin and agency are performatively distributed across the social and discursive field. There is a clear difference between the personal websites of adopters from the 'consumption-driven' US and the European 'care-driven' countries. The reasons can be many, but it seems to be the case that the general adoption policy of the country has an influence on what the adopters will and will not speak of in the practices and discourses of mediating adoption on the internet.

In order to enhance MDA as a theory and methodology, R. Scollon (2001b) points to four crucial areas in which MDA needs to develop more sophistication: 
agency, representation, multimodal discourse and social structures. In this chapter we wish to highlight that, additionally, the following areas need attention:

- The need for an analyst to specify and enumerate the mediational means used to mediate action in a site of engagement provides an important locus that links materiality, culture and practice, but the range of methodological tools can be extended in useful ways by reflexively attending to new media audiences and the practices of scaling and re-mediation (Bolter and Grusin, 1999).

- MDA crucially refocuses our attention on the importance of documenting how texts (and thus discourse) are engaged and come to have 'effects' in actual practices. However, it tends to have a realist focus on those practices - i.e. that they must occur in material sites of engagement - and a particular conception of the human actor as the source of agency. To date there has been little consideration of non-human actants, virtual practices and the complexity of virtuality and its impact on mediation itself.

- Nexus analysis has focused upon linear and cyclical notions of time within an epistemology of chronological time, but it is crucial to understand how temporality is attended to and constructed in discursive practices, and how different temporalities (and scales) are contingently aligned by different actors.

It is our view that MDA has an opportunity to draw together a variety of approaches to practices of mediation, the situated use of cultural tools and technologies, and richer conceptions of 'the social,' mediation and network.

\section{Notes}

1 New work in MDA, in fact, highlights how people themselves can be mobilized (in various semiotized forms) as cultural tools to perform mediated actions (Randolph, 2000).

2 Lemke's (2003) notion of 'traversal' is useful here. The whole adoption process could be seen as a 'traversal:' the adoptive parent(s) has/have to make sense of and navigate a mass of information from official, public and private sources.

3 Examples and quotations from the data corpus are indicated by the code [Adopter: Country], e.g. [Julie: US]. DK $=$ Denmark, Danish is translated into English and names are anonymized.

4 www.catalog.com/fwcfc/info2.htm.

5 www.homepages.wwc.edu/staff/stirra/china/stats/statsdisplay.htm.

6 www.groups.yahoo.com/group/a-parents-china. 


\title{
8 Multimodality, genre and design
}

\author{
Theo van Leeuwen
}

\section{Multimodality}

Many writings in the area of multimodal discourse analysis explore the 'grammars' of different semiotic modes (e.g. O'Toole, 1994; Kress and van Leeuwen, 1996, 2002; van Leeuwen, 1999; Martinec, 1998, 2000, 2001) and this work is by no means completed. Comparisons between the various 'grammars' are especially needed. We need to know more both about the extent to which different modes can do the same kind of communicative work and about the extent to which they differ in their semiotic potential, and we need to know more about the difference between doing the same kind of communicative work through one mode or through another. But what is also needed is research on the way different modes are integrated in multimodal texts.

The work on multimodality cited above takes its cues for the most part from linguistics, and this approach still has much potential. With regard to the question of how different modes are integrated in multimodal texts, there is, for instance, room for a more systematic exploration of the theory of cohesion (e.g. Halliday and Hasan, 1976; Martin, 1992), as for instance in van Leeuwen's work on verbal and visual conjunction (1991) and Martinec's work on cohesion in action (1998). Is it possible to speak of 'lexical cohesion' between words and images, or of 'exchange structure' in musical dialogues, or of 'referential cohesion' between the action, the dialogue and the music of a film? At the same time, when linguistic methods of cohesion analysis are applied to multimodal texts, they will inevitably have to be adapted and modified, and cross-fertilised by the disciplines that have traditionally studied the 'non-linguistic' modes of the multimodal mix - art and design theory, for instance, musicology, and 'non-verbal communication'.

In this chapter I will depart from the concept of 'genre' as it has been developed in systemic-functional linguistics over the last 30 years or so (e.g. Hasan, 1978; Martin, 1992; Ventola, 1987). I will not only ask whether genre analysis can be applied to multimodal texts, but also explore how it will have to be modified when 


\section{Theo van Leeuwen}

we transfer it from the domain of 'monomodal', linear texts to multimodal, nonlinear texts, that is, to texts that: (1) foreground visuality, not just by using images, but also by using composition (layout), typography and colour; and (2) are deliberately designed to allow multiple ways of reading, multiple uses, regardless of whether this is achieved through electronic technology or not. In doing so I will, for the most part, rely on examples that I have already used elsewhere, but rethink them in the light of the particular questions I pose in this chapter.

\section{Genre}

The concept of 'genre' is not only used in linguistics, but also in the disciplines that have traditionally studied modes such as visual communication, musical communication and action, for instance in film studies, art history and musicology. In these areas the term does not necessarily have the same meaning, and it is important to remember this when we do cross-modal work and therefore have to commune with disciplines that have long experience with modes whose study is new to linguists. At the broadest level, however, these disciplines, like linguistics, use the term for 'types of text'. Where they differ is in the kinds of characteristics (or combinations of characteristics) they use to describe specific genres. Genres may, for instance, be characterised on the basis of their content. In film studies 'Westerns' would be described in this way, as typically set in a particular time and place, using certain stock characters and typical plot structures, and so on. But other film genres might be typified on the basis of their form or the semiotic modes they employ, for instance the musical, or on the basis of their truth claims, for instance documentaries versus fiction films. Disciplines also differ in the use they make of the concept of genre. Often it plays a role in judgements of quality. The best texts are then considered to be sui generis, typical only of their author, and 'genre' pieces are looked down upon as works in which writers or artists follow a recipe rather than creating an original work, although this is not necessarily applied to older works such as the still lives and biblical genre pieces of old masters like Rembrandt.

In systemic-functional linguistics, genres are characterised in terms of their functions, in terms of what they do, initially as more or less unavoidable templates for communicative action, more recently as resources for communicative action that can be combined in different ways, some clichéd perhaps, others more original. This reinstates the possibility of agency and innovation, moving away from various forms of structuralist determinism in which, for instance, story telling was seen as 'the ability to generate narratives (messages) from the structure of a code' (Barthes, 1977: 80), towards a more Bakhtinian conception of genre, in which the logic of genre is not an abstract, but a culturally and historically situated logic, and in which genres are resources for authors, so that we have to ask what 
'the possible generic sources of a given author' or 'the artist's generic contacts' are, and focus on the 'interrelationship of tradition and innovation' (Bakhtin, 1984: 157).

The following brief analysis can serve to rehearse the key characteristics of the systemic-functional linguistic approach to genre.

\begin{tabular}{|c|c|c|}
\hline Text & Stages & Some realisations \\
\hline $\begin{array}{l}\text { Don't have time to make } \\
\text { a fuss of your feet? }\end{array}$ & $\begin{array}{c}\text { Suggesting the addressee } \\
\text { might have a problem } \\
\downarrow\end{array}$ & $\begin{array}{l}\text { Question; 2nd person } \\
\text { address }\end{array}$ \\
\hline $\begin{array}{l}\text { Scholl Foot Smooth } \\
\text { Shower Scrub }\end{array}$ & $\begin{array}{c}\text { Offering a solution } \\
\qquad \downarrow\end{array}$ & Name of product \\
\hline $\begin{array}{l}\text { Exfoliates and activates } \\
\text { cell renewal; } 24 \mathrm{hr} \\
\text { moisturisation }\end{array}$ & $\begin{array}{l}\text { Describing the effect of } \\
\text { the product } \\
\qquad \downarrow\end{array}$ & $\begin{array}{l}\text { Statements; material clauses } \\
\text { or nominalisations with the } \\
\text { product as agent; 3rd person }\end{array}$ \\
\hline $\begin{array}{l}\text { Scholl Foot Smooth } \\
\text { Shower Scrub }\end{array}$ & $\begin{array}{c}\text { Reinforcing the solution } \\
\downarrow\end{array}$ & Name of product \\
\hline $\begin{array}{l}\text { Because the skin on your } \\
\text { feet is different and needs } \\
\text { its own special care }\end{array}$ & $\begin{array}{l}\text { Providing a reason for } \\
\text { why addressee needs } \\
\text { the product }\end{array}$ & $\begin{array}{l}\text { Reason conjunction; } \\
\text { statements; relational } \\
\text { clauses; 2nd and 3rd person }\end{array}$ \\
\hline
\end{tabular}

\section{Linear succession of stages}

One cornerstone of systemic-functional genre analysis is the idea that genres are linear concatenations of communicative moves ('stages'), each of which constitutes a particular communicative act, for instance 'suggesting that the addressee might have a problem', 'offering a solution', etc.

\section{Stage boundaries mark shifts in the use of semiotic resources}

The boundaries between these stages are marked by shifts in linguistic realisation. The boundary between 'suggesting a problem' and 'offering a solution,' for instance is marked by a change from direct address to indirect address and from questions to statements. The stages need not consist of one sentence only, as in the short example above. It is quite possible for a single 'suggesting a problem' stage to contain a range of questions, or for a single 'offering a solution' stage to contain a series of first-person or third-person statements. 
Each stage is a distinct move in a strategy to reach the overall goal

The example text above is an advertisement and its overall goal is to persuade the reader to buy the product. Each stage in the generic structure is a step in that direction. In other words, genres are communicative strategies or procedures, ways of achieving specific communicative goals. In the example, the product is first made relevant to the reader ('if you have this problem you'd better pay attention'). Then the product is offered as a solution for this problem. And finally this solution is reinforced in several ways, by sheer repetition as well as by arguments. Of course the 'problem-solution' genre is only one of a number of possible persuasive strategies - for instance, it would also be possible to simply state what the product is for and heap praise on it.

\section{Some stages are optional or allow for choice between alternatives}

Some stages are 'optional' - a slightly shorter version of this ad, say without the final 'reason', would be totally acceptable, as would a version adding more reasons, and/or a few sentences of effusive praise. But if the 'problem-solution' strategy is chosen, the ad must at the very least have one 'problem' and one 'solution', and advertising's overriding concern with ensuring 'recall' of the brand name, makes repetition or reinforcement fairly fundamental as well. Such optionality has been represented in various ways, for instance by means of flowcharts (Ventola, 1987).

\section{Multimodal stages}

In my own first attempts to apply the concept of genre to multimodal analysis, I made three assumptions which, in hindsight, were perhaps motivated by a desire to keep this model intact. As will be seen, this works for some multimodal texts, but not for all. My assumptions were: (1) that a given stage could be realised by several alternative modes; (2) that a given stage could itself be multimodal, realised by several different modes at the same time; and (3) that the relations between the modes within a stage could be elaborative or extensive. I will discuss each of these points in turn.

\section{A given stage can be realised by several alternative modes}

This idea can be illustrated with another simple example, the recipe, as discussed, for instance by Eggins (1994). A typical opening stage in a recipe is the 'enticement', which aims at whetting the appetite of the readers, so as to persuade them to try it. In many recipe books this stage is realised verbally, e.g. as follows: 
A typical Balkan dish and a glorious way to serve the biggest, most succulent mushrooms you can find.

But it is equally common to find visually realised enticements, pictures that serve the same function, and also form the opening stage of a recipe, as in Figure 8.1.

The choice between visual and verbal realisation may depend on a number of factors, for instance on the medium (recipes in magazines more often feature visual enticements, perhaps, than recipes in books) or on cultural factors - as Martinec has shown (2003), the 'instructions' (e.g. 'stir in the grated cheddar cheese') that follow the enticement are usually verbal in English recipes while in Japanese recipes they are often visual.

\section{A given stage can, itself, be multimodal}

A Cosmopolitan article on keeping fit opens with a picture of Catherine Zeta-Jones and the caption 'Catherine Zeta-Jones keeps fit with a round on the golf course'. Thus, a stage we might call 'role model endorsement' sets the scene for the suggestions and instructions that will follow. It is a single stage, but it uses both image and text. The same applies to the headline in Figure 8.2: the dolphin is realised visually as well as verbally.

\section{The relations between the modes can be elaborative or extensive}

In multimodal stages, Halliday's (1994) concepts of 'elaboration' and 'extension' can be used to specify the relation between the modes. In the case of 'elaboration', content realised in one mode is restated through another mode in specific ways, for instance by providing an explanation, or an example, or a summary. This concept is similar to Roland Barthes' (1977: 39-41) concept of 'anchorage,' with the proviso that 'anchorage' is less inclusive and more specific, focusing only on the way verbal captions can narrow down the content of images and make it more specific. Barthes thought that images are more polysemic, more open to multiple interpretations than language. This is certainly true for many images, but the opposite can also be the case.

In the case of 'extension' one mode adds new, related content to the content expressed in another mode. Barthes (1977: 41) used the term 'relay' here, defining it as a 'complementary relationship' in which word and image are 'fragments of a more general syntagm'. In the Catherine Zeta-Jones example, for instance, the picture shows the 'agent' (the person who 'keeps fit') and the words convey what she does (keeping fit by playing golf), so that the two together form the equivalent of a single clause, a single message. The heading in 


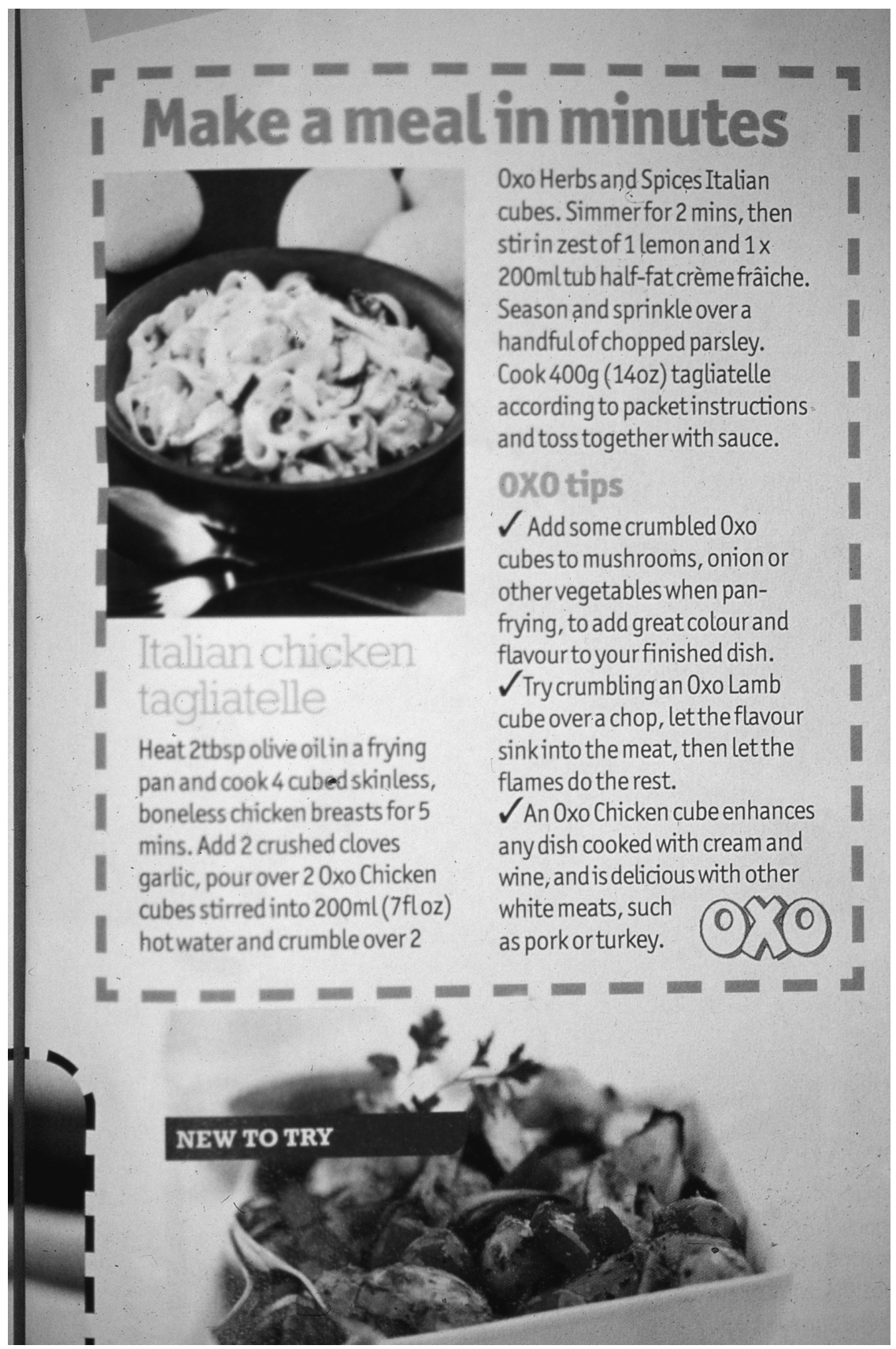

Figure 8.1 Visually realised 'enticement' 


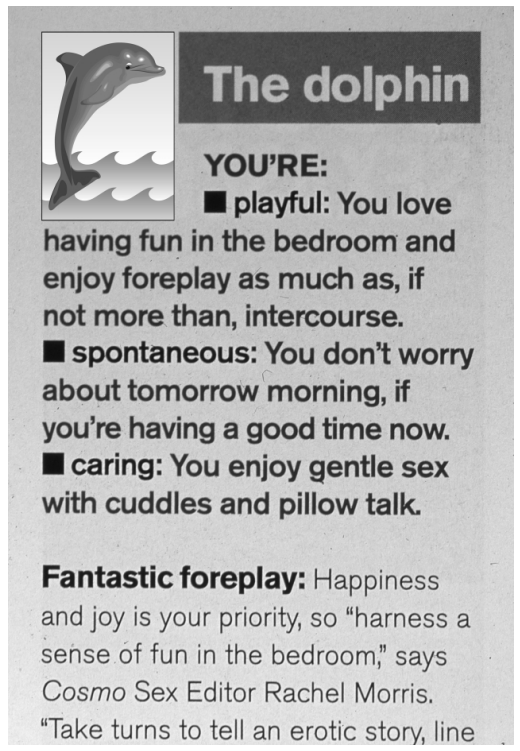

Figure 8.2 'Dolphin’ (Cosmopolitan, September 2003: 149)

Figure 8.2, on the other hand, is an example of 'elaboration'. Here, the picture adds more detail, 'specifying' the verbal message. Needless to say, the two can go together. The picture of the dolphin also contains an element of 'extension', as it shows a background, a setting. Such a setting could also have been realised linguistically, through a 'circumstance of location', but in this instance it is not.

However, the approach sketched here has limitations. The whole may be more than a concatenation of interrelated parts, as, in an earlier article (van Leeuwen, 2004), I tried to explain with reference to the famous Kitchener poster (Figure 8.3).

It might be thought that the text merely 'elaborates' the image in this poster. Both form an 'appeal', one with words, the other with a look and a gesture. But the two appeals are very different. The visual appeal is direct and authoritative, the verbal appeal indirect, a statement rather than a direct 'command'. And the two are not concatenated in linear fashion. They fuse, like elements in a chemical reaction. They become a single appeal that is at once direct and indirect, at once personal and official. And this fusion is effected by the visual style. There are no frame lines to separate image and text, and the visual style provides unity and coherence between the drawing and the typography. For this kind of semiotic 'reaction' process we do not seem to have any useful analytical tools at present. 

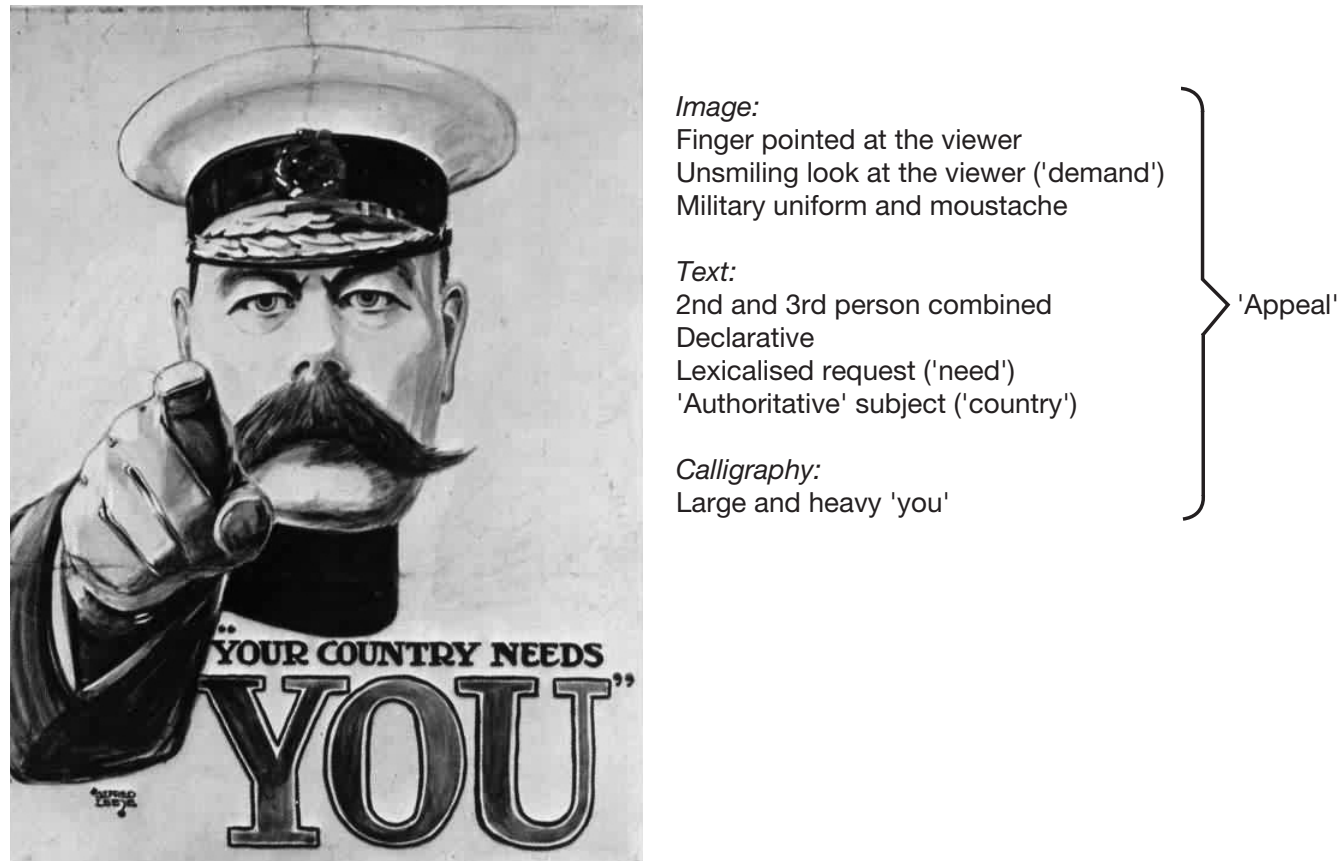

Figure 8.3 Kitchener poster

The analysis of an excerpt from a Cosmopolitan article on sexuality (see p. 81) describes the stages themselves in terms that are not mode-specific. 'Characteristics', for instance, could be displayed visually or described verbally. The realisations in the third column, on the other hand, are mode-specific. As can be seen in Figure 8.4, a headline can become a headline because of its position, its framing, its large and bold typography - as well as because of its truncated grammar. Again, the boundaries between the stages are not just marked by shifts in linguistic realisation (e.g. the shift from relational clauses for formulating general characteristics to imperative clauses for formulating expert advice) but also non-linguistically. Each 'characteristic', for instance, has its own bullet point and its own colour: the characteristics themselves ('playful', 'spontaneous' etc.) are lettered in black, the rest of the text is lettered in pink. The boundary between the 'characterisation' stage as a whole, and the 'elaboration' stage is marked, not only by leaving extra interlineal space between the paragraphs, but also by a transition from pink to black lettering, and from bold to normal weight. The generic structure of the text is thus multimodally realised, through layout, colour and typography, and these different modes fuse in the realisation, rather than that they have distinct functional roles to play. 


Text
YOU'RE Dolphin
playful: You love having
fun in the bedroom and
enjoy foreplay as much
as, if not more than,
intercourse.

- spontaneous: You don't worry about tomorrow morning, if you're having a good time now.

- caring: You enjoy gentle sex with cuddles and pillow talk.

\section{Fantastic foreplay:}

Happiness and joy is your priority, so

'Harness a sense of fun in the bedroom', says Cosmo Sex Editor Rachel Morris
Realisations

Framed; Illustrated; Large bold type in white on pink background; Nominal group only

Characterisation:

Characteristic 1

Bold, pink type;

$\downarrow \quad$ 2nd person;

Mental processes of affect related

to sex

Characteristic 2

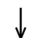

Characteristic 3

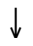

Elaboration of

Characteristic 1

Generalised restatement

$\downarrow$

Expert mediated advice
Additional inter-lineal space

Starts with characteristic 1 in bold type; Black type reduced in size; Opens with relational clause to expert.
Imperative clauses, attributed

\section{Reading paths}

Another complication needs to be added. My first attempts at applying systemicfunctional genre theory to multimodal texts also rested on the principle of the reading path, which was first worked out in Reading Images (Kress and van Leeuwen, 1996). Genres, in the systemic-functional genre model, are templates for communicative activities, linear processes, processes that unfold over time. I used the principle of the reading path to reintroduce linearity in the case of spatially structured texts, for instance images. 


\section{Theo van Leeuwen}

Reading paths, Kress and I had argued, are created by differential salience, by the degree to which particular textual elements attract the reader's or viewer's attention over and above other elements. Differential salience can be encoded by a range of different visual features which can combine in various ways, for instance size, tonal contrast, colour, etc. As we formulated it at the time:

Composition sets up particular hierarchies of the movement of the hypothetical reader within and across the different elements of the text. Such reading paths begin with the most salient element, from there move on to the next most salient element, and so on. Their trajectories are not necessarily similar to that of the printed page, left-right and top-bottom.

(Kress and van Leeuwen, 1996: 218)

Again, this works for some spatial texts. Some spatial texts do have clearly encoded reading paths. But with other texts it is difficult to agree on whether any particular reading path is more plausible than any other. In an earlier article, for instance, I analysed the text in Figure 8.4 in a way that I still think is reasonably plausible:

we might hypothesise the following reading path: from image 1 (left page), via the headline, to image 2 , the drawing, and then to image 3 (the photo at the bottom right of page 2 , and (via the photo on the left page?) back to the headline, the box and the main text.

(van Leeuwen, 1992: 215)

The analysis is visually represented in Figure 8.5.

I concluded that reading path analysis 'allows an integrated analysis of the generic structure of the text, for such an analysis stands or falls, of course, with the possibility of a sequential(ised) reading' (van Leeuwen, 1992: 215).

But many spatial compositions have several elements that are more or less equal in salience. The home page of Sony's website, which Sony did not allow us to reproduce here (but see Figure 8.6 for a visual representation of the site), is divided into two main sections. The top section has, on the left, a 'head and shoulders' picture of a glamorous blonde model smiling at the viewer, and on the right, the words 'Welcome to the world of Sony' and below that, somewhat less salient, the words 'What's new'. The bottom section features a symmetrical display of four rectangular frames with the names and logos of specific products. The girl is clearly the most salient element of the page, followed by 'Welcome to the world of Sony' and then by 'What's New'. We can therefore assume that these elements are designed to be read in that order. But the rectangles in the bottom part of the page are more or less equal in salience. Here a specific reading path can not be assumed - to be precise, 24 reading paths are theoretically possible. The design of the page can be said to encode a 'beginning', the picture of the girl, 


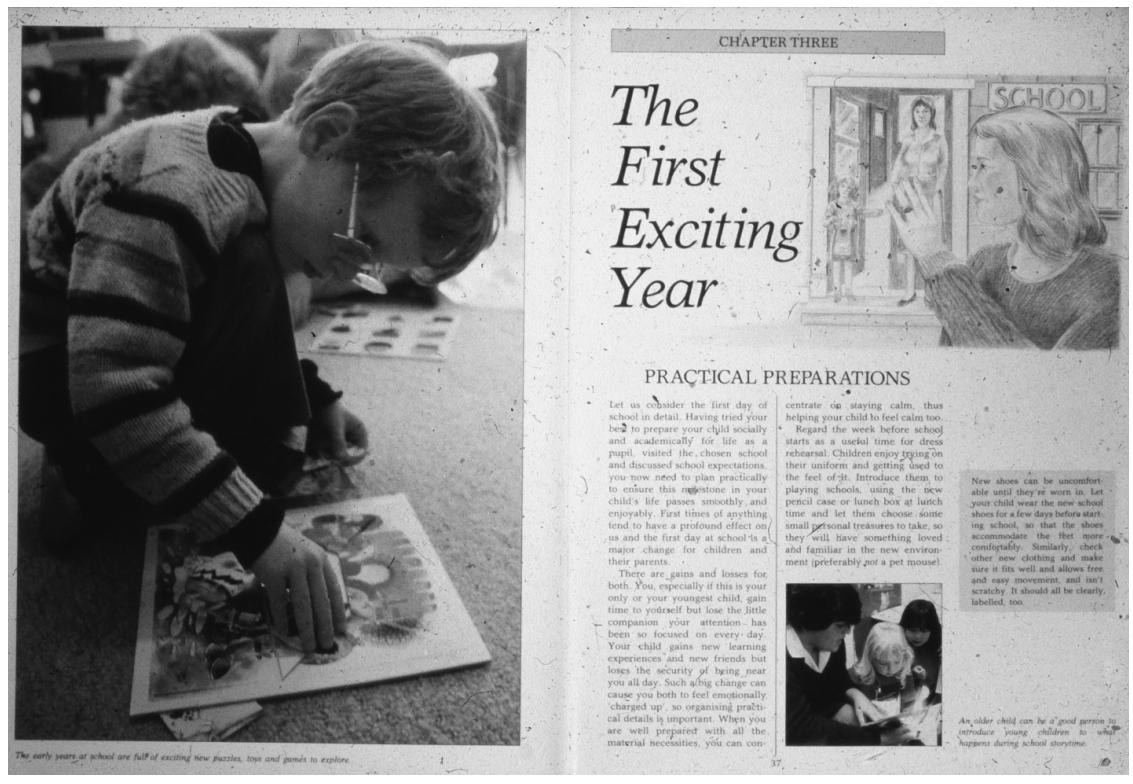

Figure 8.4 'The First Exciting Year' (from Luck, 1990)

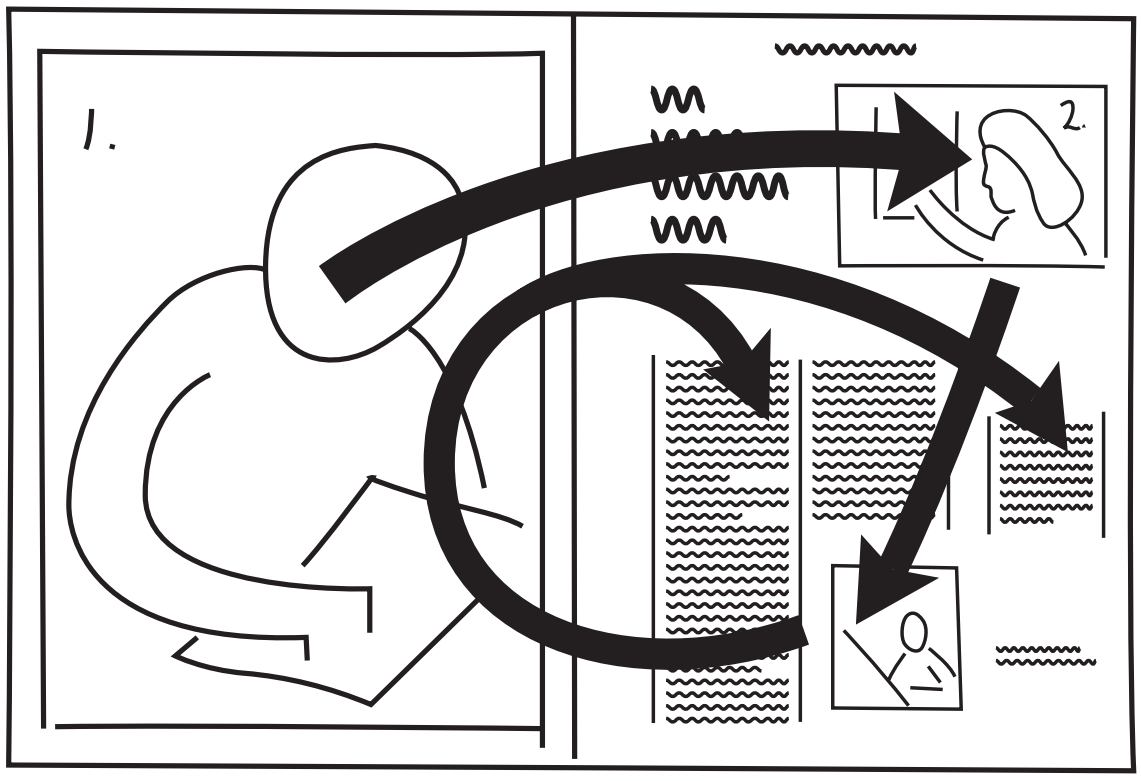

Figure 8.5 Analysis of the reading path of Figure 8.4 


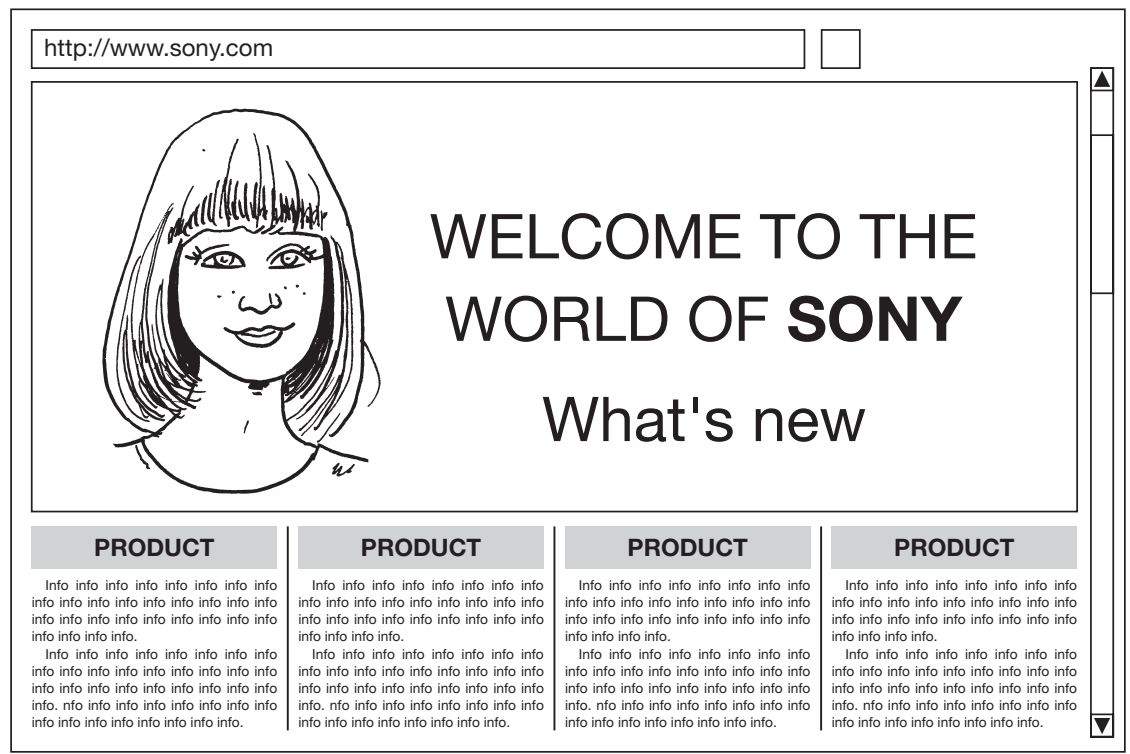

Figure 8.6 Visual representation of Sony home page

and a second stage, the words 'Welcome to the world of Sony' and 'What's New', but it does not provide an 'ending'.

However, what readers actually do when they read ('use') such texts will still follow a single, linear reading path that could be experimentally studied by using a television eye marker and that forms a single, staged, goal-oriented process that could be analysed with the methods of genre analysis described above. The important difference is that now we study, not the structuring of the text, but the structuring of the reading (using) process. Nevertheless, to make such structured and purposeful reading processes possible, the elements of the text that the reader selects as the specific stages of his or her reading path must still have semiotic characteristics that will allow them to function as these specific stages. A particular reading process might, for instance, involve the following stages:

Welcome

Product choice

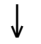

Product information

$\downarrow$

Price

$\downarrow$

Ordering 
But this reader-activated 'reading path' is only possible if the text has elements that can realise the communicative activities of 'offering a welcome', 'providing a product choice' and so on, and allows them to be read in the above order. In other words, the text becomes an environment facilitating a number of staged, goaloriented reading processes. However, the text itself is no longer a staged, goal-oriented process. It is an environment for such processes, and must be analysed as a kind of map, a spatial structure allowing a number of trajectories, or as the layout of a building, a spatial structure designed to facilitate a range of specific activities. Analysis must therefore take place at two levels:

- Visual analysis of the text, to study the environment of the staged, goaloriented process, and the pathways it allows.

- Observational, 'ethnographic' genre analysis of the user's trajectory, to study actual staged, goal-oriented reading processes, and so access the (usually internalised) generic patterns that inform it.

If such analyses are carried out with larger numbers of users, they will bring out the degree to which different users follow the same trajectories, and hence the degree to which the spatial or quasi-spatial ('virtual') composition of the environment constrains what can be done in it.

\section{Two examples}

I will try to make things more concrete by means of two examples. The first is a museum exhibition in the Old Royal Observatory in Greenwich. The successive rooms of this exhibition present the episodes of a narrative that recounts the problem of determining longitude for the purpose of navigation at sea, and its eventual solution, after a number of complications, in the form of a clock that could keep accurate time at sea. Within this narrative, some of the rooms form a kind of descriptive digression, showing the living and working quarters of the first Royal Astronomer, and the final room functions as a narrative Coda in the sense of Labov's functional analysis of the genre of narrative (1972), as we will see in more detail below.

Figure 8.7 shows the layout of the first room of the exhibition.

Using the principles of composition analysis outlined in Kress and van Leeuwen (1996), we can analyse this room as a triptych structure. Given is the left wall, on which are hung a large, dark seventeenth-century painting (1) depicting the building of the Observatory and an engraving (2) showing John Flamsteed, the first Astronomer Royal. The wall that faces visitors when they enter the room functions as Mediator, and is itself structured as a triptych, to be analysed below. The New is a large and very dark seventeenth-century painting showing a storm 


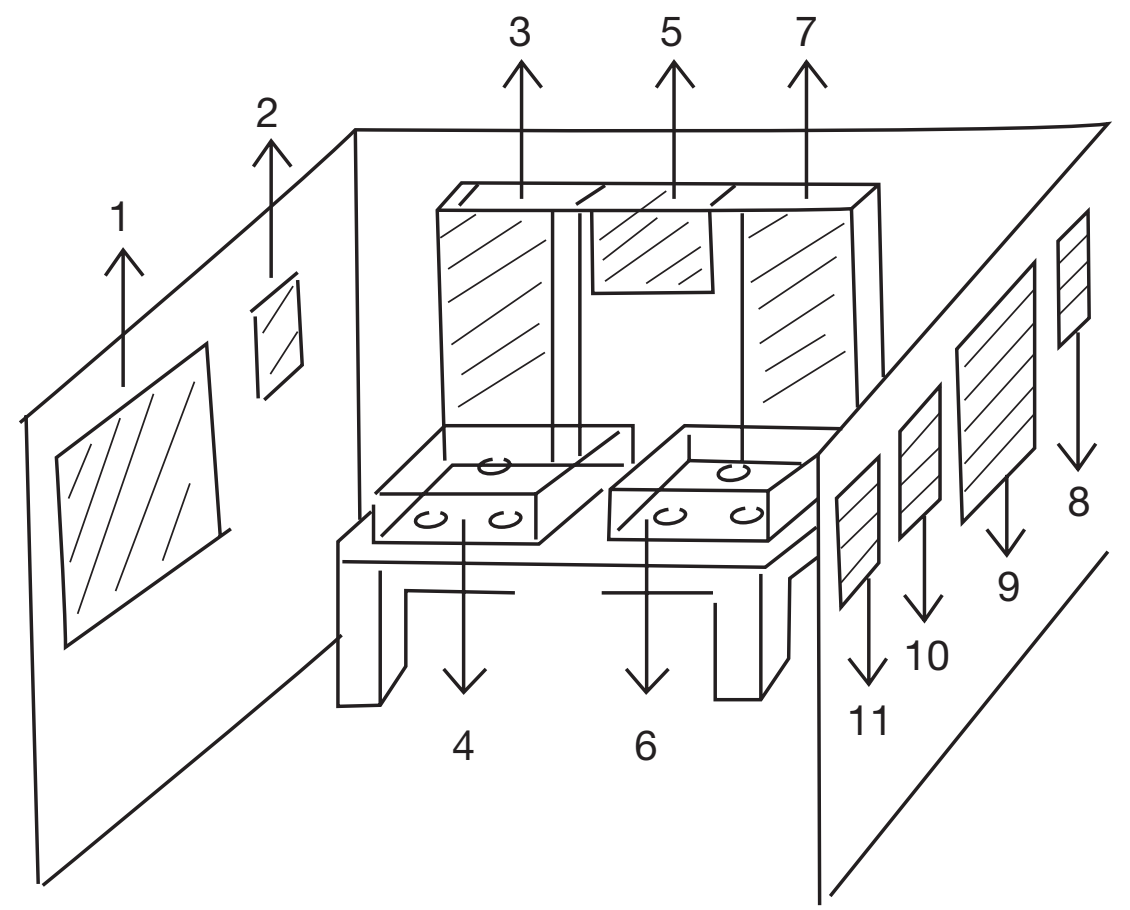

Figure 8.7 The first gallery of the Old Royal Observatory 'story of time' exhibition

wrecking a ship (9), a chart showing the zigzagging trajectory of a ship sailing the east coast of South America (8) and engraved portraits of King Charles II (11) and Christopher Wren, who built the Observatory (10).

The Mediator is by far the most salient item in the room, due to its lighting and its position, immediately facing the visitors when they enter the room. Its Given is a text panel explaining how King Charles II ordered the building to research the problem of determining longitude at sea (3), and a glass case displaying objects relating to the Observatory (a book, seals, an ordinance). Its own Mediator is a highly placed monitor with a computer animation showing the Observatory being built, in time-lapse fashion (5). As this exhibit has a moving image and luminous colour, it is by far the most salient item in the room. New, finally, is another text panel, explaining the problem of longitude (7) and a glass case displaying objects related to navigation (a compass, a ship's logbook etc.).

Observing the trajectory of 60 visitors, I found that all but one of the visitors skipped the left wall and immediately went to the leading exhibit, first watching the animation, then reading the panels and glancing at the objects in the display cases. Thirty-eight of the visitors did not even glance at the right wall, 13 looked 
at it briefly, on their way out, and only nine studied exhibits 8 to 11 more carefully. Clearly the composition of this room played a large role in structuring the visitors' reading paths, even though in principle a multitude of reading paths should have been possible.

Analysing this reading path as a staged, goal-oriented process, visitors are first provided with the 'instigatory' event, the event that gets the ball rolling (the building of the Observatory). This event is then elaborated in two ways, by providing further detail (the role of the King), and by giving the reason for the event (the navigation problems encountered because of the difficulty of accurately determining longitude). The room as a whole thus provides the Orientation of the narrative (Labov, 1972) that is about to unfold:

\section{Orientation:}

Narrating the instigatory event

$\downarrow$

Providing additional detail

$\downarrow$

Stating the reason behind the instigatory event

While the first of these three 'sub-stages' is realised visually, through a computer animation, the others are multimodally realised - through text, image and objects.

The final gallery has a Centre-Margin structure (Kress and van Leeuwen, 1996), as shown by the floor plan in Figure 8.8.

The main text panel (C) indicates the theme of the gallery: 'Keeping Time'. Four main sections deal with different aspects of time: the history of concepts of time (D1), from linear time as conveyed in the Bible, to modern scientific time (D2); the standardisation of time (B); types of time such as 'Relative Time', 'Biological Time', 'Human Time' (E); and types of time keeping, including those of other cultures $(\mathrm{F})$. The central exhibit $(\mathrm{H})$ is a very large clockwork in a glass case. It has a loud tick and chimes every 15 minutes.

Again observing the 'reading paths' of 60 visitors, I found that, on entering the room, all visitors immediately faced the central exhibit, but only nine went up to it to have a closer look. The rest glanced at it for a brief moment and then either turned left (21 visitors) or right (30 visitors). In short, there was no common pattern either in what they did or did not look at, or in the order in which they surveyed the exhibits. They crisscrossed freely through the room, finding their own trajectory.

The 'reading path' of the exhibition as a whole is highly biased towards linearity. Each room leads directly to the next room, and the passageways between the rooms are narrow. It is difficult to go against the flow. But the final room is 'nonlinear'. It is also the only room that does not directly relate to the story of solving 
the problem of longitude. Thus it functions as a Coda to the narrative, as the element that makes the story of time (the central element in the room) relevant to the here and now of the visitors - leaving it to them to determine that relevance for themselves.

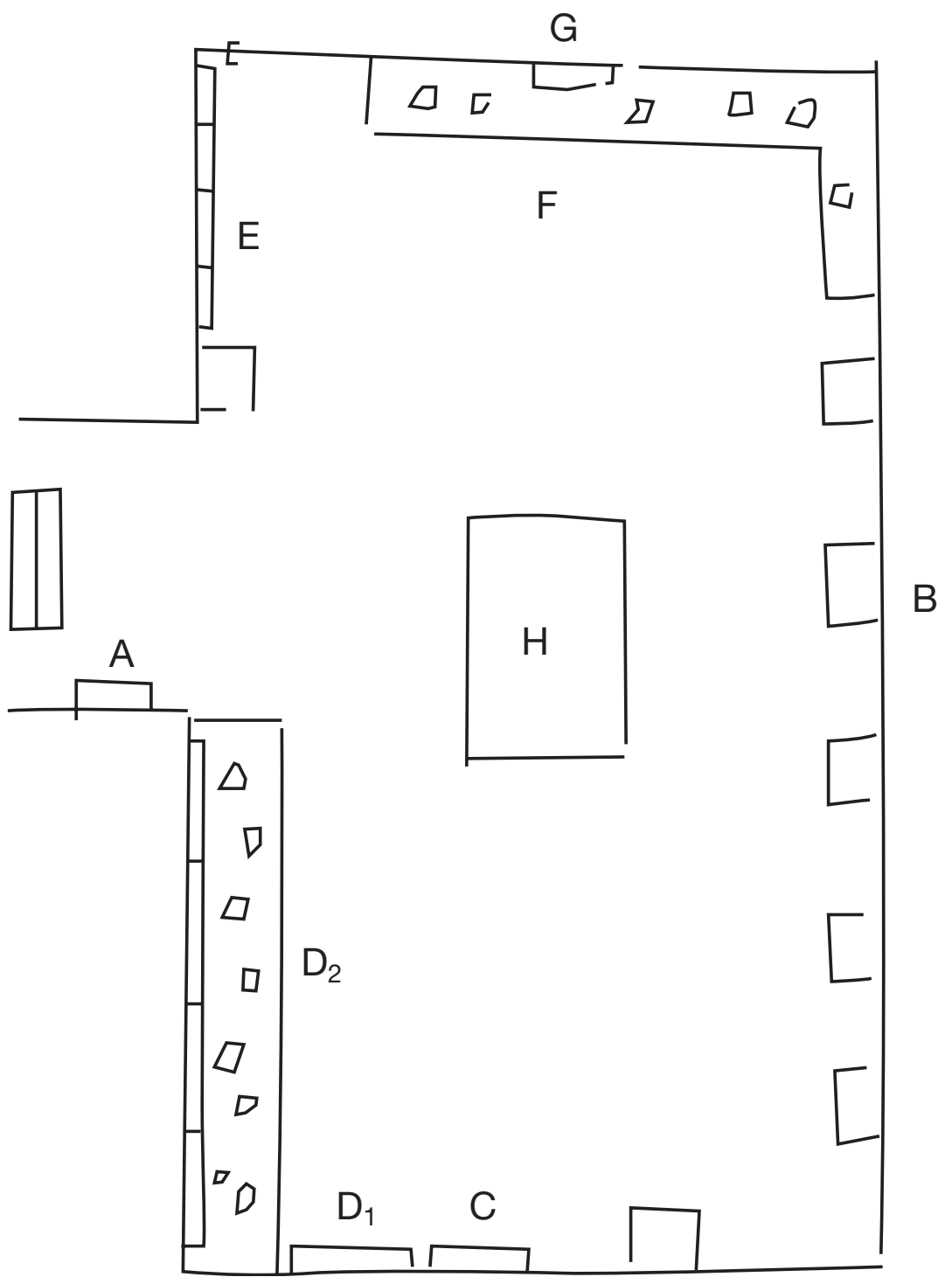

Figure 8.8 Final gallery of the Old Royal Observatory 'story of time' exhibition 
My second example is a CD-ROM for children called Dangerous Creatures, produced by Knowledge Adventure in 1994. Dealing with wild animals, it can be explored in three ways - through the alphabetically organised index, through particular themes such as 'habitats', 'weapons' etc., and through a 'guide interface'. Choosing the guide interface produces a screen displaying 12 guides, each able to provided a different 'tour' of the database - 'Amazon Adventure', 'African Safari', 'Coral Reef Dive', 'Native American Stories', 'Tales from Asia' etc. Here, I will concentrate, not on the internal structure of the 'rooms' (here screens) that constitute the stages of the process, but on the overall structure of the 'exhibition' (here 'database'), mapping it as a topological analytical structure (Kress and van Leeuwen, 1996: 101-103). Figure 8.9 maps a small section of the tour of the 'Aboriginal storyteller' in this way. To explain it I will need to describe the screens and their links in some detail.

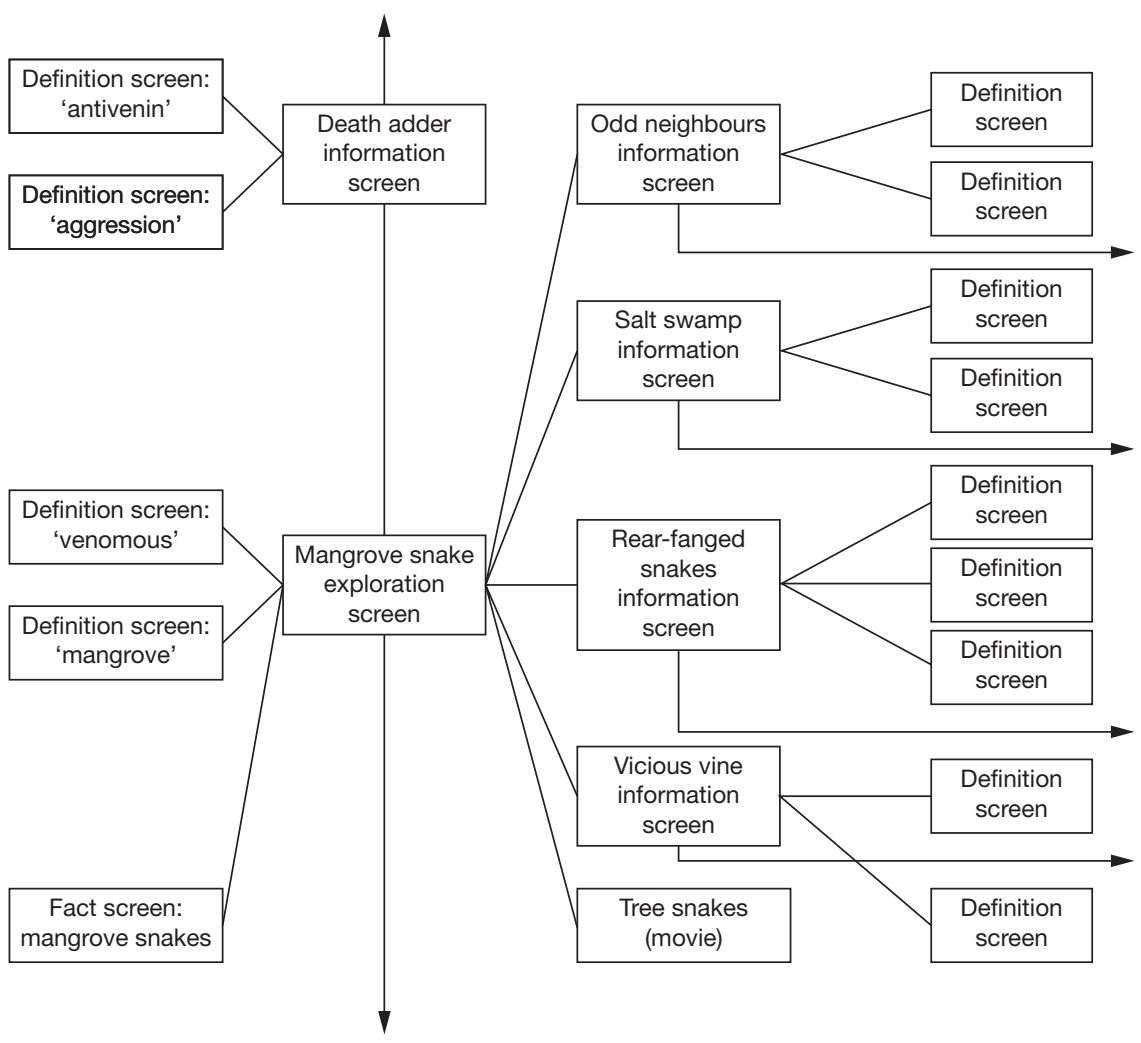

Figure 8.9 Section of 'Aboriginal guided tour' (Dangerous Creatures, Knowledge Adventure, 1994) 


\section{Theo van Leeuwen}

The 'death adder information screen' has a headline 'Death adders' top right, and includes two pictures showing more or less inert snakes against a neutral background. There are three boxes with explanatory written text, unrelated titbits of knowledge about snakes.

\section{Death adder}

There is a good reason that this Australian snake is called the 'Death Adder'. Before an antivenin was developed, half the people bitten by it died. Luckily, the death adder is not very aggressive and bites only if touched.

But there is also a spoken text, read by the female voice of the 'guide', the 'Aboriginal storyteller':

In that time there was not yet death. It was the fault of the first humans that death was led into the world (didgeridoo music starts at this point). For the moon came down to the earth and said to them: 'If you carry my pets across the river you will rise again after you have died and so live forever' (didgeridoo music fades out). But the humans refused. They were afraid of the moon's pets which were all deadly snakes. So the moon said: 'Silly humans, now when you die you will stay dead and I will always send you poisonous snakes to remind you that you disobeyed me.'

The 'death adder screen' links to two 'definition screens' - clicking on the italicised words of the written text produces a superimposed text box with a spoken and written headline (e.g. 'amphibians') and an explanatory text:

Animals that are cold-blooded, lay eggs, and have moist skins. Frogs, toads, and salamanders are amphibians. When amphibians are babies, they have gills and must live in the water like fish. As they grow up, they lose their gills, grow lungs and eventually must live on land.

After returning to the death adder screen, the user can either go back or follow the guide to the 'Mangrove snake exploration screen'. The picture on this screen is larger and more dramatic than the pictures in the 'Death adder information screen', showing a snake which raises its head menacingly. The text, too, is more dramatic, and not accompanied by 'subsidiary texts':

Coiled and ready to strike, a mangrove snake opens its mouth in warning. Its threats should be heeded - like many wasp-coloured animals, it's venomous. The snake lives in South-East Asia, spending its days resting in branches above saltwater mangrove swamps and hunting in the evening. Its venom isn't lethal to humans, but the big snake's bite could be quite painful. 
At the same time the voice of the guide continues the story:

One of those snakes was the mangrove snake. One day he sat complaining to his friend, the whipsnake: 'Yeah, I am very poisonous, but I am so slow, the humans are always chasing me and I must bite them when they catch me. It is quite exhausting.' The whipsnake, who was very fast, but perfectly harmless, said: 'Let me have your poison teeth, so the humans won't hate you anymore, and since I am too fast to catch, I won't need to bite them.' The mangrove snake agreed and ever since he has been only poisonous enough to kill his food and humans don't bother him.

What links these two screens? It depends on whether you focus on the speech or on the writing. From the point of view of the guide's story, this screen is the next episode in a narrative. From the point of view of the written text, it is an additional item of information about snakes.

The 'Mangrove snake exploration screen' links to various other information screens, providing yet other morsels of relatively unconnected information on the same topic: more on rear-fanged snakes, more on saltwater swamps, and so on. The layout of these screens is similar to that of the 'Death adder information screen', but the Aboriginal story does not continue. Instead, a male voice provides an item of information unrelated to the other information on the screen:

How can you tell snakes and legless lizards apart? Look for eyelids.

There is also a link to a movie loop and a 'fact screen'. This 'fact screen' (every 'exploration screen' has one) contains a heading ('Mangrove snake') and three separate 'facts', each accompanied by an icon. To the right of the facts are three pictures, a representation of the snake itself, without setting; a map showing its habitats; and a picture comparing its size to a human being. In all, there are no less than eight links to choose from, so the 'Mangrove snake exploration screen' does allow some 'free' exploration of the database.

Clearly this environment allows more choice. It can be read as an illustrated narrative, by following the spoken story of the Aboriginal storyteller, as mapped in Figure 8.10.

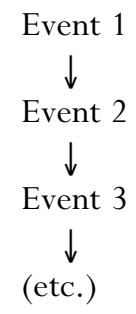


92 Theo van Leeuwen

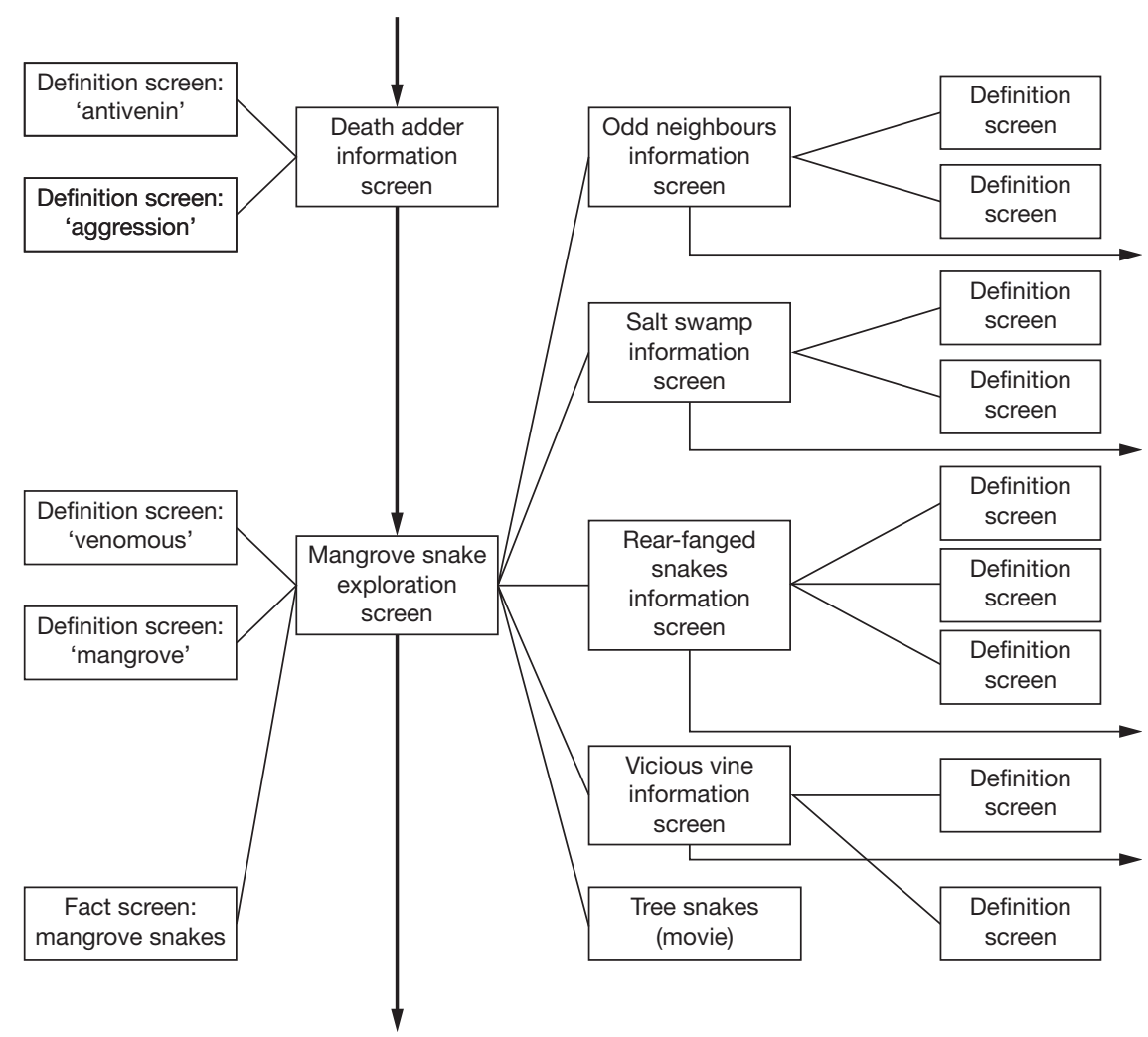

Figure 8.10 Reading path through a section of the 'Aboriginal guided tour'

Or it can be read as an information genre in which morsels of facts about a particular topic are accumulated, and elaborations and explanations of terms explored according to the user's interest, as mapped in Figure 8.11.

Fact 1

$\downarrow$

Explanation of term

$\downarrow$

Fact 2

$\downarrow$

Additional detail 1

$\downarrow$

Additional detail 2

$\downarrow$

Explanation of term

$\downarrow$

(etc.) 


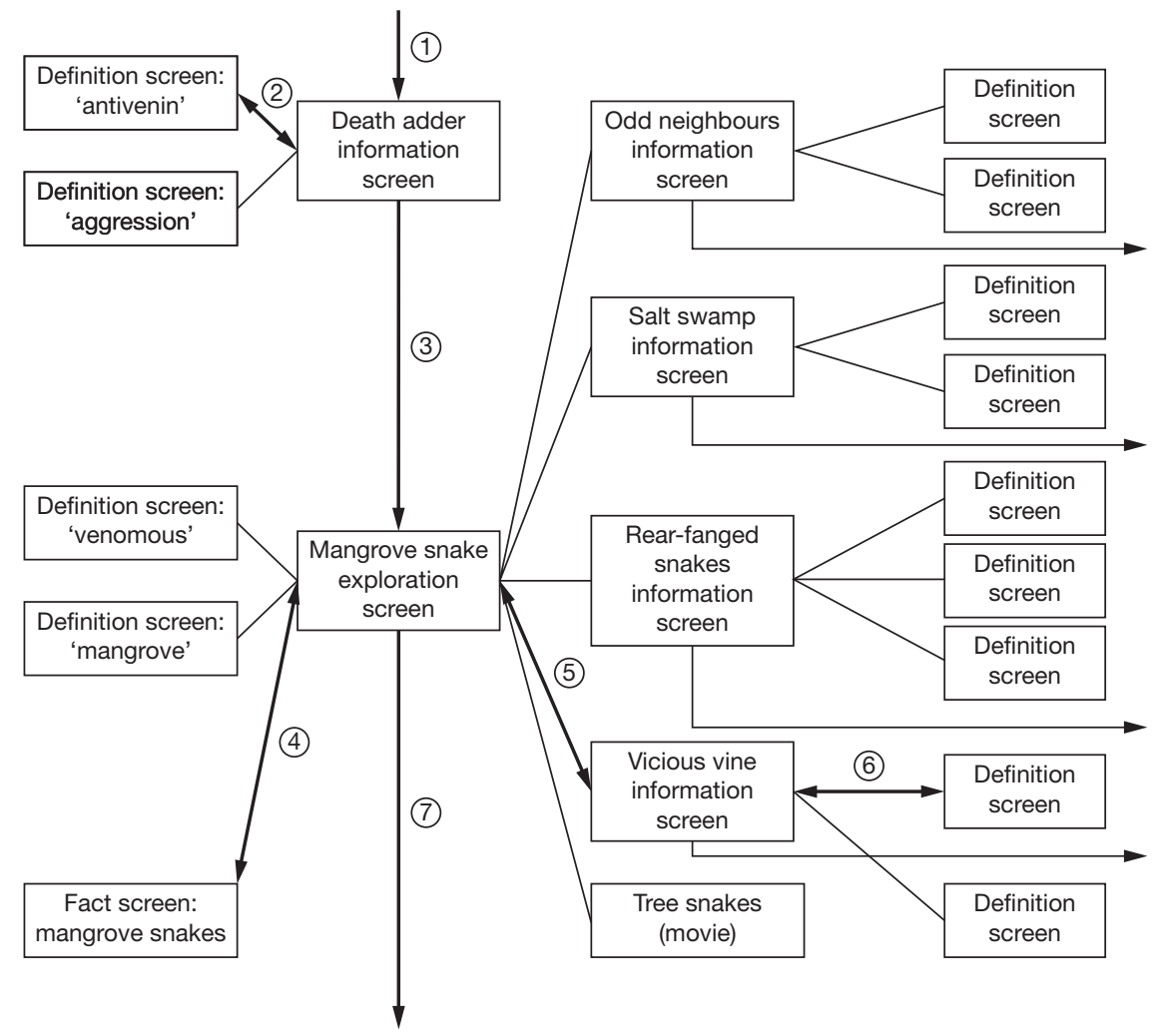

Figure 8.11 Alternative reading path through the same section of 'Aboriginal guided tour'

Clearly, this is a less linear environment than the exhibition in the Old Observatory. But that does not mean there are no constraints upon the user. Users can be positioned either as accumulators of unrelated facts, of 'quiz knowledge', or as listeners to a story, but they cannot, for instance, make up their own story, or make the items of information relate to each other in such a way that they become relevant, that they become knowledge you can do something with, rather than quiz knowledge. By structuring knowledge according to this 'quiz' model, Dangerous Creatures controls meaning just as much - maybe even more - than other, more linear texts. As Umberto Eco has said (1979: 9): in the 'open text' 'you cannot use the text as you want, but only as the text wants you to use it ... a an open text outlines a "closed" project of its Model Reader as a component of its structural strategy.' 


\section{Mediational means/cultural tools: questions and mini projects}

\section{Questions for discussion}

1 All mediational means come with affordances and constraints on action. Give an example of how one particular mediational means makes some kinds of actions and social identities possible while restricting others.

2 Wertsch makes a distinction between 'explicit' and 'implicit' mediation. Give an example of each of these and discuss how they might function differently.

3 As discourse analysts, the main kinds of mediational means we are traditionally interested in are verbal utterances and written texts. Often such utterances and texts are 'resemiotized' or transformed into objects, actions or identities. Can you think of some examples of this?

4 Van Leeuwen discusses how multimodal genres embody affordances and constraints by creating reading paths. What are some of the features that govern reading paths in such texts?

\section{Mini projects}

1 Choose a particular mediated action familiar to you and enumerate the mediational means used to perform it. Try to make a distinction between those mediational means that are 'explicit' and those that are involved in what Wertsch calls 'implicit mediation'. In the case of implicit mediation, what methods did you use to detect these 'less transparent' mediational means?

2 Collect data from your own interaction using different mediational means (such as face-to-face conversation, mobile or land-line telephony, internet web pages, email, instant messaging or computer chat). Examine how these mediational means affect how you present yourself and construct your identity and how discourses are 'resemiotized' or transformed through the use of different mediational means.

3 Gather a small corpus of multimodal texts which you consider to be of the same genre and plot the reading paths, the functional stages these paths lead through, and how these stages are realized in terms of linguistic, visual or auditory features. 


\section{Part III Practice}





\title{
9 Introducing practice
}

\author{
Rodney H. Jones and Sigrid Norris
}

\begin{tabular}{|c|c|}
\hline Practice: & $\begin{array}{l}\text { Used as a count rather than a non-count noun. } \\
\text { Narrowly defined social actions with a clear material } \\
\text { existence in the world, as well as a psychological } \\
\text { correlate in the habitus of social actors. } \\
\text { An action involving entrenched beliefs, values and } \\
\text { emotions. } \\
\text { Real-time mediated actions that have been linked to } \\
\text { other actions in ways that are recognizable to a } \\
\text { particular group of social actors. } \\
\text { A historical accumulation of mediated actions - within } \\
\text { the habitus of social actors - performed over a period } \\
\text { of time, which are understood by other social actors to } \\
\text { be 'the same' social action. }\end{array}$ \\
\hline
\end{tabular}

As a theory of how discourse and identity are implicated in situated social actions, MDA is essentially a theory of social practices. According to Scollon, social practices are the basis of all social actions (Scollon, 2001b), and thus the basis of all claims and imputations of social identity. The study of social practices links individuals and their cognitive and social development to the socio-cultural environments in which they reside. In order to understand how 'practice' fits into mediated discourse theory, however, it is necessary to distinguish the way the term is conceptualized in MDA from the way it is used in other approaches in the social sciences. 
The term 'practice' is particularly popular in modern social analysis. While its earliest use probably dates back to Aristotle (who distinguished praxis - everyday actions - from theoria - contemplation), more contemporary uses often come out of the Marxist intellectual tradition which emphasizes the inherently ideological nature of social practice. CDA, for example, sees practice as the habitualized ways in which people reproduce relationships among social actors, resources and settings (Chouliaraki and Fairclough, 1999), and perceives the purpose of discourse analysis as discovering how discourse constitutes and is constitutive of social practice.

MDA shares with critical discourse analysis and other approaches concerned with social practice the notion that a practice, as opposed to an action or activity, constitutes some kind of linkage between action, identity, ideology and power. Where it departs from these approaches is primarily in the 'scale' upon which it conceptualizes the term 'practice.' First of all, rather than as a non-count noun referring to collections of actions, as it is used by most social scientists, mediated discourse analysts use the term as a countable noun, usually to refer to a single action or set of actions that are so closely linked as to be practically indivisible. Thus, while others speak of, for example, the practice of 'gift giving' (Bourdieu, 1977) or the practice of 'sheep farming' (Chouliaraki and Fairclough, 1999), MDA takes a much narrower approach to practice, speaking of, for example, the practices of 'handing' (Scollon, 2001b), 'greeting,' 'using chopsticks' and 'waiting in a queue' (Scollon, 2001c), preferring to see larger activities like gift giving or sheep farming as constellations of linked practices which it calls 'nexus of practice.' The main reason for the narrowness in scope is analytical practicality. It is quite difficult to speak of 'sheep farming' or 'gift giving' as clearly defined entities with an unambiguous material basis in the world or a clear psychological basis in the minds of those who engage in them. Seeing practices more narrowly allows us to more easily identify their occurrence and analyze how they are linked to other practices in real time.

What, then, is the difference between a social practice and a mediated action? The answer to this question lies precisely in these real-time linkages. According to Wertsch (1998) the term 'practice' is used to speak of mediated actions when they are instances in a chain of actions that have a history within a particular group of social actors and within the cognitive development of an individual. Bourdieu (1977) puts it more simply when he defines a practice as an action with a history. Scollon (2001c) defines a practice as 'a historical accumulation within the habitus/historical body (Bourdieu, 1977; Nishida, 1958) of the social actor of mediated actions taken over his or her life (experience) and which are recognizable to other social actors as "the same" social action.'

As we move through our social worlds we appropriate social practices within our habitus (Bourdieu, 1977). At the same time, these practices become 'frozen' 
in the mediational means we have available to take action (Norris, 2002b, 2004b). In fact, mediational means are only available as mediational means or, what Wertsch calls 'cultural tools' insofar as they are embedded within some social practice and insofar as that social practice has been appropriated into the habitus of the users. Mediational means thus arise as the 'codification' of social practices (S. Scollon, 2001).

Given this narrower definition of practice, the search for values, ideology and relationships of power in social practices that concerns many social analysts cannot be satisfied through analyzing practices themselves but, rather, should focus on the ways particular practices are linked in real time to form a nexus of practice. It is at this nexus that individuals build their social identities - and often marginalize other social identities through their actions; and it is these linkages of practices which, over time, become social groups or 'communities of practice' (Lave and Wenger, 1991; Jones, 2001; S. Scollon, 2001) that advance ideological agendas and reproduce relationships of dominance.

The chapters that follow explore how mediated actions become practices by being linked with other actions in real time, and how they consequently come to define not only 'what social actors are doing' but also 'who they are.' In Chapter 10 , Filliettaz explores how participants in service encounters make use of various mediational means to create a historical context for their actions - in ways that make them recognizable as social practices to other social actors. In Chapter 11, Lemke further explores the importance of temporality in the definition of practice, showing how the actions that players of a computer game take are linked in recognizable spatio-temporal sequences which he, after Bakhtin, calls chronotopes. Finally, in Chapter 12, Rowe uses the concepts of 'situation definition' and 'hybrid activity type' to analyze how different nexus of practice are formed in the interaction among children at an interactive science exhibition. 


\title{
10 Mediated actions, social practices, and contextualization: a case study from service encounters
}

\author{
Laurent Filliettaz
}

\section{Contextualization and mediated discourse analysis}

The problem of contextualization has long been a key issue in contemporary approaches to discourse. It has been central in various disciplinary subfields concerned with the description of actual language use. It has also been a factor in epistemological and methodological debates among different analytical paradigms such as CA, CDA, and interactional sociolinguistics (see Duranti and Goodwin, 1992; Gumperz, 1999) regarding the local or global character of context (Cicourel, 1992; Schegloff, 1992), or its deterministic vs. emergent relation to situated interaction (Gumperz, 2001).

Unlike many other approaches, MDA does not consider the notion of 'context' a fruitful concept to account for the complex relations between discourse and society. Scollon (2001a), for example, views the notion of context with suspicion, since it is associated with approaches to discourse that focus in the end primarily on language and see 'contextual information' merely as an external set of background determinations:

Many theories of language and of discourse start out with a focus on 'social action' such as speech act theory, pragmatics, interactional sociolinguistics, and CDA but then somehow in practice tend to become focused only on text. Other aspects of social action and other mediational means than language and discourse are backgrounded as 'context.' Unfortunately, this can lead to a distorted understanding of the relationship between discourse and social action.

(Scollon, 2001a: 4)

In order to account for the complex links relating discursive forms with situated social practices, MDA investigates alternative solutions to the notion of 'context.' It does so in at least three ways: 
- By stating a 'principle of social action' (Scollon, 2000), MDA acknowledges the idea that discourse does not consist exclusively of producing and interpreting utterances, but is best described in terms of the social actions carried out by language users. It aims at shifting the focus away from discourse to the human actions being taken, and therefore argues that social actions should be seen as central and primary units of analysis.

- By conceiving of language as a mediational means, MDA sees discourse as one type of cultural tool contributing to the construction of social actions, but explicitly refuses to see language use as the sole means by which actions are taken (see Scollon, 2001a; Scollon and Scollon, 2003). Because texts necessarily 'under-represent the meaning present in the actions' (Scollon, 2001a), other semiotic means, such as material objects or non verbal conduct, are taken into account. From such a multimodal perspective, physical artifacts are not seen any more as 'contextual' or background elements, but as units of analysis that play a central role in our understanding of how human actions are carried out in society.

- By exploring how actions and discourses move through time (see Scollon, this volume; de Saint-Georges, 2003), MDA takes into consideration the various rhythmic patterns that constrain mediated actions and aims at making explicit how locally negotiated actions are embedded in long-term 'timescales' that link actors, objects, language, and practices both with history and with future states (Scollon, 2002b). Here again, the historical trajectories intersecting in a 'nexus of practice' are not perceived as 'contextual' or 'peripheral' information. Rather, their analysis is seen as necessary for the understanding of the action at hand.

- By 'expanding the circumferences of discourse' not just to take into account contextual information, but also to broaden the scope of what linguists interested in actual language use should be able to account for, MDA provides a fruitful alternative to models that focus primarily on text or talk and that artificially conceive clear-cut boundaries between language and 'extra-linguistic' realities such as action, culture, history, and objects.

\section{Contextualizing service encounters: a case study}

In their recent work, Ron and Suzanne Scollon have often based their arguments on mundane examples taken from everyday life in order to stress the idea that actions such as lighting a camping stove (Scollon, 2002a), having a cup of coffee (Scollon, 2001a), or buying a book (Scollon, 2002b) can tell us a lot about discourse, action, and social practice.

At first glance, service encounters can be regarded as relatively elementary social practices. If one returns for instance to Merritt's definition ${ }^{1}$ of service 


\section{Laurent Filliettaz}

encounter, one can indeed characterize such interactions as highly predictable, predetermined by a restricted set of scripted actions, and engaging clearly defined and interdependent social roles. However, when faced with empirical data, one cannot fail to notice that service encounters turn out to be far more complex and unpredictable than we intuitively imagine them to be (see Aston, 1988; Filliettaz, 2004d).

From this perspective, interactions between service providers and clients can be viewed as a very relevant domain of investigation for MDA. The social practices involved in service encounters are mediated by various types of linguistic means: the position of a service provider, for instance, requires an ability to advise clients, to facilitate their choices, to coordinate with other colleagues, to place phone calls, and to find specific information in a catalogue. Focusing solely on these linguistic means, however, gives rise to a distorted and incomplete picture of the semiotic realities taking place when clients and service providers meet. In such settings, joint actions are not taken exclusively through language use, but very often also incorporate nonverbal conduct and references to material objects accessible in the physical environment (see Filliettaz, 2004a). Such elements cannot be ignored by the analyst and should be given central attention within a multimodal approach to discourse.

The data used for this case study are extracted from a large corpus of more than 350 interactions that were audio-recorded in a department store in Geneva during the spring of 2001. ${ }^{2}$ This data collection took place during a four-month period of ethnographic fieldwork focusing on how shop assistants and clients coordinate their actions in the context of encounters referring to goods associated with complex technical knowledge. Three specific settings were therefore selected: (a) a sports department; (b) an electronics department; and (c) a do-it-yourself and gardening department.

The excerpt transcribed below is from a service encounter recorded in the do-it-yourself department in July 2001. It is extracted from a five-minute long interaction between a 50-year-old female client (C) and a 25-year-old female assistant (A). The transcription is a translation from French. ${ }^{3}$

(1) $C$ : er a compass do you have a compass?

$A$ : er we might . come and have a look well by compass you mean a small thing for the car right? [A and $\mathrm{C}$ are walking towards the appropriate aisle]

$C$ : Yeah

(5) $A$ : maybe this could work

$C$ : if it's the same that I already have uh ::

$A$ : well let me show you and then you will see [A and $\mathrm{C}$ reach the aisle where compasses are]

C: XX I was looking for something a little bit bigger 
(10) $A$ : well we don't have anything big here

$C$ : something that would be that big at least [C performs an iconic gesture]

$A$ : yeah something as big as this we don't have we only have small things for the car uh: you might check if by chance they have one in the electronics department right below the sports department

(15) $C$ : yeah all right I'll have a look there

$A$ : Yeah

$C$ : because my husband he still hasn't understood . that . a compass points to the North $<$ A laughs $>$. so if one turns around like this it points like this if one turns around like this it points like this if one turns around like this . it points . like that [while talking, C progressively accomplishes a 360 degrees rotation] $<$ yes of course $>$ so er : . I have to give him a little lesson but with a small thing such as this one it's not so convenient $<$ A laughs $>$ I would like a nice compass it might even be :: a gift for his birthday uh : for next year but $<\mathrm{A}$ laughs $>$ yeah really when one puts a compass like this $<$ yes of course $>$ it indicates where we are <yes of course $>$ right? it indicates where WE are . so he says to me uh :: the arrow. I say but the arrow always shows you where the North is <well yes $>$ then he goes on asking so where is the North? . and I say you just have to turn around until the arrow points to the North $<\mathrm{A}$ laughs $>$. but he still hasn't understood. so with a little thing such as this one a tiny little sphere that is even half hidden he will not understand so I'd like to buy him a nice compass $<$ A laughs $>$. thanks

$A$ : you're welcome [pause $3 \mathrm{sec}$.]

$C$ : you must meet strange people sometimes don't you?

$A$ : no it's a pleasure precisely because we meet a lot of different people and that's what's great

[A laughs] [C's cellphone rings]

Before proceeding to a more detailed analysis of this excerpt, I would like to start by making a couple of brief comments about what is going on during this sequence. What makes this example of a service encounter particularly interesting to me is the rather complex ways in which the agents negotiate the joint actions they are engaged in. In the first section of their encounter (lines 1 to 16), the client and the assistant seem to be contributing mainly to a commercial exchange: the client performs a request ('Er a compass do you have a compass?'); the assistant makes an offer ('er we might come and have a look'); the client utters an explicit refusal ('I was looking for something a little bit bigger'); and finally, the assistant proposes an alternative solution ('you might check if by chance they have one in the electronics department right below the sports department'). At this stage of the encounter, speech seems to be primarily a matter of exchanging information in order to achieve some 'transactional' goal. It is highly determined by social 


\section{Laurent Filliettaz}

practices that shape what could be viewed as a particular kind of 'institutional interaction'4: a service provider pursues the goal of a client and tries to satisfy their needs. Through doing this, she contributes to enhancing the profit of the company by which she is employed.

However, important changes occur in the second part of the encounter. The client could have simply ratified the assistant's advice and gone to the electronics department in order to check if more appropriate compasses were sold there. But instead, in an extensively developed turn, she chooses to display elements of her private life to the assistant, talking of such things as her husband, who does not understand how compasses work, and the lesson she wants to give him. In this section of the interaction (lines 17 to 31 ), the goals ratified by the interacting agents consist much more of 'having a conversation' than of accomplishing a commercial transaction. This has visible effects on the organization of discourse as well as on the situated identities displayed by the participants.

This twofold organization of the encounter raises interesting questions in terms of professional discourse and of theorizing the relationship between discourse and social practices: how do the assistant and the client proceed in order to articulate an institutional and public practice with the sharing of ordinary and private experiences? What do such intimate considerations bring to the construction of joint actions? In what sense do they help the participants elaborate a mutually ratified 'context' for their interaction? To what extent are such constructions mediated by language? In the following paragraphs, I will try to give some elements of answer to this set of questions by exploring some of the conceptual tools developed by MDA.

\section{$A$ discursive account of timescales}

As mentioned above, MDA argues that it is crucially important not to restrict the scope of action to the narrow and momentary lapse of time during which it is actually performed. Rather, one should systematically take into consideration the fact that the actors, objects, or places that intersect in the 'nexus of practice' are embedded in larger timescales: they are at the same time emanations from the past and prefigurations of possible futures (see Scollon, 2002b; Scollon and Scollon, 2003).

In our example, the sequence of interaction between the client and the assistant incorporates many such trajectories. From the perspective of the assistant, this encounter is one element in a series of encounters carried out with other clients during the same day and over a longer period of time. Moreover, this encounter is one among a vast array of other routinely accomplished tasks associated with the position of a professional sales assistant (arranging goods on shelves, attending team meetings, making stocklists, etc.). It is precisely because of such past experiences and other actions external to the recordings that the assistant can expect to 
satisfy the client's request ('we might . come and have a look well by compass you mean a small thing for the car right?') and is able to project a possible immediate future for her ('you might check if by chance they have one in the electronics department right below the sports department').

Similarly, from the perspective of the client, the transaction she tries to accomplish should no longer be seen as a decontextualized isolate. It is tightly linked with past experiences and future projects. Quite interestingly, it should be mentioned that the client herself makes elements of her timescale explicitly accountable to the assistant: she recalls past events (the problems faced by her husband while using a compass) and anticipates future actions such as the lesson she wants to give to her husband ('I have to give him a little lesson') or the gift she plans to offer him for his birthday ('it might even be :: a gift for his birthday uh : for next year').

These segments of her trajectory are constructed discursively by means of textual constructions of variable complexity. If anticipated actions are briefly evoked by single sentences, the reconfiguration of past experience gives rise to a prototypical case of story-telling in conversation. From line 23 on, the client performs a complete narrative in the technical sense defined by Labov or Gülich and Quasthoff (1986): she utters narrative propositions that enter in a temporal relationship ('he says . . . I say . . . he goes on asking . . . I say . . . he still hasn't understood') and privileges a 'replaying mode' of telling in which she tries to 'make things present' by performing direct reported speech and sharing numerous evaluative attitudes towards her husband. In other words, the client not only explains to the assistant how difficult it is for her husband to master a compass, but she replays a moment of past action during which she desperately tried to demonstrate how compasses work.

These 'pre-action anticipations' and 'post-action narratives' can be seen as linguistic accounts of the client's life trajectory. They show how tightly social actions are intersecting with each other in everyday experience. In our example, these discursive accounts of timescales assume various pragmatic functions in the construction of a mutually ratified action frame: they enable the participants to bridge the public and institutional nature of the encounter with the sphere of privacy and make explicit how the present they share is deeply shaped by larger projects.

\section{Motives and contextualization}

Elements identified in the preceding section have not only to do with time but also with motives, another of MDA's central concepts. In Scollon's view, defining the motives associated with actions raises important methodological issues to social sciences, since one can always identify a multitude of possible candidates as motives for human action. As a solution to this 'general shakiness of any analytical 


\section{Laurent Filliettaz}

process that might attribute motives' (Scollon, 2002b), Scollon proposes that motives are primarily discursive constructions:

Put in contemporary terms ... the causes of that action are discursive constructions, not behavioral primes, though they might well have been constructed 'in advance' as anticipations. That is immaterial to the case. In this view of human motives, whether they are post-action narratives or pre-action anticipations, any and all motives are matters of discourse, not psychological or material primes.

(Scollon, 2002b: 8)

From this standpoint 'motive analysis' does not aim so much at identifying fundamental or 'true' causes for the action, but consists in paying attention to how participants ascribe explanations to the actions in which they are engaged.

In our example, it is important to stress the idea that timescales and motives seem to be closely interrelated: when expressing past experiences and future projects, the client explains the reasons why she takes part in the encounter and ascribes causes to her presence in the do-it-yourself department. Analytical philosophers - especially Anscombe (1957) - have clearly shown that a theory of action must distinguish between 'what the agent aims at or chooses' - their intentions - and 'what determines the aim or choice' - their motives. From this perspective, one could say that the discursive expression of timescales precisely aims at making the client's motives accountable for the assistant.

This being said, it begs a further question: why does the client make her motives visible in these circumstances? In what sense do these explanations contribute to contextualizing her mediated actions? As a tentative answer to these questions, I would like to argue that such mediational means seem to satisfy crucial pragmatic functions, both on the objective level of the commercial transaction at hand, and on the more subjective level of the management of the relationship between the interacting agents (Filliettaz, 2002, 2003). On the level of the transaction taking place, discursively expressed motives help the client to justify why she cannot accept the assistant's offer: the compasses available in the shop are not satisfactory because they are felt to be incompatible with the client's needs in the practices she refers to (giving a lesson, making a gift): 'I was looking for something a little bit bigger'; 'so with a little thing such as this one a tiny little sphere that is even half hidden he will not understand.' In other words, motives seem to clarify the 'felicity conditions' of this economic transaction and contribute to specify under what conditions the client guarantees her engagement in the joint action.

The expression of motivational information is also not unrelated to more subjective components that shape interpersonal encounters. As Habermas (1984) has clearly shown, in the wake of Goffman (1959), interactants often engage in a 
sort of 'theatrical representation' in which they aim to manage the image they give of themselves. By sharing subjective personal experiences, they accomplish face work and negotiate what one could call the dramaturgical dimension of their joint action. From this standpoint, the story-telling and anticipatory discourse associated with the expression of motivational information help the client to present herself as competent, devoted, and obliging: she knows how to master a compass and wants to help her husband to do so. The assistant seems to adopt a highly empathic attitude regarding the drama played by the client, as shown by the frequent backchannel signals (<yes of course $>$, $<$ well yes $>$, etc.) and laughs. Motivational information thus also helps the agents to position themselves with regard to the relation they build with each other.

\section{Cognitive artifacts as mediational means}

As argued by Scollon and Scollon, it would be a great mistake to pay exclusive attention to discursive mediational means. In the excerpt under analysis, the presence of a material object such as the compass obviously plays a central role in the ability of the interacting agents to frame the actions in which they are engaged. More precisely, compasses in the interaction seem to assume successively three distinct semiotic positions:

- In the client's request and in the initial section of the encounter, the compass appears as a discourse topic: it is present in the environment under the form of a linguistic sign but is not yet incorporated in any physical object.

- In contrast, when the client and the assistant reach the appropriate aisle where compasses are sold (lines 6 and 7), the transactional object takes physical shape. It is not only a semantic content referred to by speakers, but a real object whose material properties are accessible to the agents and give rise to various appreciations: 'I was looking for something a little bit bigger'; 'so with a little thing such as this one a tiny little sphere that is even half hidden he will not understand.' At this level, the compass as mediational means does not satisfy the 'felicity conditions' of the transaction and leads to a reorientation of the client.

- Beyond its 'linguistic' and 'material' modes of existence, it seems that at certain points in the encounter, the compass also functions as a 'cognitive artifact,' which is to say as an external device that stands for, refers to, or represents a thing that exists in the world (Norman, 1993). Although the interactants never physically handle the object of transaction, the client simulates its manipulation by accomplishing a 360 degrees rotation around an axis: 'so if one turns around like this it points like this if one turns around like this it points like this if one turns around like this . it points like that'. In 


\section{Laurent Filliettaz}

these circumstances, the compass functions as a symbol embodied in the situation by gesture. This simulation is crucially important in the client's discourse: it enables the client to transpose the object from the transactional setting to other practices in which it is used. It also leads her to express internalized actions and discourses associated with the compass in her past experience.

Taking into consideration the various semiotic faces of the compass in our example shows how central this mediational means can be in the present circumstances. Indeed, it is mainly this object, with its various material characteristics, that connects the multiple practices integrated in the present nexus: the practice of a service encounter, the practice of using a compass, the practice of giving a lesson, the practice of making a gift for a birthday. Not only does it shift from one possible practice to another, but it travels through time (the past, the present, and the future), and among various actors (the client, the assistant, the husband). In sum, it can be seen as an essential element of cohesion in the various contexts experienced and discursively represented by the interacting agents.

\section{Conclusion: reframing a social practice}

To conclude, I would like to return briefly to the final comment made by the client before her cell phone rings. After the completion of her narrative, she thanks the assistant and seems to initiate a closing sequence. She then briefly addresses the assistant by saying: 'you must meet strange people sometimes don't you?'

Her question produces various interesting effects on the situation. First, it contains an appreciation of her own conduct and manifests a reflexive attitude regarding what has happened in the encounter. The client and the assistant are not only acting together, but they are also sharing considerations about how their actions have been carried out. Second, this statement ascribes a judgment of 'strangeness' to her contribution to the encounter. By doing so, she makes explicit that service encounters are framed by underlying expectations, and that her behavior may be seen as challenging such expectations: in her view, simulating the handling of a compass and proposing an extended narrative of past and private experience are not usual contributions associated with the role of a client.

In sum, this example shows that discourse assumes important functions in the way actors orient themselves in mediated actions: it makes social practices visible by expressing some of the premises that frame the situation (see Goffman, 1974); and it enables the participants to negotiate these premises by taking distance with the frame. From this standpoint, it becomes crucially important to go beyond a clear-cut delimitation between deterministic and more constructionist approaches to action. Preceded by general cultural expectations, but necessarily negotiated in 
specific situations, mediated actions do not come down to a predetermined set of scripted conducts. Nor can they be described satisfactorily as strictly emergent processes. Rather, they are best conceived as a combination of both typified social knowledge and interpersonal negotiation, in which language intersects with other mediational means.

By exploring the various ways in which action and discourse may be related, MDA aims to bring some discipline and systematic methodology to such a finegrained conceptualization of mediated action. It is in this sense that it proposes to go beyond a strict delimitation opposing 'text' and 'context' and to elaborate new approaches for describing the complex linkages between language and society.

\section{Notes}

1 '. . a an instance of face-to-face interaction between a server who is "officially posted" in some service area, that interaction being oriented to the satisfaction of the customer's presumed desire for some service and the server's obligation to provide that service' (Merritt quoted by Aston, 1988: 27).

2 In order to deal with frequent space shifting, the data were collected by means of a light recording device. Seventeen volunteer sellers had been equipped with microphones and portable mini-disc recorders. The clients were informed about the recordings by means of posters made visible at the entrance of the store. Additional information was provided to those who wanted to know more about the research. The recording was complemented by fieldnotes.

3 I use the following transcription conventions: (.) (..) indicate appropriately timed pauses; (::) indicates that the syllable is lengthened; underlining indicates overlapping talk; and square brackets ([ ]) mark nonverbal behavior or events; uninterpretable sequences are transcribed with XXX.

4 Following Drew and Heritage (1992: 22), one can define institutional interaction as follows:

Institutional interaction involves an orientation by at least one of the participants to some core goal, task or identity (or set of them) conventionally associated with the institution in question. In short, institutional talk is normally informed by goal orientations of a relatively restricted conventional form. 


\title{
11 Place, pace, and meaning: multimedia chronotopes
}

\author{
Jay Lemke
}

We make meaning along our lives' traversals: across real and virtual spaces, across multiple institutions, genres, media, and semiotic systems. We do so in real time, across multiple timescales of action and activity, from the blink of an eye to the work of a lifetime. But how do we succeed in coherently integrating the meaning of a moment into the meanings of minutes, days, months, and lifetimes? How do momentary actions come to be seen as situated activities and social practices?

In this chapter, I develop a conceptual framework within which to give accounts of how the prior coherence of places and of the discursive imaginaries of multiscale projects helps us constitute meaning through time. I use Bakhtin's notion of the chronotope (Bakhtin, 1981b) to represent culturally typical movements and pacings along trajectories of activity, and combine this with my own development of the principle of heterochrony, according to which meaningful activities are linked across timescales by our use of discursive-semiotic artifacts (Lemke, 2000a).

To make these issues more concrete, I illustrate meaning-making across both real and virtual environments, by focusing on how temporal and spatial coherence is achieved in the interactive, immersive, multimedia environment of a computer gameworld.

\section{Theory as toolkit}

I began my intellectual and academic life as a theoretical physicist, so I have a profound regard for the value of theory, but also a considerable skepticism about the excessive claims sometimes made for it. Theories are not meant to be 'master discourses' providing the keys to the kingdom. They do not consist of universal and timeless or culture-free objective truths. They are simply assemblages of intellectual tools. In the case of well-developed theories these tools have long been found to work well together, complementing and extending one another in doing the work of some paradigm of inquiry. There is a continuum, and usually 
a historical continuity in theory development, from bricolage to paradigmatic theory, but the stuff of theory remains merely an assemblage of tools, not truths.

In a sense, this view of theory as assemblage of tools is entirely parallel to R. Scollon's (2001a) notion of a nexus of practices insofar as an intellectual tool is nothing at all apart from the practices in which we use it, and the kind of assemblage a theory represents is, indeed, a nexus in Scollon's sense: an emergent system of interdependent practices, discursive and non-discursive, always material, organized around some recognizable activity (here the activity of theorybased inquiry), and the product of a specific history. Indeed, it is the product of history on short timescales and long ones, from the interpretative instantiation of the theory in the course of a specific 'application' of it, to our own biographical and educational ontogenesis as users of the theory, to the socio-cultural history of the development of theory in the context of a variety of long-lived social institutions. I put 'application' in quotes because I do not believe that theory remains unchanged when we bring it to use in a particular inquiry. The practices of tool-using necessarily enter into the mediated action of an inquiry in ways that require them to be modified and adapted as they are co-ordinated with other practices to get something done. They are differently adapted in each case, though we can of course construct some invariants and similarities from case to case to imagine a certain stability to our tools or cultural practices. Tool and practice are nouns, but nouns I want to use for naming processes, not things; they have a different sort of identity and stability from things, despite grammar and its sometimes misleading semantic connotations. A theory, as an assemblage of toolsfor-practice, an abstract system of imagined relationships among classes of partial similarities of observable processes or actions, is about as little like a thing you can have, know, or believe in, as I can imagine.

What kinds of tools form a useful toolkit for asking and answering questions about the continuity of action and meaning through time? Certainly we need a serviceable semiotics of discursive and non-discursive meaning-making as action: a multimedia semiotics, a multi-modal semiotics, a semiotics of action. I tend to make my own tools of this kind (Lemke, 1995, 1999, 2002b) but their historical roots lie in the linguistic social semiotics of Michael Halliday (1978) with some borrowings from C.S. Peirce (1998) and M.M. Bakhtin (1981a, 1981b). Extending them to a semiotics of action and multimodality, including visual semiotics and the semiotics of sound has been the work of a large community which shares these roots (Kress and van Leeuwen, 1996, 2001; Thibault, 2000; van Leeuwen, 1999).

We also need a phenomenology of space and time, which may not yet be a theory of how time, space, and movement are used as semiotic resources, but which alerts us to how our experience of time and space play a role in what is meaningful to us (Merleau-Ponty, 1945/1962; Husserl, 1992; Heidegger, 1996). Bourdieu (1972, 1990), especially his critique of Claude Levi-Strauss' 


\section{Jay Lemke}

structuralism regarding the importance of pacing and timing is very important here. The contrast between the view of space and time in modern physics and the phenomenological view, particularly of time, and the development of models of social space and place in postmodern social geography (Crang and Thrift, 2000; Lefebvre, 1991; Thrift, 1996) opens up many possibilities for conceptualizing timing, pacing, duration, built space, abstract space, felt space, etc.

Finally, we need some sort of social ecology, a theory of the complex ecological systems that human societies and our artifacts form as integral parts of larger 'natural' ecologies (Gunderson and Holling, 2002; Salthe, 1993). This, too, is not quite a theory as yet, but we need from it: concepts such as interdependence, organizational hierarchies (which are not the same as power or control hierarchies), emergence, and most importantly, timescales. When our fundamental tools, and our objects of inquiry, are processes rather than things or persons as such, it is not just spatialextensional scales from small constituents to large aggregations that matter, but how processes that occur on short timescales become embedded in and potentially cumulative towards longer timescale processes (Lemke, 2000a).

How do they? My basic theoretical tools for posing and answering this question are the concepts of heterochrony and semiotic artifact. In the general theory of complex systems which are organized across multiple scales (e.g. molecules within organelles within cells within tissues within organs within organisms within ecosystems ...), the laws of physics and chemistry (themselves tools, of course, embedded in practices) more or less require that processes on vastly different timescales be independent of one another (basically because they can't efficiently transfer energy, and so information, back and forth). But in human eco-social systems the addition of semiotic artifacts, such as material texts or architectural blueprints, means that events distant in time can become indirectly coupled to one another (e.g. design and construction) and so events on short timescales (which happen quickly) such as drawing a blueprint or reading one, and processes that take place slowly, over much longer timescales (like building a cathedral) become coupled or linked. In eco-social systems with material meaning-carriers (signifiers, signs), processes on very different timescales do exchange information (this is heterochrony), not via direct energy-coupling but through the indirect means of signusers (writers and readers who are also enactors of other sorts of material action) interacting with semiotic artifacts (material structures that can carry meaning for us) that, as things (not processes, or at least not for present purposes) persist across timescales that are long compared to the timescale of 'writing' or 'reading' them.

Here, too, the notion of a nexus of practices is useful. For it helps us to understand how discursive processes (which are essentially semiotic processes in my terms, generalizing from discourse and language to all semiotic modalities) come to be interdependent in activity with other material processes (like holding the pencil, or tearing on the dotted line), so that the use of semiotic artifacts can 'guide' 
material activities like placing a stone in building a cathedral. (Of course the cathedral itself is a semiotic artifact no less than the blueprint for its construction, but the nexus of practices in building it from the blueprint is different from that of, say, reading the cathedral as a historical 'document.') We often use one semiotic artifact in the practices of constructing another, and this is in fact a direct generalization of the principle of intertextuality.

How do our tools work together as a theory? Imagine yourself walking down the nave of a gothic cathedral. You feel the space and its complexity phenomenologically even as you 'read' its architectural plan semiotically and combine those meanings with the ones you make by reading the visual images of its stained glass windows and the textual inscriptions on gravestones underfoot. You are engaged in an activity, in a whole set of activities on different timescales, from a glance down to a step forward, from walking to 'touring the cathedral' to 'seeing the town' to 'being on vacation.' You are doing all these things in every moment, not one now and the others later.

You are moving at a certain pace, and rushing down the nave full-tilt would vastly change your experience of the space, the meanings you could make of images and texts, and the meaning for you of the activity itself. Not to mention that you would be behaving in a culturally inappropriate manner for the type of place you are in. Around you other people are engaging in the whole range of typical and appropriate activities for a cathedral setting, and for a particular time of day and day in the year. You could read their activities as signs, just as they could read yours. You can sign the visitor's book and leave a semioticmaterial trace that can be read hundreds of years from now, as we read such signs from times past. Reading the material signs in the cathedral, some created a very long time ago, influences our present behavior, and our present behavior thus becomes in some small part a moment in long-term processes of social continuity and cultural change.

As we move through our tourist day, we are producing a trajectory that traverses across settings and activities. In seeing the town we are now in the cathedral and now in the park or the museum, we are at lunch in the café on the square or resting on a bench by the river. In each setting there are different expectations, different affordances, things it's possible to do and things it's culturally appropriate to do. There are different semiotic artifacts available, cueing us in to actions we can perform with them (ordering from the menu, seeing the museum piece in light of the accompanying description, re-experiencing the square overlaid with a performance in son et lumiere). We move from setting to setting, from institution to institution, from genre to genre of semiotic artifact, from activity to activity. And they are not, for us, at the time, or retrospectively, disconnected. They are experienced with a continuity, they can be coherently narrated, the trajectory as a whole has a meaning for us, even if it may not be easily rendered in words. 


\section{Jay Lemke}

I use the concept of traversal (Lemke, 2002a, 2003) to foreground continuity across difference: across different media, settings, institutional expectations, activities, etc. I appropriate from Mikhail Bakhtin the notion of a chronotope for the culturally typical movements from place to place, each with its own characteristic timing and pacing, that characterize complex extended human activity every bit as much as they do the spatio-temporal organization of action in a novel (Bakhtin, 1981b).

\section{Space and time in The Sims}

The Sims [Deluxe Edition; Maxis, 2002] has been called by its principal designer, Will Wright, more of a 'software toy' than a game. It is regarded as an innovative and pioneering game largely because prior popular games were mainly about achieving hard-programmed puzzle-solving or foe-vanquishing goals whereas The Sims has no such goals or criteria of winning or losing, and the use of artificial intelligence (AI) programming techniques in its design makes for surprisingly life-like behavior by the simulated characters in the game.

Wright and his company came to The Sims from prior experience developing their equally pioneering SimCity series [Maxis 1989, 2003], in which the player-user could build model cities and their infrastructures and manage them dynamically in response to the needs of their imaginary populations.

The SimCity heritage is most evident in The Sims in the tools provided to the player-user for building homes or remodeling existing ones. What is new is the ability to create individual inhabitants, or import them 'off the shelf.' They have assignable personality traits, rather like characters in familiar role-playing fantasy games (e.g. Baldur's Gate, Everquest), but they also have 'moods': degrees of happiness or need (hunger, sleep/energy, socializing, calls of nature, etc.). You can create a household group of one to six 'sims' (simulated persons) and move them into a pre-fab or purpose-built house. Once in the house, they begin to 'live' by moving around, talking to one another (in a language that has recognizable intonation and attitude, but nonsense vocabulary), using the toilet, demanding food or sleep, etc.

The initial point of the game is to make them happy (or torment them, if you so choose). In addition to the basic 'Living' mode, you can put their lives on hold while you Build (re-model the house) or simply Buy (and place purchased furnishings in the rooms of the house). You are a voyeur in their lives, seeing their actions, interpreting their desires, and monitoring their needs by means of a graphic display of mood and other state variables. You can intervene in their on-going activity by issuing commands for them to interact with objects in the house: use the toilet, make coffee, go to bed, change clothes at the dresser, etc. ${ }^{1}$

My initial concern here is to sketch out something of the role of space and time, place and pace, in The Sims, and then go on to show how conceptual tools such as 
chronotopes, traversals, and heterochrony can be applied in making sense of the development of meaningful action across sites, media, and timescales.

Consider first the semiotics and phenomenology of space and place. In the spirit of an action-centered or processual approach, let us not ask what the spaces and places of The Sims are, but rather how we know them through what we do. If we simply start the game, we can observe the inhabitants going about the business of their lives, and this includes seeing them walk from room to room, climb stairs from level to level, and walk around tables and other objects. We see the spaces of this place as they are defined by actions undertaken within them. But we can also change our own viewpoint on the household, by altering the angle of our isometric perspective and shifting view between upstairs and downstairs. We can also zoom in and zoom out, changing the scale of images relative to the viewing screen.

The Sims does not allow us to actually see the gameworld as if through the eyes of a character in it (first-person perspective), which some other games do (e.g. Doom, Quake). But it does allow us to get to know space and place in two other, very powerful ways. One is an affordance of the 'Buy' mode, in which having purchased an item of furnishing from a menu we can position and place this item somewhere in the house where it fits. With the kinesthetic sense of moving the mouse, integrated with a visual display of locations and pre-existing objects, we maneuver the new item to a position where it is not in conflict with other objects. Just as in real life, we come to know space and place through such actions, and not simply by passive observation or by watching the actions of others. In the Build mode, we can go further and create or delete sections of walls, and we can re-surface the floors. In these ways, too, we come to know the spaces and places of the gameworld. We also are forced by the logic of the game and of architectural form to consider relationships of interior and exterior views, and of walls that define spaces and rooms above and below on different floors.

I should say here that I use both the term space and the term place because the former connotes the abstract, available geometric volume, while the latter reminds us that real (or virtual) spaces are always also places, defined by what they contain and by the actions we perform in them. How then are space and place used as semiotic and phenomenological resources in The Sims?

Spatial resources can be used to separate scenes and places, at various distances, and to create multi-scale assemblages of items, from the artifacts and appliances in a kitchen, to the rooms of a house, to the houses of a neighborhood (all visible in The Sims). Walls can separate and so can lawns, outdoor spaces, rivers, highways, etc. Conversely, spatial resources can be used to connect: as doors connect rooms or interior and exterior spaces, and walks or paths (indoor and outdoor) connect locations. Even windows connect; in The Sims you can really see through a window to the actual scene outside or inside. Movement itself can connect as our viewpoint moves from place to place in the house (or to the pool outside) or 


\section{Jay Lemke}

as we observe a sim move in these ways. In 'Buy' and 'Position' mode, we usually avoid placing an object so as to block a doorway, enacting our knowledge of connection and separation. In Build mode, we create doorways and align vistas and pathways, as well as creating separating walls and thinking about where the window and door should be placed in a bathroom.

The topology and topography of place in the gameworld affects the action: how far is it to the nearest toilet when a Sim has an urgent need? Is the television that needs to be turned off before collapsing on the bed to rest en route to the bed or in a different direction? You can't maintain a conversation, or propose a kiss, between characters unless they find themselves in the same room at the same time.

Separation and connection, placement, and distance are not just enabling and constraining facts of life regarding action, they are also resources for expressive meaning-making. Interior design layout and placement, architectural organization of spaces and places afford expressive semiotic potential for the player-user, and in fact the sims themselves respond to room design as a factor in their happiness.

Artifacts are not considered part of a space, but they are certainly part of a place, if we define place (or occupied space) in terms of what can be done there. Much of the structural organization that defines a place depends on the relative positioning of artifacts within it (as a room is given its character by the arrangement of its furnishings). If the sofa in front of the television faces away from it, rather than towards it, affordances for action change.

The dynamics of space and place makes an immediate connection to time and pace, and these too are semiotic and phenomenological resources. When we experience space, whether by walking through it, using objects in it, positioning its moveable elements, or re-modeling its 'fixed' elements, we do so on some timescale. The aspects of time (and aspect, with its formal grammatical sense, is a particularly apt term here) are relevant for all action: duration, rate or pace, repetition and cycles or rhythms, acceleration and deceleration, incipience and termination. 'Timing' can mean the punctual moment in time when something happens, and it can also mean the relative rates at which processes take place. Timescales are the characteristic times or rates of processes: the time for a process to complete, the time for a full cycle to return to any point. Phenomenologically, we can feel that an activity has a leisurely pace or a hurried, pressured pace of varying degree. We might also judge, semiotically, that an event happened at just the right moment (Gr. kairos), or too soon, or too late (by degree). We may feel phenomenologically that events are taking place much too slowly (bored) or much too quickly (frantic). Some actions are materially or semantically on-going or completed and completable or not, repeatable or not, and interruptible/ resumable or not. Some actions are also reversible or not, not just in their outcomes, but also in their processes. 
This view of temporality provides a rich repertory of conceptual tools for analyzing how time plays a role in action and meaning. Consider some aspects of temporality in The Sims.

There is a clock that runs in the Living mode, visible on screen in a control panel area superimposed at the bottom of the household scene. User-players can change the rate of the clock, and the associated actions of the sims and other game events to fast and ultra-fast settings. Normal time in The Sims runs much faster than in life outside the gameworld (24 hours passes in about 30 minutes). You cannot slow down gametime, but you can pause the game and stop the clock, by command, or automatically when you leave Living mode for Buy, Build, or other mode options. This creates a complex relationship between time as experienced by and relevant to the sims in the game and time for the user-player.

Activities, which are discrete routines (prepare breakfast, read a book, take a nap or a bath), have in some cases inherent fixed durations that may be relatively longer or shorter. In other cases duration may be variable depending on need (e.g. a longer nap when more rest is needed). Some routines may be interrupted and others not, some can be instantly terminated and others will run on for a while after you try to terminate them. Activities can usually not be resumed, or only from some specified point. There are cyclic activities, from frequent bladder relief to once-a-day breakfasts, trips to work, etc. There are timescales in the game from the short ones of specific menu-commanded activities, to the longer ones (multiple days) that it takes to develop a friendship or relationship by repeated positive social interactions or to move up a career ladder (often by acquiring more friends and business contacts, and so on a timescale one order of magnitude longer than that for developing friends).

But how do activities on shorter timescales cumulate to forward projects on longer timescales? For this we turn to other conceptual tools: chronotopes and heterochrony.

\section{Chronotopes and heterochrony in The Sims}

Chronotopes are typical movements from place to place with their associated times of passage and pacings of events. In Bakhtin they are associated with the spatio-temporal organization of narratives, and represent the first insight that space and time were themselves narrative, and so semiotic, resources which could be flexibly and creatively manipulated and deployed, and were not simply givens, backdrops to plot and action. There need not in principle be any chronotopes in The Sims: every day could be different, time spent in any given place could be different from one occasion to the next, the next place we go from here might

only randomly be the same as the last time. The pacing of events might have 


\section{Jay Lemke}

no relationship to place. Chronotopes represent a kind of routinization of life on longer timescales than individual events or activities. They provide a measure of predictability and a sense of expectation about how long we should spend somewhere, how fast events should take place in this setting vs. that one, what should come next.

For the sims themselves, there are some default chronotopes. They have a cultural routine for the day: getting up, using the toilet and shower, getting dressed, having breakfast, greeting other members of the household, going to work, coming home, eating dinner, using the toilet again, watching television or talking with friends and family, going to bed. There are typical places associated with these activities, and typical timings of events. We move from bedroom to bathroom to kitchen; events pass slowly in the bedroom (sleep, dreams), less so in the bathroom (long soaks in the tub to quick relief), and in the kitchen may include a hurried breakfast to be on time for the carpool (it doesn't wait long, and if you miss it you may be fired). But the joy of playing the game comes from altering these default routines, sending the sims to swim in the pool, read a book, dance with each other, get romantically involved. Players create chronotopes in organizing narrative meaning in the daily life of their sims. We work with and against the default chronotopes of the game (which tend to emerge from a hierarchy of needs, so they are not strict: a sim may decide to play a video game before breakfast). Other games have much more predictable chronotopes (e.g. in role-playing fantasy games, we often find slow-paced travel, preparation against attack, fast-paced fighting, slow healing after the fight, more travel and finally rest as a typical chronotope, with each element happening in its own typical time and setting and with its own typical pace of events).

User-players of course also have chronotopes in relation to their activity of playing the game. These can differ significantly from those created for their ingame characters' lives. The user comes to the game in the Neighborhood screen, where time does not pass, and events are generated by our own actions. We then usually enter a household and observe the mood-state of our sims, perhaps pausing the game on our arrival, if we had not done so before we quit the game. We can leisurely interpret the graphic displays for time, degree of rest, hunger, need for fun and socializing, etc. We can plan out what each of our sims is going to do for the first hours of the coming day. We unpause the game and the action begins, the sims following our instructions, but sometimes deviating for their own needs, or when unforeseen events occur (a visitor at the door, the phone rings). The pacing of our experience in the Living household is much faster than in our reading of the mood displays while the action is paused. We can also switch into Buy mode or Build mode, and each of these has its own typical activities and pace: Buying and placing are fast, Building is slow; each involves phases of planning, acting, and amending. The house we see, as a virtual space of potential actions, is a different 
place in Living (paused vs. running), Buying, and Building modes. In each of these virtual places there are different activities and pacings. And we enact a traversal across these spaces in playing the game.

Our player trajectory constitutes a traversal insofar as it moves across spaces with different affordances for activity, different media and semiotic artifacts. It instantiates a chronotope to the extent that it is culturally typical and repeated, with definite expectations. But whether typical or not, how do we cumulate meaning and longer-term activities, agendas, or projects along such traversals?

Heterochrony is the mixing of timescales, the coupling and interdependence of processes that occur very quickly, on short timescales, and those that take place over much longer periods of time. Perhaps the most important aspect of heterochrony is the coupling of short-term meaningful action with long-term projects, persistence, and cumulation over time. The persistence of a type of action is enabled by the persistence of the actants (Latour, 1987) which participate in it. Actant is Latour's borrowing from Greimas' semiotics of narrative as a term to stand for both human and nonhuman participants, for agents, patients, and instruments in a process or activity. For all that process as such is characterized by energy and dynamics, it is matter that provides inertia for the persistence of structure in time, and so for the persistence of the signs that an interpreting agency can read as information some long time after or, at least, long compared to the timescale of inscribing the information in matter or interpreting its traces there as meaningful. Every process is in this sense a nexus, not only of practices but of practitioners and what they practice with and upon (cf. Halliday's (1976) analysis of the semantics of participants in material process clauses in language). As Peirce points out, a sign is not functional as a sign until the representamen, the material signifier, is joined to its object, the signified, by the action of creating the interpretant which links them, i.e. by the action of some material system that does the work of interpretation, the work of semiosis (Lemke, 2000b; Peirce, 1998). So, in all signmediated activity we need the material signifiers and interpreters, and in all activity that participates in heterochrony, it is their material persistence that enables them to participate at the same time in short-term practices and long-term processes, continuing to enable homologous interpreting practices to re-occur even at great distance in time.

Any trace of action left in matter can be read as, at the least, an indexical sign of the occurrence of that action in the past. Our actions in every present moment are only possible because of the affordances of material artifacts and conditions, each of which potentially influences the shape of our actions not just through its material form and properties, but also through the meaning it may have for us. The semiotically mediated bearing of the traces of the past on present events creates heterochrony, an interdependence of short-term events and long-term trends and projects. 


\section{Jay Lemke}

In The Sims, there are many ways in which virtual material persistence (i.e. the material memory of the computer translated into observable images and actions) affords cumulation of activity and meaning over longer timescales. The built architectural space of the house itself can function as an environmental memory, enabling persistent affordances for some kinds of action and not others. The inventory and spatial placement of the furnishings of the house also does so. The character of the individual sims persists from their creation and their original basic traits (degree of neatness, playfulness, etc.) persist unchanged and do influence behavior in each moment. The continuing material persistence of each sim, as such, provides affordances for momentary actions (e.g. conversation, renewal of friendship previously established).

Much of what persists also changes, on some specific timescale. The skill levels of each sim, reported in the graphical display of the game state, slowly increase with learning and practice (e.g. cooking skill by reading cookbooks). The state of friendships and other relationships advances or retreats with successful or unsuccessful interactions and the passage of time (friendships must be maintained or they erode). Career ladder advancement depends partly on skills and partly on social contacts and changes much more slowly. Moods on their various dimensions change with passing time (bladders fill, energy wanes) and with activities (drinking coffee, taking a nap) much more quickly than relationships, skills, or careers develop. But in all these cases there is cumulation of the consequences of momentary activities in these longer-term cumulative indices, and the indices in turn are 'read' by the game program in each cycle and influence short-term sim behavior.

Player-users also read these indices as they are graphically displayed, and we too adjust our instructions to the sims accordingly. If we are promoting a friendship or a courtship, we notice eroding relationship indices and move to strengthen these bonds. We cannot write notes to ourselves within the game, to be read later as reminders of projects in progress, though we can create a chronological 'photo album' of snapshots that might serve a similar function, or set the game to automatically export webpages depicting our evolving households. (The new Sims 2 will also support making 'home movies.') Most of the cumulation of information across events is tracked and displayed by the program itself, automatically. Still, I often write myself notes and reminders of what is needed for the next play session. I have created neighbors as prospective friends for my original sims. The very existence of their occupied house in the Neighborhood screen, and the existence of these new sims serves as a material reminder of my long-term friendship-building project, even as it makes it materially possible in the game.

Ed Hutchins, Chuck Goodwin, Ron Scollon, and other analysts of situated or distributed cognition and mediated cultural activity have shown in great detail how 
meaningful activity is mediated by artifacts, documents, and persistently available other persons in related roles (Goodwin, 2000, 2002; Hutchins, 1995a; R. Scollon, 2001a). An analysis in terms of chronotopes and heterochrony extends this perspective to longer timescales and longer-term projects that entrain many specific activities in different times and places.

I have only sketched here the beginnings of such an analysis for the role of space, place, time, pace, and material semiotic artifacts and actants across a range of extensional and temporal scales for one virtual gameworld. I believe however that such simplified worlds are now complex enough to embody the key elements and strategies shared with the far richer repertoires of sign-mediated activity in our own lifeworlds. Certainly they are a good deal easier to study.

\section{Further steps}

What I have provided here is only an outline and a prospectus for the much larger project of doing an activity-centered analysis of the semiotics and phenomenology of heterochrony in gameworlds. I have not mentioned the specific role of text and discourse as such, nor issues of how we integrate meanings across verbal and visual modalities. These are also central to my research interests. Analyses also need to be made across a range of different gameworld genres, because each simplified gameworld will foreground only some of the key principles and strategies at work in making meaning through space and across time.

Meanings made within gameworlds also connect to meanings made across the constructed boundaries between gameworlds and lifeworlds. We need to understand traversals that construct meaning as we enter and leave the gameworld, and as we find the themes and images of the gameworld re-presented to us in other media elsewhere in our lives. As I go about the routine matters of my own daily life at home, I now find my experience in The Sims overlaid on its meanings for me as I remark how game-like aspects of my life are. And there is a real possibility that my lifeworld choices and actions, as well as these reflective meanings, will change as a result of my gameworld experiences.

On a larger scale, as I have discussed elsewhere (Lemke, 2004), many gameworlds today are part of transmedia 'franchises' that show themselves to us in many guises across time, space, settings, and media. Gameworlds associated with the Lord of the Rings franchise present themes and images, philosophies and ideologies, that we re-encounter in films, books, toys, other games, and a vast array of commercial merchandise. How do we make meaning across these instantiations of the franchise? How do we critique and critically analyze the power of these post-modern media to continue to influence us even as our new traversal lifestyles (Lemke, 2002a, 2003) begin to give us some freedom from individual institutions, genres, and media? 


\section{Jay Lemke}

From analysis within gameworlds we need to look outward, beyond individual texts, traversals, and genres to begin to more fundamentally and more comprehensively understand how we make meaning, and how we are oftentimes led to make meaning, not only across media, but across the places and moments of our lives.

\section{Note}

1 To get a better sense of the game, you can view still photos of game scenes or demonstration videos (www.gamespot.com/pc/strategy/sims/index.html?q $=$ sims or www.thesims.ea.com/us/index.html?menu=about\&content=about/index.html), but really you need to play it yourself (neither difficult nor expensive). 


\title{
12 Using multiple situation definitions to create hybrid activity space
}

\author{
Shawn Rowe
}

Analysts working in a variety of traditions (i.e. critical discourse analysis, mediated discourse, nexus analysis, symbolic interactionism, activity theory, sociocultural analysis) look to interlocutors' beliefs about what sort of discursive activity they are involved in as a crucial part of reconstructing and understanding situated utterances and actions. ${ }^{1}$ In Gumperz's terms:

The hypothesis is that any utterance can be understood in numerous ways, and that people make decisions about how to interpret a given utterance based on their definition of what is happening at the time of interaction.

(Gumperz, 1982b: 130)

This 'definition of what is happening at the time' goes by a variety of names: situation definitions (Goffman, 1959; Linell, 1998; Rommetviet, 1988; Wertsch, 1984, 1985a), frames (Bateson, 1972; Goffman, 1974), schema (Bartlett, 1932), language games (Wittgenstein, 1958), or activity types (Levinson, 1978) to name a few of the most recognizable. Perhaps the most detailed analysis of situation definitions is that by Goffman $(1959,1974)$ who put the definition of the situation as the basis of social interactions. But whereas for Goffman the definition of situation and its management are chiefly projections of social actors, I draw on the work of Linell (1998), Scollon (1998), and Wertsch (1984, 1985a) to define the term 'situation definition' as a socioculturally particular type of activity or context that specifies what we are doing at a given moment or what we take to be the background against which our utterances and actions are to be interpreted.

The place of situation definitions in teaching and learning activities is of interest in a mediated discourse (Scollon, 1998) or mediated action (Wertsch, 1991, 1998) approach. From the point of view of mediated discourse, learning may be thought of as the appropriation of mediational means for both cognitive and communicative purposes which include but are not limited to the development of identity as a member of particular communities of practice (Scollon, 1998: 3-5). This process 


\section{Shawn Rowe}

includes learning how to use particular mediational means that carry their own social, cultural, and historical affordances and constraints to define situations.

In this chapter, I explore some ways in which interlocutors can invoke multiple situation definitions to create activity spaces where multiple ways of knowing and discursive goals coexist. I call these hybrid activity spaces. They are interesting to those studying learning as mediated discourse because in hybrid activity spaces the power to define the situation may shift as interlocutors move creatively and strategically among multiple social languages (Bakhtin, 1981a), speech genres (Bakhtin, 1986) and ways of knowing and demonstrating knowledge.

The first part of the chapter is a theoretical discussion of meaning making as a process of contextualization and deals with three aspects of situation definitions that relate to meaning making, agency, and power:

- $\quad$ situation definitions establish contexts for making meaning;

- $\quad$ situation definitions are dynamic and only partially shared;

- situation definitions are associated with authority.

The second part of the chapter draws on transcripts of group interaction in an interactive science museum to show some of the ways that social languages and speech genres are invoked by both adults and children to establish multiple situation definitions and finally hybrid activity spaces. I conclude with a discussion of the affordances and constraints of hybrid activity spaces and their implications for understanding agency in learning.

\section{Situation definitions establish contexts for making meaning}

We often make a distinction between literal meaning (denotation) and other kinds of meaning (connotation), but even the literal meaning of a word (much less an action) is not its dictionary definition. Literal meaning is contextual, constructed, and situated (Gee, 1999) since it is dependent on physical and socio-cultural contexts of uttering and acting and the responses to those utterances and actions given by interlocutors (Hanks, 1996). To assign meaning to a given string of movements or sounds is to 'lay down a set of our own answering words' (Voloshinov, 1973: 102) that contextualize the action and/or utterance and construct a 'situated meaning' (Gee, 1999) out of both it and our response to it.

Situation definitions are part of constructing situated meanings because they concern 'the way in which objects and events in a situation are represented or defined' (Wertsch, 1985a: 159), and they are thus intimately related to the possible meanings that utterances, actions, and objects have for interlocutors at a given moment. Wertsch takes this meaning of situation definitions from the work 
of Rommetviet (1974) who stresses 'that any situation, event, or object has many possible interpretations and that speech serves to impose a particular interpretation and create a temporarily shared social reality' (Wertsch, 1985a: 160). Making meaning of actions and utterances thus involves the imposition or recognition of the context(s) within which they appear, and that recognition has to do with establishing situation definitions.

The contexts within which an utterance or action may have meaning are potentially limitless, so the problem is to understand how we as interlocutors or as analysts decide which contexts are more or less appropriate and relevant at a given time for making meaning of a given utterance or action. Speakers and respondents have at their disposal a host of strategies such as indexicality (Silverstein, 1976) and contextualization cues (Gumperz, 1982b) for making certain contexts relevant at a given moment and thus certain objects, people, actions, beliefs, etc. salient for making meaning.

But to say that such strategies simply index contexts is somewhat misleading. It encourages us to assume that the contexts of speaking always exist first before we speak. Some of course do, but contextualization cues can also be used to create contexts. For Gumperz (1982b: 131) contextualization cues are 'the means by which speakers signal and listeners interpret what the activity is, how semantic content is to be understood and how each sentence relates to what precedes or follows.' Contextualization cues include 'any feature of linguistic form that contributes to the signaling of contextual presuppositions.'

Contextualization cues are thus examples of how situated and literal meanings are both constituted by contexts and constitutive of contexts. Language is full of contextualization cues. More accurately, different social languages (Bakhtin, 1981a) exploit different grammatical and lexical and pragmatic aspects of language as contextualization cues (Gee, 1999). Part of becoming a member of a social group is mastering the contextualization cues appropriate to a given social language that indicate (and create) the conditions in which that social language is relevant.

\section{Situation definitions are dynamic and only partially shared}

Once they have been established, however, situation definitions are neither monolithic nor static. While open conflict between situation definitions is rare (Goffman, 1959: 9), multiple situation definitions often do exist simultaneously since 'interlocutors may differ and may change in their representations of the same set of objects and events' (Wertsch, 1985a: 159) or because 'actors sometimes entertain more or less competing situation definitions of the interaction in which they are involved' (Linell, 1998: 236). 


\section{Shawn Rowe}

Wertsch and Linell both argue that the existence of competing situation definitions and the process of coming to share situation definitions is a crucial feature of learning. The process by which novices come to share situation definitions with experts is an important element of socio-cultural accounts of learning. The key to learning in these accounts is establishing and maintaining a shared situation definition - one that the expert has already mastered and the novice may not yet share. This state of shared situation definition is what Rommetviet (1974) calls intersubjectivity. Intersubjectivity names what we presuppose as minimally shared when we participate in a conversation. Rommetviet stresses its provisional, negotiated nature:

The basic problem of human intersubjectivity becomes a question concerning in what sense and under what conditions two persons who engage in a dialogue can transcend their different private worlds. And the linguistic basis for this enterprise is not a fixed repertory of shared literal meaning, but very general and partially negotiated drafts of contracts concerning categorization and attribution inherent in ordinary language.

(Rommetviet and Blakar, 1979: 7)

This contract further concerns rules for role taking and intermeshing of participant goals and motives. Intersubjectivity thus underlies all successful communication and learning and exists 'when interlocutors share some aspect of their situation definitions' (Wertsch, 1985a: 159). But establishing and maintaining intersubjectivity involves establishing and maintaining shared situation definitions which, in turn, involves establishing and maintaining agreement (or assuming agreement) on ways of categorizing and attributing the intentions of participants, the motives of activity and goals of actions, and the roles and positionalities of participants as speakers and audience, whether addressees or onlookers.

In this sense, learning is the appropriation of cultural tools for both communicative and cognitive purposes, and the first step in this process is negotiating shared situation definitions. But since situation definitions are not static and monolithic, neither is the state of intersubjectivity that allows for learning: 'Intersubjectivity exists when interlocutors share some aspect of their situation definitions. Typically this overlap may occur at several levels, and hence several levels of intersubjectivity may exist' (Wertsch, 1985a: 159). But they may also be only partially shared and may change over the course of an interaction with negotiation. That negotiation may be explicit ('Wait, I thought we were having a friendly conversation ...'), or different situation definitions may be made relevant through the use of different contextualization cues.

Of course, this does not mean that interlocutors or analysts always 'pick up' the 'right' contextualization cues. It does not even mean that interlocutors or 
analysts share complete understanding of the cues or the contexts the cues help create. But as part of everyday activity and communication, we act as if we do in fact share them. This process, however, takes work because meaning making is an active process of contextualization, or as Linell (1998) argues, recontextualization and learning is in part the process of becoming expert at using appropriate contextualization cues that create or subvert intersubjectivity.

\section{Situation definitions are associated with authority}

Situation definitions are associated with authority, but this is not a neutral process. Situation definitions have a moral character since they carry rights and responsibilities for interlocutors (Goffman, 1959: 9-13). Making meaning by recontextualizing utterances and actions requires what Gee calls 'recognizing and being recognized' as a particular type of person engaged in a particular kind of activity. To be making meaning is to be involved in the production and transformations of Discourses, 'socially accepted associations among ways of using language, of thinking, valuing, acting, and interacting, in the "right" places and at the "right" times with the "right” objects' (Gee, 1999: 17). The processes of recognition work that are part of making meaning through Discourses are far from passive. Both the producer and the consumer of Discourse are intimately involved in the continuation and/or transformation of the Discourse. Speaking and acting, we (re)create and transform our world. For each word, we 'lay down a set of answering words' (Voloshinov, 1973: 102) as part of an ongoing dialogue that reproduces or transforms the culturally specific values assigned to the particular linguistic and non-linguistic 'members' resources' (Fairclough, 1989) that we use to enact and recognize Discourses. In the process we become 'members' of particular social groups (or communities of practice - Lave and Wenger, 1991; Rogoff, 1990) as we master and/or appropriate (Wertsch, 1991, 1998) particular ways of using particular resources as part of particular Discourses. We change in the process, but so does the Discourse. As Gee puts it:

The key to Discourses is 'recognition.' If you put language, action, interaction, values, beliefs, symbols, objects, tools, and places together in such a way that others recognize you as a particular type of who (identity) engaged in a particular type of what (activity) here and now, then you have pulled off a Discourse (and thereby continued it through history, if only for a while longer). Whatever you have done must be similar enough to other performances to be recognizable. However, if it is different enough from what has gone before, but still recognizable, it can simultaneously change and transform Discourses. If it is not recognizable, then you're not 'in' the Discourse.

(Gee, 1999: 18) 


\section{Shawn Rowe}

Being in a social group by using a Discourse brings us back again to the place of situation definitions and contextualization cues in learning. Becoming a fluent member of a given group means recognizing which resources are relevant to enacting and recognizing such membership. And recognizing the value of members' resources means being able to correctly define the situation and the relevant contexts, identities, cultural models, and other linguistic and nonlinguistic Discursive resources relevant to that situation. Because this recognition is active, we can do more than simply respond to given situation definitions; we can also enact them, thereby (re)creating a given context that allows for different ways of being certain kinds of people using certain kinds of things to engage in certain kinds of activities that may be more to our liking or our benefit than others. The authority to define situations is the authority to determine what kinds of people engaged in what kinds of activities with what things we are at a given moment (Goffman, 1959: 9-13). The authority to define situations is the authority to author one's own life and circumstances rather than simply to respond to what is given.

\section{Hybridity through multiple situation definitions: an example}

In order to illustrate these three aspects of situation definitions used to create a hybrid activity, I will now turn to the analysis of a family group activity with a somewhat strange kind of object. In this case, two young boys, their father, their older sister and their grandmother interact around an interactive museum exhibit called The Great Gravity Race. The exhibit consists of an inclined plane with two wheels that roll from the top to the bottom. The wheels each have three weights that can be moved to one of three positions - from closer to the outer edge of the wheel to closer to the axle. Where the weights are positioned determines the relative acceleration of the wheels as they move down the ramp.

I have reproduced the first three minutes and last one minute of a six-minute transcript in Figure 12.1. The transcript is read left to right as a musical score. Agents are listed in order of their appearance at the exhibit. As new agents enter the setting, a new box or cell is added for them. Each box or cell contains two lines. The bottom line details the agents' actions. Just above that in the same box is a line that details the agents' talk. Bold type separates the talk from the action. The transcripts thus capture both talk and action as they develop over the course of an activity within a group (Rowe, 2003). They also visually represent which actions and utterances co-occur and which are constructed by more than one person. Each utterance is numbered. Overlapping and latched speech are treated as single utterances following a coding procedure outlined in Rowe (2002). 


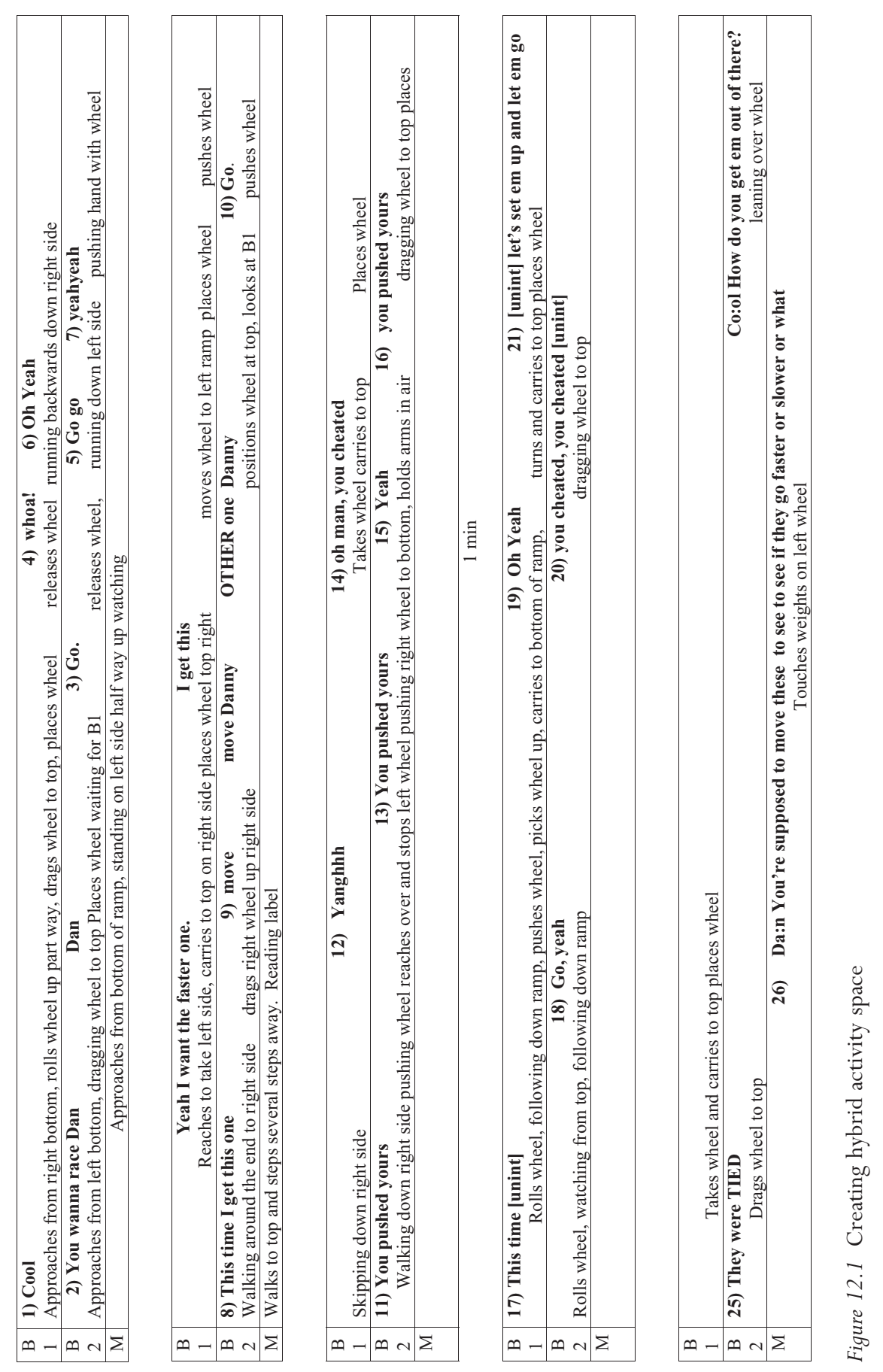




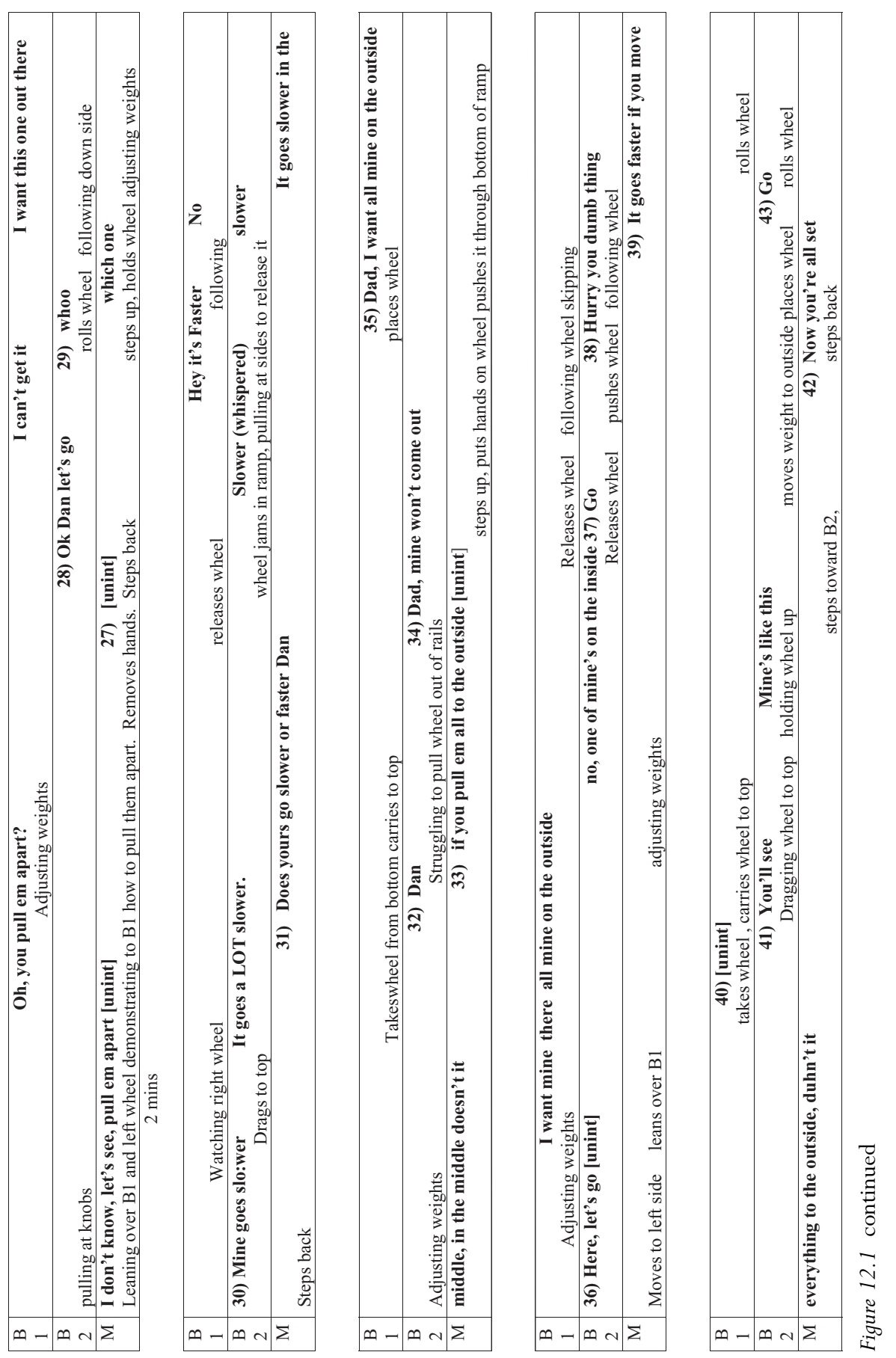




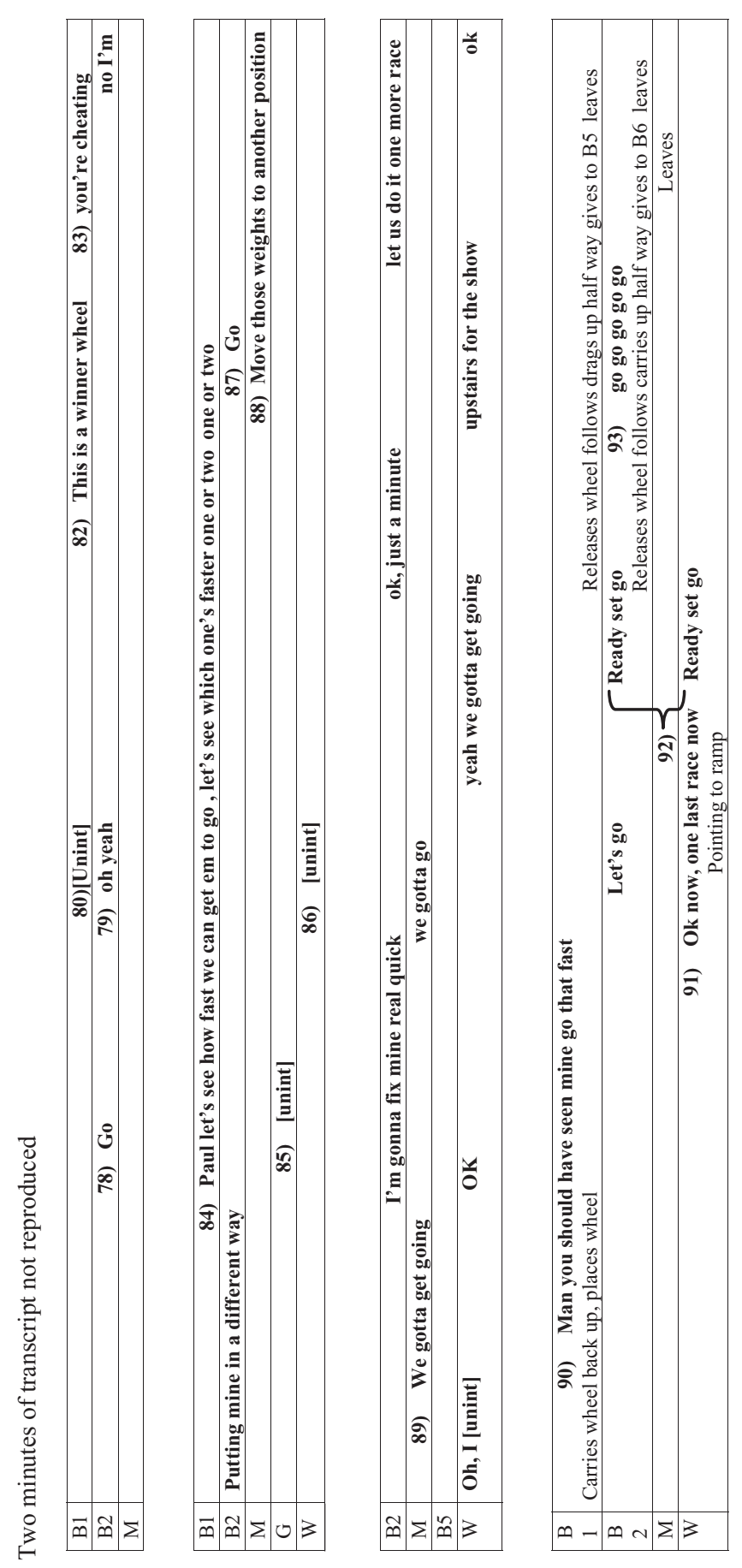




\section{Shawn Rowe}

In the transcript (in Figure 12.1), two boys under 10 (B1 and B2) and a man (M) are the initial members of the group, but they are joined by an elderly woman (W). B1 and B2 begin with an explicit situation definition, 'racing' (utterance 2). At least in the beginning of the transcript the boys certainly see the activity as a competition. They urge 'their' wheels on to victory, assessing the wheels' performance through a variety of evaluations (i.e. utterances 4, 5, 6, 7, 15, 18, 19, 24, 25). They negotiate procedure (utterances 8, 9, 21) and perhaps explain their perceived wins and losses by accusing each other of cheating (utterances 11 , $12,13,14,16,20)$. They also argue over procedure (utterance 9). B2, who defines the activity as 'racing,' also takes responsibility for signaling simultaneous starts - (utterances 3, 10, 22). It is only in utterance 26 ('Da:n, you're supposed to move these to see if they go faster or slower or what') that $M$, having read the label, makes an authoritative bid for a different situation definition: 'moving the weights and observing the results.' The otherwise innocuous phrase 'supposed to' suggests that there is a preferred way to use the exhibit that the boys have not yet tried. This leads M and B1 to work together to adjust the weights on B1's wheel, but B2 has already moved on to rolling his wheel. He observes that it now 'goes slower' stressing that it goes 'a LOT slower' (utterance 30). M models the same kind of procedure for B1 with his question in utterance 31. B2 and B1 disagree over the result, but $\mathrm{M}$ offers an explanation, ('it goes slower in the middle') the second half of which is cast as a question/statement that seeks affirmation/ agreement from B1 ('in the middle, doesn't it' (utterance 31)). M continues to stress a 'moving the weights and observing the results' situation definition by explaining (utterance 33) what will happen if all the weights are moved 'to the outside,' a suggestion B1 takes up immediately. B2, in the meantime, has jammed his wheel in the ramp diagonally and despite his attempts to remove it must now ask $M$ for help (utterance 34). B1, however, can't move the weights himself, and asks $M$ to help him as well. They remove the stuck wheel and adjust the weights. They roll the wheels and B2 urges his on (utterance 38), but the enthusiastic evaluations of progress are not present here, suggesting that the boys have at least temporarily adopted the man's situation definition. In utterance 39, M extends his explanation of the activity, reinforcing the situation definition of 'moving the weights and observing the results.' He offers to help B2 make a final adjustment by stepping up to him when he pulls the wheel out of the ramp, but he steps back as soon as B2 succeeds. The next two rolls (not reproduced here) seem to return to the situation definition 'racing,' with synchronized starts, pushing of the wheels to speed them along, and exclamations of victory and defeat.

Three minutes later, the boys are indeed still 'racing' as the next reproduced roll demonstrates with its synchronized start, exclamations and gestures of winning and losing, with B1 calling his wheel a 'winner wheel' (utterance 82) and a return to the discourse of cheating (utterance 83). But now there is a response 
to the accusation of cheating that draws its validity from the second situation definition. B2 claims that he is not, in fact, cheating but adjusting the weights ('No, I'm putting mine in a different way' (second part utterance 83)). He thus moves strategically between the two situation definitions in order to 'explain' what he is doing as legitimate.

At this point, B1 also offers his own proof that he, in fact, is participating in this second situation definition as he makes his own bid at (re)establishing the situation definition from 'racing' to see which boy wins to OBSERVING which wheel is faster (utterance 84). In the process he appropriates the voice of his father who introduces the idea of seeing which wheel is faster and which slower in utterances 26, 31, 33, and 39 as part of establishing the situation definition of 'moving the weights and observing the results.' Both boys then show that they can use the right 'contextualization cues': in this case moving the weights ('putting mine in a different way' (utterance 83)) or observing ('see which one's faster' (utterance 84)) as part of participating in 'moving the weights and observing the results.' But they have not abandoned the idea of 'racing' either. The hybrid nature of the situation is captured in B1's utterance number 84 , a hybrid utterance that draws on both situation definitions. At first he suggests that they should 'see how fast we can get them to go' ('racing'), but he quickly reformulates the goal in terms of a comparison to see which goes 'faster and slower' ('moving the weights and observing the results'), the way that $\mathrm{M}$ has done up to that point.

The boys thus show flexibility in moving from one situation definition to the other, adopting and abandoning one or the other strategically to explain their actions at different points during the course of the activity. $M$ gets one more chance to reinforce the 'moving the weights and observing the results' definition when $\mathrm{W}$ joins the group and evidently says something to him about what the boys are doing, as his utterance 88 and her response indicate. B2 exploits the hybrid space created by the two co-existing definitions in his parts of utterance 89 , employing the 'preferred' idea ('moving the weights') in 'I'm gonna fix mine real quick' to argue for 'one more race' ('racing'). W accepts the argument and the situation definition of 'racing,' helping to define it as a race in utterance 91 and to synchronize the start in utterance 92 .

\section{Hybrid activity spaces and agency}

I have argued that when multiple situation definitions co-exist a hybrid situation emerges. I have further argued that by appropriating (or at least deploying) the mediational means for indexing two situation definitions at once the two boys in this example have acted with strategic agency, exploiting the hybrid situation to pursue their own agenda within the frame of a 'preferred' or more official agenda. This is important not just for understanding how they create and maintain their 


\section{Shawn Rowe}

agency through the strategic use of mediational means, but also how they appropriate mediational means for performing situated identities.

The hybrid situation links different kinds of mediational means to different kinds of identities. In this sense, hybrid activities are similar to the hybrid texts described by Chouliaraki and Fairclough (1999: 143) that mix social practices, genres, and social languages. Because of their view (consistent with symbolic interactionist approaches in general) that texts are part of both the (re)production and transformation of social practices, Chouliaraki and Fairclough (1999: 14) consider hybridity to be both a strategy for establishing hegemony and a strategy for resistance or the creation of 'non-repressive dialogues.' The ability to move critically among genres and social languages in a hybrid text for strategic reasons is the ability to be an empowered agent: 'We might say that people are active - agents - to the extent that they are capable of pursuing collective or individual strategies in their discourse' (Chouliaraki and Fairclough, 1999: 14).

I argue, following Bakhtin, and Chouliaraki and Fairclough, that just as the presence of multiple social languages and speech genres can create hybrid texts, multiple situation definitions can create hybrid activity spaces like the one the boys in the transcript exploit. I further argue, following Chouliaraki and Fairclough (and Goffman and Scollon), that because the ability to define the situation is tied to some agentive authority, the ability to move strategically among situation definitions is a sign of agency. Because different situation definitions carry with them different affordances for speakers (especially in terms of their perceived authority), speakers can borrow the powerful voice(s) associated with and realized in situations strategically to realize alternative agendas and practices. When agents can manipulate the situation definition, they can reframe the ongoing activity in ways that may help to create more equitable interactions. When more equitable interactions exist, there is a more inclusive possibility for agency that means more people have a chance at 'getting in on' defining situations and learning to move strategically among them. This, in turn, opens new possibilities for our understanding of the purposes of learning in all sorts of learning and teaching situations. We can begin to see how agency and identity and empowerment are just as much important outcomes of education as concepts and facts and knowledge generating processes.

\section{Note}

1 The writing of this work was supported by the National Science Foundation under Award No. ESI-0227619. Any opinions, findings, and conclusions or recommendations expressed in this publication are those of the author and do not necessarily reflect the views of the National Science Foundation. 


\section{Practice: questions and mini projects}

\section{Questions for discussion}

1 Based on your readings of the chapters in this section, what is the relationship between practices, mediated actions, and mediational means? How do the different authors conceive of this relationship differently?

2 In his chapter, Filliettaz notes that discourse intersects with other mediational means to frame social practices by making the underlying premises of those practices more visible. Discuss how this occurs in the example he gives and try to think of some of your own examples.

3 According to Rowe, social actors sometimes use multiple situation definitions to create hybrid activity spaces, which allow them to act in strategic ways and create more equitable situations. How does this occur in the example that he gives? Can you think of your own examples?

4 In his chapter, Lemke, drawing on the work of Bakhtin, introduces the concept of chronotopes, culturally typical movements and pacings along trajectories of activity. What is the relationship between chronotopes and practices and how might they affect the ways practices are linked?

\section{Mini projects}

1 Choose a particular computer game that you are familiar with and discover which practices are embedded within the game.

2 Go to a store and try to purchase a particular item, involving a sales clerk's help. After your expedition, note down the practices underlying your and the sales clerk's actions.

3 Visit a museum and follow the actions that a particular group of social actors take within this setting. Do they create hybrid activity spaces and can you define them? 



\section{Part IV}

Sites of engagement 



\title{
13 Introducing sites of engagement
}

\author{
Sigrid Norris and Rodney H. Jones
}

Sites of engagement: The 'real time window' opened through the intersection of social practices and mediational means that enables a mediated action to occur.

The convergence of social practices that opens this window.

The window which makes certain actions (lower or higher order) the more focused or less focused points of attention of participants.

The orientation towards time and space, distributed in built environments, social practices, and the habitus of individuals, that people bring to situations.

In the previous sections the concepts of mediated actions, mediational means, and social practices have been discussed. In this section we will turn to how actions, mediational means, and social practices converge in moments of 'real time' and at actual locations, both physical and virtual.

Every mediated action is viewed as taking place within a site of engagement. Scollon (1998, 1999, 2001a) defines the site of engagement as the real-time window that is opened through an intersection of social practices and mediational means that make that action the focal point of attention of the relevant participants. As Scollon (2001a: 4) points out, 'the idea of site of engagement takes from practice/activity theory and interactional sociolinguistics the insistence on the real-time, irreversible, and unfinalizable nature of social action.' It also takes from interactional sociolinguistics and conversation analysis a concentration on the focal points of attention of the participants who are acting. 


\section{Sigrid Norris and Rodney H. Jones}

Norris (2002a) broadens the notion of site of engagement by defining it in the following way: 'A site of engagement is the real-time window opened through the intersection of social practice(s) and mediational means that make that lower (or higher) level action the focal point of attention of the relevant participants, and radiates from there encompassing the intersection of practices and mediational means that make those lower and higher level actions the less focused or un-focused points of attention of the relevant participants.' What is important in this definition is the addition of the notion of different levels of action and, more importantly, the notion of focused action as constituting a continuum from focused action to less focused and finally to unfocused actions of participants.

One of the difficulties of operationalizing the concept of sites of engagement is locating them in time. As Scollon pointed out in the first section of this book, at any given moment there are at least six different cycles of time occurring. In the first chapter of this section, Jones takes up this issue, as well as the issue of focused attention developed by Norris (2002a). He argues that sites of engagement are amalgamations of the patterns of orientation towards time and space that participants bring to these moments and locations of social action mediated through what he calls attention structures.

Another important issue to consider when discussing sites of engagement is how we as researchers contribute to the construction of such sites through our own actions, and how multiple trajectories of actions and practices of both the researcher and the researched converge in these sites of engagement. In her chapter, de Saint-Georges examines how researchers and participants jointly construct sites of engagement, which she describes as time/space stations that are connected through the trajectories that people create with their anticipatory discourse. 


\title{
14 Sites of engagement as sites of attention: time, space and culture in electronic discourse
}

\author{
Rodney H. Jones
}

One of the least theorized concepts in mediated discourse analysis is that of the site of engagement, those moments in time and points in space where mediated actions happen. According to R. Scollon (2001b), these moments and locations are to be defined not so much in terms of time and space as in terms of the convergence of social practices which opens a window for mediated action to occur. Questions remain, however, as to where and how sites of engagement actually exist in relation to 'real time' and 'real space.' As R. Scollon (this volume) points out, time is always more complex than 'a moment,' consisting of multiple, overlapping 'timescales,' and space, as noted by Scollon and Scollon (2003), is always more complex than a physical location, consisting of the interaction among the built environments, the relationships among participants, and the meanings assigned to the various semiotic tools introduced into the space. Thus, the same moments in time and the same points in space may for some people function as sites of engagement whereas for others they may not. In fact, like social actions, sites of engagement are concrete, specific irreversible and unfinalizable (R. Scollon, 2001a: 4). At the same time, it is 'at' these sites, that more durable social practices, social identities and social groups are constructed.

Computer mediated communication presents further challenges to those interested in the relationship between time/space and mediated actions, involving additional layers of time (synchronous, asynchronous) and the convergence of multiple built environments. The aim of this chapter is to explore the ontology of sites of engagement and to examine the usefulness of this concept in understanding action and identity. In particular, it examines how sites of engagement occur in computer mediated interaction among members of different communities that form around different nexus of practice (R. Scollon, 2001a). Sites of engagement, I argue, are not 'objective' moments or locations, but rather the results of orientations towards time and space that participants bring to interaction, mediated through what I call attention structures: cultural tools that reside partly in built 


\section{Rodney H. Jones}

environments, partly in the social practices that grow up within communities and partly in the habitus (Bourdieu, 1977) of individuals.

The data for this analysis come from two separate studies of computer mediated communication, one focusing on secondary school students in Hong Kong, ${ }^{1}$ and the other focusing on gay men in the same city. ${ }^{2}$ Both studies employed a multimodal ethnographic methodology for data collection (Jones, 2001a) which included individual and group interviews, text logs of interactions, 'screen movies' of participants' computer use and 'site movies' of the places where participants operated their computers, as well as participants' reflections on their own actions and motivations.

\section{Cyberspace/cybertime}

Much contemporary writing on new communication technologies (see, for example, Barnes, 2003; Meyrowitz, 1985; Turkle, 1995) emphasizes how they affect our sense of time and space. Technology, we are told, 'dislodges social situations from physical settings ... and results in new configurations of social experience' (Waskul, 2003: 25). This perspective is perhaps best exemplified by McLuhan's (1964: 3) assertion that electronic media have been 'abolishing both place and time as far as our planet is concerned.'

This focus on the separation of physical space from virtual spaces, or what has come to be known as 'cyberspace' (Gibson, 1984), has fostered a bifurcated view that sometimes obscures the ways 'cyberspace' and physical spaces interact (Hine, 2000) as well as the fact that people do not ever just reside in one space at a time. They inhabit multiple spaces, various built spaces, geographical spaces, political spaces and personal spaces. 'Cyberspace' is just one more. Similarly, we also orient towards multiple timescales as a matter of course; timescales of personal schedules, of natural cycles, of histories of people and objects, in what Blommaert (2004) (see R. Scollon (this volume)) calls 'layered simultaneity.'

Actual ethnographic investigations, such as those I will be drawing on for this chapter (see also, for example, Hamman, 1998), reveal that interactions through computers more often than not are extensions of off-line practices and interactions rather than separate from them. Far from having been 'abolished' by new media, physical spaces and 'real time' remain central to communication on-line. For two gay men looking for potential sexual partners in a chat room, for example, much of their discussion involves talking about where they are physically in relation to each other and when they might meet up physically in the future. For secondary school students chatting with their friends on computers placed in the living rooms of their crowded urban flats, the internet has radically altered the spaces in which they live and their interaction with parents and other family members within these spaces. As they skillfully shift their attention among computer mediated 
interactions, homework, watching television, downloading and sharing music files and interacting with physically co-present others, they subvert the systems of space and time maintained and policed by the attention of their family members.

'Cyberspace,' then, does not create a 'separation' of spaces so much as additional layers of space within which participants can maneuver. However, the ways that different groups of people with different purposes navigate these multiple spaces are different. People construct time and space through their social practices, their shared goals, plans, and the conventions that build up around their interactions. Cyberspace is actually part of a combination of orientations towards space/time associated with social practices and social identities, orientations towards physical spaces, conceptual spaces, perceptual spaces and social spaces (Strate, 1999). And it is at the nexus of these different spaces and timescales that the notion of the site of engagement becomes more useful than more traditional conceptualizations of time and space, because it sees spaces and times as arising from actions. Rather than saying that actions occur 'in' or 'at' sites of engagement, says R. Scollon (2001a: 159), it would be more proper to say that actions occur as sites of engagement. Through our actions we set into motion spatial and temporal entrainments, trajectories that determine how we strategize future actions and how we remember past ones. It follows, then, that time and space are never 'neutral' but, rather, reflect the ideologies embedded in the actions and practices communities perform together.

Perhaps, the most important contribution to the discussion of how different communities use space and time comes from Edward T. Hall $(1959,1966,1976)$. Hall maintains that members of different cultures operate on different systems of time which organize their perception of such things as 'appropriate' intervals, and whether or not they tend to orient towards a single activity at one time or juggle multiple activities, what Hall calls 'monochronic' and 'polychronic' orientations.

Hall is similarly concerned with how different groups communicate through the way they use space, in particular in regard to territoriality - how we exert control over the various spaces we inhabit.

Hall's ideas form much of the framework with which I analyze my data. The mediated discourse approach I take differs from Hall's, however, in two important ways. First, while Hall is chiefly concerned with how unconscious ideas about time and space cause misunderstandings between people of different cultures, MDA is interested in how people employ the 'tools' of time and space, both consciously and unconsciously, to open 'windows' within which mediated actions can take place. Second, Hall tends to separate 'culture' along ethnic or national borders, talking, for example, of the different ways Americans and Japanese understand time and space. In contrast, MDA shuns such essentialist notions of culture (Jones, $2001 \mathrm{~b})$, preferring instead to speak of the nexus or intersection of practices (R. Scollon, 2001a) upon which people build individual and group identity. 


\section{Rodney H. Jones}

When I speak of 'gay Chinese men' and 'Chinese secondary school students,' I am less concerned with their 'gayness' or their 'Chineseness' as I am with the intersection of social practices they are performing which give rise to particular social occasions. Social practices and social identities both require and make possible different orientations towards time and space which, themselves, become tools for claims and imputations of social identity.

\section{The 'there there'}

When Gertrude Stein uttered her famous indictment of Oakland: 'There's no there there,' she certainly did not mean to suggest that there was a lack of physical space in that city. What she really meant was, 'there are no sites of engagement there which allow the particular convergences of social practices and cultural tools which I desire.' When looking for the 'theres' that are 'there' in computer mediated communication, we must examine the social practices participants engage in, and which 'theres,' or spaces, they regard as significant. We must also examine how these different 'theres,' some physical, some perceptual, some conceptual, interact with one another.

In computer mediated communication, there are at least five kinds of space towards which users can orient their attention:

1 The physical spaces in which they are operating their computers (such as offices, homes, cybercafés), both in terms of the immediate built environments and the geographical coordinates of these spaces;

2 Virtual spaces created by the interfaces they are using to communicate (chat rooms, ICQ contact lists, web pages);

3 Relational space created by the 'state of talk' between participants;

4 Screen space - the actual space of users' screens upon which they arrange various elements (windows, toolbars, writing spaces, video screens);

5 Third spaces - spaces inhabited by neither participant but rather referred to in the course of interaction (bars, saunas, classrooms, shopping centers).

These spaces represent negotiated social orientations that are not totally independent, but instead overlap and affect one another. What is happening in virtual spaces helps shape the actions and identities that are possible in physical spaces and vice versa. Computers can allow a fifteen-year-old girl to enact the identity of an 'obedient daughter' in physical spaces while simultaneously engaging in a relationship with a boyfriend nobody in her crowded urban flat knows she has. The death of pop star Leslie Cheung in the 'media space' can turn a gay chat room normally used for 'fast pick ups' into a space for mass mourning. Even the weather in physical space can have a profound impact on how virtual space is 
oriented towards. 'You can measure the typhoon signals by the number of people online,' the webmaster of the gay chat room I investigated told me. 'By typhoon signal eight the place is full.' Similarly, physical spaces and virtual spaces determine how participants manage and orient towards screen space. One gay man who shared a flat with his family said:

while I am going to the chat room or looking at gay (porn) pictures, or browsing any gay websites, I open some word documents or games as backup or to cover the banner ads in the chat room and websites. If any family member suddenly comes near me while I am doing some gay-related activities on my computer, I immediately open the word documents or open the game page.

One way of understanding how different groups engaged in different practices orient towards these different spaces and communicate these orientations is by examining how they discursively 'index' space in their use of deixis - demonstratives (this, that), deictic adverbials (here, there, where), and nouns referring to particular places. While this can only give us part of the picture (as often the most deeply engrained orientations towards space, are not referred to explicitly in discourse), deixis can still reveal much about where participants think they are, what they think they are doing and who they think they are being. Schegloff (1972) notes that references to space in conversation have three functions: (1) to index location; (2) to establish 'membership,' and (3) to index the topic. Similarly, Hanks (2001) sees every case of the construction of 'here' and 'there' as a sociocultural construction depending on and reflecting how the people see the world and how they see themselves in it.

A breakdown of how these two different groups talked about the spaces they oriented towards in a corpus of chats from the gay men $(n=260)$ and the secondary school students $(n=170)$ can be seen in Table 14.1.

The figures suggest that the gay men are much more focused on the physical spaces they inhabit at the time of interaction than the secondary school students. This is chiefly because the social practice they are engaged in has as its goal the

Table 14.1 Percentage of space deixis (this, that, here, there, where, proper/common nouns referring to places)

\begin{tabular}{lllllll}
\hline & Physical & Virtual & Relational & Screen & $\begin{array}{l}\text { Exophoric } \\
\text { (third spaces) }\end{array}$ & Other \\
\hline Gay men & 53 & 17 & 7 & 1 & 13 & 9 \\
Secondary students & 16 & 39 & 3 & 3 & 37 & 2 \\
\hline
\end{tabular}




\section{Rodney H. Jones}

transformation of an orientation towards virtual space into an orientation towards physical space (Jones, 2004a). Physical spaces, including features like whether participants live alone or with their families, and the relative distance they live from a Mass Transit Railway station, play a crucial role in participants' social identities. Many, in fact, use either the name of the district where they live or some description of their physical living situation ('live alone,' 'hve place') as their screen names in the chat room.

Participants' orientation towards physical spaces is also intimately connected with their orientation towards time, a view of the interaction that sees it as having clear episodes and intervals pointing towards some future goal. The significance of these physical spaces is not just in their present use, but also in their potential as future sites of engagement, and from the onset of the interaction the participants work to construct these sites of engagement through anticipatory discourse (de Saint-Georges, this volume). As one participant put it:

the first thing that not only I require but also the other one is the PLACE, if we are sure we have place to have fun, then we will keep talking. After making sure that there is a place for us to have fun, we start to talk more deeply.

At the same time, these physical places, both present ones and future ones, depend on virtual spaces (chat rooms, picture-sharing sites) for their existence. It is interaction in these virtual spaces that turns physical spaces into places. References to this type of space also play an important role in communicating identity and activity. In Example 1 (Box 14.1), Participant A mobilizes an orientation towards the virtual space of the chat room to claim a certain kind of moral identity. In Example 2 (Box 14.1), A uses this orientation to accuse his interlocutor of dishonesty or inconsistency.

A third important space for these participants is one that is rarely referred to explicitly, but which pervades and supports the interaction: relational space or the

\section{Box 14.1 Examples}

\section{Example 1}

$A$ : do u have bf?

$B$ : of course l'm single that why I come here

B: u?

$A$ : so u look for bf here?

\section{Example 2}

$A$ : we talked but then you said that you didn't actually play outside the relationship

$A$ : which is fine - tho beggars the question about why yr here with that profile! 
space created by the 'state of talk.' The number of explicit references to this space is far less, participants referring to it only when it is seen to be in need of repair. The degree to which participants orient towards it, though, can be seen in the frequency of their use of the deixis 'here?' or 'there?' after pauses in the interaction long enough to be perceived as threatening this space. The 'here' or 'there' they are referring to is not a physical space but, rather, a state of attention towards the interaction, what Holmes (1995) calls a 'shared deictic center.' Interestingly, and consistent with the findings of Holmes, participants most often refer to relational space with the adverb 'here?' (whereas in telephone conversation participants are more likely to say, 'are you there?'), suggesting that orientation towards relational space in $\mathrm{CMC}$ is seen as less distant. One of the chief goals of participants in this kind of interaction is to maintain control over relational space, to 'keep the conversation going,' for once a conversation is terminated the possibilities of transforming that conversation into something more evaporate. In contrast, the students seem less oriented towards maintaining relational spaces through a constant state of talk. Rather, their interactions are more fluid, occurring at varying rhythms, with many not really having clear beginnings or clear endings as conversations migrate from physical spaces like school corridors to virtual spaces and then back again.

There is in my data from the gay men a sixth use of deixis not accounted for in Table 14.1: a use of deixis to refer not to any external physical or virtual space but, rather, to the space of one's own body, or the 'self.' Some examples, are: btm here, swimmer style top here and A: wot $r$ u wearing now / B: just a $T$ here. These selfreferential deixis, which are not found at all in my secondary school data, have the effect of inviting one's interlocutor to experience one's physical space with them through a description of the body or 'self.' They index physical space partly to erase it, creating a sense of physical intimacy.

While the gay men move strategically across boundaries of physical spaces, virtual spaces, the tenuous spaces of their electronic intercourse and the spaces of their bodies, the students appear to be mostly oriented towards third places, schools, shopping malls, electronic game centers, and it is really these places that virtual spaces are extensions of. They hardly ever mention the physical spaces where they are operating their computers. One reason for this is that, unlike the gay men who seek to decrease the separation between physical and virtual space, for many of the students, the social practices they are engaging in (playing on-line games rather than focusing on their homework, engaging in sometimes illicit interactions with friends) depend on their maintaining this separation. One of the chief ways computers amplify social actions for them is through enabling them to extend the territory upon which they can act to realms to which others (parents, siblings, teachers) have no access and cannot police. Computer mediated communication simultaneously facilitates connectivity and privacy. The best thing about 


\section{Rodney H. Jones}

ICQ, one participant noted, is that 'no one will know what we are talking and doing in ICQ.' Another said, 'sometimes when I find that it is not convenient to talk on the phone, ICQ provides me a convenient means to communicate with others and to secretly disclose information.'

Along with indexing third spaces where they and their friends interact, the students spend much of their time building new spaces for interaction: virtual spaces like ICQ contact lists, forums, diaries, message boards, and the environments of on-line games. The number and variety of on-line spaces they inhabit is far more than the gay men, and each of these spaces has its own geography, timescales, and 'sense of gravity.' Each also affords different ways for users to enact 'presence.' As one participant put it:

In the space of reality, you can only have one identity. It is a student with good academic result and manner, obedience toward parent, kindness, happiness and love. In cyberspace, you can have many identities. You can be a good fighter . . in $<<$ Jing Yong On-line $>>$ or $<<$ Gu Long On-line $>>$, gallant male in ICQ, attractive female in chat room and a bad guy speaking foul language in the forum.

Perhaps the most important role new communication technologies play for these students is to afford them greater control over personal space and personal distance, not just in the physical environments they inhabit, but also in the virtual ones. In situations where participants are not physically co-present, the notions of personal space and personal distance are more usefully seen in terms of 'presence': the degree to which one makes oneself available and the way one reacts to the availability of others. Engaging in an ICQ messaging session, signing a friend's guestbook on their home page, contributing to a discussion in an on-line forum and taking on the identity of an avatar in an on-line game all involve different degrees and kinds of presence. Even the software most popular with the students, ICQ, allows users to modulate 'presence.' Whereas in the java-based interface in the gay chat room, users make themselves available to all the other users in the room simultaneously, requiring them to control presence in a much more explicit way by, for example, ignoring or rejecting the advances of other users, ICQ allows users to be 'visible' only to selected others, or to appear in various 'modes,' such as 'not available,' 'extended away,' and 'available to chat.' These ways of enacting 'presence' are often extensions of patterns of personal space that have developed in students' physical interactions with their friends. In a sense, while for gay men on-line spaces are seen as routes to off-line spaces, for these students, off-line spaces are in many ways routes to on-line spaces. 


\section{Timescales and trajectories}

There is also some variation in the ways members of these two communities talk about and make use of time. The most obvious one is that the timing in the gay men's interactions is more fixed and more consistent over interactions. One can almost predict by counting turns when, for example, a picture might be exchanged or a phone number might be negotiated. The on-line interactions of the students occur on multiple timescales - an interaction tonight might be a continuation of a conversation that started in the school lunch room this morning or a week ago, and these conversations are often embedded in longer timescales of relationships as school calendars, class timetables, assignment due dates, movie schedules, and TV timetables.

Clearly, the gay men are also influenced by multiple timescales, checking emails, surfing the internet while they are chatting and, within the social practice itself, chatting with multiple potential partners at once. But their orientation when engaged in this particular social practice is more focused on the rhythms of the immediate interactions, rhythms that are mapped progressively along particular intervals towards a relatively clear goal. In fact, as 'operating' the chat room makes significant demands on users' attention, both in terms of their cognitive attention, and in terms of the amount of attention they are meant to demonstrate to interlocutors, it is difficult to do many other things. Whereas the average time between turns in the students' chats was 6 minutes 23 seconds, with some gaps between turns lasting more than an hour; for the gay men, the average time between turns was 34 seconds, and pauses of much longer length resulted in moves to repair the relational space, like those discussed above, or a termination of the interaction. One participant wrote:

How long is too long to wait for a reply from someone in a chat room? It depends on different conditions. If I am really horny at that moment, I would say reply within 10 seconds is acceptable. If more than that, I would guess the guy is no longer interested in me, unless he told me to wait.

The norms concerning turn taking are very different in the students' interactions. One participant said:

If the other side is someone you really want to talk with, you will be willing to spend time waiting for the other side's reply. Sometimes I just casually ask others 'Have you had the dinner?' I might have asked ten people but I would not wait for all of them to reply to me.

The orientation towards time in the students' interactions, then, tends to be more polyfocal. They engage in interaction on many timescales at once, some 
synchronous, some asynchronous, as they consult one another on the homework assignment due tomorrow, leave a message to someone about a bit of gossip heard yesterday, or just say a momentary 'hi' to a friend while surfing the internet. They have become masters of distributing their attention over homework assignments, electronic social interactions, listening to music, watching television, talking on the telephone and interacting with family members to the point where it is difficult to separate out and measure their different activities. When asked the question, 'How much time do you spend on ICQ,' most participants could not answer it, saying things like: 'How do I know? The ICQ is on all the time.' Even individual conversations are rarely as focused as those engaged in by the gay men. 'Normally,' said one student, 'those who talk to me in ICQ can talk about many things within a minute.'

The students' orientation towards time on-line contrasts with the orientation dominant in their off-line lives, which is highly scheduled and policed by a linear view of time. They go through their days moving from classroom to classroom at a rhythm fixed by the institution, are repeatedly told to 'pay attention' to one thing at a time, and then return home where there are times they are allowed to do some things, and times they are not. Their lives are situated in cultural and institutional expectations punctuated by significant times: dates of public examinations, for example, and deadlines for university applications.

Time, in this powerful Discourse (Gee, 1996) promoted by their parents and teachers, is seen as a commodity one spends to gain future reward. But it can also be wasted. One spends time wisely doing constructive things (like homework) and wastes time doing 'unconstructive' (primarily relational) things (like chatting on ICQ). 'Wasting time' is seen as a display of laziness, selfishness or moral turpitude. For most of these students, conflicts with their parents over computer use centered on the notion of 'wasting time.' One participant said of his parents:

They do not know how to use computers and what I am doing with my computer. But they would ask me not to waste time as they always see me sitting in front of the computer. I do not care.

This view of time that talks of it as being spent and wasted has at its foundation a fundamentally monochronic orientation. One should spend time on a particular task until it gets done. On-line, however, students are able to subvert this Discourse through mixing and blending timescales and activities. On-line interaction provides an escape not just from the space of the family, but also from its time. The escape, however, is rarely complete, as their family members make intermittent interactional demands on them or question 'what they are doing.' Thus, students must often perform conflicting orientations towards time 
simultaneously, acting polychronically in virtual spaces while performing a monochronic orientation for their parents.

There is a similar case of disjuncture between temporal orientations in different spaces in the data from the gay men. While it is expected that users normally distribute their attention among a variety of interlocutors, the orientation towards time that one must display to each of these interlocutors is more monochronic. One must create the impression of undivided attention through the timeliness and appropriateness of one's responses. Multitasking is something that everyone does, but few admit to. One participant wrote in his diary:

Those who respond promptly I will see that as a sign of their interest and good integrity. I also tend to use their response time to see how serious they are in making a conversation. There are some who are talking to lots of people at the same time and maybe doing something else such as watching TV or listening to music. I find that annoying. I tend to leave the chatroom with people like those. To me, I give my $100 \%$ attention to the person I am chatting to and I expect the same in return.

Demonstrating this orientation towards time which is at odds with the pattern of orientation evident on these men's screens does have its social purposes. According to Hall (1976), a monochronic orientation towards time often has the effect of promoting intimacy or a sense of privacy. Monochronic time, he writes, 'is like a room with a closed door' (20). It 'seals off people . . and intensifies relationships' (19). This orientation also, though, indexes a powerful Discourse in these men's off-line lives, a Discourse of romance which determines the different kinds of relationships and possibilities invoked through different practices of giving and getting attention.

\section{Sites of engagement as sites of attention}

I do not mean to suggest that my participants orient themselves towards time and space the way they do in these interactions because they are gay men or because they are secondary school students. Rather, what I am interested in is how they use these different patterns of orientation towards time and space to open up sites of engagement in which the social practices through which these identities can be enacted can converge.

Participants construct sites of engagement for particular practices through fairly durable patterns of orientation towards different spaces and different timescales. These patterns are in some ways 'built into' the mediational means they use to take action: the technology, through its potential for creating virtual space as well as new ways of managing physical space, and into the interfaces of the software 


\section{Rodney H. Jones}

applications that people use. They are also built into the practices of the community, its norms of interaction and the range and types of social identities it offers. Finally, these patterns exist in the habitus (Bourdieu, 1977) of the individual participants' ways of operating that have become as much part of the body as of the mind. They are among what Bourdieu (2001: 37) calls 'the schemes of perception, appreciation and action that are constitutive of habitus.'

I call these patterns of orientation attention structures. Attention structures are themselves cultural tools, as basic as languages and systems of counting, made available by the sociocultural environment, mastered by individuals, passed onto others, built into the frozen actions (Norris, 2004b) of our architecture and furnishings, and appropriated strategically to open up sites of engagement. Sites of engagement are, then, made up not just of the physical spaces we inhabit and the timescales and trajectories that flow into them, but also, and more to the point, those aspects of space and time that we are inclined to pay attention to. We construct sites of engagement through our attention. According to R. Scollon (2001a: 4), sites of engagement operate to make particular mediated actions 'the focus of attention of the relevant participants.' Norris (2002a) goes even further, defining sites of engagement as means of making various lower- and higher-level actions the focused, less focused or un-focused points of attention of participants.

I take the term attention structures from Lanham (1993), whose work falls into a category of literature focusing on 'attention economies,' (Goldhaber, 1997; Lankshear and Knobel, 2003). The idea of 'attention economies' is that, in an age of information overload, what gives value to information is the amount of attention it can attract. The real currency of the information age is not information, but attention. Whether or not this theory holds true on the macro-economic level, it is, and has always been, an important principle in the micro-economics of social interaction. All interpersonal communication is based on attention: getting attention and 'paying attention.' Not only is attention organized around behavior, but behavior is organized around attention. Lanham uses the term attention structures to refer chiefly to technological means of helping people deal with the overload of information carried by 'the rich signal' associated with the digital revolution. But all signals, no matter how rich, require some kind of attention structure to make sense of them, some way of knowing what to attend to and what not to attend to. These attention structures reside partly in the mediational means and partly in the ways people use these mediational means in patterned interaction that reproduces some aspect of their social identity. Attention structures take form in our socio-cultural worlds, and are reformed as we interact with those worlds.

In many ways attention structures are related to frames as conceptualized by Bateson (1972) as well as the attentional tracks of Goffman (1974). But, whereas frames and attentional tracks are chiefly theorized around the participants and their interaction, attention structures are distributed across social structures, physical 
structures, conceptual structures and relational structures. They exist in houses, on computer screens, in bouts of ritual teasing and in tightly choreographed practices of seduction as well as in the minds and bodies of users.

Most studies have focused on attention as a cognitive mechanism or, rather, collection of mechanisms which include alertness, orientation, detection, facilitation and inhibition (Schmidt, 2001). In social interaction, however, attention is not just an individual cognitive process, but also a kind of commodity that interlocutors trade in interaction. When we speak of 'attention,' we are really speaking of two separate but interrelated systems. The first of these we can call the cognitive attention system, the system individuals use to mentally distribute their attention across the various activities they are involved in. The second we can call the social attention system, the system participants use to display attention and to interpret displays of attention by others (Jones, 2003).

One of the most important aspects of attention structures is that they involve the distribution of both of these two kinds of attention, and sometimes, as we have seen, these different kinds of attention can be distributed rather differently across different spaces and different timescales. In both of these communities we have seen a difference between the way people use time and space and the way they 'perform' time and space to those with whom they are interacting or other co-present parties.

The management of time and space in multiple sites of engagement requires what R. Scollon (1997) calls interperformativity: the ability to distribute attention in different ways on different timescales and in different spaces. These multiple orientations towards time and space also invoke larger Discourses within which particular attention structures are valued, promoted and reproduced in the service of particular ideologies (Blommaert, 2004). Sites of engagement, then, are sites of political struggle between competing Discourses with competing attention structures. These struggles pervade both on-line interactions as well as the off-line ways that students, for example, react to how their teachers make them use computers in school, or the ways that gay men treat their sexual partners once they meet up with them.

Sites of engagement, therefore, are convergences not just of social practices, but of individuals and their histories, of schemes, scripts and plans, of social identities, of architectural or software designs, and of the various Discourses we participate in with their patterns of fixing social relationships of power and of marginalizing certain kinds of social identities and practices. They are, says R. Scollon (2001a), the historical outcomes of social practices embodied in cultural tools and appropriated into the habitus of individuals and the homologous habitus of groups.

On a practical level, theoretical attention to how sites of engagement are formed through different patterns of orientation towards time and space might help those 


\section{Rodney H. Jones}

interested in literacy to answer questions like how attention structures developed in on-line interaction affect students' responses to school-based activities, and help those interested in sexuality or public health understand how the attention structures that gay men make use of in on-line interaction affect the ways they orient towards each other when they finally meet. In this sense, sites of engagement, and the attention structures that activate them, are heuristic devices, both for participants and analysts. They are points where social practices and social identities converge, and where a single action like inviting somebody to chat in a chat room can be traced to the interplay of larger Discourses and relations of power in the sociocultural environment.

\section{Notes}

1 Computer Mediated Communication and Youth Literacy in Hong Kong: A Participatory Ethnographic Approach (Principal Investigator in collaboration with Dr David Li). Hong Kong RGC Competitive Earmarked Research Grant \# 9040856. www. personal.cityu.edu.hk/ en-cyber/Cyberkids/Home.htm.

2 An Ethnographic Study of Computer Mediated Communication among Gay Men in Hong Kong. City University of Hong Kong Small Scale Research Grant \# 9030988. www.personal.cityu.edu.hk/ en-cyber/cybertongzhi.htm. 


\title{
15 From anticipation to performance: sites of engagement as process
}

\author{
Ingrid de Saint-Georges
}

\section{Process in discourse analysis}

With its aim of contributing knowledge to the understanding of agency, social action and social change, mediated discourse analysis has sought since the beginning to develop concepts and ideas to show how actions and discourses acquire their meanings from the positions they occupy within historical sequences of events. In this perspective, one important notion in mediated discourse analysis is that people, objects, tools and discourses have a history and project a future. They move, each at their own rates and on their own timescales, along trajectories (Scollon and Scollon, 2004; S. Scollon, 2001; R. Scollon, this volume). This focus on trajectories has come to be an important component of nexus analyses. It naturally invites us to enlarge the scope of traditional discourse analysis and to move beyond the level of single events to start addressing issues such as how social realities are constituted across time and spaces, and what kind of methodological and theoretical tools we need to conceptualize how events, people, ideas, objects and knowledge evolve over time.

In this chapter, I explore how the sites of engagement that constitute a research process are constructed by researchers and participants and connected to one another through actions and anticipatory discourses. I examine how distant discourses and actions become linked to constitute this research process and attempt to describe how, as a researcher, I fit into time myself as my research evolves. I outline various moments where I enter into relationships with the participants, and sketch the evolution of the research process from determining a zone of identification to interacting in complex tasks with the participants. Finally, I reflect in more general terms upon the kind of topics diachronic data may lead linguists to examine and discuss some of the implications that adopting a processual view of discourse may have for discourse analysis. I hope to show how mediated discourse analysis can help us think about how to construct more complex processoriented studies. 


\section{Ingrid de Saint-Georges}

\section{Trajectories as data}

To ground my reflections on how a research process is constituted across time and space, I have chosen to examine three threads of linked actions and interactions. These threads are drawn from ethnographic research I carried out at 'Horizons,' a vocational center located in Belgium which provides training in manual trades to long-term unemployed youth. This data consists of excerpts from fieldnotes, shots from video-recorded actions and excerpts from documents collected in the course of my observations of the activities of a group of individuals being trained in sheet-rocking. My description and analysis of this data will partly take the form of an introspection since, as a researcher, there are many times where I have only access to the chain of mediated actions I carried out myself. I cannot reconstruct the other participants' trajectories towards a particular moment of work since I was not present to observe how they prepared or oriented to this work outside of the moments when we met. ${ }^{1}$

Looking at these documents and notes as material traces of my history of dealings with the sheet-rocking group, the following timeline can be reconstructed, with several landmark events or sites of engagement conceived as space/ time stations:

- Space/time station 1. June 18, 1999. Horizons/Namur, Belgium. In June 1999, I begin pilot fieldwork at Horizons in view of developing a research project to meet doctoral requirements at Georgetown University. On June 18, I ask Henry, the monitor in sheet-rocking for permission to carry out observation on the work site when he and his group are working. This is my very first encounter with a member of the group.

- Space/time station 2. June 23, 1999. Arch Town, Belgium. On June 23, 1999, I join the sheet-rockers' group and spend one day observing their work, which consists in the building of an arch in a house. I video-tape part of the work done on that day.

- Space/time station 3. December, 1999. Washington, DC, US. In August 1999, I return to Georgetown and start writing about my time with the sheetrockers. In December of 1999, I hand in a proposal with my 'action-plan' for my actual fieldwork, which will begin in January 2000. This proposal recontextualizes some of the moments lived with the sheet-rockers.

- Space/time station 4. Early March, 2000. Horizons, Belgium. I resume fieldwork in January 2000. At the beginning of March, I request from Henry the permission to visit his group again. This is the point at which my trajectory and the group's trajectory meet again after a long interval without interactions.

- Space/time station 5. March 5, 2000. Namur, Belgium. I prepare the material I will need for carrying out observations with the group. 
- Space/time station 6. March 6, 2000. Apartment Town, Belgium. I spend the day observing activities linked to partitioning a mansard-roofed apartment.

- Space/time station 7. Between June 2000 and May 2003. Namur, Belgium/ Washington, DC, US. I carry out my analysis and write up my research work on the basis of the data gathered.

- Space/time station 8. December-July, 2004. Brussels, Belgium. I transform and revise my analysis and write up the current chapter.

- Space/time station 9. After editorial transformation by the authors of this book you are now reading this chapter somewhere else as a part of your own trajectory.

I view sites of engagement as space/time stations (Gu, 2002) and follow Hägerstrand and $\mathrm{Gu}$ who propose that individuals' trajectories sometimes diverge and sometimes converge. When they converge, they cross paths on specific 'social occasions' or stations, which can be thought of as spatially and temporally bounded experiential spaces (a home, a work site, a city, etc.) within which individuals can engage in individual or joint actions. Individuals can open up a variety of sites of engagement within these space/time stations. Thus, stations are not 'practico-inert containers of action' (Crang and Thrift, 2000: 2). Rather, through the actions of the participants these space/time stations are both constituted and transformed over time. They are thus best conceived 'as process and in process (that is space and time combined in becoming)' (Crang and Thrift, 2000: 3, emphasis in original). What I would like to consider now is how these space/time stations become connected so as to start integrating into trajectories. I would like to propose that one methodological way in which we can attempt to capture the unfolding of trajectories is by looking at the relationship between what people anticipate they will do (anticipation) and how these chains of anticipation and action start weaving the threads of practice and mediational means across sites of engagement.

In the next section, I will show through the analysis of the empirical data how sites of engagements become connected through the anticipatory discourses and the actions of the participants.

\section{Anticipatory discourse: from anticipation to performance}

One of the ways in which actors in the world construct events across time and space is by first projecting those events and then trying to find ways to realize them. An overwhelming part of our everyday behavior indeed consists of consciously or unconsciously projecting outcomes and finding means for accomplishing them. We set agendas, plan, prepare and organize courses of action; we anticipate events and processes and work to avoid or realize them. Our plans 


\section{Ingrid de Saint-Georges}

follow their courses or are disrupted. Noting that very few studies had been done regarding how individuals orient towards the future, Scollon and Scollon (2000) have proposed that closer attention should be paid to studying what they have called 'anticipatory discourses' (see also S. Scollon, 2001; de Saint-Georges, 2003; Filliettaz, 2004c). The analysis of anticipatory discourses could be defined as the study of 'the ways in which discourse may be used to produce possible or impossible actions in the future' (R. Scollon, 2002c: 5). It invites us to explore how discourses about future actions figure in the production of these social actions: are they simply a part of the mechanisms through which we reason about actions or do they play a part in 'generating' actions? These issues can be explored through the analysis of three threads in the empirical data.

\section{Thread 1: the trajectory of a practice}

The very first traces I have of an encounter with a member of the sheet-rocking group are a few notes in my fieldnote book:

(1)

Friday night. 06/18/99

make an appointment $\rightarrow$ Monday: masons; Wednesday: sheet-rocking with

Henry, who asks me who I am, if I work as a social worker; seems open to my

presence on the work site no problem. Will give me a cap and overalls; we

change clothes on the work site to not dirty his van. Direct. To the point

Let us concentrate on the three future-oriented propositions, 'Wednesday: sheet-rocking with Henry,' 'will give me a cap and overalls' and 'we change clothes on the work site,' and the actions that emanate from this first encounter. First, while I write the text above to record an encounter prior in the day, this note is also a reminder to myself about a future engagement (the plan to meet on Wednesday). Ladrière notes that for an activity involving a plurality of actors to occur, the actors must at some point develop convergence in their understanding of the activity in question (Ladrière, 2001: 277). This includes communicating to each other the timing of the activity. Making an appointment thus forms part of a 'dynamic of occasions' (de Fornel, 1993: 97) and appears as a mode to start constituting an intersubjective future between the parties scheduling the encounter. This 'scheduling discourse' is linked to the site of engagement opening on Wednesday June 23 (space/time station 2) when I join the group to do observations of their work. Our project to meet thus concretizes into a real encounter, enabling me to pursue my research and establish a relationship for future encounters.

The 'intention' expressed by Henry to bring me cap and overalls does not present the same degree of commitment since this discourse does not lead to action. 
Henry actually forgets to bring them (intention does not lead inevitably to action) and as a result I do not change clothes on the work site as I have been instructed to in this first encounter with Henry. Many months later, however (space/time stations 5 and 6), as I prepare to resume observations of the group's work, I put in my bag work clothes I intend to wear on the work site as I have been directed to do in this June encounter with Henry. As I groom myself for work the next day, Henry's initial discourse about changing clothes on the work site has now been 'submerged' as part of my practices (Scollon and Scollon, 2004: 18). This practice has moved from the explicit level of discursive explanation to the more implicit appropriation of the meanings of this discourse on a behavioral level.

\section{Thread 2: the trajectory of a mediational means}

On my first day with the sheet-rockers (Wednesday June 23, 1999 - space/time station 2, construction of an arch), Henry asks me if I would agree to film the work done during the day. He would like to produce pedagogical materials for future trainees who might not have the opportunity to learn how to construct an arch hands-on. They could learn about it through viewing the video. One of the effects of this request is to change significantly my perception of what is 'possible' or 'practicable' for my ongoing research. I can start designing a research project that takes this technological possibility into account. I state these ideas in the proposal I write in December 1999 (space/time station 3). The data collected during pilot fieldwork has now become a resource to design an 'action-plan' for the actual fieldwork I aim to begin in January 2000:

Regarding the video-recording of the data, it should be noted that the Center has recently acquired a video-camera. The purpose of this purchase is to be able to document the work on the different work sites... I learned of this project in the course of doing my pilot fieldwork, when one instructor requested that I video-tape the different stages of the work for that day. ... By using this video-camera, I will thus be able to fulfill [the following] function: ... record the mediated actions necessary for my analysis. To ease the analysis of the discourse dimensions, I also plan to tape-record verbal activities taking place on work sites and use this audio-recording for the discourse analysis aspect of my research.

Proposals usually qualify as text of the 'rational planning' type: they are usually produced in anticipation of carrying out research and have discursive characteristics of rationalistic texts. As Dant and Francis (1998: 3.3) ${ }^{2}$ note, the 'traditional model of rational planning would suggest that these plans stood as directives to 


\section{Ingrid de Saint-Georges}

future action.' However, viewed in this historical perspective we see that this plan has as much a retrospective character as a prospective one. On the one hand, the 'working plan' of video-taping activities became a 'rational plan' only 'after [it] acquired a coherence during courses of action, not in advance of such action' (Dant and Francis, 1998: 4.2). On the other hand, as a plan, the proposal fails to detail what exact course of action should be taken on the work site (e.g. when to begin and stop video-taping, how to approach asking participants if one can video-tape, etc.). It does not in fact so much create 'strategies' for action as it 'programs the strategies [I] already have' (Mintzberg, quoted in Dant and Francis, 1998: 2.10) and present them formally, leaving it to the moment of situated actions to find practical ways to implement these strategies.

In fact, the implementation of the plan is not without difficulties. Bridging the gap between the formal plan and the actual realization of the action of video/audio-taping on the work site becomes an object of struggle as indicated in a note I write to myself in the morning of March 6, 2000 on my way to Horizons. I write in my fieldnote book as an injunction for the day:

(3)

I must manage to tape record more on the work site; I am afraid to ask and to impose; I must, I must, I must;

While the repeated 'I must' does not generate the fact that I later taped exchanges on the work site, I would suggest, however, that it stands in a determinate relationship to my action of taping. For Campbell (1996), sociologists have on the whole been more concerned about the meanings of action rather than on the way in which action is constructed. For him however:

Truly to adopt the actor's perspective is to regard action as an accomplishment and to recognize that it is the outcome of a struggle: something which has to be achieved against resistance, being in effect the end product of a willed effort involving certain given processes of 'determination.'

(Campbell, 1996: 158)

Understanding the subjective meanings of an action suggests Campbell (1996: 160), moreover 'involves ascertaining the role played by emotion, imagination, effort, attention and will':

In this respect the actor's capacity to create and manipulate meaning has to be regarded as a critical resource employed to accomplish acts and not simply that which 'gives' actions their meaning.

(Campbell, 1996: 160) 
What these comments from Campbell highlight is that, in writing this note to myself, I am neither seeking to " "make sense of things", or "render them accountable"' (Campbell, 1996: 159) as for example ethnomethodologists might suggest, nor does it constitute a form of decision-making (my decision is already made). I am trying to exert agency as a researcher despite the difficulties I perceive for realizing my goal. I am thus not so much using discourse to reflect about a future action as I am using it as an impetus to accomplish an ordinary action.

Later in the course of the day, I write as an evaluative afterthought in my notebook:

Finally, I feel quite free to film and to tape.

I am performing smoothly the audio-taping I had feared I would not be able to perform in the morning.

\section{Thread 3: from design to production: the trajectories leading to a site of engagement}

All the actions mentioned above (the pilot fieldwork, the filming, the proposal, the preparing of clothes to change on the work site, the decision to audio-tape) constitute anticipatory actions and discourses leading to my observations of actual work on the work site. On March 6, the work to be carried out is the renovation of an apartment where the sheet-rockers have been asked to construct interior walls. This work inscribes itself in numerous other trajectories than my own: the trajectories of the various workers, the trajectory of the architect's planning of the work, the trajectory of the apartment's history etc., such that we could consider this moment of work as:

a point at which historical trajectories of people, places, discourse, ideas and objects come together to enable some action which in itself alters those historical trajectories in some ways as these trajectories emanate from the moment of social action.

(Scollon and Scollon, 2004)

Let us consider two phases in the realization of this work: its design and its production.

The design of the work

Kress and van Leeuwen (2001: Chapter 3) distinguish between what they call the faculty of 'design' of individuals - which is to say their ability to draw on available 


\section{Ingrid de Saint-Georges}

semiotic modes and resources to conceptualize, project and imagine how a given semiotic structure should be produced - and the ability for 'production,' which is to say their ability to implement the design in a given form. In the case of construction work, the 'design' is often the task of the architect and is couched in blueprints and set of specifications, such as this one, produced for the realization of the interior walls:

(5)

Article 68.03: non-bearing partitions

\section{Work description.}

Fixed partitions made of metal frames with internal insulator and plaster board coating.

2. This work comprises.

This work concerns the carrying into execution of light dividing walls.

The characteristics of this partition are conceived as to meet the

requirements of the NBN SO1-400 and reach at least category 11b.

The on-site trial of a partition with simple frame coated with two boards

on each side, insulated by $50 \mathrm{MM}$ glasswool - 16 kg/M3 (MS 100/2.50.2. A)

falls within category 11a-Rm $(100-3150 \mathrm{~Hz}) 52 \mathrm{~dB}$.

A. METAL FRAME

Simple metal frame composed of iron sections galvanized by heat, $0.6 \mathrm{MM}$

thick, METAL STUD MSH (u) type and MSV (C) from GYPROC, which is to say:

- tracing of the work in the presence of the architect;

- depending on situation, punctual cleaning of the coat at the butt and ceiling maintained in order to bond the finishing touches;

- implementation of peripheral break-away bands constituted, depending on the thickness to be reached, of compressed glasswool, or padding;

- Assembling of the frame according to the manufacturer's prescriptions, width of the iron sections $\mathrm{L}=50 \mathrm{MM}$;

[CONTINUES]

Even without understanding the professional jargon used by the architect in referring to materials that are to be used in the work process, it is clear that this document refers to an ensemble of norms and requirements, which either indicate how to use the material (usually according to manufacturer's prescription) or specify legal requirements (e.g. regarding sound proofing [52 dB]). The document thus functions as a set of instructions, which carry a number of responsibilities with them and which are caught within a larger normative Discourse of construction work. The document however remains rather sketchy about the work processes that the workers should effectively carry out to produce the partitions. If the 
specifications can remain under-determined in this way, it is because they rely on precise and well-known scripts within the domain of practice of sheet-rocking and make sense in relation to regular, organized, socially meaningful occupational practices. It is also these practices and scripts that the trainees have to learn if they want to become sheet-rockers in their own right.

\section{The production of the work}

The physical production of what the blueprint represents - its articulation in a material form (a wall partition) - includes moving from modes and resources understood abstractly to examining how actors use their embodied skills to accomplish the physical actions necessary to implement the design. The excerpt described below was filmed during the construction of the partitioning walls and is one example of this recontextualization of the architectural discourse into action. In this sequence, Henry, the monitor, is making measurements, while Billy (standing) and Norbert (sitting) are watching. Then, Norbert starts looking around before uttering, 'The drill, Billy,' and he is scanning the room to try to locate the drill. Henry then intervenes and turns towards the back of the room. Pointing towards the window-ledge with his measuring stick he says, 'it's there' and then resumes his work. At this point, Billy starts his move to fetch the drill.

In this moment of work many practices are engaged and multiple agendas interact to construct a unique site of engagement. For example, the measuring is in compliance with the normative Discourse of the blueprints and specifications; my filming inscribes itself in the academic Discourse of research; the action of measuring is just one step in a highly scripted sequence of actions which will constitute the higher level of action of 'partitioning a room' and is constitutive of the nexus of practices of sheet-rocking. In bearing responsibility for the measurements, Henry acts as the one in charge of fulfilling the contract he has with his client but, in monitoring the actions of the trainees, he also acts within the pedagogical Discourse of training. Through concentrating his attention in multiple directions and engaging in several lines of action simultaneously, Henry thus seeks to fulfill his several agendas.

Norbert's request for the drill can, in the same way, be shown to have multiple functions. In anticipating the tool ahead of the moment of drilling, the request is meant to move the sequence of action forward. But anticipating the next step in the action sequence has also another function. Through the request, Norbert also displays that he has knowledge and expertise about this action sequence. The request thus also positions him as a worker taking initiatives. The form of the request also has an impact on the manner of acting. In requesting the drill, Norbert uses a direct request which in other kinds of circumstances could appear facethreatening. However, Dumas (2001) proposes, in certain contexts such as this 


\section{Ingrid de Saint-Georges}

one, the direct form may cue the need to comply with the request without delay. Likewise, the utterance seems here almost to 'generate' the immediate reaction of Billy to look around the room for the drill. The form finally indexes a certain form of power over Billy. Although Norbert is a trainee like Billy, he is already an old-timer at Horizons. Through requesting Billy to perform a task for him (rather than performing it himself), Norbert displays qualities of leadership and initiative that are usually regarded as a sign of progress and good evolution at Horizons. As a newcomer, Billy does not question the old-timer authority of Norbert and responds by complying with the request. Anticipatory discourse (the directive) in this case is used to prompt an action (compliance with the request), as well as construct an identity.

\section{Implications for discourse analysis}

In this chapter, I have suggested one way in which a processual outlook on data could be developed. To capture the dynamic evolution of discourses and actions, I have drawn from the theoretical notion of anticipatory discourse. Methodologically, I have used ethnographic field notes and other artifacts collected during fieldwork to document moves from anticipation to performance.

In my view, the trajectory approach put forth by mediated discourse analysis is intellectually attractive because of its ability to shed light on new and important areas of inquiry. The data analyzed suggest a few directions that could be fruitfully taken to further our understanding of discourse in ways that we have not done much so far.

First, in the domain of genre analysis, it calls for developing a better understanding of texts oriented towards the future (procedures, specifications, plans, agendas, etc.) as opposed to the past (narrative accounts). Paying attention to how actions and discourses are located in time also promises to renew the discussion regarding the functions of discourse in relation to action (can it 'generate' action in the strong sense or is it part of the mechanisms through which we reason about action?).

Another area for study it opens up is to pay more attention to the specificities of time as a semiotic mode mediating social interactions. In this area, we need to construct a much more complex understanding of how humans are 'organizers of complex temporal arrangements and assessment' (Star, 1997: 6.4). We also need to get a better grasp of how objects, representations, institutions, etc. and their respective timescales oppose resistance to individuals' actions. As Star (1997) puts it:

We organize ourselves in time, guessing, modeling, depending on the timings of other people and things. Sometimes things unfurl as planned; more often, 
there are twists and tangles along the way. How we manage these twists is in some sense what makes us quintessentially human, what ties us to the world.

(Star, 1997: 6.2)

A truly ecological approach to interaction must thus necessarily involve developing a much more complex and solid understanding of this dimension.

Paying attention to the specificities of time as one mode of becoming of things, events, identities, representation is also the only way to proceed if we want to address seriously the issue of change, a process that necessarily consumes time. In this chapter I have considered very local changes (the transformation of the physical space of an apartment, the semiotic transformation of my representations over time, etc.); but what scales do we have to take into account if we consider more important changes?

In a world that is ruled by the 'cult of urgency' (Aubert and Roux-Dufort, 2003), it will probably be a challenge to carry out the long-term longitudinal studies required to make an epistemological breakthrough in this domain. Studying time and its effects may be, in this way, a form of resistance to the short-term views that characterize so much of the discourses and actions of our time.

\section{Notes}

1 This introspective approach as a methodology was first suggested and developed in S. Scollon (2001).

2 Dant and Francis (1998: 3.3; 1998: 4.4; 1998: 2.10) and Star (1997: 6.4; 1997: 6.2) are references to paragraphs of an electronic document. 


\section{Sites of engagement: questions and mini projects}

\section{Questions for discussion}

1 Jones, drawing on the work of Hall, discusses how different social groups develop different patterns of orientation towards time and space, and how these different patterns affect the way they construct sites of engagement and the kinds of actions that can be taken at these sites. Think of an example of a physical space towards which different kinds of people orient differently and how these different orientations affect the actions they can take there.

2 Jones says that people's orientation towards time and space is governed by what he calls attention structures. Think of a situation (driving on a highway, listening to a lecture, navigating the internet), and discuss how the structuring of attention is achieved through external features of the environment, norms of behavior associated with particular groups, and practices that have been learned by individuals and appropriated into their habitus.

3 De Saint-Georges talks about how anticipatory discourse acts to limit and shape the kinds of actions we are able to take. Can you think of some examples of this?

\section{Mini projects}

1 Look closely at Jones's chapter and consider your own computer habits: ask yourself who you communicate with using computers and where you locate yourself in relationship to the other participants. How do you construct time and space through your own social practices, shared goals, plans, and the conventions that have built up around your interactions? Analyze logs of your computer mediated communication for space and time deixis. What does your analysis reveal?

2 Think about time/space stations in your own life. Through which trajectories and what kind of anticipatory discourse are these connected? Describe how these time/space stations evolve into joint sites of engagements. 


\section{Part V}

Agency 



\title{
16 Introducing agency
}

\author{
Rodney H. Jones and Sigrid Norris
}

\begin{tabular}{|c|c|}
\hline Agency: & $\begin{array}{l}\text { Traditionally, the individual's intentionality as con- } \\
\text { structed through discursive actions. } \\
\text { MDA's approach to agency goes beyond the individ- } \\
\text { ual, viewing it as integrated - and in tension with - the } \\
\text { actor's habitus, the mediational means employed } \\
\text { and the social practices involved in constructing a } \\
\text { mediated action. }\end{array}$ \\
\hline & $\begin{array}{l}\text { Agency is always distributed among participants, } \\
\text { mediational means and discourses. }\end{array}$ \\
\hline
\end{tabular}

Traditionally, the notion of agency has been associated with concepts like 'will' and 'intentionality' and seen to spring from the individual's consciousness acting upon the environment. At the root of most discussions of agency in linguistics and other social sciences is what Wertsch (1998) calls 'methodological individualism,' a tendency to take individuals as the unit of analysis and to perceive them as bounded, autonomous and as exercising independent control over their actions (see also Lukes, 1977).

There is, however, a significant tradition in the social sciences that has challenged this view (see, for example, Burke, 1966; Dewy, 1938; Taylor, 1985; Vygotsky, 1981), insisting on the need to go beyond the individual mind when considering human action - and it is in this tradition that mediated discourse analysis approaches the question of agency. It is, in fact, the primary premise of mediated discourse analysis that human action is never a matter of individual agency, but instead a product of the 'tension' between the agenda of the individual 
and the agendas embedded in the mediational means made available in the sociocultural setting and appropriated into the individual's habitus as components of social practices. Agency is always distributed (Al Zidjaly, 2004; Hutchins, 1994; S. Scollon, this volume) among human actors, mediational means and the various discourses that circulate through them. It is always something that is negotiated between individuals and their social worlds.

How exactly this negotiation takes place and the role agency plays in the production of the social actor and the social world, are questions that require further study. According to R. Scollon (2001a), questions of how agency is distributed, enacted, represented and contested are among the most crucial ones faced by mediated discourse analysis. There is, for example, much evidence (Fung, 1994; Hsu, 1953; Scollon and Scollon, 2001; S. Scollon, this volume) to suggest that different configurations of 'culture' produce different conceptions of the self and patterns of negotiation between the individual and society.

Central to MDA's approach to agency is the work of Kenneth Burke, for whom agency is chiefly a matter of perspective. In his Grammar of Motives (1969), Burke proposes that an action can be approached from any of five points of view: the scene, the social actor, (what Burke calls 'the agent'), the mediational means (what Burke calls 'agency'), the mediated action (what Burke calls 'the act') and the purpose of the action (see also R. Scollon, 2002). From this perspective, the study of agency is seen not so much in terms of objectively attributing responsibility for social actions, but rather in terms of understanding how those we study position themselves in various relationships to their actions, and understanding how we as observers position ourselves when we formulate interpretations of those actions. Burke (1969) makes the point that when we attribute motives to actions, we are not so much describing the internal states that led to these actions but, rather, we are defining situations and conceiving social actions in ways that others can understand and accept. In other words, the discursive explanation and attribution of agency within social interaction, is, itself, a cultural tool for the construction of identity (see Norris, this volume). Thus, any analysis of agency must focus on the tension between the way agency is constructed by individuals in their discourse, and the way it is interpreted by others as actions unfold.

Another way our understanding of agency is affected by perspective is in how its operation appears to change depending on the scope of our observation or the horizon of our awareness. Agency on one timescale, that of a momentary, situated action, for example, might appear quite differently when evaluated from the perspective of a longer timescale, a larger activity, a lifetime, or an economic or political cycle (Jones and Candlin, 2003; S. Scollon, this volume). Similarly, agency seems much easier to attribute to individuals when considering momentby-moment actions. When these actions are seen as parts of larger social practices, 
identity constructions and discourses, however, the distributed nature of agency becomes much more apparent (see Norris, this volume).

Finally, agency is intimately connected to questions of power and domination. The central question here is, again, one of perspective. Power is not so much a matter of who 'has' agency as much as of who is able to control the positioning through which motives are assigned and exchanged, often through controlling the timescales and trajectories along which actions are defined (Blommaert, 2004).

In the following chapters, these issues of perspective and power in agency are developed and applied to specific situations. In Chapter 17, Suzie Scollon notes how agency is distributed across actors, time, mediational means and discourses in the practice of filling out a census form. This pattern of distribution, she argues, can only be understood by tracing trajectories of agency in the history of the culture or cultures involved, in the historical bodies of the participants, and in the interaction order of the moment when a census form is filled out.

In Chapter 18, Sigrid Norris considers agency as a tool in the construction of social identity in the context of gender relations. In her study of the discourse of two women, one married and one divorced, she explores how life choices are constructed in discourse, and how these choices are embedded in the societies and communities of practice to which these women belong. 


\title{
17 Agency distributed through time, space and tools: Bentham, Babbage and the census
}

\author{
Suzie Scollon
}

On a day in early April, 2000, Mrs Kang receives an envelope in the daily mail addressed to the 'head of the household.' When she sees the envelope containing forms for the decennial population count, buried in a stack of promotional mail offering special credit offers and the like, she sets it aside. She not only cannot speak or read English, she speaks only rudimentary accented Mandarin and cannot read the small complex Chinese characters on a corner of the envelope saying that Chinese forms are available by calling a certain phone number.

The next day, a friend at Mrs Kang's English language class tells her about the identical envelope she received and tells her that she saw that there was a special form for overseas Chinese to fill out, but her husband had advised her against it, saying 'this doesn't have anything to do with you.' Her husband's attitude had partly to do with thinking the complex characters were meant for Chinese from Hong Kong or Taiwan, not China, and partly to do with his intention to return to China after a few years. Mrs Kang thinks no more about the matter.

Some days later, there is a knock on the door. Mrs Kang, who lives in an apartment complex in the inner city, looks through a peephole and sees a strange African American man who is not one of her neighbors. She is afraid to open the door, with her husband at work at a Chinatown restaurant and her sons away at school.

After a few days of looking in vain for work, Mrs Kang returns to the Chinatown Service Center at a nearby church for another English class. Mrs Ng explains to the class that the results of the census will affect funding for their language classes and other services such as emergency health care. She offers to help students fill out the forms and return them to the Census Bureau, assuring them that all personal data will be kept confidential.

Students express concerns that by revealing personal information such as their home address they will lose their residence rights. Mrs $\mathrm{Ng}$ patiently explains that, unlike in China, the green cards that give them the right to employment and residence in the country are not tied to any particular address. The benefits would go to communities and not to individuals. 
Mrs Kang agrees to let Mrs Ng help her fill out a form for herself and her family. She finds not only the questions confusing but the order in which they are asked. She feels inadequate having questions explained to her in Mandarin, just as she had as a schoolgirl some decades before, and not being able to read the simplest questions. She doesn't know whether her son, who is a college student, should be counted as part of her household.

\section{Who is the agent?}

If we ask who the agent is in the counting of Mrs Kang, her husband and her son, the answer is by no means simple. The question 'Who is the agent?' makes the basic assumption that agency is a property of the individual, a body in a cultural, historical and institutional vacuum (Wertsch et al., 1993). In Goffman's (1974) terms, however, the three who are counted are but figures, with Mrs Kang and Mrs Ng sharing in the animation of Mrs Kang as principal in an act authored by countless Bureau of Census employees and their predecessors over a span of centuries.

In this chapter I will show how agency as a motive force toward an end is distributed through time, space and tools as well as actors in cycles of discourse and action. ${ }^{1}$ Mrs Kang and Mrs Ng, immigrants from different countries in different decades, each a speaker of a dialect of Fujian Chinese unintelligible to the other and a speaker of Mandarin as a second language, share enough experience in common discourses to collaborate in filling out a form that resemiotizes (Iedema, 2001) discourses originating on other continents in other centuries. These langues are what Wertsch (1991) refers to as mediational means, as are the census form, with its letters, characters, shaded areas, arrows, numerals and blank lines, the pen, the clipboard, the furniture and lights and the space in the classroom.

Agency in modern times has been uncritically construed as involving a single actor, an autonomous individual with a simple intention. From being defined as 'an intervening action toward an end,' in the mid-seventeenth century, agency acquired a sense of 'action personified, a source of action toward an end,' in the late eighteenth century $(O E D, 1993)$. By the late twentieth century, the theory of radical choice conceived of the human agent as a disembodied ego acting on a horizon with no anchoring in space, time or personal history (Taylor, 1985: 35).

Elsewhere I have argued that language needs to be analyzed from three points of view: the langue or language with a historical provenience typically identified with a nation state; the idiolect or linguistic habitus, the collectivity of resources used by an individual to navigate her social world; and the speech community resources used by everyone in the community (S. Scollon, 1977). I have shown how the English used by children in a particular speech community evolved out 


\section{Suzie Scollon}

of the collective resources of other langues present, including Chipewyan, Cree and French (S. Scollon, 1982). Here, I argue that the agency of any action must similarly be understood from the point of view of the discourses provided by the nation, the historical body of the actor, and the interaction order (Scollon and Scollon, 2003, 2004).

In an era with megacorporations spending megabucks in advertising campaigns to control our every purchase while seeming to offer choice, it is imperative that we seek to understand how agency is distributed socially, culturally and historically. Even an action as seemingly uncomplicated as completing a census form can be demonstrated to entail very complex networks of distributed agency converging in time and space under the mutual influence of disparate discourses. Any action occurs at the nexus of a historical human body, a social interaction order, and discourses in place (Scollon and Scollon, 2003, 2004). Thus, an act of enumeration takes place when a person, either alone or in interaction with others, fills out a form that resemiotizes utilitarian and national discourses through the means of questions printed with space for responses. The place, typically a home, where the act takes place carries its own discourses. The convergence of these discourses in a particular moment is mediated by what we call interdiscursive dialogicality (Scollon and Scollon, 2003).

Agency in census enumeration is distributed across discourse cycles centuries in duration, global in spatial extension and embodied in material objects and biological persons. Mrs Kang's behavior, not only her action of migrating from Fujian to the Atlantic seaboard, but also her actions of avoiding census forms and finally consenting to have Mrs $\mathrm{Ng}$ fill out a form for her, as well as her communication with Mrs $\mathrm{Ng}$ during the filling out of the form, has been shaped by multiple discourses: Chinese imperial edicts; techniques for registering families used by the Guomindang and Japanese; the Soviet passbook system for internal migration; and regulations of the Ministry of Public Security of the People's Republic of China (Cheng and Selden, 1997). Mrs Ng's behavior in assisting Mrs Kang is shaped not only by her own experience of education in Manila, Singapore and the US and later immigration, her knowledge of English and Mandarin and the US decennial census, but also by authors like Locke, Hume, J.S. Mill, Benjamin Franklin, Jeremy Bentham and Thomas Malthus whose ideas shaped discourse in the American colonies, as well as Charles Babbage who drew up plans in the mid-nineteenth century for an 'analytical engine,' the forerunner of the computer, which was not actually built until 1946.

Understanding agency requires understanding human motives. Kenneth Burke in 1945 (Burke, 1969 [1945]) proposed an analysis of human action and agency that would go beyond the abstract analysis of linguistic form, looking at the human actor as a participant in a drama, contained within and interacting with a scene. As he considered linguistic accounts of action to be subject to different motives 
on the part of the one representing the action, he called his scheme a 'grammar of motives.'

According to Burke, 'the basic unit of action is the human body in purposive motion' (Burke, 1969: 16). To describe the action of Mrs Kang in allowing Mrs $\mathrm{Ng}$ to count her in the census, we might say she is complying with the circumstances in which she finds herself at a Social Service Center that provides her with instruction in English, which she considers necessary to her survival in a foreign land. Burke would consider this a scenic motive. He would not consider her an agent in that she did not have the intention of being counted but simply went along with it after some resistance.

If Mrs Kang was not the author of her act, neither was Mrs Ng. She might be considered the author of whatever she said that resulted in her writing words on the census form beyond reading the words on the form, but she did not author the form itself. She might also have authored some of the words with Mrs Kang as principal taking responsibility for the words.

But what of a census enumerator? At a very basic level, it is clear that a census taker who is paid by the number of people enumerated has more incentive to complete the form than the ordinary citizen who has no idea what, if any, benefit might accrue from cooperating with the enterprise. But even here, the real incentive to count comes not from the individual, but from the US Bureau of the Census as an agency of the government, a bureaucratic office that resemiotizes utilitarian and nationalistic discourses in computers which spew out forms to be filled out by citizens with or without the help of hired or voluntary enumerators, and whose agency extends back to the Industrial Revolution and the 'felicific calculus' of Jeremy Bentham.

Borrowing from Braudel, Blommaert writes of the 'layered simultaneity' of three timescales that are present in every action: the longue durée, the time of intermediate political or economic cycles, and événement or event-time, defined as 'the short time, measured on individuals, everyday life, our illusions, our understandings and awareness' (Braudel, 1969: 45-46). Participants in social events have a restricted horizon of awareness of historical, social structural causes of those events and can exert agency only in the immediate time frame and from their own angle of awareness. The multiple contradictory perspectives which come together at the moment of the event form distinct trajectories with different origins developing at different speeds. 'Synchronicity . . . combines elements that are of a different order but tends to obscure these fundamental differences' (Braudel, 1969: 128).

In what follows, I will sketch out significant discourses in the longue durée, the intermediate political and economic cycles, and event time, describing first Western and American layers and then Chinese ones. I will then show how these layers come together in the moment of census taking in interdiscursive dialogicality and layered simultaneity. 


\section{The development of the census in the West}

The idea of the census developed straight out of Utilitarianism, for example, and since the modern computer arose out of census taking, it is no stretch of the historical fabric to say that contemporary uses of computers for such functions as public opinion polls and market surveys are a direct realization of the thinking of the Utilitarian philosophy of Jeremy Bentham.

(Scollon and Scollon, 2001 [1994]: 116)

To answer the question 'who is the agent?' we need to consider not only the actors currently present in the situation and the discourses they embody but also discourses embodied in the census form, which go back centuries in time. The questions on the form were authored by various Bureau of Census employees, and they were laid out on the form by a design team. But the author or strategist of the master plan of counting may be said to be Jeremy Bentham (1748-1832), whose 'felicific calculus' of happiness as 'the greatest good of the greatest number' entailed the imagination of a machine capable of carrying out unimaginably repetitive calculations.

Many would consider public opinion polls and market surveys to be silly progeny indeed, descended from Jeremy Bentham who thought happiness could be calculated and Charles Babbage who conceived what became the technology for the endless calculation of questionable items. Burke argued that it is in its becoming that technology most fully represents the human agent, since his inventing of it is an act, and a rational act (1969: 109).

The implication is that those of us who must use the technology are not agents who author our acts but objects or, at best, instruments in a drama that began 200 years ago. The history of who said or wrote what in the chain of events that led to the modern census would reveal early agents who could not have foreseen what their acts would engender:

Remember always that no modern instrument could have been invented, or could be produced, without the use of a vast linguistic complexity. A traffic signal seems very simple, but its production, distribution and operation requires a set of interlocking linguistic acts that would require a century to trace in their particularity. If we are not to be lost in such a maze of particulars, we must build from the essential humanity of dramatist or dialectic lore in general, considering it as central to the contemplation of the human tragi-comedy.

$$
\text { (Burke, } 1969 \text { [1945]: 319) }
$$

By 'linguistic act,' Burke meant any motion represented by a verb and having 'connotations of consciousness or purpose' (1969 [1945]: 14). As Burke notes, 
Bentham had asserted that motion had to be conscious and purposeful in order to be considered a human act.

Burke simplified acts that go into the operation of traffic signals by categorizing them within a hierarchy of acts on a continuum with acts of creation at one end and jobs or occupations involving sheer motion at the other (Burke, 1969 [1945]: 14). Office jobs on the latter end, which entail filing, bookkeeping, recording, accounting and the like, are acts belonging to a maze of particulars such as the motions of employees of federal regulatory agencies or commercial producers of traffic regulatory signs (cf. Scollon and Scollon, 2003: 190-192). People working in offices of the Bureau of the Census are instruments in the operations of the census just as the computers that fill innumerable buildings are.

These instruments, both human and mechanical, and the ideas that gave rise to them in the nineteenth century, are mediational means themselves embedded in longer histories, political and economic projects and exercises of power and domination that can be traced all the way back to the supposed act of God, recorded in the Book of Numbers of the Old Testament, commanding Moses to take a census. Early inventories of people made in Babylonia, Palestine, Persia, China and Egypt sought to control particular individuals for purposes of tax, military service or labor (Brittanica, 1990; Ho, 1959). They counted only particular categories of persons such as family heads or males of military age and tended to be inaccurate, as it was not in the individuals' interest to be counted. The first recorded census was ordered by Servius Tullius, sixth king of Rome, in 550 BC. This was a register of adult male citizens and their property which determined political status, military obligation and taxation.

Foundational discourses of utilitarianism and nationalism resulted in the compulsion to enumerate the population of the American colonies beginning with the decennial census of 1790 . The US decennial census was designed to balance the counting of population for apportioning seats, an incentive for states to maximize their counts, against the distribution of taxation, an incentive for states to minimize their totals.

When the first decennial census results of 1790 showed runaway growth in the thirteen original colonies, Thomas Malthus was moved to write his essay on population in which he argued that at that rate of natural increase food production could never keep up. The fertility rate for the white population in 1800 was about twice the highest rate of the baby boom in the 1950s (Crosby, 1994: 168). Crosby attributes the fecundity of the colonists to the bounty of the land and the generosity of the native population which allowed the settlers to survive and multiply on easily available maize. The bounty of the land gave rise to ambition, self-confidence, self-satisfaction and self-righteousness, according to Crosby (1994: 176).

Beginning in the nineteenth century, decennial censuses became the practice in Europe and the New World (Arel, 2002). Though language has always been 
intimately related to nationalism, national censuses until the mid-nineteenth century did not inquire into language. An item on langue parlée, 'spoken language,' was first proposed at the International Statistical Congress held in Brussels in 1853. French was the language of the Congress, which was convened to establish international standards of demographic statistics and census categories. At the Vienna session of the Congress in 1857 the question of language was buried by reference to 'nationality.'

Similarly, the US began including questions about language in the 1870 census. Before that and continuing to the present there seems to be more concern with establishing race under the guise of ethnic identity (Leeman, 2005). Changing immigration patterns with increased numbers of Jews from Germany and Eastern Europe as well as Mexicans brought heightened attention to language and a new question, regarding ability to speak English, in the 1890 census. By 1910 the Census Bureau was attempting to classify foreign-born residents by mother tongue. In 1950, after decades of limited immigration mostly from western Europe, no questions about language were included. However, by 1980, with increasing immigration, largely from Asia and Latin America, there were questions on home language use as well as English-language ability.

In the intermediate timescale of political and economic cycles, the influx of new immigrants has diversified the population, creating new needs for census data and, at the same time, complicating the gathering of pertinent data. The implementation of Executive Order 13166 signed into law by President Clinton on August 11, 2000 requires accurate data on languages spoken by different segments of the population. While this act sought to institute language rights in accordance with the Civil Rights Act of 1964, the Bush administration's 'war on terrorism' and the institution of Homeland Security has brought an atmosphere of suspicion of, and by, foreign nationals and immigrants and fear of deportation, with consequent reluctance to speak with government representatives of any kind. Political currents thus exert pressure on the event time of potential census encounters.

\section{Discourses embodied in Chinese immigrants}

Although some discourses resemiotized in census forms can be traced to their roots, others, such as those rooted in the historical bodies of immigrants and census takers, can be unearthed only through a process of reconstruction by observation of behavior and linking that to sociological and historical documents. Immigrants carry with them displaced discourses embodied in their every movement even as they internalize the bureaucratic discourses of their intended homeland.

Reluctance to speak with officials on the part of immigrants such as Mrs Kang may stem from experience in China as much as from current circumstances in the 
US. In China, census taking goes back as far as the fourteenth century, when 'yellow registers' enumerated the entire population and resembled modern census returns with listings of age, sex and occupation. Comparable returns were not collected until after 1776 (Ho, 1959). Land survey handbooks known as 'fish scale maps and books' contained summaries of land, each parcel described with the name of its owner, other property, amount of taxes and labor services borne by each household. These registers were compiled until the end of the Qing dynasty in 1911. Emphases and methods of enumeration underwent important changes through the centuries.

Buried in the US Congressional Record is a section translated from an edict issued by the Emperor T'ai-tsu, who ruled China from 1368-1398. Under this emperor, each household was issued a hu-tieh or 'household certificate' in which was recorded information as to members and property. On December 12, 1370 the Board of Revenue received an imperial edict that underscored the seriousness of accurate counts (emphasis added):

You, officials of the Board of Revenue, will send out proclamations ordering the provincial and local authorities to get all the population within their respective jurisdiction officially registered, and all the names of the people entered into the offical registers. The number of persons of each household must all be written down without falsification. Each household is to be given a household certificate with a half seal on each side so that the two parts will tally. . . . Those households whose tallies agree will be treated as subjects in good standing; if they do not agree, the family will be placed on the list of those liable for military service. If it is discovered in the course of checking that some local officials have falsified the returns, those officials are to be decapitated. Any common people who hide from the census will be punished according to law and will be drafted into the army.

(Board of Revenue, 1370)

It is not known how many violations of this edict were punished during T'ai-tsu's reign, but Ho reports that in subsequent centuries enumerations were far from accurate. Shanghai county, for example, left many females out of the count, recording a sex ratio of 460 males to 100 females. Another county omitted children, and one county reported a drop of 5,000 in the number of households between 1391 and 1551 (Ho, 1959: 11). Merging of clans to lighten or escape the tax burden was rampant.

In the intermediate timescale, the system of population registration and control that developed soon after the founding of the People's Republic of China in 1949 'effectively denied the Chinese people freedom of residence and movement, placing decisions in this realm in the hands of the state' (Cheng and Selden, 1997: 28). 


\section{Suzie Scollon}

Citizens were required to apply for permission to change their residence and to keep their residence registration current.

With the 1953 census, registration procedures were implemented in Shanghai and other major cities with the issuance of new and very detailed household registration books that recorded the birth, death, residence, education, and occupation of every household member (Cheng and Selden, 1997: 33). The State Council promulgated a 'Directive on Dissuading Peasants from Blind Influx into Cities,' which urged hundreds of thousands of peasants to return to their villages. This was followed in 1955 by 'The Directive Concerning Establishment of a Permanent System of Household Registration,' signed by Premier Zhou Enlai. This new directive encompassed countryside as well as cities. Cheng and Selden (1997: 35) consider this directive the beginning of a shift in emphasis from population registration to migration control.

A ration system for grain and other staples as well as cotton and cloth was established, resulting in increasing difficulties for illegal migrants in obtaining food. Eligibility for food rations, subsidized housing, health care and pensions was restricted to urban residents who were members of a danwei or work unit. Only about 10 percent of the population qualified. Position defined by household and work unit was graded into seven categories of grain-supply cards. Rural residents were required to provide for their own food needs. Registration was intimately tied to food rationing.

In 1958 every Chinese citizen was required to be registered in a household registration book that constituted proof of 'the identity of citizens' (Cheng and Selden, 1997: 41). In both city and countryside, persons were recorded by workplace and location rather than kinship as in the former registration system. Husband and wife living and working in two different locations were registered in separate households, with children normally registered with their mother. People were allowed to move from large cities to smaller ones or to the countryside, but not vice versa. Moving-in certificates became required for moving into cities.

\section{The moment of census taking}

Scollon and Scollon (2003) draw connections between Braudel's concept of three timescales and the nexus of practice composed of the historical body that takes social action, the discourses in place through which action is taken, and the interaction order (Goffman, 1961) within which it is taken. Using these insights, and building on Pan's earlier work on the ways Chinese immigrants navigate the Chinese translation of the form used in the 2000 census, Pan and S. Scollon (2004) did a nexus analysis of the moment of enumeration involving Chinese immigrants, including the filling out of forms and the participation in interviews. We 
uncovered sociopolitical discourses embodied in census forms and census enumerators as well as the immigrants we attempted to interview.

At the moment of filling out a form, discourses in place, including those fossilized (or frozen) in the form itself (Norris, 2004b), interact with the interaction order and the historical bodies of the participants. We opened up the circumference of the moment to map the objects, discourses and persons, and the histories they bring with them into the common task of census enumeration. We examined how discourse, including the interaction order, becomes fossilized in census forms, how these residues of prior actions become the mediational means for succeeding actions, and how agency is embodied in the skills required to complete a form as well as the motivation to do so.

We have seen how census taking originated in the longue durée and how it has evolved in the intermediate political and economic cycles in Europe, North America and China. Discourses of Christianity, imperialism, utilitarianism and nationalism have been resemiotized in US census forms in English and again in translation. These forms fossilize an interview sequence of questions and answers as well as a sequence of questions with multiple-choice responses of the kind used in standardized tests developed during the twentieth century (Pan, 2003). They resemiotize an authority structure and a participation structure with words and visual semiotics.

Historical bodies of participants such as Mrs Kang and Mrs Ng contain residues in habitus of their previous experience or lack of experience in filling out forms or interacting with strangers who represent the government, in their homes or in municipal registration centers. Older persons lack experience with multiplechoice questions, while anyone who has been schooled in the late twentieth century in the US answers these as second nature.

The interaction order is also embodied, as well as dialogue in various varieties of language and literacy in different writing systems. To Mrs Kang's habitual dialogue in Northern Min, her mother tongue, was added interaction in Putonghua (Mandarin) when she entered school in the vicinity of Fuzhou, where she acquired some literacy in simplified Chinese characters. In modern China the practice of census enumeration has been to send census takers to homes to count residents. Forms are not filled out by residents but by census takers, who keep an eye out for residents not reported by heads of households.

Whatever layers of language and interaction patterns are embodied may shift when a person moves to a foreign land where some family members are more familiar with the new language than others. Children may have fluency but not authority to speak to census enumerators and may have little experience with translation and interpretation.

Social workers like Mrs Ng not only have the linguistic skills necessary to help immigrants with bureaucratic forms but also the experience over a ten-year cycle 


\section{Suzie Scollon}

to know that they can be much more effective in this task than strangers who go from door to door. They can also enlist cooperation from immigrants as they have a history of helping with forms that directly benefit people who are attacked and need emergency crisis intervention, for example.

Mrs $\mathrm{Ng}$ thus exercises agency in event time, with the motive of increasing funding by enumerating more residents in her service area. Her action in the event is enabled by experience in intermediate cycles and motivated by anticipation of further cycles.

Agency in census taking is thus distributed over cycles of discourse and action taking place in separate locales initiated by different actors with a plethora of mediational means including Bentham's felicific calculus and Babbage's analytical engine.

\section{Conclusion}

We have seen that an action such as filling out a form is done by one or more particular persons at a particular place at a particular moment, yet is never independent of other persons, places, times or discourses. As Blommaert (2004) argues, globalization affects language usage anywhere, anytime: through ideology, which is both historical, in the sense of Foucault's archive, and present in the immediate context; and through habitus, or what we prefer to call the historical body. In a text such as a census form, meanings are simultaneously produced in historical layers, not all of them conscious or accessible to agency.

Blommaert points out that state bureaucracies maintain their power by insuring that their laws prevail at any given moment, no matter what a particular person carries in their historical body. He contends that in our global world system, persons who travel across state boundaries face official encounters that are inherently unequal in that the discursive resources are stacked in favor of the bureaucrat. Though the discourses that converge in an official event or document constitute distinct layers in time and space, through a process of layered simultaneity they all pass through a filter of the state discourse that prevails at the moment of the encounter, with this prevailing top layer eclipsing all earlier layers brought into the encounter by the itinerant. What Blommaert terms 'synchronization' is a means by which bureaucratic agents retain power by collapsing layers of times and places into the event of the moment, thereby eradicating events of other times and places stored in the historical bodies of the subjects over whom they rule.

\section{Note}

1 This chapter is based on a study, 'Sociolinguistic Research on Immigration Characteristics and Experiences,' carried out under the auspices of the US Bureau of the Census, Yuling Pan, principal investigator. 


\title{
18 Habitus, social identity, the perception of male domination - and agency?
}

\begin{abstract}
Sigrid Norris
... what appears, in history, as being eternal is merely the product of a labor of eternalization performed by ... institutions such as the family . . .
\end{abstract}

(Bourdieu, 2001: viii)

According to Nishida (1958) and Bourdieu (1977) social identity is embedded in cultural and social currents, constructed through social and societal histories, and internalized by the individual as habitus. Certainly, identity is constantly constructed on a micro level, where an individual's identity is claimed, contested, and re-constructed in interaction and in relation to the other participants (R. Scollon, 1997). Such constructions are often, if not always, expressed as elements through lower-level, higher-level, and/or frozen actions (Norris, 2002a, 2002b, 2004a, 2004b). But social identity is also constructed in relation to others who may not be present at a given moment (Goffman, 1959) and it is always constructed through schemes of perception.

In this chapter, I elucidate the interconnections between habitus, social identity construction, and two women's construction of male domination. ${ }^{1}$ In order to demonstrate this complexity, I draw on nexus analysis and multimodal interaction analysis as my methodological frameworks (Scollon and Scollon, 2004; Norris, 2004b); I take into consideration the performance of sequential and simultaneous actions and the (not necessarily intentional) re-production of practices on different timescales as constructed in the histories and cultures of the individuals and the societies that they belong to; and I discuss the two women's identity and power construction, and thereby investigate what role - if any - agency plays in the process. ${ }^{2}$

\section{Data and method}

I look at two representative excerpts taken from a year-long ethnographic case study of two women living in Germany. ${ }^{3}$ One of the women, Anna, is married 


\section{Sigrid Norris}

and has three children, while the other woman, Sandra, is going through a divorce and has two children. During the year of data collection, I visited Anna and Sandra and their families (who lived close to each other and spent much time together) four times and lived with them for about four months in all, quickly becoming a part of their families during my first stay. While I was living with the two women, I shared their lives. I went shopping with Sandra and Anna; tagged along when they dropped off/picked up their children at preschool and school; read the books, magazines, and newspapers that they read; met their extended families and social networks; watched the TV programs that they watched; and listened to the music that they listened to. All the while I was jotting down fieldnotes, had the video recorder running every so often and audio taped the women when video recording was not possible. During the eight months that I was not staying with Anna and Sandra, the women wrote day-diaries, audio taped some of their own interactions, collected the books, magazines, and newspapers that they were reading, and the CDs that they were listening to, and sent me this material on a regular basis. Furthermore, I have studied the social histories of the two women through family narratives, and learned about the practices of identity construction that Anna and Sandra acquired while growing up.

The social identity constructions and the women's perceptions of male domination found in these two excerpts are found throughout my personally collected 60 hours of video and audio data of naturally occurring interactions, several hours of informal sociolinguistic interviews, and an abundance of fieldnotes. The two examples illustrate the complexity involved when we start studying social identity construction in more than one mode and on more than one time scale (Lemke, 2000a, 2000b; Norris, 2002a, 2002b, 2004a, 2004b; Scollon and Scollon, 2004); when we take the cultural projections and societal currents that are embedded in the individual's habitus into consideration; when we analyze the actions within their practices (Scollon, 1998); and when we investigate the power relationships that are being constructed and reconstructed (Bourdieu, 2001). Such a complex analysis brings with it the challenge to balance the micro analysis of the examples with the macro analysis of historical information that cannot possibly be explicated in a short chapter like this, perhaps resulting in shortcomings on either side. However, I believe that it is crucial to bridge micro and macro analysis in order to advance our understanding of human interaction, identity construction, and power relations. By bridging micro and macro, a micro analysis is greatly informed by the macro analysis, as our understanding of the macro societal and cultural underpinnings allows for a richer micro analysis.

\section{Interaction and identity construction}

As I demonstrate elsewhere (Norris, 2002b, 2004a, 2004b), a person seldom acts only on one level of consciousness. Usually we find that individuals perform 
simultaneous higher-level actions, each of which is constructed out of a multiplicity of lower-level actions performed through the use of various communicative modes. Every action that is performed by an individual claims at least one of the individual's identity elements, so we find that individuals always construct several identity elements simultaneously (Norris, 2002b). Concurrently, each action displays some kind of power relation - or better, as T. Bartlett (2004) suggests: an array of power relations. Just as one action can have different simultaneous meanings, it can claim more than one identity element, and/or a variety of power relations (see also Norris, 2002b, 2004a, 2004b).

During these excerpts there are no male participants present, and yet, both women demonstrate that they construct at least some of their actions according to what we can interpret as their internalized perceptions of male domination. It is this portrayed power-relationship that I am particularly interested in here, as this seems to be the power relationship that the participants themselves experience as the strongest one.

\section{A sociolinguistic interview}

During a sociolinguistic interview, Anna was asked to describe who she perceives herself to be. The interview was conducted on a morning that Anna had chosen. When the interviewer entered Anna's apartment that day, and throughout the interview, Anna was ironing her family's clothing, her daughter was playing behind her on the floor, and Anna was watching a soap opera, as illustrated in the first image of Figure 18.1. ${ }^{4}$

The interview started with the request 'well, talk a bit about yourself, about your identity.' Anna starts her narrative at the point when she was born, and moves quickly through the early years by listing dates and events, before she pauses and then says, 'I actually got where I am today and what I do today in quite a round-about way.' At this point she starts telling her social history from her youth to now, as represented in the transcript below.

The transcription conventions are adopted from Tannen (1984): each period indicates a $1 / 2$-second pause; : indicates lengthening of vowels; - marks abrupt cutting off of sound; ? marks rising intonation; , marks phrase-final intonation (i.e. more to come); $Z$ indicates latching or (in the following excerpt) continuous talk; and CAPITALS illustrate emphatic stress:

(1) als Jugendlicher ...

(2) ich wollte nicht Hausfrau werden,

(3) und mich von einem Mann abhängig machen,

(4) das wollte ich alles nicht ...

(5) aber dann 


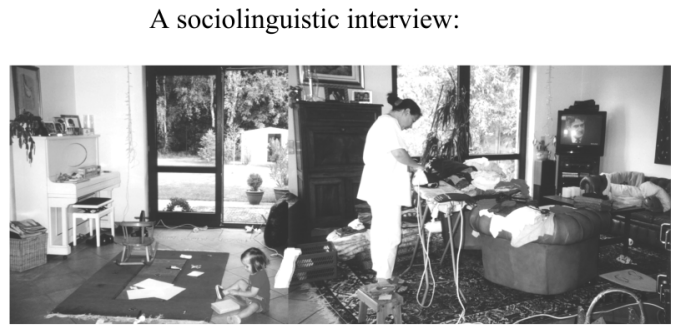

Setting up the computer:

der hat mich an sowas nie rangelassen

he never let me do anything like this

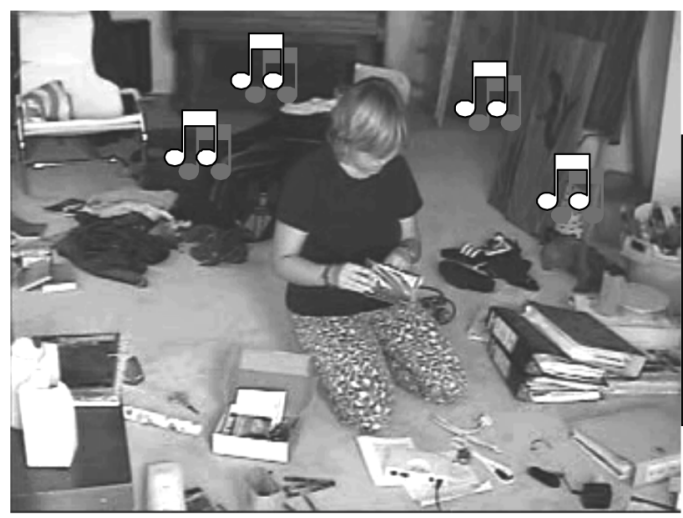

Loud hard-rock type music with lyrics like:

I wanted love, but it's gonna

kill me, you swear you're

faithful, that was a lie,

you've cheated on me with

half of this city, you aren't

worth it, bye-bye.

\section{ich werde es schaffen}

\section{ich mach später da weiter}

I will manage to do this

I'll continue there later

Figure 18.1 Identity construction and perception of male domination

(6) hab ich irgendwann Robert kennengelernt

(7) und dann

(8) wurden auf einmal

(9) alle Grundsätze über den Haufen geschmissen

(10) und dann

(11) war auf einmal alles ganz anders

Translation of the excerpt:

(1) as a youth ...

(2) I didn't want to become a housewife, 
(3) and make myself dependent upon a husband,

(4) I didn't want any of that ...

(5) but then

(6) I met Robert at some point

(7) and then

(8) suddenly

(9) all principles were overthrown

(10) and then

(11) suddenly everything was completely different

At this point, Anna talks about her family and how every one of the family members is important to her (for about five minutes). Then she starts talking about her current place in life ${ }^{5}$ :

(12) und nach wie vor bin ich auch .. so zufrieden

(13) mit all dem was ich mache.

(14) ich bin zufrieden mit meinem Haushalt,

(15) bin zufrieden mit dem Partyservice,

(16) als Ausgleich zum hier-

(17) Haushalt und Familienleben?

(18) wobei ich das nich:t • sehe • als .. ä:hm ..

(19) .. wie soll ich sa:gen,

(20) .. als Gelegenheit mich hier ..

(21) finanziell unabhängig zu machen von Robert -

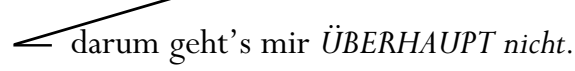

Translation:

(12) and I am as .. content as ever

(13) with everything I do.

(14) I am happy with my household,

(15) I am happy with the party service,

(16) as a balance to here-

(17) household and family life?

(18) while I do:n't . see . this as .. a:hm ..

(19) .. how shall I pu:t it,

(20) .. as an opportunity to make myself here ..

(21) financially independent from Robert

that's not AT ALL what this is about. 


\section{Sigrid Norris}

\section{Actions}

As mentioned earlier, during the course of the interview Anna is ironing, her daughter plays in close proximity, and Anna watches a soap opera. Thus, what we find here are several higher-level actions being constructed simultaneously (Norris, 2002a, 2004a, 2004b). Each higher-level action - the telling of a social narrative, ironing, watching TV, or interacting with her daughter - is constructed through chains of lower-level actions. For example, the telling of the narrative is constructed through a chain of utterances, a chain of glances at the interviewer, a chain of gesture units, a chain of postural shifts, and a chain of head movements; while the higher-level action of ironing is constructed through several chains of object handling: a chain of movements taking an item of clothing from a basket to place it on the ironing board, a chain of movements of the iron, a chain of movements of the pieces of clothing that are being ironed, and a chain of movements of folding the ironed clothes. Similarly, the higher-level action of watching TV and the higher-level action of interacting with her daughter are being constructed through a number of chains of lower-level actions.

Some of these many chains of lower-level actions happen simultaneously to construct one and the same higher-level action, as for example, when the chain of head movements coincides with the chain of gaze shifts when Anna either glances at the interviewer or at the TV. Alternatively, some of the chains of lower-level actions are coordinated with two (or more) higher-level actions, as for example, the chain of gesture units can only be performed when Anna's hands are free, and the iron is placed on the ironing board. When the iron is placed on a piece of clothing during the gesture, the gesture has to be performed at great speed, so that the piece of clothing does not burn. Thus, coordination and timing are of great importance when crossing chains of lower-level actions that simultaneously construct different higher-level actions.

\section{Practices}

Each higher-level action is part of a practice. The higher-level action of telling about herself can be portrayed as the practice of a sociolinguistic interview or, for Anna, the telling of personal narratives, or the telling of narratives in general. ${ }^{6}$ The higher-level action of ironing can be described as the practice of ironing, or as part of the practice of being a housewife (in Germany). The higher-level action of interacting with her daughter can be viewed as the practice of mothering, or can again be described as part of the practice of being a housewife. The higherlevel action of watching a soap opera, or of watching TV in the morning, again falls under the rubric of the practice of being a housewife.

Each practice is embedded in the historical development of the society. The practices, according to which Anna produces her actions of ironing, interacting 
with her daughter, and watching TV in the morning, display some of the normative historical meanings of a nuclear family within Anna's community of practice (Lave and Wenger, 1991), which in turn is embedded within the normative historical meaning of a nuclear family within German society. The practice of telling a narrative, on the other hand, can be theorized as happening on an overarching level, as it is not limited to housewives, but is in fact a practice that is acquired by each and every person through family interaction and schooling.

All practices are embedded in a person's habitus, and all practices show signs of power structures within family, community, and society. As Bourdieu (2001: 37 ) points out, '[t]he effect of symbolic domination (whether ethnic, gender, cultural or linguistic, etc.) is exerted not in the pure logic of knowing consciousness but through the schemes of perception, appreciation and action that are constitutive of habitus.'

\section{Social identity}

Anna's actions, consistent with the practices that they (re)construct, also give us insight into Anna's social identity. The action of telling a narrative both displays Anna's identity as an interviewee (complying with the request to talk about her own perceived identity) and her self-perceived identity as a housewife. The actions of ironing, watching TV in the morning, and interacting with her daughter, also display Anna's identity as a housewife.

\section{Perception of male domination}

When we now take a closer look at the narrative sections above, we find that Anna problematizes the concept of the 'housewife' and male domination. There, Anna says, 'I didn't want to become a . . . housewife, and make myself dependent upon a husband, I didn't want any of that.' Here, the power relationship, the dependency of housewife upon husband is directly addressed. But, what is more, here Anna portrays agency and free will through her choice of wordings.

Then she goes on by saying, 'but then I met Robert at some point and then suddenly all principles were overthrown and then suddenly everything was completely different.' As soon as Robert is introduced in the narrative, the voice shifts to passive, illustrating that some unknown force brought about a great change in her life. Here, agency and free will are no longer claimed.

In this section of the social narrative, Anna depicts the historical development of her social identity from not wanting to become a housewife to ending up in exactly that position, and in doing so assigns the historical development of her social actions from past to current as progressing towards the normative social identity of a housewife. While the normative male/female power-difference and 
male domination in a nuclear family is addressed directly, and agentively contested in the beginning of the excerpt, Anna shifts to a passive voice later on, when she adopts just that normative power difference. Thus, as soon as Anna introduces Robert in the narrative, she speaks with a less powerful voice.

The second section of Anna's transcribed narrative (lines 12-22), where she starts by saying 'and I am as .. content as ever with everything I do.' - Anna again uses active voice. She starts listing, 'I am happy with my household, I am happy with the party service,' and then displays hesitance in the next two lines, saying 'as a balance to here- household and family life?' - as marked by the glottal stop after 'here' and the rising intonation after 'family life.' The following three lines are produced at a much slower speed, with several short pauses and elongations (lines 18-20), where she says 'while I do:n't . see . this as .. a:hm .... how shall I pu:t it, .. as an opportunity to make myself here ..' - then she speeds up (in lines 21-22), uttering an 11-word-long intonation unit, saying 'financially independent from Robert that's not AT ALL what this is about.' - emphasizing the word(s) 'at all.' The speed in lines 21-22 and the emphasis demonstrate that Anna believes that she does not want to be financially independent. She then continues with her narrative, explaining that she only works as a caterer sometimes, and only works because she enjoys it.

This narrative projects the narrator's identity elements. Like a boomerang, Anna's narrative veers away from her portrayed identity as a housewife, when she comments that she is happy with the party service, only to slow down in lines 16 and 17 and reverse course, slowing down even more in lines 18-20, before returning at fast speed to the current identity location of the narrator in lines 21 and 22 .

Here, Anna's talk evidences the social norm of a housewife being dependent upon a husband as a conscious decision, pointing to the self as agent with a free will. In other words, this section of the narrative points to the self as transcending the social norms of society through free will and as a meaning-making conscious agent. As Bourdieu points out:

Symbolic power cannot be exercised without the contribution of those who undergo it and who only undergo it because they construct it as such. But . . . one has to also take note of and explain the social construction of cognitive structures which organize acts of construction of the world and its powers. It then becomes clear that, far from being the conscious, free, deliberate act of an isolated 'subject', this practical construction is itself the effect of a power, durably embedded in the bodies of the dominated in the form of schemes of perception and dispositions (to admire, respect, love, etc.) which sensitizes them to certain symbolic manifestations of power.

(Bourdieu, 2001: 40) 
When we follow this thought, we can surmise that Anna's display of free will, in expressing her desire to take on the normative submissive position of housewife and of not wanting to be financially independent from her husband, is a social construction that is deeply embedded in a society's history. Likewise, when Anna constructs her agency in the first section of the narrative by explaining that she had not wanted to take on the submissive role of housewife and to become dependent upon a husband in her youth, she in fact portrays herself as a normal youth. Youth in Germany at the time when Anna was growing up commonly contested social norms of the nuclear family. Here again, we can claim that the agency that is depicted, or the free will of not wanting to be dominated by a male partner that is expressed, actually is a manifestation of social behavior that is deeply rooted in the communities of practice that the individual belongs to.

But next we want to ask ourselves what happens when an individual suddenly leaves a community of practice? In the following example, Sandra is moving from a house to an apartment because of her divorce. By profession, Sandra is an architect, an artist and a part-time caterer with her friend Anna. ${ }^{7}$ She considers herself a stay-at-home mother, however, and schedules her work around her children. Before separation she and her husband had assumed stereotypical gender roles.

\section{'he never let me do anything like this'}

At the moment of this excerpt, loud music is playing, and Sandra is sitting on the floor, setting up the computer and telephone, as depicted in the second image of Figure 18.1. ${ }^{8}$ The researcher is sitting across from her in a chair, and Sandra's sons are playing in the hallway. Only Sandra is speaking, and has just declared, 'he never let me do anything like this.' Before Sandra puts all the pieces back into the boxes and stops working on the computer, she says, 'I will manage to do this.' gets up from the floor and concludes, 'I'll continue there later.'

\section{Actions and practices}

During this brief excerpt, Sandra performs several simultaneous higher-level actions: she works on the computer, interacts with the researcher, and watches her children, who are playing in the hallway. Some of the chains of lower-level actions are overlapping, so that Sandra's talk about the computer, for example, partly constructs the higher-level action of working on the computer and simultaneously partly constructs the higher-level action of interacting with the researcher. Certainly, we can see that each higher-level action is also part of a practice.

The action of working on a computer is embedded in the practice of computer use; the action of interacting with the researcher can be viewed as the practice of interacting with a familiar person in general; and the action of watching her 


\section{Sigrid Norris}

children falls within the practice of mothering. ${ }^{9}$ However, while Sandra is without a doubt constructing the higher-level actions of interacting and mothering as practices, she does not construct the higher-level action of working on the computer within a common practice. She has not (yet) acquired the knowledge that is necessary to perform such actions within a practice. Here, she is (still) a novice within the community of practice of computer users. She calls specialists or friends for help, reads instruction manuals with great care, and tries to decipher abbreviations like 'the USB,' which are taken-for-granted within the community of practice.

\section{Social identity, levels of discourse, and perception of male domination}

Sandra's higher-level action of working on the computer is an attempt to acquire a new practice and, as pointed out earlier in the chapter, actions and practices allow us to perceive an individual's social identity. When we consider the first general statement - 'he never let me do anything like this' - which Sandra utters before she starts working on the computer, we find that the talk projects her own historical development of a social identity from wife to divorcee, and from acceptance of the symbolic power of male domination to learning to overcome it. While Sandra and her now ex-husband had enacted normative gender roles and Sandra had taken on the identity of a housewife, she now explains her obvious non-belonging to the community of practice of computer users by fusing normative male behavior with technical knowledge.

When we take this utterance, and then look closer at her actions of working on the computer, we see that Sandra is doing something that she stated she could not do while she was married. As Bourdieu (2001:38) points out, 'the dominated, often unwittingly, sometimes unwillingly, contribute to their own domination by tacitly accepting the limits imposed.' While Sandra no longer accepts the prior perceptions of imposed limits, she has not yet acquired the necessary - in her perception "normatively male' ${ }^{10}$ - practices that allow her to live her life as a single mother without constant struggle and frustration. During this time of learning new practices, Sandra takes on the identity of a divorcee.

This divorcee identity can be seen as a temporary social identity, which was invoked as soon as Sandra's identity of wife was negated, but her identity as a single mother was not yet developed. This temporary divorcee identity is displayed at three different levels: the general, which is constructed through actions that concern the divorce by and large; the continuous, which is constructed through long-term actions, whose starting points coincide with the divorce and are permanent; and the immediate, which is constructed through performing actions that Sandra's ex-husband used to perform. These levels of identity can be thought 
of as vertical constructions, ${ }^{11}$ where the general builds the highest level, the continuous builds the mid-level, and the immediate builds the lowest level.

When linking the utterance - 'he never let me do anything like this' - to her actions of doing this, Sandra displays a general divorcee identity. She also constructs this general divorcee identity by listening to the music, as the lyrics, 'I wanted love, but it's gonna kill me, you swear you're faithful, that was a lie, you've cheated on me with half of this city, you aren't worth it, bye-bye,' suggest. Simultaneously, Sandra's actions of working on the computer are due to, and in the middle of, her move out of her house into an apartment. The move is a longterm action that has its starting point in the divorce and which is permanent. Thus, the mid-level of a continuous divorcee identity is constructed. Concurrently, Sandra works on the computer, which is a task that her ex-husband used to perform, which constructs her immediate divorcee identity.

While these three vertically constructed levels of her divorcee identity are constructed through the duration of the various actions, these levels of identity are also constructed through various communicative modes simultaneously in a moment of time. The most obvious level in a moment of time is the lowest level or the immediate identity construction: Sandra is working on the computer, displaying her frustration with the task through her intonation, facial expression, and her use of print, as well as gesture. However, when you take a close look at the surroundings in image 2 of Figure 18.1, you will see moving boxes, stacks of clothing, books, paint brushes, and much more. This layout 'tells' of the move that Sandra is going through, and allows us to observe that this very moment is simultaneous to, and part of, a vertically higher level of action. Now, when we observe that at this very moment loud music is playing, and when we consider Sandra's account during playback when she was asked about the music - 'yes. I needed that. he yells everything out. my frustration had to go somewhere. when he yells, that makes me feel better instantly.' - we can be sure that Sandra's choice of music displays her general divorcee identity. The lyrics, the hard rock, the intensity, and the volume all depict the general frustration that Sandra is feeling at that moment. Thus, Sandra's divorcee identity is particularly salient at this time because it is constructed on three vertical levels simultaneously.

\section{Projection to the future and perception of male domination}

Looking at the utterance of the excerpt, when Sandra stops working on the computer and says - 'I will manage to do this.' - her utterance projects to the future, which is evident by her use of the future tense. While the utterance can be seen as just projecting the future outcome of her current actions of setting up the computer, it can also be interpreted as simultaneously operating on both higher levels of discourse, indicating that Sandra will manage to complete the move and will 


\section{Sigrid Norris}

manage to learn new practices that enable her to live as a single mother. When taking these higher levels of discourse into consideration, we can see that this utterance projects Sandra's future development of her social identity as a single mother. This utterance then, projects away from her current actions and her current identity of a divorcee, to her new, not yet mastered identity of a single mother.

Because of the divorce, the accepted male domination in Sandra's life, as practiced throughout the time that she was married, was suddenly absent, leaving her identity without the known boundaries and limits. This vacuum led her to reconstruct her identity from housewife to single mother. However, in order to accomplish this task, she had to go through stages of learning new practices and with them new schemes of perception.

Such a period of learning also brings with it many struggles and much frustration, which can be read off her facial expression, or can be heard in the music that she is listening to. During this period of learning, Sandra constructs a semi-new identity, the divorcee identity. This identity formation runs through phases from housewife to single mother and is in a constant flux; it is a continuum, which entails part of the single mother identity from the very beginning of change, and elements of the housewife identity even at the point when the identity of a single mother is fully constructed.

The stages of the divorcee identity are visible in the long-term study when taking a closer look at the vertical constructions (Norris, 2002b). While initially all three levels of a divorcee identity are present almost constantly, the immediate, and also the continuous construction of this temporary identity fade away with time, while the general divorcee identity changes and eventually becomes fully reconstructed as the single mother identity.

The stages of the divorcee identity are also visible when we look around the apartment. For example, we find a painting that Sandra produced early on in the divorce process, which she called 'Family.' This painting depicts a mother and two children. She often looks at the painting and says 'that is our family.' She also depicts one-adult-two-children families in some of her other paintings. Such repetition appears to have two functions: first, Sandra seems to be trying to come to terms with her new family structure; and, simultaneously, she is providing her children with a new scheme of perception, making the new family structure real in her art and through her verbal declarations.

Sandra's assurances that a family can exist consisting of one adult and two children contradict the norms of the nuclear family which are deeply embedded in the historical social development of the society. And, the depiction of this family structure in her art supplies this non-normative family structure with permanence, giving it more reality than the mode of language alone would be able to provide.

Here, Sandra actively constructs a new single mother identity. Her actions, even in the moment of the above excerpt, portray agency. Her utterance - 'I will 
manage to do this.' - emphasizes this agency. Nevertheless, Sandra did not take a completely agentive role in the higher-level action of constructing her divorcee identity. This non-agentive side becomes obvious in much of her talk (outside of this example) and also in the music and the lyrics 'you've cheated on me with half of this city.' She had not anticipated having to change her social identity from housewife to single mother, in fact, and she uses her art to re-construct her own understanding of a family. Thus, agency, although practiced in the immediate does not necessarily coincide with agency in higher levels of discourse.

However, the projected agency that Sandra portrays in her immediate actions, developing new practices, enables her to cultivate new perceptions and to readjust her habitus. As Sandra moves through the phases from housewife to single mother, the acquired one-adult-two-children family structure becomes the norm for this family unit, and Sandra constructs a clear single mother identity.

\section{Conclusion}

These two examples demonstrate that habitus, social identity construction, and perceived male domination are interconnected. While agency and free will are projections of the individual that are often constructed through the communicative mode of language, such portrayed agency and free will appear to be deeply embedded within society and the communities of practice which the individual belongs to, so that we need to question whether we can speak of agency and free will at all.

The above excerpts show two seemingly contrasting examples. While Anna's excerpt could be taken to illustrate that depicted agency and free will may have little to do with conscious decision, Sandra's excerpt could be taken to show that agency and free will are linked to choice. We may presume that Sandra could also have constructed her identity in different ways; she could have held on to the perceived imposed limits that she had accepted during marriage, and thus embraced male domination and the composition of a nuclear family as a given. There are many imaginable identity constructions that she could have adopted, yet, she chose this one. However, thinking about Anna once more, we may also conclude that she chose to take on the identity of a housewife wholeheartedly, to embrace the norms of society, and not infringe on expectations. We can reasonably argue that Anna chose to watch TV during the interview, or we can say that she chose to iron the family's clothing at that very moment. Individuals choose many of their actions on a moment-by-moment basis, yet, we can argue that their choice often is limited by their internalized perceptions, social and cultural norms, and social histories, which are all intertwined in an individual's identity construction. Even though agency and free will may only be possible in a limited way for any individual, it does appear to be an important aspect in 


\section{Sigrid Norris}

identity construction, and, as Dostoevsky has pointed out so splendidly, when arguing in his most poetic way on grounds of agency: 'One's own free unfettered choice, one's own fancy ... that is that very "most advantageous advantage", (Dostoevsky, 1960: 23).

In mediated discourse analysis, we take the mediated action as our unit of analysis, which focuses on the 'social actors as they are acting' (R. Scollon, 2001) and emphasizes the irresolvable dialectic between action and the material means that mediate social action (Wertsch, 1998; R. Scollon, 2001). Many actions that an individual performs, or to put it in other terms, most mediated actions, at least in part, are a result of some choice - however minute - that the social actor performing the actions has arrived at. This leads to the conclusion that agency and free will are just as much an aspect of a person's identity construction, as the habitus that makes this very choice possible for the individual.

\section{Notes}

1 I am using the term 'male domination' in this chapter, because the two women focus on this aspect. However, we could certainly (and maybe more accurately) speak of female submissiveness in these cases, as Deborah Tannen has kindly pointed out to me.

2 I would like to thank Maurice Nevile for his helpful comments on an earlier draft of this chapter.

3 While the actual study was completed after a year, I am in contact with Sandra on a regular basis, and my understanding of her identity construction is informed by this continuous contact.

4 Also, see some discussion of this moment in Norris, 2004 Analyzing multimodal interaction: a methodological framework, London: Routledge, p. 55 (where the image was first published in Plate 2.9) where I discuss the function of proxemics.

5 I continue with the line-numbering to make it easier for the reader to follow the argument later.

6 Certainly, Anna's narrative is unavoidably tied up with the trajectory of my relationship with her, with my socio-cultural position and gender; however, in this chapter I do not focus on this aspect.

7 Please note that Sandra perceives the catering as a profession, while Anna perceives it as a pastime.

8 This image was first published in Norris, 2004 Analyzing multimodal interaction: A methodological framework, London: Routledge, p. 85 (Plate 4.1).

9 I claim here that Sandra performs this action as part of the practice of 'mothering' while I claim in the above example that Anna performs the very same action of watching her children as part of the practice of 'being a housewife,' as this is the view that the social actors themselves take.

10 Sandra no longer believes that working on the computer is a 'male practice.'

11 I speak here of vertical (simultaneous) constructions - which, in fact are hierarchical constructions - to differentiate them from horizontal (simultaneous) constructions which may also be hierarchical. 


\section{Agency: questions and mini projects}

\section{Questions for discussion}

1 S. Scollon argues that agency is distributed over participants, times, mediational means and discourses. Give an example of what she means by this and discuss the implications for this in assigning responsibility for our own and others' actions.

2 S. Scollon cites Blommaert in arguing that one way that power is exercised is by controlling the timescales upon which agency is represented. Explain how this occurs.

3 Explain the relationship between actions, practices, and social identity in light of Norris's argument.

4 Given that agency is deeply embedded in the social practices of the communities in which individuals participate, do you think that we can speak of individual agency and free will?

\section{Mini projects}

1 Choose an action in your everyday life and analyze how agency is distributed in this action on three timescales: the longer cultural/ historical timescale of the mediational means, setting and participants, the intermediate timescale of the personal histories of the individuals involved, and the timescale of the interaction order.

2 Ask a person you know to record a brief autobiography. Analyze their account, noting how they assign agency in regard to different aspects of their lives and how their participation in particular communities of practice affects how agency is enacted and represented. 



\section{Methodology and concluding remarks}

Mediated discourse analysis 



\title{
19 Methodological principles and new directions in MDA
}

\author{
Sigrid Norris and Rodney H. Jones
}

\section{MDA: methodological principles}

The method mediated discourse analysis uses to attempt to answer the theoretical questions about discourse and social action outlined in the introduction of this book, is referred to as nexus analysis (Scollon and Scollon, 2004). ${ }^{1}$ Rather than a strict methodology, nexus analysis is a set of heuristic tools that aim to guide researchers as they position themselves in relationship to research participants, to the questions being asked, and to the actions and discourse that will shape their data. In fact, as evidenced by the chapters in this volume, MDA makes a point of eschewing dogmatism when it comes to methodology, making room for the analyst to introduce any data collection and analytical tools they deem useful within MDA's broad focus on social action.

Scollon and Scollon (2004) divide nexus analysis into three basic steps: (1) engaging the nexus of practice; (2) navigating the nexus of practice; and (3) changing the nexus of practice. Each of these steps is really a kind of reflective process, involving a multitude of contingencies and constant interactive decision making on the part of the researcher. Since each nexus of practice is different, mediated discourse analysts must, to a large degree, be prepared to chart their own courses through those they are studying, applying whatever means seem appropriate given the knowledge that they have at any given point.

The first step, engaging the nexus of practice, requires researchers to come to a clear understanding of their own relationship with the nexus of practice they aim to study. Mediated discourse analysis does not presuppose the kind of clinical objectivity many approaches in the social sciences do but, rather, presupposes the opposite: that the researcher will always have some kind of stake in what they are studying and that the research process requires constant reflection on the nature of this stake and the kinds of perspectives and limitations it gives rise to. Scollon and Scollon (2004) call this reflective process 'establishing the zone of identification,' a zone within which the interests of the researcher and the interests of the participants somehow overlap. 


\section{Sigrid Norris and Rodney H. Jones}

Establishing a zone of identification is also the first step to achieving an emic (or insider's (Pike, 1967)) point of view on the kinds of actions, mediational means and discourses that will arise as the focus of the study. From their 'zone of identification,' the researcher gradually enters more into the life-worlds of the participants - learning from them which actions are critical to produce certain social identities and how to bring about social change for that group.

Research in mediated discourse analysis, therefore, is always participatory (Jones, 2002c; Jones et al., 1997). Participants in the nexus of practice being studied are not viewed as objects to be studied, but rather as co-researchers who have a crucial say in deciding what the research is about. For the researcher, this means being relentless in examining their own interests and biases and prioritizing the actions, tools and discourses to be studied, not based on those that are of interest to them, but based on those that are central to the lived experiences of the participants.

This initial step of identifying those actions, tools and discourses may include any number of methods including a review of media texts about the issue or issues the researcher is interested in, informal observation at relevant sites, individual or group interviews and surveys of participants. It is important, however, for the researcher to remember that the purpose of such techniques is not to 'gather data,' but rather, to get an idea, in collaboration with participants, about the contours of the interaction order (Goffman, 1983; Scollon and Scollon, 2004) to be studied and the kinds of discourses and other mediational means that cycle through it. In other words, the point of this exercise is not to collect data, but to determine the kinds of data that will need to be collected.

The second stage, what Scollon and Scollon (2004) call 'navigating the nexus of practice,' is where the researcher begins engaging in data collection and analysis. Unlike many other approaches where the processes of data collection and data analysis are seen as discrete, in mediated discourse analysis, data analysis is ongoing, constantly informing the kinds of data that need to be gathered.

As can be seen in the chapters throughout this volume, what distinguishes data in mediated discourse analysis is that it is multimodal and multiperspectived (Jones, 2001c). In other words, data are frequently gathered in a number of different modes (audio, visual, textual) and from different points of view or subjectivities (which often correspond to Ruesch and Bateson's (1968) 'four kinds of ethnographic data': members' generalizations about their behavior at this nexus of practice; the experiences of individual participants; 'objective' observations by the researcher; and comparisons between the researcher's point of view and that of participants).

The kinds of analytical processes that guide this gathering of data include the analysis of persons (their histories and habits and the role the actions under examination play in their lives); the analysis of discourse and other mediational 
means (using one or more of the approaches to discourse analysis discussed in the introduction to this book, with a particular emphasis on how discourse is 'resemiotized' or transformed into objects and social practices); the analysis of trajectories and timescales (the ways actions act as points along historical movements of action, discourse and mediational means); and the analysis of motives (the examination of how the 'force' for actions is distributed among social actors, cultural tools and discourses over time and space).

This stage also crucially involves participants. In order to verify the usefulness of the direction in which we are heading with our data collection and analysis, the researcher stops at incremental points along the way to share their findings in some form that is accessible to participants and discusses with them how closely the researcher's understanding matches their own.

Scollon and Scollon call the final step in nexus analysis 'changing the nexus of practice,' emphasizing the underlying goal of all mediated discourse analysis to produce positive social change. It is important to note that 'changing the nexus of practice' is conceptualized as part of the research process rather than simply as a byproduct of it, and thus it is to be approached with the same attitude of openmindedness, reflexivity and contingency.

Indeed, this process of change is something that actually begins in the first stage. From the moment researchers enter the nexus of practice, they are changing it in some way. Their actions, such as recording conversations, taking visual images, collecting objects and texts and doing discourse analysis, are actions within the nexus of practice. Mediated discourse analysts are, in a sense, always analyzing (and inviting participants to analyze) their own actions. Much of what is to be done in this final stage, therefore, involves exploring how the nexus of practice already has changed over the course of the research: how the relationships between researcher and participants and among participants have changed, and how both researchers and participants approach mediated actions within this nexus given the kinds of perspectives on those actions that have developed through the research.

Research in mediated discourse analysis is an exercise in resemiotizing or transforming actions through reflection and analysis. The semiotic transformations produced by the analysis are subsequently resemiotized into 'new actions' or new ways of doing things or seeing things, both on the part of the researcher, and on the part of the participants. Thus, for Scollon and Scollon (2004: 178), this final step is really a reconfiguration of the question with which the researcher begins: 'What actions can you take as a participant-analyst in this nexus of practice that will transform discourses into actions and actions into new discourses and practices?' This transformation is never a matter of the analyst taking unilateral action to change the nexus of practice in a way that is more to their liking but, rather, a matter of working together with participants to produce a heightened awareness of the problems and the possibilities that the nexus of practice presents. 


\section{Sigrid Norris and Rodney H. Jones}

\section{New directions in MDA}

This book has delineated some new directions in mediated discourse analysis, presenting work by scholars from diverse disciplines such as conversation analysis and ethnomethodology, linguistic anthropology, psychology, and sociolinguistics. Such disciplinary diversity illustrates that MDA is not just another narrow disciplinary subfield but, rather, an approach that links many different perspectives in the social sciences, allowing for - and even demanding - interdisciplinarity.

While some disciplinary and sub-disciplinary divisions encourage the researcher to consider their research objectives quite narrowly, MDA - as an overarching approach to discourse - allows the incorporation of theoretical and methodological perspectives from any given social discipline or sub-discipline without binding the researcher to narrow boundaries. With this book, then, we have attempted to highlight the value of interdisciplinarity in two ways: first, we have included chapters that draw from diverse disciplines; and second, we have included chapters from authors who are themselves proponents of an interdisciplinary approach.

When looking back at the preceding 18 chapters, it becomes apparent that all of the scholars included are particularly concerned with the concepts of time and place (or space) in their attempts to understand: (1) the everyday mediated actions people perform; (2) the mediational means that people use; (3) the practices that become evident through people's actions; (4) the sites of engagement that are being constructed through actions, practices and mediational means; and (5) the agency that is distributed, or sometimes displayed within singular actions. This focus is doubly important as it represents an important new direction in mediated discourse analysis. Therefore, we would like to end by reviewing how the authors have grappled with these issues.

\section{Time}

Ron Scollon illustrates (in Chapter 3) that actions are rhythmically entrained to at least the following six different (but integrated) pace-makers (Zeitgeber): the cardiac-respiratory cycle: pulsations of the heart and of breathing; the metabolic cycle: ebbs and flows of ingestion, digestion, and elimination, pain cycles, drowsiness cycles; the circadian cycle: 24-hour revolution of the earth about its axis; the lunar cycle: 28-day revolution of the moon about the earth; the solar cycle: 365-day revolution of the earth about the sun; and entropic cycles: formation and decay of material substances.

In Chapter 4, Maurice Nevile shows that utterances and manual actions can simultaneously function in smaller as well as larger action sequences, displaying timed layering of actions. Consequently, he illustrates how simultaneous actions can be multiply sequenced in real-time. 
Ingrid de Saint-Georges, on the other hand, looks at anticipatory discourse and the resulting actions in Chapter 15, delineating a process-oriented view of the construction of several landmark events - or sites of engagement - conceived as space/time stations. Thus, she focuses on the trajectories that result from, and are part of, anticipation and real-time actions.

In Chapter 18, Sigrid Norris illustrates that a person usually performs simultaneous actions, which all may have a different starting and end-point and be of a different duration - picturing actions of different duration as vertical constructions that are partially performed in real-time and partially performed (and interpreted and re-interpreted) in the histories of the individuals. Furthermore, she links personal and societal histories with real-time actions.

\section{Place/Space}

James V. Wertsch discusses Vygotsky's two approaches to mediation (in Chapter 6), calling it 'explicit' and 'implicit' mediation (i.e. human social versus mental processes). While we may not be able to speak of place/space in the traditional sense here, this differentiation is one of space after all: external of a human's mind, and therefore explicit; or internal of a human's mind, and therefore implicit. While such distinction is never absolute, the distinction between social space and mental space is of great importance, because these two forms of mediation operate in different ways and have different implications.

Paul Mcllvenny and Pirkko Raudaskosky explore place/space on two levels: first, they look at virtual space in their chapter on adoption (Chapter 7); and second, they investigate the actual movement of an adopted child from one place to another. The place/space distinction, however, between virtual and actual, quickly becomes blurred as they show how one is not necessarily distinct from the other.

Theo van Leeuwen illustrates in Chapter 8 how reading paths are largely structured by the composition - of a museum room or a CD Rom - showing that there are specific constraints within the place/space that is available for the reader's use.

Laurent Filliettaz also essentially investigates the constraints and affordances of place/space in Chapter 10, when he discusses a specific service encounter. He surmises that service encounters are best conceived as a combination of both typified social knowledge and interpersonal negotiation, in which language intersects with other mediational means - one of which would be space.

In Chapter 12, Shawn Rowe also concerns himself with affordances and constraints, investigating hybrid activity spaces and their implications for understanding agency in learning. Such hybrid activity spaces - which are not places may be, but do not have to be, shared, constructing situated meaning. 


\section{Sigrid Norris and Rodney H. Jones}

Time and place/space

Jay Lemke develops a conceptual framework in Chapter 11, within which to give accounts of how the prior coherence of places and of the discursive imaginaries of multi-scale projects help to constitute meaning through time. Thus, prior understanding of time and place make the creation of meaning through time and place possible without, however, restricting it to the prior experience.

Rodney H. Jones illustrates in Chapter 14 that participants construct sites of engagement for particular practices through fairly durable patterns of orientation or attention structures - towards different places/spaces and different timescales. In his argument, attention structures of the participants organize time and place/space.

Suzie Scollon shows in Chapter 17 how agency is distributed through time and space. Similar to Norris's point (above), she integrates the history of the participants and also incorporates the various places that social actors embody because of their personal histories. She further combines the times and places of the mediational means (here the census), illustrating a vast complexity.

\section{A last note}

When we set out to put this volume together, we had in mind to write a book that demonstrates the diversity of scholarship that is essential for MDA. We further wanted to make the book accessible to a diverse readership without assuming a prior knowledge of mediated discourse analysis.

Now, looking back, we see that the book has accomplished much more than we had set out to accomplish: the book illustrates the concern of all authors in this volume with the concepts of time and place/space - no matter which disciplinary direction they come from. Such concern with these major concepts ties each chapter to the others, constructing this book as even more of a complete whole than we had hoped for.

\section{Note}

1 For a more detailed outline on how to conduct a nexus analysis, see Scollon and Scollon, 2004. 


\title{
20 Postscript
}

\author{
Gunther Kress
}

In reading Discourse in Action I cannot but feel a near overwhelming sense of a mounting 'wave' of research and writing signalling the beginning of entirely new ways of conceiving of meaning and representation, in short, of the significance of human social action. Many of the disciplines invoked in the book will be recognizable to its readers - forms of discourse analysis, Vygotskian psychology, ethnography of different kinds, semiotics, conversation analysis, multi-modal analyses, post-modern philosophy. Yet, in this book they appear not as distinct 'takes' on an issue, as discrete modes of working in autonomously constituted fields, but as a new, 'combined' means of dealing with the issues raised by a field newly sketched. As the editors put it in their framing introduction, mediated discourse analysis approaches the question of how discourse is a matter of social action by posing two questions: "The first question it asks is "What is/are the action(s) that is/are being taken here?" and only after answering this question does it go on to ask: "What is the role of discourse in this/those action?"

From the perspective of much or most work in the last century, it is to stand things on their head - or maybe from a present perspective at long last to realize which way round is the right way up. It makes it possible to treat the question of representation and communication as one kind of social action among all other kinds of social action, to see all social action as the making of meaning. That is the achievement of the editors of the volume. They, clearly, have a sense of a necessary new framing of the problem-domain. And, clearly, some of the contributors share that perspective too; and the work of all the contributors is well integrated into the jigsaw of that new picture.

My own history in the area of representation starts with the battle of Linguistics, in Australia and in the UK, to gain 'acceptance' and 'respectability' in the academic community. In the 1960 s this was done - in the mainstream versions of the discipline - around the question of the autonomy of the discipline through an assertion of language as a phenomenon, itself, autonomous from the domain of the social. What was the case for Linguistics may have been true for other 


\section{Gunther Kress}

disciplines in their different ways. In Discourse in Action the question 'what is to be accounted for' is radically different to that question posed in the 'contributor disciplines' represented here when acting on their home turf, so to speak. Discourse analysis, for all its concern with social environments or psychological location, remains focused on the abstraction, 'discourse'; sociolinguistics, for all its attention to the social, remains, in the end, focused on the linguistic linked to the social. In this book these approaches are brought together to work jointly, in multiple overlays, connections and inter-weavings. In other words, a new domain is being staked out, the domain of human action as meaning.

Domains set the boundaries of the field of enquiry, and in that field those who do the work develop the means and tools they need for their task. The tools that are available at any moment are always those that come from domains differently defined, tools made to do different kinds of jobs, the tools of the past. So if at times there is a lack of fit of (old) tool to (new) task then that is how it is bound to be: the old has to furnish the means for dealing with the new. Theories are not invented in a void; theories are responses by those who face specific problems to the need to deal with the problem. And if new ways of seeing the world emerge and they produce new problems, then, here in this book, that is faced head on. In his early chapter Ron Scollon writes: 'actions are always complex, never simple, and, second, the relationships between discourse and non-discursive action are also complex.' He, like others in the book, then proceeds to confront that complexity in pretty uncompromising ways: starting with the - in other theoretical frames unlikely - example of fitting a new wooden floor in their house, he moves from that to hiring a tool, the floor-nailer, and soon we are in a world where the social, the biological and the physical worlds all interact and impinge on this anything but autonomous and isolatable event. But by then we are in a world in which there are, as yet, no theoretical floor-nailers, ready to hand and easy to hire.

I am suggesting that we are witnessing a paradigm-shift, and we might as well be aware of it. This book is one instance among others: it is strongly inspired by the work of Ron and Suzie Scollon (as, for instance, in their most recent Nexus Analysis); but it takes inspiration also from the work of those who work in the 'New Literacy Studies'; from Wertsch's neo-Vygotskian work; and from Jim Gee's 'expansion' of work on Discourse, and on representation in conjunction with digital media. Close to my interests, there is the work around the multiple means for representation, the work in Multimodality, moving away from the focus on 'language' alone.

All this suggests a kind of Kuhnian paradigm-shift. Yet, what I think is happening is less the challenge to one paradigm and its final inability to cope, than something new happening somewhere else. In other words, neither Linguistics nor Discourse Analysis are being challenged directly; nor do I think that they will crumble away 
in the short term. Rather, a new means of working with a new set of issues in a newly configured field is developing alongside these established, and still dominant, enterprises. There are attempts to set forth new paradigms, at least in outline, as I have indicated. As yet the modes of working of the contributor disciplines are still recognizably discrete, not yet unified, not as yet an emergent new theory. All is yet to play for. This book is laying down some clear markers of where and how the work should be happening. In that it makes its strong contribution.

GRK, 31 August 2004 


\section{References}

Akhutina, T.V. (1975) Neirolingvisticheskii analiz dinamicheskoi afazii (The neurolinguistic analysis of dynamic aphasia), Moscow: Izdatel'stvo Moskovskogo Gosudarstvennogo Universiteta.

Al Zidjaly, N. (2002) 'The construction of the mental patient identity in the prepatient phase in Oman,' paper presented at Sociolinguistics Symposium 14, Ghent, Belgium, April 4-6.

Al Zidjaly, N. (2005) 'Communication across ability-status: a nexus analysis of the coconstruction of agency and disability in Oman,' $\mathrm{PhD}$ dissertation, Georgetown University: UMI.

Anagnost, A. (2000) 'Scenes of Misrecognition: maternal citizenship in the age of transnational adoption,' Positions: East Asia Cultures Critique, 8(2): 389-421.

Anderson, R.J., Hughes, J.A. and Sharrock, W.W. (1989) Working for Profit: the social organisation of calculation in an entrepreneurial firm, Aldershot: Avebury.

Anscombe, G. Elisabeth M. (1957) Intention, Oxford: Blackwell.

Arel, D. (2002) 'Language categories in censuses: backward- or forward-looking?,' in D. Ikertzer and D. Arel (eds), Census and Identity: the politics of race, ethnicity, and language in national censuses, Cambridge: Cambridge University Press, pp. 92-120.

Aston, G. (ed.) (1988) Negotiating Service. Studies in the Discourse of Bookshop Encounters, Bologna: CLUEB.

Aubert, N. and Roux-Dufort, C. (2003) Le culte de l'urgence. La société malade du temps, Paris: Flammarion.

Austin, J.L. (1962) How to do Things with Words, Oxford: Oxford University Press.

Bakhtin, M.M. (1981) The Dialogic Imagination: four essays by M.M. Bakhtin, translated by C. Emerson and M. Holquist, edited by M. Holquist, Austin, TX: University of Texas Press.

Bakhtin, M.M. (1981a) 'Discourse in the novel,' in M. Holquist (ed.), The Dialogic Imagination, Austin, TX: University of Texas Press.

Bakhtin, M.M. (1981b) 'Forms of time and of the chronotope in the novel,' in M. Holquist (ed.) The Dialogic Imagination, Austin, TX: University of Texas Press.

Bakhtin, M.M. (1984) Problems of Dostoevsky's Poetics, Manchester: Manchester University Press.

Bakhtin, M.M. (1986) Speech Genres and Other Late Essays, translated by V.W. McGee, edited by C. Emerson and M. Holquist, Austin, TX: University of Texas Press. 
Barnes, S.B. (2003) Computer Mediated Communication, Boston: Allyn \& Bacon.

Barthes, R. (1977) Image, Music, Text, London: Fontana.

Bartlett, F.C. (1932) Remembering: a study in experimental and social psychology, Cambridge: Cambridge University Press.

Bartlett, T. (2004) 'Collaborative Power in Intercultural Development Fora,' paper presented at the Sociolinguistic Symposium, Newcastle upon Tyne, UK: April 1-4.

Barton, D. and Hamilton, M. (1998) Local Literacies: reading and writing in one community, London: Routledge.

BASI (Bureau of Air Safety Investigation) (1996) Boeing 747-312 VH-INH, Sydney (Kingsford Smith) Airport, New South Wales, 19 October 1994, Investigation Report 9403038, Department of Transport and Regional Development, Australia.

Bateson, G. (1972) Steps to an Ecology of Mind, New York: Ballantine.

Berlant, L. (1997) The Queen of America Goes to Washington City: essays on sex and citizenship, Durham, NC: Duke University Press.

Bernstein, B. (1990) The Structure of Pedagogic Discourse: class, codes and control, Vol. VI, London: Routledge.

Blommaert, J. (2004) Discourse: a critical introduction, Cambridge: Cambridge University Press.

Bollinger, D. (1990) Hardwood Floors: laying, sanding, and finishing, Newtown, CT: Taunton Press.

Bolter, J.D. and Grusin, R. (1999) Remediation: understanding new media, Cambridge, MA: MIT Press.

Boswood, T. (2000) 'Strategic writing and organizational identities,' PhD dissertation, City University of Hong Kong, Department of English.

Bourdieu, P. (1972 [1977]) Outline of a Theory of Practice, Cambridge: Cambridge University Press.

Bourdieu, P. (1990) The Logic of Practice, Stanford, CA: Stanford University Press.

Bourdieu, P. (2001) Masculine Domination, Stanford, CA: Stanford University Press.

Braudel, F. (1969) 'Histoire et sciences sociales: La longue durée,' in Ecrits sur l'histoire, Paris: Flammarion, 41-83 (original in Annales E.S.C., XIII, 4, oct.-déc. 1958, 725-753).

Braudel, F. (1981) The Structures of Everyday Life: the limits of the possible (Civilization and Capitalism, Vol. I), New York: Harper \& Row.

Brittanica (1992) The New Encyclopaedia Brittanica, 15th edition, Chicago: Encyclopaedia Brittanica, vol. 3: 22-23.

Bruner, J. (1990) Acts of Meaning, Cambridge, MA: Harvard University Press.

Burke, K. (1950) A Rhetoric of Motives, Englewood Cliffs, NJ: Prentice-Hall.

Burke, K. (1966) Language as Symbolic Action: essays on life, literature and method, Berkeley, CA: University of California Press.

Burke, K. (1969 [1945]) A Grammar of Motives, Englewood Cliffs, NJ: Prentice-Hall.

Button, G. (ed.) (1993) Technology in Working Order: studies of work, interaction, and technology, London: Routledge.

Callon, M. (1991) 'Techno-economic Networks and Irreversibility,' in J. Law (ed.) A Sociology of Monsters: Essays on Power, Technology and Domination, London: Routledge.

Campbell, C. (1996) The Myth of Social Action, Cambridge: Cambridge University Press. 


\section{References}

Cartwright, L. (2003) 'Photographs of "waiting children": the transnational adoption market,' Social Text, 21(1): 84-109.

Cheng, T. and Selden, M. (1997) 'The construction of spatial hierarchies: China's Hukou and Danwei systems,' in T. Cheek and T. Saich (eds) New Perspectives on State Socialism in China, Armonk, NY: M.E. Sharpe.

Chouliaraki, L. and Fairclough, N. (1999) Discourse in Late Modernity: rethinking critical discourse analysis, Edinburgh: Edinburgh University Press.

Cicourel, A. (1992) 'The interpenetration of communicative contexts: examples from medical encounters,' in A. Duranti and C. Goodwin (eds), Rethinking Context: language as an interactive phenomenon, Cambridge: Cambridge University Press, pp. 291-310.

Clark, K. and Holquist, M. (1984) Mikhail Bakhtin, Cambridge: Cambridge University Press.

Cole, M. (1990) 'Cultural psychology: a once and future discipline?' in J.J. Berman (ed.) Nebraska Symposium on Motivation, 1989: Cross-cultural Perspectives, Lincoln: University of Nebraska Press, vol. 37, 279-335.

Cole, M. and Levitin, K. (in press) The autobiography of Alexander Luria: a dialogue with the making of mind (Preface), Mahwah, NJ: Lawrence Erlbaum Associates.

Couper-Kuhlen, E. and Selting, M. (eds) (1996) Prosody in Conversation: interactional studies, Cambridge: Cambridge University Press.

Crang, M. and Thrift, N. (2000) Thinking Space, London: Routledge.

Crosby, A.W. (1994) Germs Seeds \& Animals: studies in ecological history, Armonk, NY and London: M.E. Sharpe.

Dant, T. and Francis, D. (1998) 'Planning in organisations: rational control or contingent activity?' Sociological Research Online 3: 2. www.socresonline.org.uk/socresonline/ 3/2/4.html

Davies, B. and Harré, R. (1990) 'Positioning: the discursive production of selves,' Journal for the Theory of Social Behavior 20(1): 43-63. Retrieved Janurary 24, 1999 from www. massey.ac.nz/ Alock/position/position.htm

de Fornel, M.(1993) 'Intentions, plans et action située,' in P. Ladrière, P. Pharo and L. Quéré (eds), La théorie de l'action. Le sujet pratique en débat, Paris: CNRS éditions, pp. 85-99.

de Saint-Georges, I. (2003) 'Anticipatory discourses: producing futures of action in a vocational program for long-term unemployed,' $\mathrm{PhD}$ dissertation, Georgetown University: UMI.

de Saint-Georges, I. (2004) 'Materiality in discourse: the influence of space and layout in making meaning,' in P. LeVine and R. Scollon (eds), Discourse Analysis and Technology: multimodal discourse analysis. Georgetown University Round Table on Languages and Linguistics 2002, Washington, DC: Georgetown University Press, pp. 71-87.

de Saint Georges, I. and Norris, S. (1999) 'Literate design and European identity: visual practices of an imagined community,' International Visual Sociology Association Annual Conference. Antwerp, July 14-18.

Dewey, J. (1938) Logic: the theory of inquiry, New York: Holt, Rinehart and Winston.

Dorow, S.K. (2002) 'China 'R' Us'?: care, consumption, and transnationally adopted children,' in D.T. Cook (ed.), Symbolic Childhood, New York: Peter Lang.

Dostoevsky, F. (1960) Notes from Underground and The Grand Inquisitor, New York: E.P. Dutton. 
Drew, P. and J. Heritage (eds) (1992) Talk at Work: interaction in institutional settings, Cambridge: Cambridge University Press.

Dulong, R. (1993) 'La constitution du futur dans le présent des interactions,' in P. Ladrière, P. Pharo and L. Quéré (eds) La théorie de l'action. Le sujet pratique en débat, Paris: CNRS Editions, pp. 223-233.

Dumas, I. (2001) 'Contexts in which gestures appear in service interactions,' paper presented at the Gesture Workshop, London, April 18-20.

Duranti, A. and Goodwin, C. (eds) (1992) Rethinking Context. Language as an interactive phenomenon, Cambridge: Cambridge University Press.

Eco, U. (1979) The Role of the Reader, Bloomington, IN: Indiana University Press.

Eggins, S. (1994) An Introduction to Systemic-Functional Grammar, London: Pinter.

Engeström, Y. and Middleton, D. (eds) (1996) Cognition and Communication at Work, Cambridge: Cambridge University Press.

Erickson, F. (2004) 'Origins: a brief intellectual and technological history of the emergence of multimodal discourse analysis,' in P. Levine and R. Scollon (eds), Georgetown University Round Table on Languages and Linguistics 2002: Discourse and Technology: Multimodal Discourse Analysis, Washington, DC: Georgetown University Press, pp. 196-207.

Fairclough, N. (1989) Language and Power, London: Longman.

Fairclough, N. (1992) Discourse and Social Change, Cambridge: Polity Press.

Fairclough, N. (1995) Critical Discourse Analysis, London: Longman.

Fairclough, N. and Wodak, R. (1997) 'Critical discourse analysis,' in T.A. van Dijk (ed.), Discourse as Social Interaction, London: Sage, pp. 258-284.

Filliettaz, L. (2002) La parole en action: Elements de pragmatique psycho-sociale, Quebec: Editions Nota Bene (www.notabene.ca).

Filliettaz, L. (2003) 'Action, cognition and interaction. The expression of motives in bookshop encounters,' in C. Inchaurralde and C. Florén (eds), Interaction and Cognition in Linguistics, Frankfurt: Peter Lang, pp. 51-62.

Filliettaz, L. (2004a) 'The multimodal negotiation of service encounters,' in P. Le Vine and R. Scollon (eds), Georgetown University Round Table on Languages and Linguistics 2002: Discourse and Technology: multimodal discourse analysis, Washington, DC: Georgetown University Press.

Filliettaz, L. (2004b) 'Temps, rythme et contexte: interface pragmatique ou interference épistémologique?' paper presented at the Colloque interfaces pragmatiques. Genève, February 12-14.

Filliettaz, L. (2004c) 'The construction of requests in transactional settings. A discursive approach,' in C. Gouveia et al. (eds) Discourse, Communication and the Enterprise: linguistic perspectives, Lisbon: ULICES, pp. 79-97.

Filliettaz, L. (2004d) 'La sémiologie de l'action au service de l'analyse des textes procéduraux'. Cahiers de la section des sciences de l'éducation 103, pp. 147-187.

Filliettaz, L. and Roulet, E. (2002) 'The Geneva Model of Discourse Analysis: an interactionist and modular approach to discourse organization,' Discourse Studies 4(3): 369-392.

Freidlander, M. L. (1999) 'Ethnic Identity Development of Internationally Adopted Children and Adolescents: Implications for Family Therapists,' Journal of Marital and Family Therapy, 25(1): 43-60. 


\section{References}

FSF (Flight Safety Foundation) (1997) 'Flight crew's failure to perform landing checklist results in DC-9 wheels-up landing,' Accident Prevention, 54(5): 1-15.

Fung, H.H.T. (1994) 'The socialization of shame in young Chinese children,' PhD dissertation, University of Chicago, Department of Psychology, Committee on Human Development.

Garfinkel, H. (1967) Studies in Ethnomethodology, Englewood Cliffs, NJ: Prentice Hall.

Gee, J.P. (1996) Social Linguistics and Literacies (2nd edition), London: Taylor \& Francis.

Gee, J.P. (1999) An Introduction to Discourse Analysis: theory and method, New York: Routledge.

Gibson, W. (1984) Neuromancer, New York: Ace Books.

Gilbert, N. (1997) 'A simulation of the structure of academic science,' Sociological Research Online, 2: 2. www.socresonline.org.uk/socresonline/2/2/3.html

Goffman, E. (1959) The Presentation of Self in Everyday Life, New York: Doubleday.

Goffman, E. (1961) Behavior in Public Places: notes on the social organization of gatherings, New York: Free Press.

Goffman, E. (1963) Stigma: notes on the management of spoiled identity, Englewood Cliffs, NJ: Prentice Hall.

Goffman, E. (1974) Frame Analysis, New York: Harper \& Row.

Goffman, E. (1975) Frame Analysis: an essay on the organization of experience, Cambridge, MA: Harvard University Press.

Goffman, E. (1981) Forms of Talk, Philadelphia: University of Pennsylvania Press.

Goffman, E. (1983) 'The interaction order,' American Sociological Review 48: 1-17.

Goldhaber, M. (1997) The attention economy and the net, available online at: http: / / firstmonday.dk/issues/issue2_4/goldhaber/ (downloaded 2 June 2000).

Goodwin, C. (1981) Conversational Organization: interaction between speakers and hearers, New York: Academic Press.

Goodwin, C. (1995) 'Seeing in depth,' Social Studies of Science, 25: 237-274.

Goodwin, C. (1996) 'Transparent vision,' in E. Ochs, E.A. Schegloff and S.A. Thompson (eds), Interaction and Grammar, Cambridge: Cambridge University Press.

Goodwin, C. (2000) 'Action and embodiment within situated human interaction,' Journal of Pragmatics, 32: 489-522.

Goodwin, C. (2002) 'Time in action,' Current Anthropology, 43 (Supplemental special issue: repertoires of timekeeping in anthropology), S19-S35.

Goodwin, C. and Goodwin, M.H. (1996) 'Seeing as a situated activity: formulating planes,' in Y. Engeström and D. Middleton (eds), Cognition and Communication at Work, Cambridge: Cambridge University Press.

Grosz, E. (1999) 'Becoming . . . an introduction,' in: E. Grosz (ed.), Becomings: explorations in time, memory and futures, Ithaca and London: Cornell University Press, pp. 1-11.

$\mathrm{Gu}$, Y. (2002) 'Towards an understanding of workplace discourse - a pilot study for compiling a spoken Chinese corpus of situated discourse,' in C. Candlin (ed.), Research and Practice in Professional Discourse, Hong Kong: The City University of Hong Kong Press.

Gülich, E. and Quasthoff, U. (1986) 'Story-telling in conversation. Cognitive and interactive aspects,' in E. Gülich and U. Quasthoff (eds), Narrative Analysis. An interdisciplinary dialogue, Poetics 15. Amsterdam: North Holland, pp. 217-241. 
Gumperz, J. (1982a) Language and Social Identity, Cambridge: Cambridge University Press. Gumperz, J. (1982b) Discourse Strategies, Cambridge: Cambridge University Press.

Gumperz, J. (1999) 'On interactional sociolinguistic method,' in S. Sarangi and C. Roberts (eds), Talk, Work and Institutional Order. Discourse in Medical, Mediation and Management Settings, Berlin: Mouton de Gruyter, pp. 453-471.

Gumperz, J. (2001) 'Interactional sociolinguistics: a personal perspective,' in D. Schiffrin, D. Tannen and H. Hamilton (eds), The Handbook of Discourse Analysis, Oxford: Blackwell, pp. 215-228.

Gumperz, J. and Hymes, D. (eds) (1986) Directions in Sociolinguistics: the ethnography of communication, Oxford: Blackwell.

Gunderson, L. and Holling, C.S. (eds) (2002) Panarchy: understanding transformations in human and natural systems, Washington, DC: Island Press.

Habermas, J. (1984) The Theory of Communicative Action, London: Heinemann.

Hägerstrand, T. (1978) 'Survival and arena,' in T. Carlstein, D. Parkes and N. Thrift (eds), Human Activity and Time Geography, New York: John Wiley \& Sons, pp. 122-145.

Hall, E.T. (1959) The Silent Language, Garden City, NY: Doubleday.

Hall, E.T. (1966) The Hidden Dimension, Garden City, NY: Doubleday.

Hall, E.T. (1976) Beyond Culture, Garden City, NY: Anchor Press.

Halliday, M.A.K. (1973) Explorations in the Functions of Language, London: Edward Arnold.

Halliday, M.A.K. (1976) System and Function in Language, London: Oxford University Press.

Halliday, M.A.K. (1978) Language as Social Semiotic, London: Edward Arnold.

Halliday, M.A.K. (1994) An Introduction to Functional Grammar, London: Edward Arnold.

Halliday, M.A.K. and Hasan, R. (1976) Cohesion in English, London: Longman.

Hamman, R.B. (1998) 'The on-line/off-line dichotomy: debunking some myths about AOL users and the effects of their being on-line upon off-line friendships and off-line community,' unpublished MPhil. thesis, University of Liverpool.

Hanks, W. (1996) Language and Communicative Practices, Boulder, CO: Westview Press.

Hanks, W. (2001) 'Indexicality,' in Duranti, A. (ed.) Key Terms in Language and Culture, Oxford: Blackwell, 119-121.

Harré, R. (1998) The Singular Self: an introduction to the psychology of personhood, London: Sage.

Hasan, R. (1978) 'Text in the systemic-functional model,' in W.U. Dressler (ed.), Current Trends in Text Linguistics, Berlin: de Gruyter, pp. 228-246.

Heath, S.B. (1983) Ways with Words: language, life and work in communities and classrooms, Cambridge: Cambridge University Press.

Heath, C. and Luff, P. (2000) Technology in Action, Cambridge: Cambridge University Press.

Heideggger, M. (1996) Being and Time (J. Stambaugh, trans.), New York: SUNY Press. Heller, A. (1995) 'Where We Are at Home,' Thesis Eleven, 41: 1-18.

Heritage, J. (1989) 'Current developments in conversation analysis,' in Roger, Derek and P. Bull (eds), Conversation: an interdisciplinary perspective, Clevedon: Multilingual Matters.

Hine, C. (2000) Virtual Ethnography, London: Sage.

Ho, P. (1959) Studies on the Population of China, 1368-1953, Cambridge, MA: Harvard University Press. 


\section{References}

Holmes, M.E. (1995) 'Naming virtual space in computer-mediated communication,' Review of General Semantics 52(2): 212-222.

Holquist, M. and Emerson, C. (1981) 'Glossary of: M.M. Bakhtin,' The Dialogic Imagination: four essays by M.M. Bakhtin, Austin, TX: University of Texas Press.

Howell, S.L. (1999) 'Biologizing and de-biologizing kinship: some paradoxes in Norwegian transnational adoption,' in A.-L. Rygvold, M. Dalen and B. Sætersdal (eds), Mine - Yours - Ours and Theirs: adoption, changing kinship and family patterns, Oslo: Department of Special Needs, University of Oslo.

Howell, S.L. (2003) 'Kinning: the creation of life trajectories in transnational adoptive families,' Journal of the Royal Anthropological Institute, 9: 465-484.

Hsu, F.L.K. (1953) Americans and Chinese: passage to differences, Honolulu: University Press of Hawaii.

Husserl, E. (1992) On the Phenomenology of the Consciousness of Internal Time (J. B. Brough, trans.), London: Blackwell.

Hutchby, I. and Wooffitt, R. (1998) Conversation Analysis: principles, practices and applications, Cambridge: Polity Press.

Hutchins, E. (1995a) Cognition in the Wild, Cambridge, MA: MIT Press.

Hutchins, E. (1995b) 'How a cockpit remembers its speeds,' Cognitive Science, 19: 265-288.

Hutchins, E. and Klausen, T. (1996) 'Distributed cognition in an airline cockpit,' in Y. Engeström and D. Middleton (eds), Cognition and Communication at Work, Cambridge: Cambridge University Press.

Hutchins, E. and Palen, L. (1997) 'Constructing meaning from space, gesture, and speech,' in L.B. Resnick et al. (eds), Discourse, Tools, and Reasoning: essays on situated cognition, Berlin: Springer.

Hymes, D. (1986) 'Models of the interaction of language in social life,' in J. Gumperz and D. Hymes (eds), Directions in Sociolinguistics: the ethnography of communication, Oxford: Blackwell, pp. 35-71.

Iedema, R. (2001) 'Resemiotization,' Semiotica 137(1/4): 23-39.

Iedema, R. (2003) 'Multimodality, resemiotization: extending the analysis of discourse as multi-semiotic practice,' Visual Communication 2(1): 29-57.

Johnson, A. (2002) 'Modalities of identity negotiation in U.S. immigration interviews,' paper presented at Sociolinguistics Symposium 14, Ghent, Belgium, April 4-6.

Johnstone, B. (1990) Stories, Community, and Place: narratives from middle America, Bloomington, IN: Indiana University Press.

Jones, R. (1999) 'Mediated action and sexual risk: searching for "culture" in discourses of homosexuality and AIDS prevention in China,' Culture, Health \& Sexuality 1(2): $161-180$

Jones, R. (2001a) 'Beyond the screen: a participatory study of computer-mediated communication among Hong Kong youth,' paper presented at the Annual Meeting of the American Anthropological Association, Washington, DC, November 28-December 2.

Jones, R. (2001b) 'Mediated action and sexual risk: discourses of AIDS and sexuality in the People's Republic of China,' unpublished $\mathrm{PhD}$ dissertation, Macquarie University.

Jones, R. (2002a) 'A walk in the park: frames and positions in AIDS prevention outreach among gay men in China,' Journal of Sociolinguistics 6(3): 575-588. 
Jones, R. (2002b) 'Imagined comrades: negotiating practices and identities around sexuality in HIV in China,' paper presented at Sociolinguistics Symposium 14, Ghent, Belgium, April 4-6.

Jones, R. (2002c) 'Theories and perspectives in community empowerment,' Perspectives: working papers in English and communication 14(2): 142-147.

Jones, R. (2003) 'Interactivity: how new media can help us undertand old media', paper presented at the International Conference of Historical Linguistics, Copenhagen, August 11-15.

Jones, R. (2004a) 'The problem of context in computer mediated communication,' in P. Levine and R. Scollon (eds), Georgetown University Round Table on Languages and Linguistics 2002: Discourse and Technology: Multimodal Discourse Analysis, Washington, DC: Georgetown University Press, pp. 20-33.

Jones, R. (2004b) 'The multimodal construction of identity in on-line gay chat environments,' paper presented at Sociolinguistics Symposium 15, Newcastle-upon-Tyne, April 1-4.

Jones, R. and Candlin, C. (2002) 'The construction of risk in gay men's accounts of sexual encounters,' paper presented at the Sociolinguistics Symposium 14, Ghent, April 4-6.

Jones, R. and Candlin, C.N. (2003) 'Constructing risk along timescales and trajectories: gay men's stories of sexual encounters,' Health, Risk and Society 5(2): 199-213.

Jones, R., Scollon, R., Yung, V., Li, D. and Tsang, W.K. (1997) 'Tracing the voices of Hong Kong's transition with subject-run focus groups,' paper presented at the Second Symposium on Intercultural Communication, Beijing Foreign Studies University, October 10-15.

Karlsson, A.-M. (2002) 'Web literacy, web literacies or just literacies on the web? Reflections from a study of personal homepages,' The Reading Matrix, 2(2) [Online]. Available: www.readingmatrix.com/articles/karlsson/index.html.

Kress, G. and van Leeuwen, T. (1996) Reading Images: the grammar of visual design, London: Routledge.

Kress, G. and van Leeuwen, T. (2001) Multimodal Discourse: the modes and media of contemporary communication, London: Edward Arnold.

Kress, G. and van Leeuwen, T. (2002) 'Colour as a semiotic mode: notes for a grammar of colour', Visual Communication 1(3): 343-369.

Labov, W. (1972) The Transformation of Experience in Narrative Syntax. Language in the Inner City, Philadelphia: University of Pennsylvania Press.

Ladrière, P. (2001) 'La théorie de l'agir communicationnel et l'éthique de la discussion. Vers de nouveaux rapports entre éthique et économie,' in P. Ladrière (ed.), Pour une sociologie de l'éthique, Paris: Presses Universitaires de France, pp. 275-316.

Lanham, R.A. (1993) The Electronic World: democracy, technology and the arts, Chicago: The University of Chicago Press.

Lankshear, C. and Knobel, M. (2003) New Literacies: changing knowledge and classroom learning, Philadelphia: Open University Press.

Lantolf, J.P. (ed.) (2000) Sociocultural Theory and Second Language Learning, Oxford: Oxford University Press.

Latour, B. (1987) Science in Action, Cambridge, MA: Harvard University Press.

Latour, B. (1993) We Have Never Been Modern, London: Harvester Wheatsheaf. 


\section{References}

Latour, B. (1999) Pandora's Hope: essays on the reality of science studies, Cambridge, MA: Harvard University Press.

Latour, B. (2003) 'Is re-modernization occurring - and if so, how to prove it?: a commentary on Ulrich Beck,' Theory, Culture \& Society, 20(2): 35-48.

Lave, J. and Wenger, E. (1991) Situated Learning: legitimate peripheral participation, Cambridge: Cambridge University Press.

Leeman J. (2003) Journal of Language and Politics, 3(3) 507-534.

Lefebvre, H. (1991) The Production of Space, translated by D. Nicholson-Smith, Oxford: Blackwell.

Lemke, J.L. (1995) Textual Politics: discourse and social dynamics. London: Taylor \& Francis.

Lemke, J.L. (1999) 'Typological and topological meaning in diagnostic discourse,' Discourse Processes 27(2): 173-185.

Lemke, J.L. (2000a) 'Across the scales of time: artifacts, activities, and meanings in ecosocial systems,' Mind, Culture, and Activity 7(4): 273-290.

Lemke, J.L. (2000b) 'Opening up closure: semiotics across scales,' in J. Chandler and G. van de Vijver (eds), Closure: emergent organizations and their dynamics, New York: New York Academy of Sciences, pp. 100-111.

Lemke, J.L. (2002a) 'Discursive technologies and the social organization of meaning,' Folia Linguistica 35(1-2): 79-96.

Lemke, J.L. (2002b) 'Travels in hypermodality,' Visual Communication 1(3): 299-325.

Lemke, J.L. (2003) 'The role of texts in the technologies of social organization,' in R. Wodak and G. Weiss (eds), Theory and Interdisciplinarity in Critical Discourse Analysis, London: Macmillan/Palgrave, pp. 130-149.

Lemke, J.L. (2004) 'Critical analysis across media: games, franchises, and the new cultural order,' paper presented at the First International Conference on Critical Discourse Analysis, Valencia, Spain.

Lemke, J.L. (in press a) 'Towards critical multimedia literacy: technology, research, and politics,' in M. McKenna, D. Reinking, L. Labbo and R. Kieffer (eds), Handbook of Literacy \& Technology, v2.0, Mahwah, NJ: Erlbaum.

Lemke, J.L. (in press b) 'Video epistemology in-and-outside the box: traversing attentional spaces,' in R. Goldman-Segall and R. Pea (eds), Video Research in the Learning Sciences, Mahwah, NJ: Erlbaum.

Leont'ev, A.N. (1932) 'Studies on the cultural development of the child,' Journal of Genetic Psychology 40: 52-83.

Leont'ev, A.N. (1978) Activity, Consciousness, and Personality, Englewood Cliffs, NJ: Prentice-Hall.

Lerner, G. (in press) 'On the place of linguistic resources in the organization of talk-ininteraction: grammar as action in prompting a speaker to elaborate,' Research on Language and Social Interaction, 37 (2).

Levinson, S.C. (1978) 'Activity types and language,' Pragmatics microfiche 3: 3-3 D1-G5.

Linell, P. (1998) Approaching Dialogue: talk, interaction, and contexts in dialogical perspectives, Amsterdam: John Benjamins.

Luck, M. (1990) Your Child and Success at School, Sydney: Murdoch Books.

Lukes, S. (1977) 'Methodological individualism reconsidered,' in S. Lukes (ed.), Essay in Social Theory, New York: Columbia University Press, pp. 177-186. 
Luria, A.R. (1975) Osnovnye problemy neirolingvistiki (Basic problems of neurolinguistics), Moscow: Izdatel'stvo Moskovskogo Gosudarstvennogo Universiteta.

McLuhan, M. (1964) Understanding Media: the extensions of man, New York: McGraw-Hill.

McNeill, D. (1992) Hand and Mind: what gestures reveal about thought, Chicago: University of Chicago Press.

MacPherson, M. (1998) The Black Box: cockpit voice recorder accounts of in-flight accidents, London: HarperCollins.

Martin, J.R. (1992) English Text - System and Structure, Amsterdam: Benjamins.

Martinec, R. (1998) 'Cohesion in action,' Semiotica 120(1/2): 161-180.

Martinec, R. (2000) 'Types of process in action,' Semiotica 130(3/4): 243-268.

Martinec, R. (2001) 'Interpersonal resources in action,' Semiotica 135(1/4): 117-145.

Martinec, R. (2003) 'The social semiotics of text and image in Japanese and English software manuals and other procedures,' Social Semiotics 13(1): 43-71.

Martsinkovskaya, T.D. (1996) 'Gustav Gustavovich Shpet - life as a creative problem,' in Shpet, G.G. (1996) Psikhologiya sotsial'nogo bitiya: Izbrannye psikhologicheskie trudy (The psychology of social being: collected psychological works), (edited by T.D. Martsinkovskaya) Moscow-Voronezh: Institut prakticheskoi psikhologii.

Merleau-Ponty, M. (1945/1962) Phenomonology of Perception (C. Smith and F. Williams, trans. revised, 1981, ed.), London: Routledge.

Meyrowitz, J. (1985) No Sense of Place: the impact of electronic media on social behavior, New York: Oxford University Press.

Middleton, D. and Brown, S. (2001) The Baby as Virtual Object: Agency and Accountability in a Neonatal Care Unit, http://devpsy.lboro.ac.uk/psygroup/sb/baby.htm, last accessed January 26, 2005.

Moore-Ede, M.C., Sulzman, F.M. and Fuller, C.A. (1982) The Clocks That Time Us: physiology of the circadian timing system, Cambridge, MA: Harvard University Press.

Morley, D. (2000) Home Territories: media, mobility and identity, London: Routledge.

Mulkay, M. (1986) 'Conversations and texts,' Human Studies 9: 303-321.

Nemeth, T. (1997) 'Gustav Shpet (1879-1937),' The Internet Encyclopedia of Philosophy, www.iep.utm.edu/

Nevile, M. (2004) Beyond the Black Box: talk-in-interaction in the airline cockpit, Aldershot: Ashgate.

Nishida, K. (1958) Intelligibility and Philosophy of Nothingness, Tokyo: Maruzen.

Norman, Don A. (1993) 'Les artefacts cognitifs,' in Bernard Conein, Nicolas Dodier and Laurent Thévenot (eds), Les objets dans l'action. De la maison au laboratoire, Paris: EHESS, pp. $15-34$.

Norris, S. (2002a) 'A theoretical framework for multimodal discourse analysis presented via the analysis of identity construction of two women living in Germany,' PhD dissertation, Georgetown University: UMI.

Norris, S. (2002b) 'The orchestration of identities through multiple modes,' paper presented in the colloquium 'Modalities of Access' at the Sociolinguistic Symposium 14, Ghent, Belgium, April 4-6.

Norris, S. (2004a) 'Multimodal discourse analysis: a conceptual framework,' in P. Levine and R. Scollon (eds), Georgetown University Round Table on Languages and Linguistics 2002: 


\section{References}

Discourse and Technology: Multimodal Discourse Analysis, Washington, DC: Georgetown University Press, pp. 101-115.

Norris, S. (2004b) Analyzing Multimodal Interaction: a methodological framework, London and New York: Routledge.

OED (1993) The New Shorter Oxford English Dictionary on Historical Principles, vol. 1, A-M, Lesley Brown (ed.), Oxford: Clarendon Press.

O'Toole, M. (1994) The Language of Displayed Art, Leicester: Leicester University Press.

Pan, Y.L. (2003) 'Sociolinguistic research and survey development,' paper presented at American Association for Applied Linguistics, Arlington, Virginia.

Pan, Y.L. and Scollon, S. (2004) 'Opening the circumference of census taking: a nexus analysis,' paper presented at the Annual Conference of the American Association of Applied Linguistics, Portland, OR, May 1-4, 2004.

Peirce, C.S. (1998) The Essential Peirce: selected philosophical writings (Vol. 2), Bloomington, IN: Indiana University Press.

Penuel, W.R. and Wertsch, J.V. (1995) 'Dynamics of negation in the identity politics of cultural other and cultural self,' Culture and Psychology 1: 343-359.

Pike, K. (1967) Language in Relation to a Unified Theory of the Structure of Human Behavior, The Hague: Mouton.

Randolph, T. (2000) 'Mediated discourse analysis: the social actor as mediational means in agents' habitus,' paper presented in the colloquium 'Mediated Discourse: An Integrated Theory of Sociolinguistic Action' at Sociolinguistics Symposium 2000, Bristol, April 27-29.

Resnick, L.B., Levine, J.M. and Teasley, S.D. (eds) (1991) Perspectives on Socially Shared Cognition, Washington, DC: American Psychological Association.

Resnick, L.B., Säljö, R., Pontecorvo, C. and Burge, B. (eds) (1997) Discourse, Tools, and Reasoning: essays on situated cognition, Berlin: Springer.

Rogoff, B. (1990) Apprenticeship in Thinking: cognitive development in social context, Cambridge: Cambridge University Press.

Rommetviet, R. (1988) 'On literacy and the myth of literal meaning,' in R. Säljö (ed.) The Written Word: studies in literate thought and action, Berlin: Springer, pp. 13-40.

Rommetviet, R. and Blakar, R.M. (eds) (1979) Studies of Language, Thought, and Verbal Communication, London: Academic Press.

Roulet, E., Filliettaz, L. and Grobet, A. (2001) Un modèle et un instrument d'analyse de l'organisation du discours, Berne: Peter Lang.

Rowe, S. (2002) 'Activity and discourse in museums: a dialogic perspective on meaning making,' unpublished $\mathrm{PhD}$ dissertation, Washington University in St Louis.

Rowe, S. (2003) 'Discourse in activity and activity as discourse,' in R. Rogers (ed.), An Introduction to Critical Discourse Analysis, New York: Lawrence Erlbaum, pp. 79-96.

Ruesch, J. and Bateson, G. (1968 [1951]) Communication: the social matrix of psychiatry, New York: W.W. Norton \& Company.

Sacks, H., Schegloff, E. and Jefferson, G. (1974) 'A simplest systematics for the organization of turn-taking for conversation,' Language 50: 696-735.

Salomon, G. (ed.) (1993) Distributed Cognitions: psychological and educational implications, Cambridge: Cambridge University Press. 
Salthe, S. (1993) Development and Evolution, Cambridge: MIT Press.

Saville-Troike, M. (1989) The Ethnography of Communication, Oxford: Basil Blackwell.

Schegloff, E.A. (1972) 'Notes on a conversational practice: formulating place,' in D. Sudnow (ed.) Studies in Social Interaction, New York: Free Press, 75-119.

Schegloff, E.A. (1992) 'In another context,' in A. Duranti and C. Goodwin (eds), Rethinking Context. Language as an interactive phenomenon, Cambridge: Cambridge University Press, pp. 191-227.

Schiffrin, D. (1994) Discourse Markers, Cambridge: Cambridge University Press.

Schiffrin, D. (1996) 'Narrative as self-portrait,' Language and Society 25: 167-203.

Schiffrin, D. (2000) 'Mother/daughter discourse in a holocaust oral history: "because then you admit that you're guilty",' Narrative Inquiry 10(1): 1-44.

Schmidt, R. (2001) 'Attention,' in P. Robinson (ed.), Cognition and Second Language Instruction, Cambridge: Cambridge University Press, pp. 3-32.

Scollon, R. (1997) 'Handbills, tissues, and condoms: a site of engagement for the construction of identity in public discourse,' Journal of Sociolinguistics 1(1): 39-61.

Scollon, R. (1998) Mediated Discourse as Social Interaction, London: Longman.

Scollon, R. (1999) 'Mediated discourse and social interaction,' Research on Language and Social Interaction 32(1\&2): 149-154.

Scollon, R. (2000) 'Mediated discourse: an integrated theory of sociolinguistic action,' paper presented at the Sociolinguistic Symposium, 'The interface between linguistics and social Theory,' Bristol, 27-29 April 2000.

Scollon, R. (2001a) Mediated Discourse: the nexus of practice, London: Routledge.

Scollon, R. (2001b) 'Action and text toward an integrated understanding of the place of text in social (inter)action,' in R. Wodak and M. Meyer (eds), Methods of Critical Discourse Analysis, London: Sage, pp. 139-182.

Scollon, R. (2001c) MDA, Web essay. No longer available on-line.

Scollon, R. (2002a) 'Intercultural communication as mediated action,' paper submitted to Logos and Language.

Scollon, R. (2002b) 'Toward an ethnography of motives,' paper presented at Martin Spector Lecture in Applied Linguistics, October.

Scollon, R. (2002c) What's the Point? Can mediated discourse analysis stop the war? www. gutenbergdump.net/mdp/point.htm

Scollon, R. (2004) 'AAAL: Action, Activity, Activism, and Linguistics,' Plenary Lecture, American Association for Applied Linguistics, Portland, May 1-4.

Scollon, R. and Scollon, S. (1981) Narrative, Literacy and Face in Inter-ethnic Communication, Norwood, NJ: Ablex.

Scollon, R. and Scollon, S. (2001 [1994]) Intercultural Communication: a discourse approach, Oxford: Blackwell.

Scollon, R. and Scollon, S. (2003) Discourses in Place: language in the material world, London: Routledge.

Scollon, R. and Scollon, S. (2004) Nexus Analysis: discourse and the emerging internet, London: Routledge.

Scollon, R., Tsang, W.K., Li, David, Yung, Vicki and Jones, R. (1999) 'Voice, appropriation, and discourse representation in a student writing task,' Linguistics and Education 9(3): 227-250. 


\section{References}

Scollon, S. (1977) 'Langue, idiolect and speech community: three views of the language at Fort Chipewyan, Alberta,' Department of Linguistics, University of Hawaii: Working Papers in Linguistics 9(3): 65-76.

Scollon, S. (1982) 'Reality set, socialization and linguistic convergence,' PhD dissertation, University of Hawaii.

Scollon, S. (2001) 'Habitus, consciousness, agency and the problem of intention. How we carry and are carried by political discourses,' Folia Linguistica XXXV/1-2: 97-129.

Scollon, S. (2003) 'Political and somatic alignment: habitus, ideology and social practice,' in R. Wodak and G. Weiss (eds), Critical Discourse Analysis: theory and interdisciplinarity, Basingstoke, Hampshire: Palgrave Macmillan, pp. 167-198.

Scollon, S. and Scollon, R. (2000) 'The construction of agency and action in anticipatory discourse: positioning ourselves against neo-liberalism,' paper presented at the Third Conference for Sociocultural Research. UNICAMP, São Paulo, Brazil, July 16-20.

Scott, A.H. (1968) Census, U.S.A.: fact finding for the American people, 1790-1970, New York: The Seabury Press.

Searle, J.R. (1969) Speech Acts: an essay in the philosophy of language, Cambridge: Cambridge University Press.

Selman, P. (ed.) (2000) Intercountry Adoption: developments, trends and perspectives, London: British Agencies for Adoption and Fostering.

Selting, M. (2001) 'Fragments of units as deviant cases of unit production in conversational talk,' in M. Selting and E. Couper-Kuhlen (eds), Studies in Interactional Linguistics, Amsterdam/Philadelphia: John Benjamins.

Selting, M. and Couper-Kuhlen, E. (eds) (2001) Studies in Interactional Linguistics, Amsterdam/Philadelphia: John Benjamins.

Shields, R. (2003) The Virtual, London: Routledge.

Shotter, J. (1993) Conversational Realities: Constructing Life Through Language, London: Sage. Shpet, G.G. (1927) Vnutrennyaya forma slova (The internal form of the word), Moscow: Gosudarstvennaya Akademiya Khudozhestvennykh Nauk.

Shpet, G.G. (1996) Psikhologiya sotsial'nogo bitiya: Izbrannye psikhologicheskie trudy (The psychology of social being: collected psychological works), edited by T.D. Martsinkovskaya, Moscow-Voronezh: Institut prakticheskoi psikhologii.

Silverman, D. (2001) Interpreting Qualitative Data: methods for analysing talk, text and interaction, 2nd edition, London: Sage.

Silverstein, M. (1976) 'Shifters, linguistic categories, and cultural description,' in K. Basso and H. Selby (eds), Meaning in Anthropology, Albuquerque: University of New Mexico Press.

Silverstein, M. and Urban, G. (1996) 'The natural history of discourse,' in M. Silverstein and G. Urban (eds), Natural Histories of Discourse, Chicago and London: The University of Chicago Press, pp. 1-17.

Slembrouck, S. (2003) 'Class and parenting in accounts of child protection: a discursive ethnography under construction,' Pragmatics 13(1): 101-134.

Star, S.L. (1997) 'Anselm Strauss: an appreciation,' Sociological Research Online 2: 1, www. socresonline.org.uk/socresonline/2/1/1.html

Strate, L. (1999) 'The varieties of cyberspace: Problems in definition and delimitation,' Western Journal of Communication, 63, 382-413. 
Strathern, M. (1996) 'Cutting the network,' The Journal of the Royal Anthropological Institute (Incorporating Man) 2(3): 517-535.

Street, B. (1984) Literacy in Theory and Practice, New York: Cambridge University Press.

Suchman, L. (1987) Plans and Situated Actions: the problem of human-machine communication, Cambridge: Cambridge University Press.

Suchman, L. (1997) 'Centers of coordination: a case and some themes,' in L.B. Resnick, R. Säljö, C. Pontecorvo and B. Burge (eds), Discourse, Tools, and Reasoning: essays on situated cognition, Berlin: Springer.

Tannen, D. (1980) 'A comparative analysis of oral narrative strategies: Athenian Greek and American English,' in W.L. Chafe (ed.), The Pear Stories: cognitive, cultural and linguistic aspects of narrative production, Norwood, NJ: Ablex Publishing Corporation, pp. 51-87.

Tannen, D. (1984) Conversational style: analyzing talk among friends, Norwood, NJ: Ablex.

Tannen, D. (1993) 'What's in a frame?,' in D. Tannen (ed.), Framing in Discourse, New York: Oxford University Press, pp. 14-56.

Taylor, C. (1985) Human Agency and Language: Philosophical Papers I., Cambridge: Cambridge University Press.

Telfer, J. (1999) 'Relationships with no body? - "adoption” photographs, intuition and emotion,' Social Analysis 43(3): 144-158.

Telfer, J. (2003) 'The imagined child: ambiguity and agency in Australian intercountry adoption,' The Australian Journal of Anthropology 14(1): 72-79.

ten Have, P. (1999) Doing Conversation Analysis: a practical guide, London: Sage.

ten Have, P. and Psathas, G. (eds) (1995) Situated Order: studies in the social organization of talk and embodied activities, Washington, DC: International Institute for Ethnomethodology and Conversation Analysis and University Press of America.

Thibault, P. (2000) 'The multimodal transcription of a television advertisement: theory and practice,' in A. Baldry (ed.), Multimodality and Multimediality in the Distance Learning Age, Campobasso: Palladino Editore.

Thrift, N. (1996) Spatial Formations, London: SAGE Publications.

Turkle, S. (1995) Life on the Screen: identity in the age of the Internet, New York: Simon \& Schuster.

van Dijk, T.A. (1993) 'Principles of critical discourse analysis,' Discourse and Society 4(2): 249-283.

van Dijk, T.A. (2001) 'Critical discourse analysis,' in D. Schiffrin, D. Tannen and H. Hamilton (eds), The Handbook of Discourse Analysis, Oxford: Blackwell, pp. 352-371.

van Leeuwen, T. (1991) 'Conjunctive structure in documentary film and television,' Continuum 5(1): 76-115.

van Leeuwen, T. (1992) 'Genre and field in critical discourse analysis: a synopsis,' Discourse and Society 4(2): 193-225.

van Leeuwen, T. (1999) Speech, Music, Sound, New York: St Martin's Press.

van Leeuwen, T. (2004) 'Ten reasons why linguists should pay attention to visual communication,' in P. Levine and R. Scollon (eds), Discourse and Technology: multimodal discourse analysis, Washington, DC: Georgetown University Press, pp. 7-20.

Ventola, E. (1987) The Structure of Social Interaction: a systemic approach to the semiotics of service encounters, London: Pinter.

Voloshinov, V.N. (1973) Marxism and the philosophy of language, translated by L. Matejka and I.R. Titunik, Cambridge, MA: Harvard University Press. 


\section{References}

Vygodskaya, G.L. and Lifanova, T.M. (1996) Lev Semënovich Vygotskii: Zhizn', deyatel'nost', shtrikhi, i portrety (Lev Semënovich Vygotskii: Life, activity, traits, and portraits), Moscow: Smysl.

Vygotsky, L.S. (1934) Myshlenie i rech': Psikhologicheskie issledovaniya (Thinking and speech: psychological investigations), Moscow and Leningrad: Gosudarstvennoe Sotsial'noEkonomicheskoe Izdatel'stvo.

Vygotsky, L.S. (1962) Thought and Language, Cambridge, MA: MIT Press.

Vygotsky, L.S. (1978) Mind in Society: the development of higher psychological processes, edited by M. Cole, V. John-Steiner, S. Scribner and E. Souberman, Cambridge, MA: Harvard University Press.

Vygotsky, L.S. (1981) 'The instrumental method in psychology,' in J.V. Wertsch (ed.), The Concept of Activity in Soviet Psychology, Armonk, NY: M.E. Sharpe, pp. 134-143.

Vygotsky, L.S. (1982) L.S. Vygotskii. Sobranie sochinenii. Tom pervyi. Problemy teorii I istorii psikhologii (The collected works of L.S. Vygotsky. Volume 1. Problems of theory and history), Moscow: Pedagogika.

Vygotsky, L.S. (1986) Thought and Language, translated by A. Kozulin, Cambridge, MA: MIT Press.

Vygotsky, L.S. (1987) The Collected Works of L.S. Vygotsky. Volume 1. Problems of general psychology. Including the Volume Thinking and Speech, edited and translated by N. Minick, New York: Plenum.

Wallerstein, I. (1983) Historical Capitalism, London: Verso.

Waskul, D.D. (2003) Self-Games and Body-play: personhood in on-line chat and cybersesex, New York: Peter Lang.

Wertsch, J.V. (1984) 'The zone of proximal development: some conceptual issues,' in B. Rogoff and J.V. Wertsch (eds), Childrens' Learning in the 'Zone of Proximal Development,' San Francisco: Jossey-Bass.

Wertsch, J.V. (1985a) Culture, Communication, and Cognition: Vygotskyan perspectives, New York: Cambridge University Press.

Wertsch, J.V. (1985b) Vygotsky and the Social Formation of Mind, Cambridge, MA: Harvard University Press.

Wertsch, J.V. (1991) Voices of the Mind: a sociocultural approach to mediated action, Cambridge, MA: Harvard University Press.

Wertsch, J.V. (1994) 'The primacy of mediated action in sociocultural studies,' Mind, Culture and Activity 1(4): 202-208.

Wertsch, J.V. (1995) 'Mediated action and the study of communication: the lessons of L. S. Vygotsky and M. M. Bakhtin,' The Communication Review 1(2): 133-154.

Wertsch, J.V. (1996) 'The role of abstract rationality in Vygotsky's image of mind,' in A. Tryphon and J. Vonèche (eds), Piaget-Vygotsky: the social genesis of thought, East Sussex: Psychology Press, pp. 25-43.

Wertsch, J.V. (1997) 'Narrative tools of history and identity,' Culture and Psychology 3(1): 5-20.

Wertsch, J.V. (1998) Mind as Action, New York: Oxford University Press.

Wertsch, J., Tulviste, P. and Hagstrom, F. (1993) 'Contexts for learning: sociocultural dynamics in children's development,' in E.A. Forman, N. Minick and C.A. Stone (eds), New York and Oxford: Oxford University Press. 
Wertsch, J.V., del Rio, P. and Alvarez, A. (eds) (1995) Sociocultural Studies of Mind, Cambridge: Cambridge University Press.

Wetherell, M. (2003) 'Paranoia, ambivalence and discursive practices: concepts of position and positioning in psychoanalysis and discursive psychology,' in R. Harré and F. Moghaddam (eds), The Self and Others: positioning individuals and groups in personal, political and cultural contexts, New York: Praeger/Greenwood Publishers.

Williams, P.J. (1994) 'Spare parts, family values, old children, cheap,' New England Law Review 28: 913-927.

Wittgenstein, L. (1972 [1958]) Philosophical Investigations, Oxford: Blackwell.

Wittgenstein, L. (1980) 'Remarks on the philosophy of psychology,' vol. 1, no. 78, cited in J. Shotter (1993) Cultural Politics of Everyday Life: social constructionism, rhetoric and knowing of the third kind, Toronto and Buffalo: University of Toronto Press, p. 83.

Wodak, R. (1996) Disorders of Discourse, London: Longman.

Yelyseieva Tovares, A. (2003) 'Parents' socialization into the discourse of parenting,' paper presented at the American Association of Applied Linguistics, Arlington, VA, March.

Zinchenko, V.P. (2000) Mysl' i slovo Gustava Shpeta (The sense and word of Gustav Shpet), Moscow: Izdatel'stvo YRAO. 


\section{Index}

'Aboriginal guided tour' reading path example 89-93

actants 119

action(s) see social/mediated action(s) activity 117 ; language as 58-59; non-talk $40-43$

activity spaces, hybrid 124, 128-134

actor-network theory (ANT) 63

adoption, transnational 62-72

agency 169-171; in census taking

172-182; and social identity 183-196

airline cockpit example, EM/CA 32-44

'anchorage' 77

ANT see actor-network theory

anticipatory discourse 157-163

artifacts 101, 107-108, 116; semiotic

112-113; see also mediational

means/tools

attention structures 141-154

Bakhtin, Mikhail Mikhailovich 5-6

Barthes, Roland 77

Blommaert, J. 25, 182

Bourdieu, Pierre 50, 152, 190

Braudel, F. 30n.1, 175

Burke, Kenneth 170, 174-175, 176-177

calculation, centers of 70-71

Campbell, C. 160-161

CDA see critical discourse analysis

censuses, and agency 172-182 centers of calculation 70-71

chat rooms 141, 142-143, 144-154

China, censuses 178-180

'China Adoption Referral and Age Graphs' 71

choice/free will 190-191, 195-196

chronotopes 114, 117-119

cockpit example, EM/CA 32-44

cognitive artifacts 107-108

cohesion theory 73

communication: computer mediated 141 ,

142-143, 144-154; ethnography of 7

computer games 121-122; The Sims

114-120

computer mediated communication 141 ,

142-143, 144-154

constraints on action(s) 25

contextualization 100-101; cues, language

125, 126-127, 128; service encounters

101-109

conversation analysis see EM/CA

critical discourse analysis (CDA) 8, 98

cultural tools see mediational means/tools

culture, time/space 143-144

cyberspace 142-154

cycles 21-31; see also time/timescales

Dangerous Creatures reading path example 89-93

deixis 145,147

de Saint-Georges, Ingrid 29, 155-165 
design, faculty of 161-163

diaries, web, adoption 65-66

differential salience 82

discourse(s): anticipatory 157-163;

Vygotsky's approach 52-53

Discourse(s) 10; recognition 127-128

divorcee identity 192-193, 194-195

domination, male 185, 189-196

dual stimulation 56

'elaboration' 77, 79-81

EM/CA 32-44

engagement see sites of engagement

entextualizations see resemiotizations

entrainments 25

ethnography: of communication 7; virtual 63-64

ethnomethodology see EM/CA

événement 30n.1, 175

explicit mediation 54-56, 61

'extension' 77, 79

Filliettaz, Laurent 100-109

floor-nailer example, cycles 21-24, 27-30

Forbidden Colors Task 56

free will/choice 190-191, 195-196

frozen action(s) 17

games: computer 114-122; language as 6 Gee, J.P. 127

gender, power relations 185, 189-196

genre analysis 73-93, 164

Goodwin, C. 33

grammar, systemic-functional 7

Gumperz, J. 123

habitus 50, 152, 189

Hall, Edward T. 27, 143

Halliday, M.A.K. 7

heterochrony 112, 119-120

higher-/lower-level action(s) 17, 21, 36-40, 140, 184-185, 188,

191-195 homepages see websites

Hutchins, E. 55

hybrid activity spaces $124,128-134$

identification, zones of 201-202

identity, social 183-196

Iedema, R. 67

implicit mediation 55, 57-60, 61

inner speech 59-60

interaction, on-line 141, 142-143,

144-154

interactional sociolinguistics 7

internalizations see resemiotizations

internet: adoption $62-72$; chat rooms

141, 142-143, 144-154

interperformativity 153

intersubjectivity 126

Jones, Rodney H. 3-14, 17-19, 49-51, 97-99, 139-140, 169-171; on sites of engagement 141-154; on methodology 201-206

Kress, Gunther 207-209

language(s) 6-7, 20, 21, 101; as activity

58-59; and agency 173-174; censuses

177-178, 181; contextualization cues

125, 126-127, 128; inner form 59-60; linguistic acts 176-177; social 54; Vygotsky's meaning 53

Latour, B. 67

layered simultaneity 24, 30n.1, 142, 175, 182

learning, situation definitions 123-134

Lemke, Jay 110-122

linguistic acts $176-177$

linguistics 6-8, 207-208; cohesion 73; genre 74-76; see also language

literacy studies, new 7-8

longue durée 30n.1, 175

lower-/higher-level action(s) 17, 21, 36-40, 140, 184-185, 188,

191-195 


\section{Index}

male domination 185, 189-196

material tools see mediational means/tools

McIlvenny, Paul 62-72

MDA see mediated discourse analysis

meaning, words 57-60

mediated action(s) see social/mediated action(s)

mediated discourse analysis (MDA) xi, 4-6, 8-12, 20, 63, 71-72, 155, 204-206; and agency 169-171; and contextualization 100-101; and means/tools 49-51; and mediated action 17-19; methodology 201-204; and practice 97-99; and sites of engagement 139-140

mediational means/tools 5, 9-10, 49-51, 99, 101, 159-161; adoption 62-72; multimodality 73-93, 101; Vygotsky's approaches 52-61; see also artifacts

methodology, MDA 201-204

modes, semiotic 73-74

motives, action(s) 105-107

multimodality 73-93, 101

Nevile, Maurice 32-44

new literacy studies 7-8

nexus analysis 4, 63, 64, 72, 99,

201-203; see also social practice(s)

non-talk activities 40-43

Norris, Sigrid 3-14, 17-19, 49-51, 97-99, 139-140, 169-171; on agency

183-196; on methodology 201-206

objects see artifacts

Old Royal Observatory reading path example 85-88

on-line interaction 141, 142-143, 144-154

organization, sequential 32-44

pace see time/timescales

pace-makers see cycles

pitch 36-40

place see space/place power relations 10-11; gender 185, 189-196

practice see social practice(s)

'presence', cyberspace 148

production ability 162 , 163-164

prosody 36-40

psychological tools 49, 52

Raudaskoski, Pirkko 62-72

readiness for action 40-43

reading paths, genres $81-93$

recognition, Discourse(s) 127-128

recontextualizations see resemiotizations

resemiotizations 29-30, 203; adoption 67

Rommetviet, R. 126

Rowe, Shawn 123-134

Royal Observatory reading path example 85-88

salience, differential 82

'scaling', adoption 66-68

Scollon, Ron 18, 100, 101, 105-106, $111,139,141,201,203$; on cycles 20-31

Scollon, Suzie 101, 201, 203; on agency 172-182

semiotic artifacts $112-113$

semiotic modes 73-74

sequential organization 32-44

service encounters 101-109

'shifting', adoption 67

Shpet, Gustav Gustavovich 58-60

The Sims computer game 114-120

simultaneity, layered 24, 30n.1, 142, 175, 182

sites of engagement 139-140; attention structures 141-154; as space/time stations 156-165

situation definitions 123-134

social identity 183-196

social language(s) 54

social/mediated action(s) 3-6, 8-11, 17-19, 101; cycles 20-31; higher-/lower-level 17, 21, 36-40, 
184-185, 188, 191-195; language as 6-7; motives 105-107; sequential organization 32-44; see also social practice(s)

social practice(s) 97-99, 158-159; computer gameworld 110-122; and identity 188-195; service encounters 101-109; situation definitions 123-134; see also nexus analysis; social/mediated action(s)

sociolinguistics see linguistics space/place 27-28, 111-112, 205-206; cyberspace 142-154; hybrid activity spaces 124, 128-134; The Sims 115-116

space/time stations 156-165

speech, inner 59-60

speech act theory 7

spheres of action see space/place

standardization, tools 50-51

stations, space/time 156-165

Sterling, Ralph 71

stimulation, dual 56

synchronization 25-26, 182

systemic-functional theory $7,73-76$

technical tools 49

technologization, tools 50-51

technology, and censuses 176

texts, written 3-4; genres 74-76; multimodality 73-74, 76-81; reading paths $81-93$

theory, as toolkit 110-114

Thought and Language (Vygotsky) 53-54 time/timescales 101, 104-105, 106,

111-112, 204-205, 206; and agency

175, 180-182; chronotopes 114,

117-119; in cyberspace 142-144,

149-154; heterochrony 112, 119-120;

The Sims 116-117; space/time stations

156-165; see also cycles

'toolkits' 6; theories as 110-114

tools/mediational means 5, 9-10, 49-51,

99, 101, 159-161; adoption 62-72;

multimodality 73-93; Vygotsky's

approaches 52-61; see also artifacts

trajectories 149-151, 155, 156-165

transnational adoption 62-72

traversals 114,119

ubiations see space/place

van Leeuwen, Theo 73-93

virtual ethnography 63-64

voices 5-6

Vygotsky, Lev Semënovich 49, 52-61

waiting, adoption 68-71

websites, adoption 64-66

Wertsch, James V. 5, 18, 49; on Vygotsky 52-61

Wittgenstein, Ludwig 6, 20

word meaning 57-60

Wright, Will 114

Zeitgeber see cycles

zones of identification 201-202 


